INSTITUTO NACIONAL DE INVESTIGACIÓN AGROPECUARIA

URUGUAY

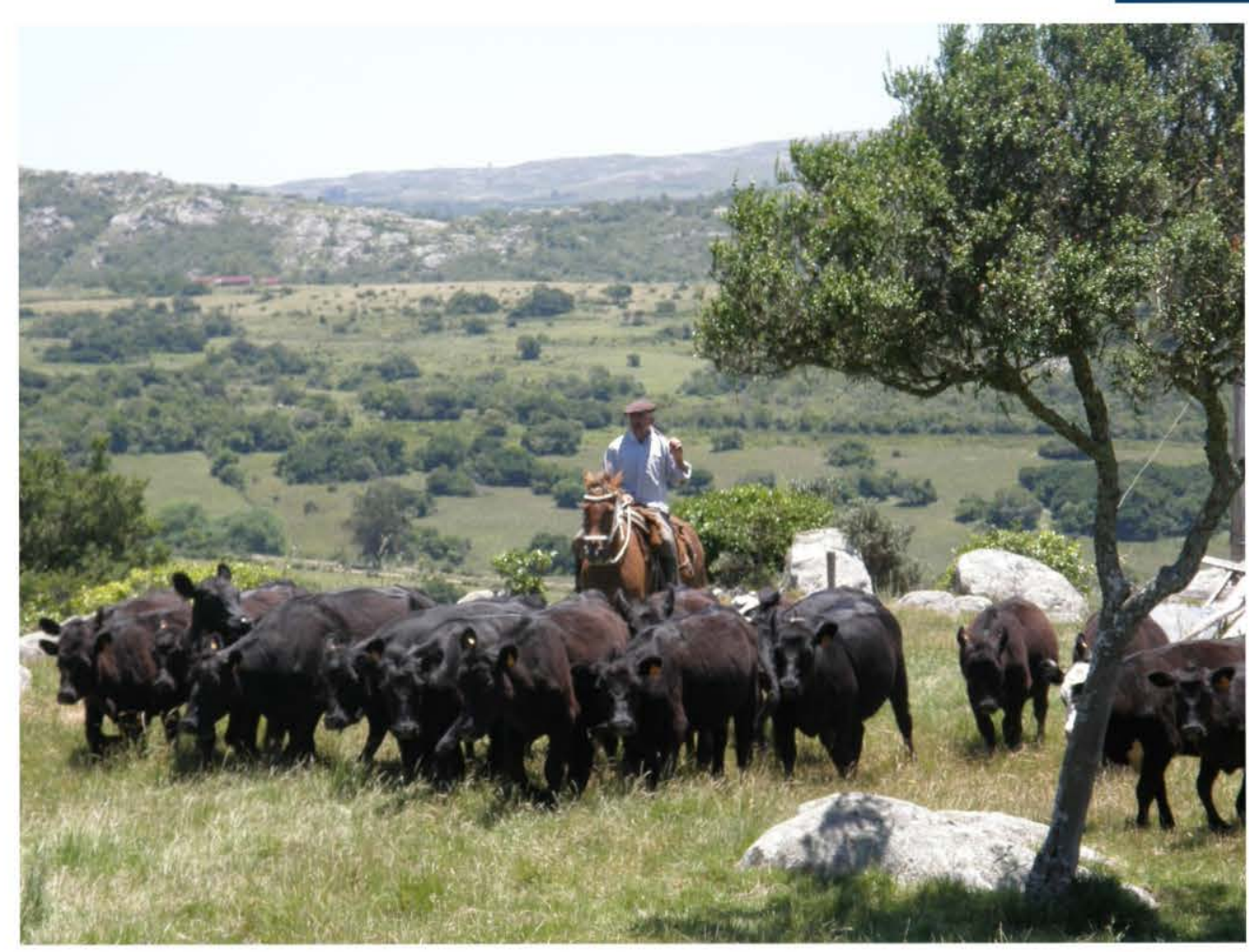

CO-INNOVANDO PARA

EL DESARROLLO

SOSTENIBLE DE

SISTEMAS GANADEROS

FAMILIARES DE

ROCHA - URUGUAY

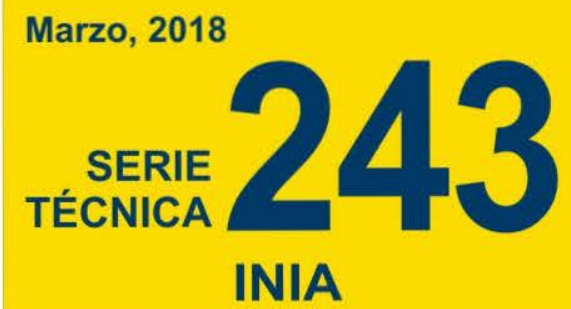




\section{CO-INNOVANDO PARA EL DESARROLLO SOSTENIBLE DE SISTEMAS GANADEROS FAMILIARES DE ROCHA - URUGUAY}

Editoras: Verónica Aguerre ${ }^{1}$, María Marta Albicette ${ }^{2}$.

Líder de Proyecto: Verónica Aguerre.

Equipo de investigación: Verónica Aguerre, María Marta Albicette, Alfredo Albín, Isabel Bortagaray, Mauricio Benvenuto, Oscar Blumetto, Gerónimo Cardozo, Andrés Castagna, Pablo Clara, Liliana del Pino, Santiago Dogliotti, Felipe García, Juan Carlos Gilzans, Carolina Leoni, Sergio Montaldo, Graciela Quintans, Andrea Ruggia, Mariana Scarlato, Santiago Scarlato, Mariana Silvera, Guadalupe Tiscornia.

\footnotetext{
${ }^{1}$ Ing. Agr. Mag. Programa de Investigación en Producción Familiar. INIA Las Brujas.

${ }^{2}$ Ing. Agr. Mag. Unidad de Comunicación y Transferencia de Teconología. INIA Las Brujas.
} 
Título: CO-INNOVANDO PARA EL DESARROLLO SOSTENIBLE DE SISTEMAS GANADEROS FAMILIARES DE ROCHA - URUGUAY

Editoras: Verónica Aguerre, María Marta Albicette.

Líder de Proyecto: Verónica Aguerre.

Equipo de investigación: Verónica Aguerre, María Marta Albicette, Alfredo Albín, Isabel Bortagaray, Mauricio Benvenuto, Oscar Blumetto, Gerónimo Cardozo, Andrés Castagna, Pablo Clara, Liliana del Pino, Santiago Dogliotti, Felipe García, Juan Carlos Gilzans, Carolina Leoni, Sergio Montaldo, Graciela Quintans, Andrea Ruggia, Mariana Scarlato, Santiago Scarlato, Mariana Silvera, Guadalupe Tiscornia.

Serie Técnica $N^{\circ} 243$

ISBN: 978-9974-38-393-7

(C) 2018, INIA

Editado por la Unidad de Comunicación y Transferencia de Tecnología del INIA Andes 1365, Piso 12. Montevideo, Uruguay.

http://www.inia.uy

Quedan reservados todos los derechos de la presente edición. Esta publicación no se podrá reproducir total o parcialmente sin expreso consentimiento del INIA. 


\section{Instituto Nacional de Investigación Agropecuaria}

\section{Integración de la Junta Directiva}

D.M.T.V., Ph.D. José Luis Repetto - Presidente

Ing. Agr., M.Sc., Ph.D. Álvaro Roel -Vicepresidente

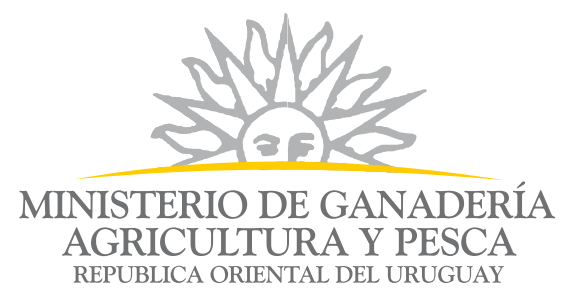

Ing. Agr., M.Sc. Diego Payssé Salgado

Ing. Agr. Jorge Peñagaricano
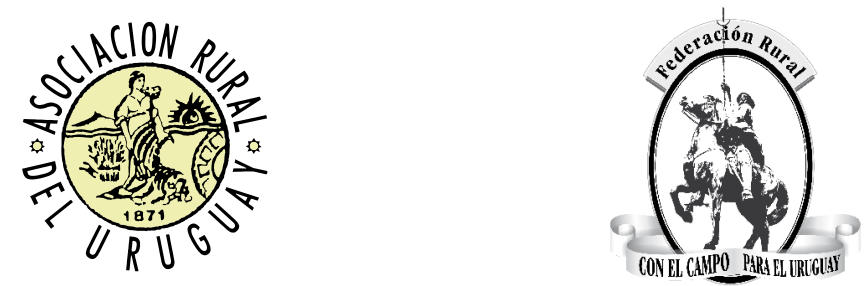

Ing. Agr. Pablo Gorriti

Ing. Agr. Alberto Bozzo
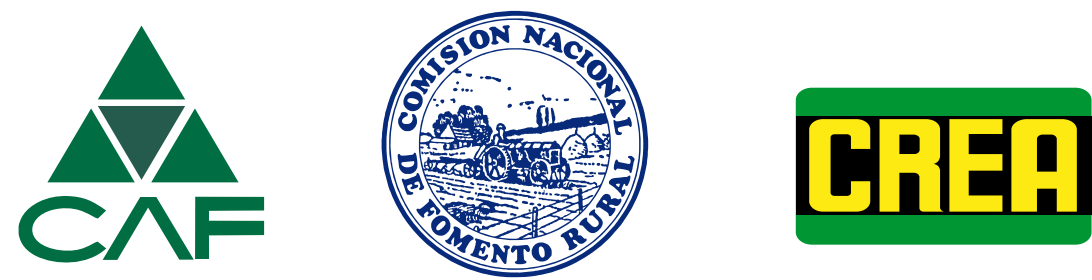



\section{CONTENIDO}

\section{CAPÍTULO I - INTRODUCCIÓN}

Página

CAPÍTULO II - MARCO CONCEPTUAL

2.1 Enfoque de Co-innovación

2.1.1 ¿Por qué aplicar el enfoque de co-innovación? ......................................

2.1.2 Los tres pilares del enfoque de co-innovación.......................................... 5

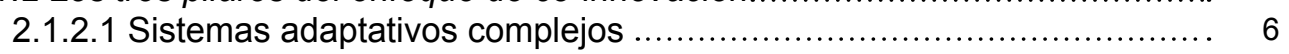

2.1.2.2 Aprendizaje social ............................................................ 6

2.1.2.3 Monitoreo y evaluación dinámicos ........................................... 7

2.1.3 Un poco de historia: De la transferencia de tecnología (TT) a los

Sistemas de Innovación Agrícola (AIS) ............................................... 7

2.1.4 Principios para la aplicación del enfoque de co-innovación ..................... 10

2.2 La intensificación ecológica como base para las propuestas técnicas ......... 10

2.2.1 Base conceptual de la propuesta técnica ........................................ 11

2.2.1.1 Trabajar con más forraje y mejorar su gestión.............................. 13

2.2.1.2 Medidas de bajo costo y alto impacto productivo para la cría y recría.... 14

\section{CAPÍTULO III - METODOLOGÍA DE TRABAJO}

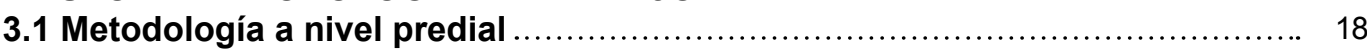

3.1.1 Etapa 1: Caracterización ............................................................ 20

3.1.2 Etapa 2: Diagnóstico .......................................................... 20

3.1.3 Etapa 3: Propuesta de re-diseño (planificación estratégica)..................... 24

3.1.4 Etapa 4: Implementación (planificación táctica), monitoreo y evaluación...... 25

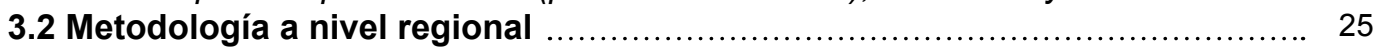

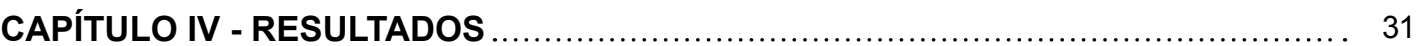

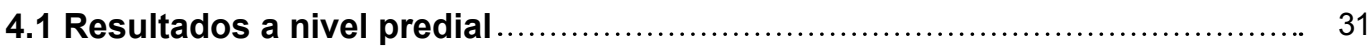

4.1.1 Etapa 1: Caracterización............................................................ 31

4.1.1.1 La familia, sus objetivos y el sistema de gestión .......................... 31

4.1.1.2 Recursos prediales............................................................. 35

4.1.1.2.1 Recursos humanos..................................................... 35

4.1.1.2.2 Suelos ........................................................................ 36

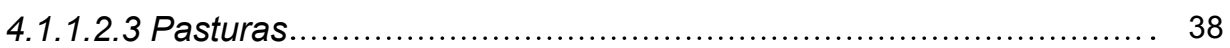

4.1.1.2.4 Infraestructura productiva .......................................... 40

4.1.1.3 Caracterización ambiental .................................................. 40

4.1.1.3.1 Integridad ecosistémica................................................. 40

4.1.1.3.2 Fauna asociada - aves .................................................. 42

4.1.1.3.3 Carbono orgánico total y sus fracciones. .............................. 45

4.1.1.4 Actividades de producción..................................................... 45

4.1.1.4.1 Descripción general y uso de tecnologías ............................. 45

4.1.1.4.2 Manejo de los animales.................................................... 45

4.1.1.4.3 Comercialización............................................................... 47

4.1.1.4.4 Carga animal y relación ovino/vacuno ............................... 47

4.1.1.4.5 Resultados productivos y económicos 2009 - 2012 ................ 47

4.1.2 Etapa 2: Diagnóstico ................................................................... 48

4.1.3 Etapa 3: Re-diseño .................................................................... 51

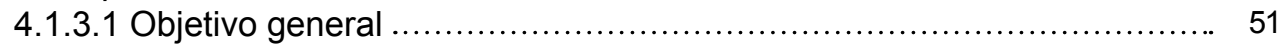

4.1.3.2 Objetivos de producción específicos ....................................... 51 
4.1.3.3 Herramientas - Medidas de manejo ............................................. 52

4.1.3.3.1 Medidas generales ................................................................ 52

4.1.3.3.2 Manejo de pasturas y animales ................................................ 52

4.1.3.3.3 Manejo de vacunos .............................................................. 52

4.1.3.3.4 Manejo de ovinos.................................................................... 53

4.1.3.3.5 Manejo de pasturas .............................................................. 53

4.1.3.4 Opciones evaluadas .................................................................... 53

4.1.4 Etapa 4: Implementación y monitoreo .................................................... 54

4.1.4.1 Implementación del plan de re-diseño .......................................... 54

4.1.4.1.1 Manejo general............................................................. 54

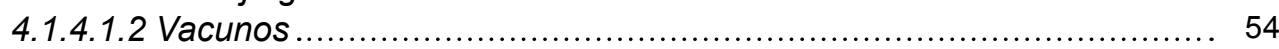

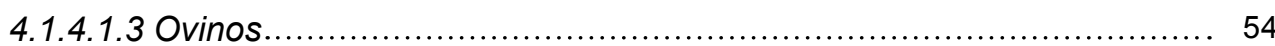

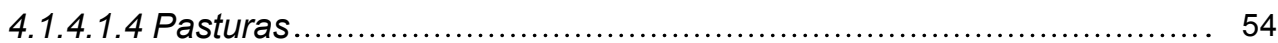

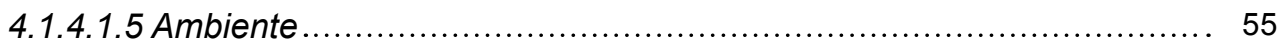

4.1.4.1.6 Gestión predial .............................................................. 56

4.1.4.2 Evolución de resultados en los predios ......................................... 56

4.1.4.2.1 Carga animal y relación ovino/vacuno ....................................... 56

4.1.4.2.2 Altura promedio de las pasturas .......................................... 58

4.1.4.2.3 Producción de forraje del predio ............................................ 59

4.1.4.2.4 Composición botánica del campo natural y doble estructura .......... 59

4.1.4.2.5 Evolución de peso de hembras de recría ................................. 62

4.1.4.2. 6 Resumen de manejos durante el entore y resultados de preñez ....... 63

4.1.4.2.7 Kilos de ternero destetado por vaca entorada ............................... 66

4.1.4.2.8 Producción de carne equivalente por hectárea ........................... 67

4.1.4.2.9 Resultado económico en ganadería........................................... 67

4.1.4.2.10 Índice de integridad ecosistémica ........................................ 69

4.1.4.2.11 Fauna asociada - aves ................................................ 71

4.1.4.2.12 Carbono orgánico total y sus fracciones .................................. 72

4.1.4.2.13 Calidad de vida ........................................................ 72

4.1.4.2.14 Planificación predial y organización del trabajo.......................... 73

4.1.4.2.15 Aprendizajes y cambios relevantes identificados por los productores 75

4.1.4.2.16 Uso de tecnologías ......................................................... 77

4.1.4.3 Integración de resultados a nivel predial ...................................... 77

4.1.4.4 Valoración de la forma de trabajo y vínculo productor-técnico ............... 84

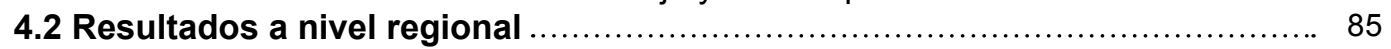

4.2.1 Una red interinstitucional que acompañó el proceso predial .................... 85

4.2.2 La visión compartida y las vías de impacto consensuadas....................... 86

4.2.3 Un plan de comunicación para trascender el trabajo en los predios............... 88

4.2.4 Monitoreo y Evaluación (M\&E), reflexión e incorporación de sugerencias..... 91

4.2.5 Evaluación final ....................................................................... 93

4.2.6 Emergentes a partir del proyecto .................................................. 96

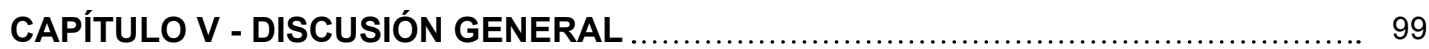

5.1 ¿Es posible innovar en sistemas de producción familiar? ............................ 99

5.2 ¿Cómo innovamos en sistemas de producción familiar? ............................ 102

CAPÍTULO VI - REFLEXIONES FINALES ...................................................... 105

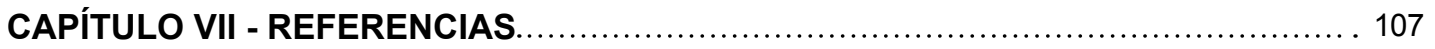

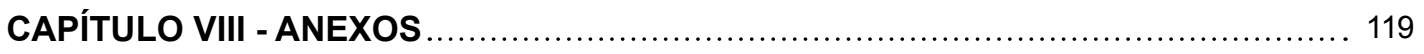




\section{ÍNDICE DE CUADROS}

Cuadro 1. Evolución de enfoques prototípicos y tipo de perspectiva para el desarrollo de innovaciones y sus respectivos atributos, adaptado de Klerkx et al. (2012), Albicette (2010) y Probst y Hagmann (2006; 2003).

Cuadro 2. Etapas del trabajo en los predios. Tomado de Albicette et al. (2016a) .......................... 19

Cuadro 3. Caracterización de los siete casos ...................................................... 32

Cuadro 4. Calidad de vida estructural integrada para los siete casos .................................. 34

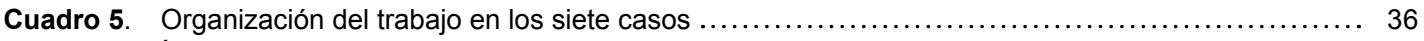

Cuadro 6. Índice de productividad suelos CONEAT para los siete casos . .............................. 37

Cuadro 7. Porcentaje de suelos según propiedades inferidas en los 7 predios .......................... 37

Cuadro 8. Área ocupada (\%) por las principales clases de capacidad de uso en cada caso................. 37

Cuadro 9. Características físico-químicas del horizonte A para los siete casos. ............................. 38

Cuadro 10. Uso de suelo al inicio del proyecto (otoño 2012) para los siete casos .......................... 38

Cuadro 11. Presencia de aves prioritarias para la conservación (Soutullo et al., 2013) en los siete casos...... 42

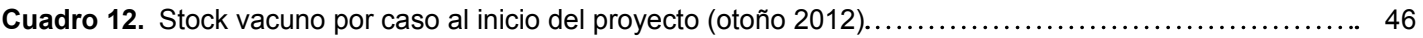

Cuadro 13. Stock ovino para cada caso al inicio del proyecto (otoño 2012) ............................... 46

Cuadro 14. Principales puntos críticos de los predios, vinculados a los principales atributos de la sustentabilidad planteados en el marco MESMIS, con los indicadores seleccionados para monitorear su evolución

Cuadro 15. Evolución de especies en el campo natural para los siete casos, valorada como Riqueza (número

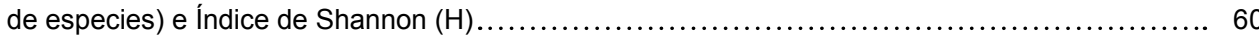

Cuadro 16. Evolución del doble estrato en campo natural para los siete casos al inicio y fin del proyecto ...... 61

Cuadro 17. Variación del Índice de integridad ecosistémica (IIE) para cada caso ........................... 69

Cuadro 18. Coeficiente de correlación de Pearson entre el Índice de integridad ecosistémica y otras variables ambientales

Cuadro 19. Riqueza de aves observada, estimada e índice de Shannon para cada caso para el año inicial (2013) y final (2015) del muestreo.

Cuadro 20. Carbono orgánico total (\%) y sus fracciones $(\mathrm{g} / 100 \mathrm{~g})$ para los campos naturales de 0 a $6 \mathrm{~cm}$ de

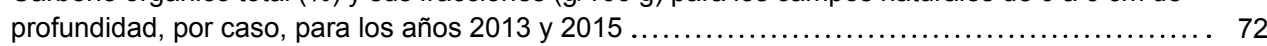

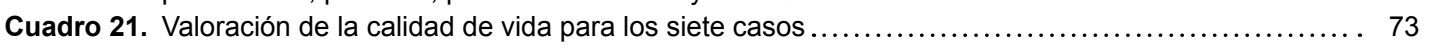

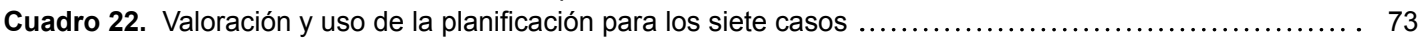

Cuadro 23. Evolución de la cantidad de trabajo y de la productividad del trabajo familiar en los siete casos..... 75

Cuadro 24. Aprendizajes y cambios más relevantes para los siete casos . . .............................. 76

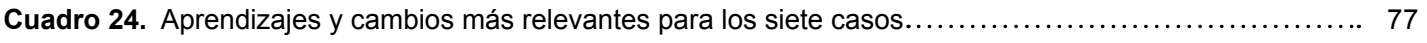

Cuadro 25. Nivel de uso de técnicas sugeridas para ganadería al inicio, medio término y final del proyecto para los siete casos.

Cuadro 26. Factores destacados por caso de la relación productor-técnico, que la diferencian de experiencias anteriores

Cuadro 27. Grupos de actores y su participación en los seis talleres de la Red de Actores Regionales (RAR)......

Cuadro 28. Vías de impacto-Modelo de resultados acordadas entre los actores de la Red de Actores Regionales (RAR)

Cuadro 29. Resumen de las actividades de divulgación implementadas en base a los dos planes de comunicación elaborados por la Red de Actores Regionales (RAR).

Cuadro 30. Registro de actividades de comunicación técnico-científicas para divulgar resultados en eventos nacionales e internacionales 2012-2016.

Cuadro 31. Principales logros, dificultades y sugerencias de mejora planteados en instancias de reflexión realizadas en los Talleres III y IV de la RAR

Cuadro 32. Resultados de la evaluación participativa final del proyecto. Se presenta el número de respuestas que evalúa en cada nivel (Excelente a Muy malo) y el valor promedio ponderado obtenido para cada aspecto evaluado 


\section{ÍNDICE DE FIGURAS}

Figura 1. Co-innovación: resultado de la interacción de tres dominios

Figura 2. Producción de carne (kg PV/ha año) bajo diferentes niveles de intensificación en los campos naturales (adaptado de Carvalho et al., 2008) ....

Figura 3. Propuesta de cambio de altura del forraje y condición corporal a lo largo del año para vacas de cría sobre campo natural (Soca y Orcasberro, 1992)

Figura 4. Abordaje metodológico del proyecto

Figura 6. Uso de tarjetas como herramienta para la elaboración de actores regionales ................... 27

Figura 7. Puesta en común de la evaluación participativa final del proyecto, donde se destaca la matriz empleada para sistematizar los resultados de cada pregunta de la encuesta y reflexionar sobre ellos.

Figura 8. Principales ideas asociadas a la visión a futuro - sustentabilidad de las siete familias............. 33

Figura 9. Factores asociados a la calidad de vida subjetiva mencionados por los productores, priorizados de acuerdo con la frecuencia de mención (Albicette et al., 2016a)

Figura 10. Principales especies del campo natural presentes en los predios, especificando nombre científico y nombre común, e indicando con un número en cuántos predios la especie estuvo presente ......

Figura 11. Índice de integridad ecosistémica (IIE) para cada potrero y global para cada caso ................ 41

Figura 12. Gremios de alimentación de las especies de aves registradas en los siete casos .................. 43

Figura 13. Especies de aves más abundantes en los siete casos .................................. 44

Figura 14. Árbol de problemas y estrategias para abordar los principales problemas identificados, común a todos los predios

Figura 15. Evolución de la carga vacuna, ovina, total y de la relación ovino/vacuno promedio de los siete casos según ejercicio.

Figura 16. Evolución de carga total (UG/ha) por caso para los tres ejercicios previos al inicio del proyecto (2009/2010; 2010/2011 y 2012/2013) y para los tres ejercicios de implementación del mismo (2012/2013; 2013/2014 y 2014/2015)

Figura 17. Evolución de la relación ovino/vacuno por caso para los tres ejercicios previos al inicio del
proyecto $(2009 / 2010 ; 2010 / 2011$ y $2012 / 2013)$ y para los tres ejercicios de implementación del

Figura 17. Evolución de la relación ovino/vacuno por caso para los tres ejercicios previos al inicio del
proyecto (2009/2010; 2010/2011 y 2012/2013) y para los tres ejercicios de implementación del

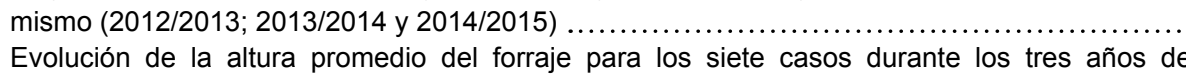

Figura 18. Evolución de la altura promedio del forraje para los siete casos durante los tres años de
implementación del proyecto y el valor de referencia sugerido por la literatura (Soca y Orcasberro, 1992). Se incluye también el registro promedio de lluvia por estación (mm acumulados)

Figura 19. Evolución de la altura de pasto promedio del predio para cada caso durante los tres años de implementación del proyecto y valor de referencia sugerido por Soca y Orcasberro (1992)

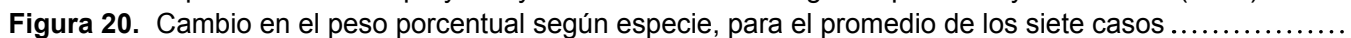

Figura 21. Evolución del estrato alto (\%) según tipo de especie, para dos potreros diferentes estudiados ......

Figura 22. Evolución de pesos de las hembras de recría $(\mathrm{kg})$ para el promedio de los siete casos según el año de nacimiento

Figura 23. Esquema de las medidas de manejo realizadas para cada año durante el período de entore y los resultados de probabilidad de preñez (estimada en función de la condición corporal de cada categoría y la preñez esperada para dicha condición), la preñez obtenida en las vacas con ternero al pie y la preñez total (incluye vaquillonas y vacas falladas), tomando como ejemplo uno de los casos del proyecto

Figura 24. Evolución del porcentaje de preñez para cada caso del proyecto y de los resultados de los talleres de evaluación de los diagnósticos de gestación vacuna para Rocha (INIA, 2015-2010) para el promedio de los 3 años previos al inicio del proyecto y para cada año de implementación

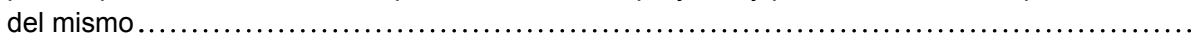

Figura 25. Porcentaje de procreo promedio por caso, para el promedio de los 3 años previos al proyecto y para cada año de implementación del mismo.

Figura 26. Kilos de ternero destetado por vaca entorada por caso, para el promedio de los 3 años previos al inicio del proyecto y los 3 años de ejecución

Figura 27. Evolución del peso de terneros al destete $(\mathrm{kg})$ por caso para el promedio de los 3 años previos al inicio del proyecto y los 3 años de ejecución. 
Figura 28. Evolución de la producción de carne equivalente $(\mathrm{kg} / \mathrm{ha})$ por caso, para los 3 ejercicios previos al inicio del proyecto (2009/2010; 2010/2011 y 2011/2012) y los 3 años de implementación (2012/2013; 2013/2014 y 2014/2015), y resultados de los predios criadores monitoreados por el IPA (2017) para los respectivos ejercicios .

Figura 29. Evolución para cada caso del producto bruto, costos e ingreso ganadero familiar promedio de los 3 años previos al inicio del proyecto (ejercicios 2009/2010; 2010/2011 y 2011/2012) y de los 3 años de implementación (ejercicios 2012/2013; 2013/2014 y 2014/2015)

Figura 30. Ingreso neto ganadero (U\$S/ha) de los siete casos para los 3 ejercicios previos al inicio del proyecto (2009/2010; 2010/2011 y 2011/2012) y los 3 ejercicios de implementación (2012/2013; 2013/2014 y 2014/2015), y resultados obtenidos en los predios monitoreados por el IPA (2017)... 68

Figura 31. Variación del IIE entre el inicio y el final del proyecto para cada potrero en cada caso ............. 70

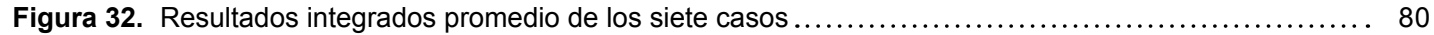

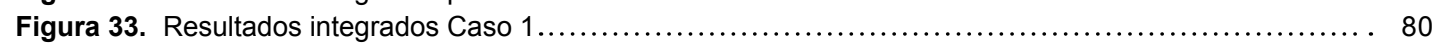

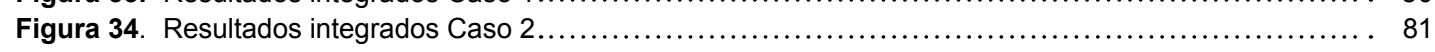

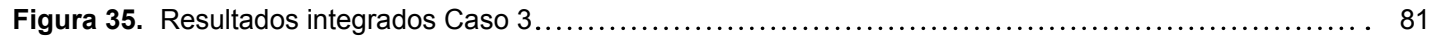

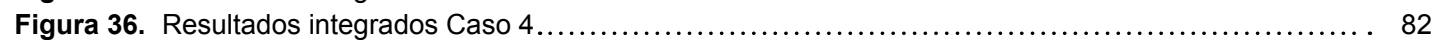

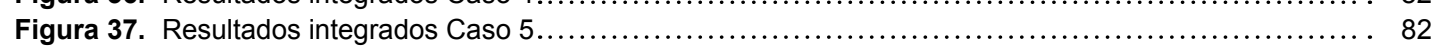

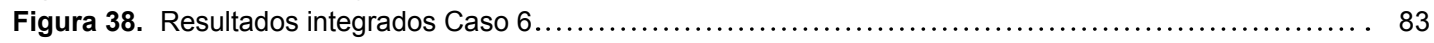

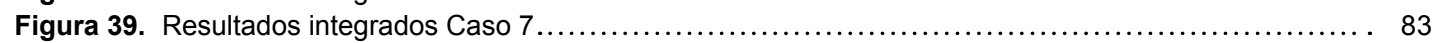




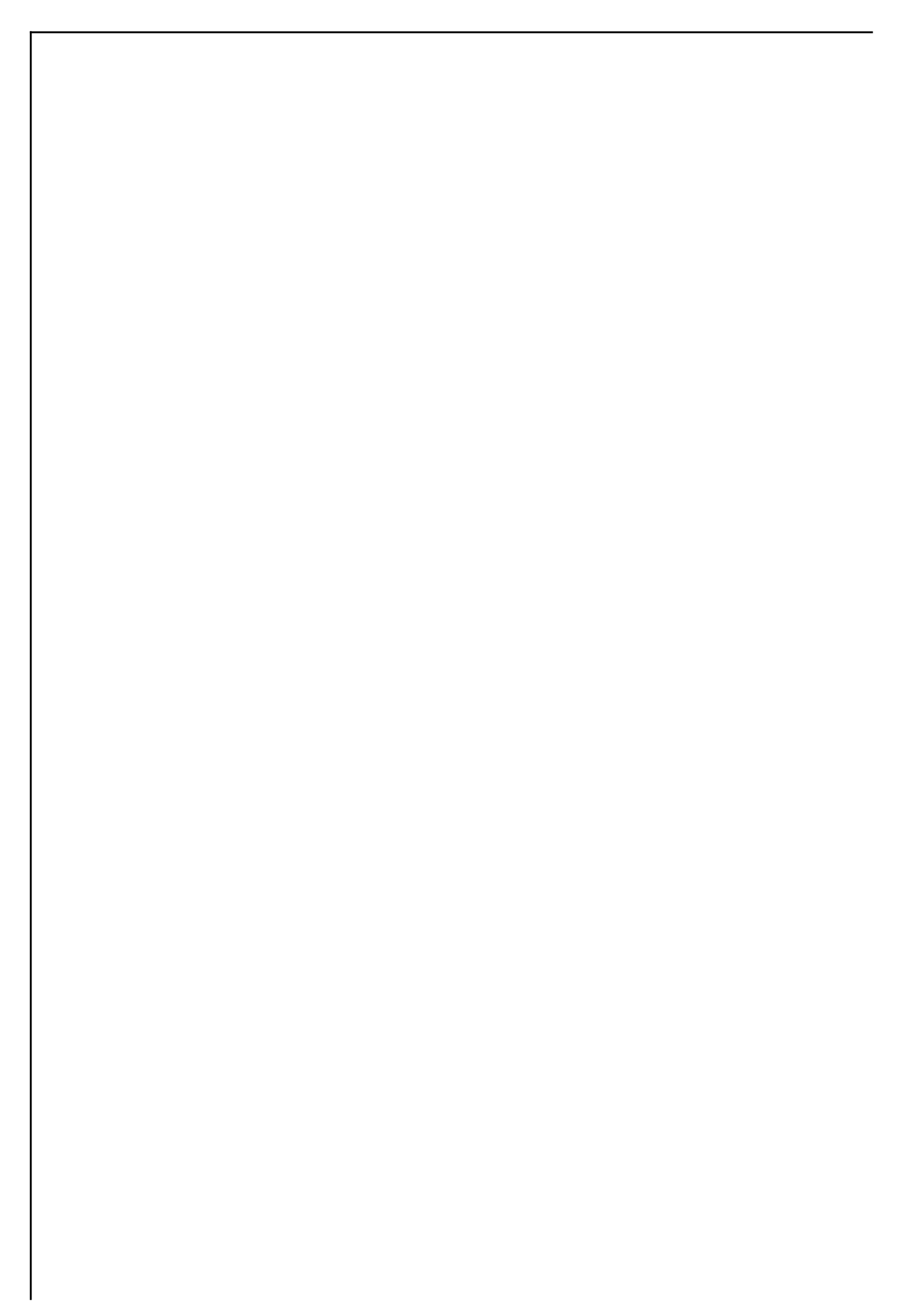




\section{PRÓLOGO}

Desde el 2006, el INIA a través del Programa Nacional de Investigación en Producción Familiar (PPF) ha ido integrando la dimensión social, en conjunto con la ambiental y la económica, a través de la inclusión de nuevos enfoques y metodologías de investigación y a fin de generar productos que contribuyan a la sostenibilidad de los productores familiares del Uruguay. Más específicamente, el abordaje de problemas complejos como los que enfrenta la ganadería familiar, obligó a incorporar y a ampliar las metodologías de investigación y los trabajos interdisciplinarios, como fue la co-innovación desarrollada en el norte y este de nuestro país.

Durante este período el PPF, en conjunto con el Programa Nacional de Carne y Lana de INIA, han venido incorporando diferentes temáticas, a la vez de haber ampliado la vinculación con diversos actores nacionales e internacionales, diversificando así la estrategia de trabajo. Específicamente en este caso, en 2009 se comenzó a trabajar en el departamento de Rocha, gracias a la iniciativa de técnicos de la Comisión Nacional de Fomento Rural (CNFR), en conjunto con las Sociedades de Fomento Rural (SFR) Castillos, San Miguel y Ruta 109 y con la Intendencia Municipal de Rocha (IMR). Este primer trabajo de diagnóstico dio origen a la formulación y ejecución de un proyecto de investigación acción participativa que se implementó entre 2012 y 2015.

Esta publicación presenta los resultados del trabajo de investigación científica y desarrollo tecnológico, de dicho proyecto "Co-innovando para el desarrollo sostenible de sistemas ganaderos familiares de Rocha - Uruguay". El mismo asumió un compromiso de integración institucional que se planteó como objetivo abordar la problemática de los productores ganaderos familiares y generar alternativas que contribuyeran a mejorar su viabilidad, teniendo en cuenta aspectos socio-económicos y ambientales. Para ello se innovó en la combinación de diferentes enfoques, metodologías y estrategias: el enfoque territorial, el de sistemas y la co-innovación; involucrando directamente a las familias productoras en los procesos de generación de conocimiento.

Queremos agradecer en primer lugar a las familias productoras que participaron activamente del proyecto, sin ellos no hubiera sido posible elaborar esta publicación. También un especial agradecimiento a las instituciones y sus representantes que participaron en el proyecto, entre ellas CNFR, SFR Castillos y SFR Ruta 109, Sociedad Agropecuaria de Rocha, IMR, MGAP en particular a los técnicos de la Dirección General de Desarrollo Rural, Sistema Nacional de Áreas Protegidas (MVOTMA), Instituto Plan Agropecuario, Facultad de Agronomía y Centro Universitario de la Región Este. Por último, un profundo reconocimiento al numeroso equipo científico y técnico-operativo de INIA, tanto permanentes como aquellos que fueron contratados para el proyecto, que, con gran profesionalismo y dedicación, construyeron una red relevante de actores vinculados y preocupados por la sustentabilidad de los productores ganaderos familiares de Rocha.

Ing. Agr. PhD. Alfredo Albín. Director Programa Nacional de Investigación en Producción Familiar. 



\section{CAPÍTULO I INTRODUCCIÓN}

La ganadería vacuna y ovina es el sistema de producción dominante dentro del sector agropecuario nacional, tanto por su extensión como por el número de explotaciones involucradas. Según el Censo Agropecuario de 2011 había 26.933 explotaciones ganaderas que ocupaban más de 13,7 millones de hectáreas (Bervejillo y Tambler, 2014 ), con la particularidad de que el $60 \%$ de dichas explotaciones eran familiares ${ }^{1}$ (Tommasino et al., 2014). La sostenibilidad de los sistemas de producción ganaderos familiares está amenazada, lo que se evidencia por la constante desaparición de los mismos, que disminuyeron un $14 \%$ entre 2000 y 2011 (Tommasino et al., 2014). Particularmente en Rocha, en 2011 existían 1996 explotaciones agropecuarias (4,5\% del total del país), de las cuales 1840 tenían vacunos y 1316 tenían ovinos (DIEA-MGAP, 2011), destacando la importancia de las explotaciones ganaderas familiares.

Los sistemas ganaderos criadores familiares en Uruguay aplican bajos niveles de tecnología y consecuentemente presentan baja eficiencia productiva con importantes fluctuaciones productivas entre años ( $\mathrm{Pe}$ reira, 2003). Existe una gran brecha entre el conocimiento disponible y las prácticas que utilizan los productores ganaderos familiares (Gómez Miller y Saravia, 2016), lo cual abre oportunidades para mejorar la sostenibilidad de la producción familiar. En la última década se ha avanzado en el conocimiento de distintos componentes del sistema de producción y en la disponibilidad de tecnologías para incrementar la productividad y la calidad de los productos. Se dispone fundamentalmente de tecnologías de procesos que requieren manejo y no necesariamente tecnologías de insumos, destacándose avances en las áreas de manejo del pastizal nativo (Soca et al., 2013; Altesor et al., 2011) y manejo de vacunos y ovinos (Quintans y Scarsi, 2013; Nabinger et al., 2011). Disponer de tecnologías de procesos validadas permite re-diseñar sistemas de producción basados en principios agroecológicos que buscan sustituir lo más posible el uso de insumos agrícolas y trabajo humano por procesos biológicos que favorecen los ciclos biogeoquímcos y la integridad de los ecosistemas. Este enfoque se ha definido como "intensificación ecológica" en contraposición a la "intensificación productiva" que busca el aumento de la productividad en base a un mayor uso de tecnologías de insumos y de energía fósil (Tittonell, 2014).

La mejora de la sostenibilidad de los predios familiares requiere del re-diseño del sistema y no puede lograrse con el ajuste o modificación de componentes aislados, que generalmente responden a avances disciplinarios. El proceso implica entender la unidad de producción como un sistema, en donde la producción es el resultado de varios procesos simultáneos que tienen un orden jerárquico, donde los de mayor orden definen los límites dentro de los cuales operan los de orden jerárquico inferior (Fresco y Westphal, 1988). Por lo tanto, las diferentes tecnologías disponibles para incrementar la productividad y la calidad de los productos deben analizarse caso a caso y establecer su viabilidad para cada contexto (Dogliotti et al., 2014). El re-diseño de las explotaciones familiares implica modificaciones en el

\footnotetext{
${ }^{1}$ En este trabajo y de acuerdo a la definición del Ministerio de Ganadería Agricultura y Pesca de Uruguay se entiende que la producción familiar cumple los siguientes criterios: explotar hasta 500 ha índice CONEAT 100, la fuerza de trabajo es provista mayoritariamente por la familia, con la colaboración de hasta 2 asalariados permanentes o su equivalente en jornales zafrales (500 jornadas anuales), la familia es directamente responsable del manejo de las actividades de producción, vive en el predio o en un radio menor a $50 \mathrm{~km}$ y obtiene su ingreso principal del trabajo en la explotación (Tommasino et al., 2014).
} 
sistema de manejo y requiere cambios en los conocimientos, las actitudes, las habilidades y las aspiraciones - KASA, por su sigla en inglés - (Rockwell y Bennett, 2004) de las personas involucradas en el proceso de toma de decisiones (Dogliotti et al., 2012).

La participación activa de los productores en el proceso de identificación de los problemas $y$ alternativas de mejora supone un cambio de paradigma en la investigación, con mayor inclusión de los productores en el desarrollo de las innovaciones (Leeuwis et al., 2002). En un enfoque tradicional de cambio técnico las nuevas tecnologías se diseñan en forma externa al sistema de producción y se adoptan por los agricultores como resultado de un proceso de "extensión", que linealmente implica toma de conciencia del problema, interés por la solución, evaluación, experimentación y finalmente adopción e innovación. En enfoques participativos, la innovación ya no se concibe como proviniendo de fuentes externas solamente, sino que ésta se desarrolla y diseña en su contexto de aplicación y con la participación de quienes manejan los sistemas y toman las decisiones (Leeuwis y Van der Ban, 2004; Gibbons et al., 1997). En este nuevo paradigma denominado Sistemas de Innovación Agrícola - AIS, por su sigla en inglés - los cambios en las prácticas agrícolas y en la organización de los sistemas hacia situaciones de mayor sostenibilidad (socio-económica y ambiental) son vistos como resultado de un proceso de trabajo en red y aprendizaje colectivo (Klerkx et al., 2012).

La co-innovación constituye una nueva forma de operativizar el re-diseño de los sistemas de producción bajo el paradigma de los AIS (Botha et al., 2016; Coutts et al., 2016; Dogliotti et al., 2014). El enfoque de co-innovación implica por definición, un proceso de aprendizaje colectivo (aprendizaje social), en un contexto intencionalmente diseñado (dinámicas de monitoreo y evaluación) basados en una visión de sistemas adaptativos complejos (Rossing et al., 2010).
Entre 2009 y 2010, INIA realizó un Diagnóstico Rural Rápido - DRR - (Schönhuth y Kievelitz, 1994) en Rocha y Castillos, con la colaboración de Comisión Nacional de Fomento Rural (CNFR), Sociedad de Fomento Rural de Castillos (SFR Castillos), Sociedad de Fomento Rural Ruta 109 (SFR R109) e Intendencia Municipal de Rocha (IMR) (Capra et al., 2009). En el mismo se constató la relevancia de los sistemas ganaderos familiares y se identificaron como principales problemas la tendencia a la desaparición de productores familiares de la zona y el envejecimiento de la población rural, a consecuencia de la emigración de los jóvenes. La estrategia empleada por los productores para contrarrestar la reducción de los ingresos había sido la intensificación productiva, asociada al uso de prácticas poco adecuadas, que ponía en peligro la conservación y calidad de los recursos naturales, afectando la productividad y condicionando su sostenibilidad. Se detectaron carencias de conocimiento en los productores sobre las alternativas tecnológicas disponibles para los diferentes rubros de producción. Sin embargo, también se identificaron oportunidades de mejorar la calidad de vida y sostenibilidad de las familias y de contribuir al desarrollo regional. A nivel predial, esto se podía trabajar mediante el re-diseño de los sistemas de producción, con una adecuada selección y orientación de actividades productivas y el uso de opciones tecnológicas más apropiadas a cada sistema. A nivel regional, mediante el trabajo articulado con las instituciones y organizaciones locales para promover el desarrollo.

El proyecto "Co-innovando para el desarrollo sostenible de sistemas de producción familiar de Rocha - Uruguay" surgió en el Programa Nacional de Investigación en Producción Familiar de INIA, buscando contribuir, desde la investigación científica y el desarrollo tecnológico, a mejorar la sustentabilidad de los sistemas de producción familiar, al desarrollo del medio rural y a aportar a la mejora de la calidad de vida de los pobladores de la Región Este del Uruguay. El mismo fue ejecutado entre abril de 2012 y diciembre de 2015. 
Teniendo en cuenta lo anterior los objetivos específicos planteados en el proyecto fueron: a) aplicar el enfoque de co-innovación con productores ganaderos familiares, con el fin de mejorar la sustentabilidad de sus sistemas de producción, b) evaluar el impacto de cambios estratégicos en la sustentabilidad de los sistemas ganaderos familiares y c) compartir los resultados con otros actores a nivel regional. La pregunta de investigación fue: ¿En sistemas ganaderos familiares, es posible mejorar los resultados productivos y económicos manteniendo o mejorando el estado de los ecosistemas, desarrollando un proceso participativo hacia el re-diseño de los sistemas de producción, sin incorporar capital externo y promoviendo procesos de aprendizaje entre productores, técnicos e instituciones?

Esta Serie Técnica tiene como objetivo sistematizar y analizar el proceso generado a partir del proyecto "Co-innovando para el desarrollo sostenible de sistemas de producción familiar de Rocha - Uruguay". En el capítulo dos se presenta el marco conceptual tomado como referencia, focalizando en los conceptos de co-innovación e intensificación ecológica. En el capítulo tres se presenta la metodología de trabajo utilizada, describiendo el trabajo a nivel predial y a nivel regional. En el capítulo cuatro se presentan y discuten los resultados obtenidos tanto a nivel predial como regional. En el capítulo cinco se realiza una discusión general de los principales re- sultados obtenidos en el proyecto. Se cierra la publicación con reflexiones finales sobre los desafíos que se plantean a diferentes actores para seguir trabajando con el enfoque de co-innovación.

Esta publicación se complementa de forma integral con materiales mucho más detallados que se encuentran en la página web del proyecto en el sitio de INIA ( $h t t p: / / w w w$. inia.uy/Proyectos/Paginas/PF_07.aspx). Dichos materiales son: (i) tres videos, el primero relata la historia completa del proyecto con testimonio de productores, técnicos y actores regionales involucrados (Versión completa - acceso web a través de código QR en Anexo 11), el segundo es una versión corta de la historia del proyecto (Versión resumen - acceso web a través de código QR en Anexo 11) y el tercero se focaliza en el trabajo conjunto entre productores y técnicos a nivel de predio, detallando la metodología utilizada (Trabajo en predios - acceso web a través de código QR en Anexo 11); (ii) siete historias de innovación que relatan lo que ocurrió en cada estudio de caso durante los tres años de implementación del proyecto (Historias de Innovación Caso 1 - 7); (iii) una guía fotográfica de aves presentes en predios ganaderos familiares (Guía fotográfica de aves); (iv) las memorias completas de los seis talleres que se realizaron con los actores regionales (Memorias Taller Interinstitucional I - VI). 

Dos marcos conceptuales orientaron el proyecto:

$\checkmark$ el enfoque de co-innovación utilizado como forma de promover y operativizar la innovación necesaria para la transición hacia sistemas de producción más sostenibles, orientando procesos de aprendizaje y generación de conocimiento.

$\checkmark$ la intensificación ecológica como enfoque para levantar restricciones productivas preservando los ecosistemas y sus servicios.

\subsection{Enfoque de Co-innovación}

\subsection{1 ¿Por qué aplicar el enfoque de co-innovación?}

De acuerdo con Leeuwis et al. (2014) se partió de la base que la promoción de la capacidad para innovar es el centro de los procesos que permiten el desarrollo, ya que la innovación es un elemento clave para la transición hacia sistemas agrícolas sostenibles.

En este trabajo se considera a la innovación en un sentido amplio, como plantean Lee et al. (2012) e incluye cualquier nueva idea o enfoque que es aplicado para crear valor. Comprende invenciones científicas, patentes, avances tecnológicos e incluso nuevas formas de hacer las cosas. Asimismo, y tal cual lo plantean Hall et al. (2005) la innovación es la aplicación del conocimiento, para lograr resultados deseados en el ámbito social, ecológico o económico. Este conocimiento puede adquirirse mediante el aprendizaje, la investigación o la experiencia y puede provenir de una variedad de fuentes y actores, pero hasta que no sea aplicado no puede considerarse una innovación (Hall et al., 2006; 2005).
El enfoque de Sistemas de Innovación Agrícola (Klerkx et al., 2012) ha venido incrementando su aceptación como forma de entender, organizar y dar soporte a la innovación. La innovación es considerada como el resultado de un proceso de trabajo en red y aprendizaje interactivo entre un grupo heterogéneo de actores: productores, proveedores de insumos, procesadores, comerciantes, investigadores, extensionistas, funcionarios gubernamentales y organizaciones de la sociedad civil (Botha et al., 2016; 2014).

Desde este proyecto se entendió que el trabajo conjunto entre productores, investigadores e instituciones utilizando el enfoque de co-innovación, podría generar un proceso cíclico de planificación, implementación, observación y reflexión que permitiera emerger la innovación a partir del aprendizaje interactivo entre los actores involucrados (Coutts et al., 2016).

\subsubsection{Los tres pilares del enfoque de co-innovación}

Desde el punto de vista teórico y de acuerdo con Rossing et al. (2010) y con los avances conceptuales de este equipo de investigación (Albicette et al., 2017), el enfoque de co-innovación es el resultado de la combinación de tres dominios (Figura 1): teoría de sistemas adaptativos complejos, aprendizaje social y monitoreo y evaluación dinámicos. Esto quiere decir que la co-innovación implica un proceso de aprendizaje colectivo (aprendizaje social), en un contexto intencionalmente diseñado (dinámicas de monitoreo y evaluación) considerando una visión de sistemas adaptativos complejos. En esta sección explicaremos brevemente cada uno de esos dominios. 


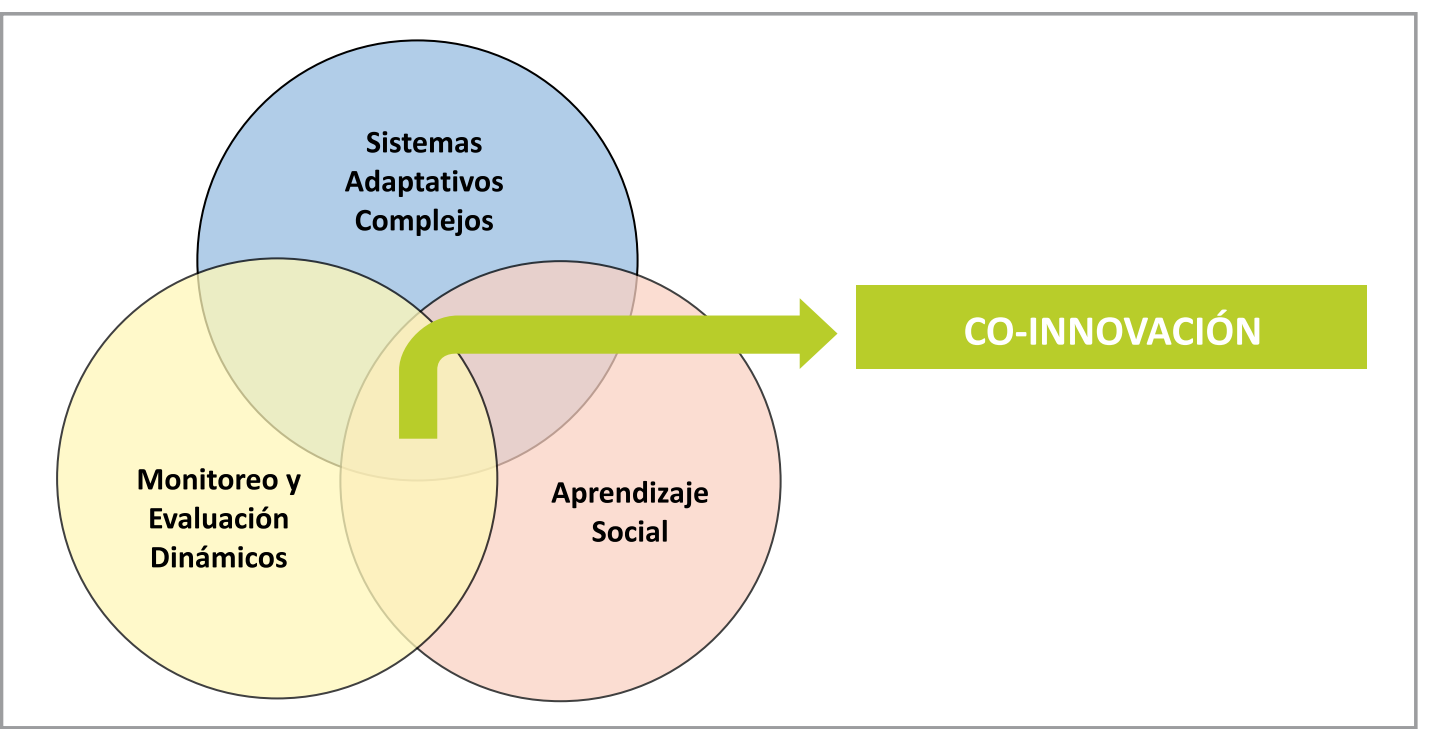

Figura 1. Co-innovación: resultado de la interacción de tres dominios.

\subsubsection{Sistemas adaptativos complejos}

En el enfoque de co-innovación, los predios y su contexto se entienden como Sistemas Adaptativos Complejos - CAS, por su sigla en inglés - (Axelrod y Cohen, 2000), en el sentido de que son múltiples componentes de sistemas interconectados (agricultores, agentes, entidades), con la capacidad de cambiar y aprender de la experiencia y hacer que las cosas sucedan en las interacciones con otros agentes (Dogliotti et al., 2012).

El abordaje a nivel predial implica un análisis considerando dos subsistemas y su relación con el entorno (Sorensen y Kristensen, 1992): (i) el sub-sistema de gestión que involucra a la familia, sus objetivos y procesos de toma de decisión y (ii) el sub-sistema de producción que involucra aspectos económico- productivos y ambientales. A nivel regional implica una visión más amplia de la innovación agrícola, vista como resultado de múltiples interacciones entre componentes de los sistemas de producción, cadenas de abastecimiento y sistemas económicos, entorno político y sistemas sociales, lo que se refleja en la idea de que la innovación es el resultado del accionar de un "Sistema de Innovación Agrícola” - AIS, por su sigla en inglés - (Klerkx et al., 2012).

\subsubsection{Aprendizaje social}

Dogliotti et al. (2012) definen aprendizaje social como un proceso en el cual se aprende individual y colectivamente a través de la interacción con otras personas o actores para resolver un problema. Durante ese proceso los mismos actores adquieren nuevas habilidades, tanto técnicas como sociales, producen conocimiento y desarrollan relaciones. Asimismo, destacan que la organización de instancias de aprendizaje social entre los diferentes actores (investigadores, productores y organizaciones) permite generar un ámbito apropiado para que ocurra la innovación. En este marco los investigadores pueden desempeñar un papel en el apoyo al aprendizaje de las partes interesadas, y en el mismo proceso aprender ellos también.

El aprendizaje para la innovación implica así un aprendizaje cognitivo (acerca de «cosas que una persona no sabía»), pero también permite que los marcos mentales constituyan la base para la búsqueda de soluciones más creativas y colectivas (Aarts 1998, citado por Rossing et al., 2010). Douthwaite et al. (2002) profundizan en este punto y vinculan la innovación con un proceso de selección por aprendizaje. Los autores plantean que los interesados se involucran con una nue- 
va tecnología y desarrollan ciclos evolutivos de selección y en sus interacciones crean recombinaciones de ideas y experiencias generando novedades. Este modelo tiene implicaciones para el manejo del cambio tecnológico agrícola (Douthwaite et al., 2002).

Para lograr un aprendizaje exitoso en el proceso se requiere una integración temprana y equidad para todos los interesados, su plena participación sin barreras y la facilitación del mismo. El diseño e implementación del proceso de aprendizaje social implica pensar, diseñar y organizar las dinámicas de grupos, así como ir informando sobre los avances y resultados (Akpo et al., 2015).

\subsubsection{Monitoreo y evaluación dinámicos}

El monitoreo y la evaluación dinámicos (M\&E) en procesos de co-innovación se utilizan fundamentalmente para promover el aprendizaje durante la ejecución del programa o proyecto, además de usarlo para la rendición de cuentas y gestión del mismo (Rossing et al., 2010; Douthwaite et al., 2003).

Para que el sistema de M\&E haga una contribución al aprendizaje de los actores, las partes interesadas deben reflexionar periódicamente sobre la validez de las hipótesis de impacto y los resultados que se obtienen durante la implementación del proyecto y no sólo al final del proceso. Esto permite incorporar las lecciones aprendidas en tiempo real, a medida que el proceso avanza (Dogliotti et al., 2012). Para ello el análisis de vías de impacto, se relaciona con el diseño de estrategias que incluyen una "previsualización" de los resultados esperados del proyecto trabajando conjuntamente con los usuarios que posteriormente utilizarán los mismos. Estos resultados esperados son la base para el proceso de monitoreo y evaluación dinámicos (Alvarez et al., 2010).

Para activar procesos de reflexión considerando los diversos actores, sus interacciones y retroalimentaciones, es necesario no sólo generar los espacios de diálogo, sino también proveerlos de una cuidadosa facilitación de los procesos grupales, para permitir que se atiendan las necesidades de todos los actores y básicamente les permita negociar entre sí (Moschitz et al., 2015). La facilitación es necesaria para generar un entorno de aprendizaje, seleccionar las herramientas adecuadas de aprendizaje y lograr una negociación activa entre los actores (Crawford et al., 2007).

\subsubsection{Un poco de historia: De la Transferencia de Tecnología (TT) a los Sistemas de Innovación Agrícola (AIS)}

La transferencia de conocimiento de forma tradicional y lineal, como un proceso descendente de las instituciones de investigación a los agricultores, sigue siendo un modelo predominante en el mundo y ha conducido a un bajo uso de muchas tecnologías agrícolas mejoradas (Moschitz et al., 2015; Hellin, 2012; Okali et al., 1994; Scoones y Thompson, 1994). Este modelo ha sido y es cuestionado y en parte se ha reemplazado por enfoques sistémicos en los cuales los productores son vistos como actores importantes del proceso de generación del conocimiento y no solo como simples consumidores de tecnologías generadas por la investigación y transferidos por los servicios de extensión para su adopción (Moschitz et al., 2015).

Una evolución de los enfoques para la promoción de la innovación se presenta en el Cuadro 1. En las últimas décadas, la comprensión teórica de la innovación ha avanzado considerablemente y el "modelo lineal hacia la innovación" dominante ha sido sustituido por otros cuerpos de pensamientos (Leeuwis y Aarts, 2011), como los Sistemas de Información y Conocimiento Agrícola (AKIS - por su sigla en inglés; Röling y Engel, 1991) y Sistemas de Innovación Agrícola - AIS, por su sigla en inglés - (Klerkx et al., 2010), entre otros. 
Cuadro 1. Evolución de enfoques prototípicos y tipo de perspectiva para el desarrollo de innovaciones y sus respectivos atributos, adaptado de Klerkx et al. (2012), Albicette (2010) y Probst y Hagmann (2006; 2003).

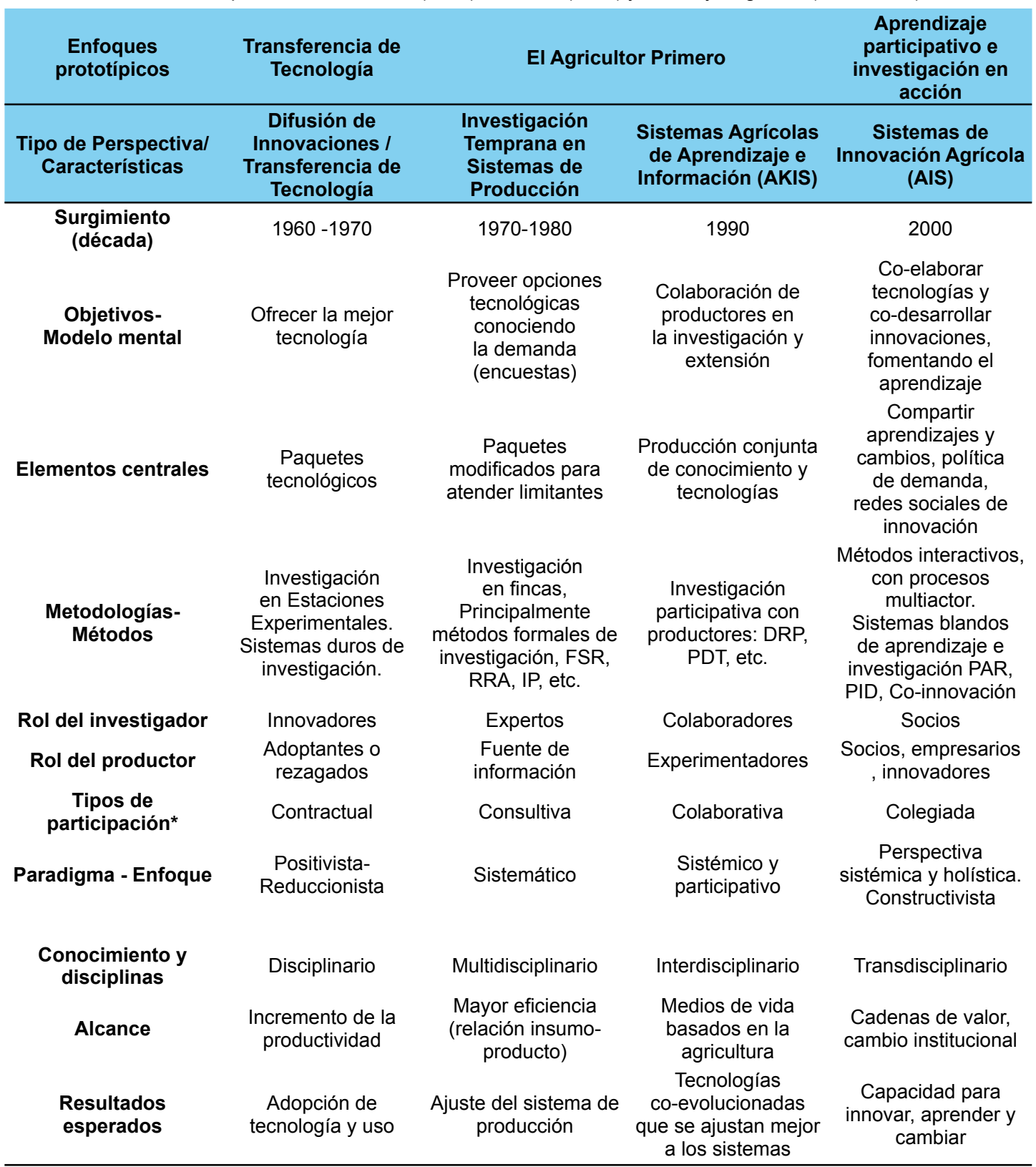

* Clasificación de Pretty, 1995. FSR: Investigación en sistemas de producción (Tripp, 1991), RRA: Diagnóstico rural rápido (Schönhuth y Kievelitz, 1994), IP: Investigación participativa (Chambers et al., 1989), PAR: Investigación acción participativa (MacDonald, 2012), DRP: Diagnóstico rural participativo (Schönhuth y Kievelitz, 1994), PDT: Desarrollo participativo de tecnologías (Van Veldhuizen et al., 2006), PID: Desarrollo participativo de innovaciones (Scheuermeier et al., 2004) 
Esta evolución ha sido marcada por algunos aspectos clave:

- Con la teoría de difusión de innovaciones (Rogers, 1995) la innovación pasó a ser el último paso del modelo lineal de transferencia de tecnología. Comenzando en la investigación básica, continuando con la investigación aplicada y adaptativa, para que finalmente los extensionistas contactaran a los productores para difundir la tecnología (Röling, 2006).

- La participación activa de los agricultores en el proceso de identificación de problemas y búsqueda de alternativas de mejora comenzó a mejorar el impacto de las propuestas generadas (Leeuwis y Van den Ban, 2004).

- La valoración de que los agricultores siempre han realizado experimentos informales con nuevas ideas que surgen de ellos o aprenden de otros agricultores, investigadores, extensionistas y medios de difusión (Horne y Stür, 2006; Van Veldhuizen et al., 2006; Waters-Bayer y Bayer, 2005).

- La concepción de que el conocimiento puede adquirirse mediante el aprendizaje, la investigación o la experiencia y puede provenir de una variedad de fuentes y actores como estaciones experimentales, agricultores, profesionales, organizaciones, empresas, organismos de extensión, etc. (Cramb, 2006; Van Huis, 2006).

- La aceptación de que en los procesos de innovación el aprendizaje es clave, lo cual es planteado en el modelo de Selección por Aprendizaje - LS, por su sigla en inglés - presentado por Douthwaite et al. (2002). Estos autores consideran tanto "el aprender haciendo" (durante el proceso de elaboración), como "el aprender usando" (durante el uso de la tecnología). De esa manera se logra un mejor entendimiento de los resultados de investigación por parte de los productores y se generan nuevas preguntas de investigación para los investigadores (Douthwaite et al., 2002). Asimismo, los aportes de los productores desde la práctica y su percepción de la tecnología (oportunidades y restricciones) mejoran el proceso de investigación (Douthwaite et al., 2001).

- Adoptando el enfoque de Sistemas de Innovación Agrícola - AIS, por su sigla en inglés - se deja de proveer la nueva tecnología a los usuarios y se pasa a la facilitación de procesos de innovación, en los cuales las nuevas soluciones a los problemas tecnológicos son co-producidos por diversos actores en un proceso interactivo de aprendizaje (Coutts et al., 2016). 


\subsubsection{Principios para la aplicación del enfoque de co-innovación}

El primer antecedente relevante con relación a proyectos diseñados en base al enfoque de co-innovación fue el proyecto EULACIAS, que se focalizó en estimular la re-orientación estratégica de predios familiares en tres estudios de caso en América Latina (Rossing et al., 2010). Uruguay era uno de los estudios de caso de dicho proyecto, donde se trabajó con productores hortícola-ganaderos (Dogliotti et al., 2014). Más recientemente ha habido avances en Nueva Zelanda con el proyecto Primary Innovation que aplica el enfoque de co-innovación para abordar los desafíos contemporáneos de la agricultura moderna (Srinivasan et al., 2016; Turner et al., 2016; Vereijssen, et al., 2016; Botha et al., 2014). Asimismo, Botha et al. (2017b) a partir de su trabajo de exploración de nueve experiencias de co-innovación, plantean que este enfoque ha ido ganando interés en los últimos años como forma de promover la innovación y el aprendizaje en la agricultura y en el manejo de los recursos naturales.

Considerando los antecedentes en Nueva Zelanda, Coutts et al. (2014) destacan que la implementación de la co-innovación es contexto-específica y adaptativa, es decir, que la co-innovación debe adaptarse a la situación particular, que a su vez cambiará con el tiempo. Los autores identificaron nueve principios que deben ser llevados a la práctica en la coinnovación (Coutts et al., 2017; 2016):

- Tomarse el tiempo necesario para entender el problema desde diferentes puntos de vista.

- Ser incluyente, asegurarse de que todos los actores necesarios estén presentes para comprender el problema, sus causas y desarrollar soluciones viables.

- Participar y valorar todas las fuentes de conocimiento, buscar nuevas ideas y tomar el tiempo para escuchar las diferentes perspectivas.

- Esforzarse por aprender unos de otros escuchando y comprendiendo activamente. Estar abierto a nuevas ideas y estar dispuesto a dejar que su propio entendimiento y perspectivas evolucionen.

- Mantener la visión compartida o la "ambición de cambio”, refrescándola periódicamente.

- Ser honesto, abierto y constructivo en las interacciones con otros participantes.

- Tener en cuenta el contexto más amplio del problema y cualquier cambio real o potencial que pueda ocurrir.

- Ser flexible y adaptable.

- Seguir el proceso de co-innovación a pesar de las frustraciones.

\subsection{La intensificación ecológica como base para las propuestas técnicas}

La intensificación ecológica promueve las funciones de soporte y regulación naturales del ecosistema por medio del manejo inteligente e intensivo de la biodiversidad, de la energía solar y de los ciclos biogeoquímicos. Desde esta concepción, la intensificación de la producción agropecuaria implica sustituir lo más posible el uso de insumos agrícolas y trabajo humano por procesos ecológicos; lo que se contrapone a la concepción convencional de intensificación donde se propone el reemplazo de la mano de obra por las tecnologías de insumo (Tittonell, 2014).

En diversos países de Latinoamérica, los sistemas productivos agropecuarios se hallan frente a un notable proceso de intensificación, que trae aparejadas ventajas y desventajas desde el punto de vista socioeconómico y ambiental. Beneficios económicos de corto plazo se encuentran frecuentemente ligados al deterioro de los recursos productivos en el mediano y en el largo plazo (Serageldin, 2003). La magnitud de tal deterioro y su reversibilidad dependen de la intensidad y eficiencia en el uso de los recursos y de las propiedades de resistencia y resiliencia de los ecosistemas (Holling, 2000). Las consecuencias sociales, económicas y ambientales de tales procesos de deterioro se encuentran a menudo estrechamente interrelacionadas. Fenómenos socioeconómicos como la migración hacia centros urbanos y la concentración de tierras y/o de otros recursos productivos cons- 
tituyen ejemplos claros de este tipo (Bucher y Huszar, 1999). Tales consecuencias recaen notablemente sobre los productores de menores recursos, en especial quienes carecen de la capacidad de compensar el deterioro en la productividad de sus tierras mediante el uso de insumos externos (Tittonell y De Grazia, 2011).

Necesitamos crear modelos de intensificación alternativos, que puedan ser adaptados a las realidades biofísicas y socioeconómicas de los diversos agroecosistemas globales, y que sean ecológicamente intensivos. Las fuentes de conocimiento para este nuevo modelo de intensificación no provienen solamente de la ciencia; los saberes locales y el estudio de la naturaleza son fuentes de inspiración claves. Los mismos principios ecológicos que permiten una intensificación sostenible de la agricultura familiar de pequeña escala, son útiles a la hora de 'extensificar' la agricultura comercial de gran escala sin la necesidad de perder productividad. Los principios son los mismos, pero los métodos tal vez no (Tittonell, 2014). A nivel mundial un ejemplo de la intensificación ecológica es la agroecología, que no es solamente una disciplina científica sino también el resultado de las acciones y estrategias de los movimientos campesinos.

\subsubsection{Base conceptual de la propuesta técnica}

La ganadería de cría en Uruguay tiene como principal base forrajera el campo natural. En general, la condición y estado del campo natural presenta síntomas claros de degradación, tanto cualitativos como cuantitativos que se explican en parte por haber sido sometidos a una elevada intensidad de pastoreo o carga animal (Boggiano, 2003). Esto genera bajos niveles de eficiencia productiva y reproductiva, bajos ingresos de los productores y alta vulnerabilidad a las variaciones climáticas (Soca et al., 2013).

La investigación nacional y regional ha avanzado en el diseño de un modelo de producción ganadera que puede resultar en aumentos significativos de producción de carne e ingreso familiar, conservando la provisión de servicios ecosistémicos (Soca et al., 2013; Carvalho et al., 2009a; 2009b).

Carvalho et al., (2008) muestran que mediante el manejo de carga variable por estaciones sería posible triplicar la producción de carne por hectárea de los sistemas ganaderos promedio del Uruguay, sin adicionar insumos externos (Figura 2).

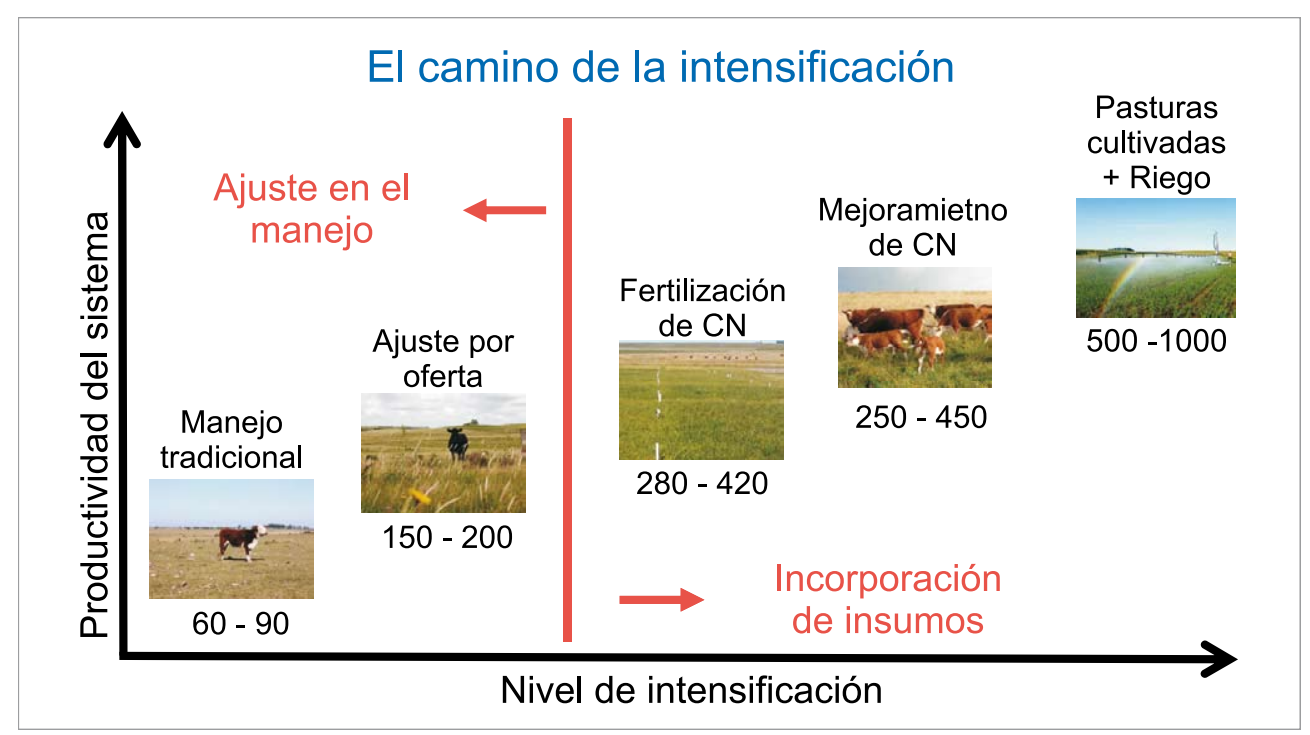

Figura 2. Producción de carne (kg PV/ha año) bajo diferentes niveles de intensificación en los campos naturales (adaptado de Carvalho et al., 2008). 
A nivel nacional, Soca y Orcasberro (1992) hacen la primera propuesta que integra el cambio de altura de forraje y condición corporal durante el año para obtener buenos resultados reproductivos en sistemas criadores basados en campo natural (Figura 3). Posteriormente otras propuestas sobre la misma base fueron desarrolladas centradas en el flujo de energía y en el control de la oferta de forraje para obtener los mismos objetivos (Do Carmo et al., 2016).

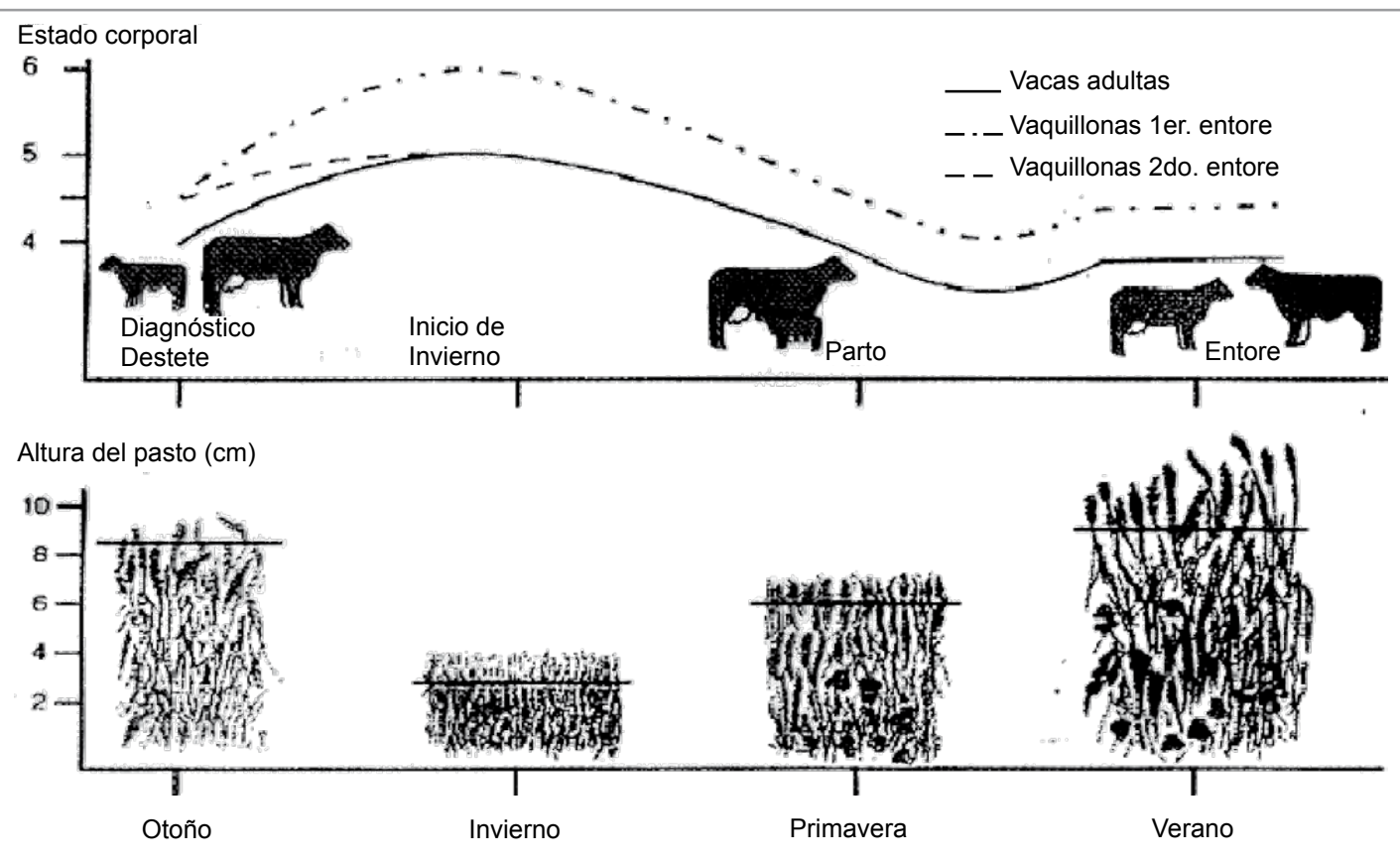

Figura 3. Propuesta de cambio de altura del forraje y condición corporal a lo largo del año para vacas de cría sobre campo natural (Soca y Orcasberro, 1992).

El control de la oferta de forraje definido como los kilogramos $(\mathrm{kg})$ de materia seca cada $100 \mathrm{~kg}$ de peso vivo animal es una de las principales herramientas para controlar la intensidad de pastoreo en sistemas de cría vacuna sobre campo natural (Do Carmo et al., 2014). Experimentos de pastoreo realizados en Uruguay demostraron que el control anual y estacional de la intensidad de pastoreo, mejoró la producción por vaca y unidad de superficie de la cría vacuna. Dichos cambios, se basaron en mejoras de la eficiencia de uso de la energía por el rodeo dado que se incrementó la producción por vaca en magnitud superior a las estimaciones del consumo de energía (Do Carmo et al., 2016). Esto se confirma con la relación positiva entre mejora de la oferta de forraje y en los niveles de hormonas (Carriquiry et al.,
2012), los cambios en la conducta espacio temporal de pastoreo (Scarlato et al., 2012) y en la adaptación metabólica de largo plazo (Do Carmo et al., 2016).

Estos trabajos han sido realizados en estaciones experimentales, considerando sólo algunos componentes de los sistemas productivos. Son pocos los trabajos que evalúen la aplicación de la información generada de manera integrada en sistemas de producción reales, considerando los objetivos del productor y su familia. A modo de ejemplo puede ser mencionado el proyecto "Redes de Referencia" desarrollado en establecimientos ganaderos en Río Grande do Sul, con resultados muy positivos, aunque con un uso importante de insumos (Santos et al., 2008). 
Estos modelos, aplicados a nivel de predio, fueron la base para el trabajo en este proyecto y se basan en la aplicación de tecnologías ecológicamente intensivas, dependiendo más del conocimiento que de los insumos. Apuntan a mantener niveles de área foliar más altos para aumentar la producción de forraje y a gestionar el pastoreo de modo de sincronizar los requerimientos animales con la oferta de forraje. Se aplican medidas de bajo costo y alto impacto productivo para la cría y recría y se complementa con el uso de tecnologías de insumo, considerando los objetivos del productor y su familia. De este modo se incrementa la producción de forraje, la producción de carne y los resultados económicos de los sistemas de cría vacuna. A su vez, aumenta la resiliencia de los sistemas ante la variabilidad climática (Nabinger et al., 2011, Soca et al., 2007).

\subsubsection{Trabajar con más forraje y mejorar su gestión}

Desde una perspectiva del campo natural, el concepto de "trabajar con más pasto" implica reducir la intensidad de pastoreo para superar la condición de sobrepastoreo, predominante en muchos de los sistemas criadores.

El incremento de los niveles medios de biomasa presentes en el tapiz genera la posibilidad de captar mayor energía solar y al mismo tiempo mejorar la eficiencia a nivel de la producción secundaria (Nabinger, 1998). Eso posibilita que una porción mayor de la energía sea destinada a mantener los restantes elementos del ecosistema, como la diversidad de fauna o la materia orgánica del suelo. A nivel regional se reportan aumentos en los stocks de carbono y una mejora de las propiedades físicas del suelo al trabajar con mayores ofertas de forraje asociado a niveles superiores de producción y acumulación del campo natural (Guterres et al., 2006; Bertol et al., 1998). Esto se explica en gran medida por la relación que existe entre la biomasa aérea y la radicular, que para el caso de los pastizales nativos adquiere mayor importancia a mayor profundidad (Ansín et al., 1998). A nivel internacional, el manejo del pastoreo es señalado como una herramienta posible de incrementar los niveles de carbono en el suelo (Conant et al., 2017).

Desde el punto de vista del animal en pastoreo, una estructura del pastizal entre 1400 y $2200 \mathrm{~kg} \mathrm{MS} / \mathrm{ha}$ o una altura entre 9 y $13 \mathrm{~cm}$ y una frecuencia de matas menor a $30-35 \%$, reducen el tiempo de pastoreo y el desplazamiento diario, lo que disminuye el costo de cosecha (Bremm et al., 2012; Da Trindade et al., 2012). Mientras que alturas de 9,5 y 11,4 $\mathrm{cm}$ maximizan el consumo animal en ovejas y vaquillonas respectivamente, a través de una mayor masa de bocado y una mayor tasa de ingestión (Gonçalves et al., 2009).

A nivel de sistema de producción, las etapas necesarias para pasar de una estructura de pasto limitante a una pastura con mayor volumen de hojas y más productiva, puede lograrse por diferentes vías. En cualquier caso, es importante promover cambios durante la primavera, que es la estación con mayor probabilidad de alta producción del campo natural. La estrategia puede implicar ajustes de la carga global, en los casos más extremos, o reorganizar la carga entre los diferentes recursos forrajeros y las necesidades de los animales. La velocidad o el impacto de un ajuste de este tipo está condicionado por la historia de uso del recurso y por las condiciones ambientales, fundamentalmente el nivel de precipitaciones en la primavera-verano. En este sentido es importante considerar que la gestión del pasto realizada por los ganaderos es por demás compleja en la medida que están involucrados modelos de toma de decisión no siempre explícitos. Al tiempo que existe una gran adaptación a las condiciones cambiantes y a los objetivos del ganadero. Por tanto, es esencial contemplar esta característica a la hora de promover cambios en este aspecto (Duru y Hubert, 2003).

El control de la carga animal es la principal medida vinculada al manejo de la intensidad de pastoreo a través de la cual se regula el flujo de energía entre la productividad primaria y secundaria en ecosistemas pastoriles (Heitschmidt y Taylor, 1991). La combinación 
de diferentes especies animales en pastoreo es otro elemento que determina la productividad primaria y secundaria del sistema, mostrando ventajas la utilización de más de una especie animal en ambientes heterogéneos (Nolan, 1996). A nivel nacional la información es clara en señalar que el pastoreo solo con ovinos o en relaciones ovino/vacuno muy altas producen una degradación del tapiz por sobrepastoreo de algunas especies y el rechazo de otras (Formoso y Pereira, 2008). Este proceso se da en el corto plazo y en mayor medida cuanto mayor sea la carga ovina, relaciones entre 1 y 3 pueden ser consideradas adecuadas en la mayoría de las situaciones.

El forraje debe ser adecuadamente asignado, considerando la altura del mismo en cada potrero y la categoría animal, según el momento del año. La demanda de energía por parte de los animales varía con el peso y estado fisiológico de los mismos, mientras que la producción de forraje varía con la lluvia, temperatura e índice de área foliar, por lo que requiere un ajuste preciso entre la oferta y demanda de forraje a asignar (Wheeler et al., 1973).

El cierre o diferimiento primaveral y/u otoñal acompañado o no de fertilización, es una tecnología sugerida para incrementar los niveles medios de biomasa de las pasturas y a partir de ahí la mejora en la gestión en situaciones de sobrepastoreo histórico. Resultados a nivel regional muestran el impacto de este manejo (Fedrigo 2015; 2011). Un resultado semejante se puede lograr con bajas cargas en estaciones con condiciones de altas tasas de crecimiento.

El pastoreo intenso a fin del verano o principio del otoño de los mejoramientos de campos es otro de los manejos recomendados que permiten el alivio de algunas áreas más deprimidas y mejora el estado de los animales, sobre todo la vaca de cría. Con esta medida se aprovecha el forraje producido en la estación de crecimiento al tiempo que se abre el tapiz para que llegue más luz y la leguminosa pueda brotar o rebrotar antes en el otoño (Carámbula, 2001).

\subsubsection{Medidas de bajo costo y alto impacto productivo para la cría y recría}

Complementario al trabajo de aumentar la cantidad de forraje y mejorar la gestión del mismo, existen diversos trabajos a nivel nacional que demuestran que la aplicación de determinadas tecnologías de bajo costo en la cría y recría, permite acompasar la oferta de pasto con la demanda animal y generar un alto impacto productivo (Do Carmo et al., 2014; Quintans y Scarsi, 2013; Soca et al., 2013; Quintans et al., 2008a; Rovira, 1996; Soca y Orcasberro, 1992).

Para la cría existen tres medidas de manejo estratégicas fundamentales que determinan el uso de la energía:

- La época y duración del entore, que realizado entre los meses de diciembre a febrero permite que los partos se concentren en los meses de máximo crecimiento de forraje. Realizar el entore de vaquillonas más temprano permite que tengan mayor tiempo de recuperación para su segundo entore, que es crítico, ya que esta categoría está aún creciendo.

- El destete definitivo realizado en marzo (6 meses de edad promedio de los terneros) permite dar tiempo a que las vacas recuperen condición corporal antes del invierno, si se las maneja en potreros con buena disponibilidad de forraje.

- El diagnóstico de gestación, realizado al menos 45 días luego de retirados los toros, permite identificar cuáles vacas están preñadas o vacías y así asignar de manera diferencial los recursos.

Complementariamente, existen para la cría medidas de manejo tácticas, que permiten corregir problemas y hacer un uso más eficiente de la energía:

- El diagnóstico de actividad ovárica, realizado a mitad de entore permite conocer el estado de la vaca (preñada, ciclando, en anestro superficial o en anestro profundo) y posibilita tomar decisiones sobre medidas 
de manejo (ej: destete temporario, destete precoz), a tiempo y en base a información objetiva, para mejorar la preñez.

- El destete temporario con tablilla nasal mejora el balance energético de la vaca, permitiendo incrementar el porcentaje de preñez. La respuesta de esta medida de manejo en términos de aumento del porcentaje de preñez depende de la condición corporal de la vaca. El destete temporario consiste en la aplicación de una tablilla nasal al ternero que está al pie de su madre, impidiéndole mamar. Esta tablilla se mantiene durante 11 a 14 días. El entablillado se debe efectuar por lo menos 40 días antes de que concluya el entore, ya que su efecto no es inmediato Es una técnica que tiene efecto en vacas en moderada condición corporal. El mayor impacto del destete temporario se logra en aquella categoría de vacas intermedia, con una condición corporal cercana a 4 unidades. No es recomendada en vacas en mal estado corporal, por ejemplo, por debajo de 3 unidades de condición, que requieren de medidas de manejo más drásticas.

- El destete precoz, mejora el balance energético de la vaca al suprimirle por completo los requerimientos de lactación, lo que permite incrementar el porcentaje de preñez. Es la separación definitiva del ternero de la vaca, a una edad tal en la que el ternero no se vea afectado en su crecimiento futuro. Es recomendable hacerlo en vacas de bajo estado corporal (menor a 3,5), en vacas de primera cría, vacas paridas muy tarde o en anestro profundo durante el entore. Se requiere que los terneros tengan al menos 2 meses de edad y un peso mínimo de 70 kilos para que se adapten a la nueva alimentación que sustituye a la leche. Se debe realizar al menos 30 días antes de que concluya el entore para que tenga efecto.

- El estado nutricional de las vacas de cría se puede conocer mediante apreciación visual, determinado su condición corporal. Evaluar la condición corporal de las vacas en momentos críticos del ciclo productivo, permite realizar un manejo por condición corporal asignando diferentes recursos según la condición de cada vaca y la condición corporal objetivo para ese momento.

Con respecto a la fase de recría, el principal concepto considerado para el desarrollo de "buenas madres" fue que el manejo diferencial de las terneras y vaquillonas de reemplazo de manera de evitar pérdidas de peso en invierno, sobre todo en el primer invierno de la ternera, permite lograr una buena tasa de crecimiento post-destete, y llegar al primer entore con dos años o menos.

En estos sistemas es muy importante realizar un buen manejo sanitario de todos los animales con énfasis en la revisión de toros, la prevención y manejo de enfermedades reproductivas y el control parasitario. 



\section{CAPÍTULO III METODOLOGÍA DE TRABAJO}

El enfoque de co-innovación (Rossing et al., 2010) fue adaptado e implementado simultáneamente, a nivel predial y regional (Albicette et al., 2017; Albicette et al., 2016b), con instancias específicas que conectaron ambos procesos (Figura 4). El trabajo se desarrolló entre abril de 2012 y diciembre de 2015 e involucró dos zonas del departamento de Rocha: (i) las Sierras, en el eje de las Rutas 109 y 15, (ii) alrededores de Castillos (Figura 5).

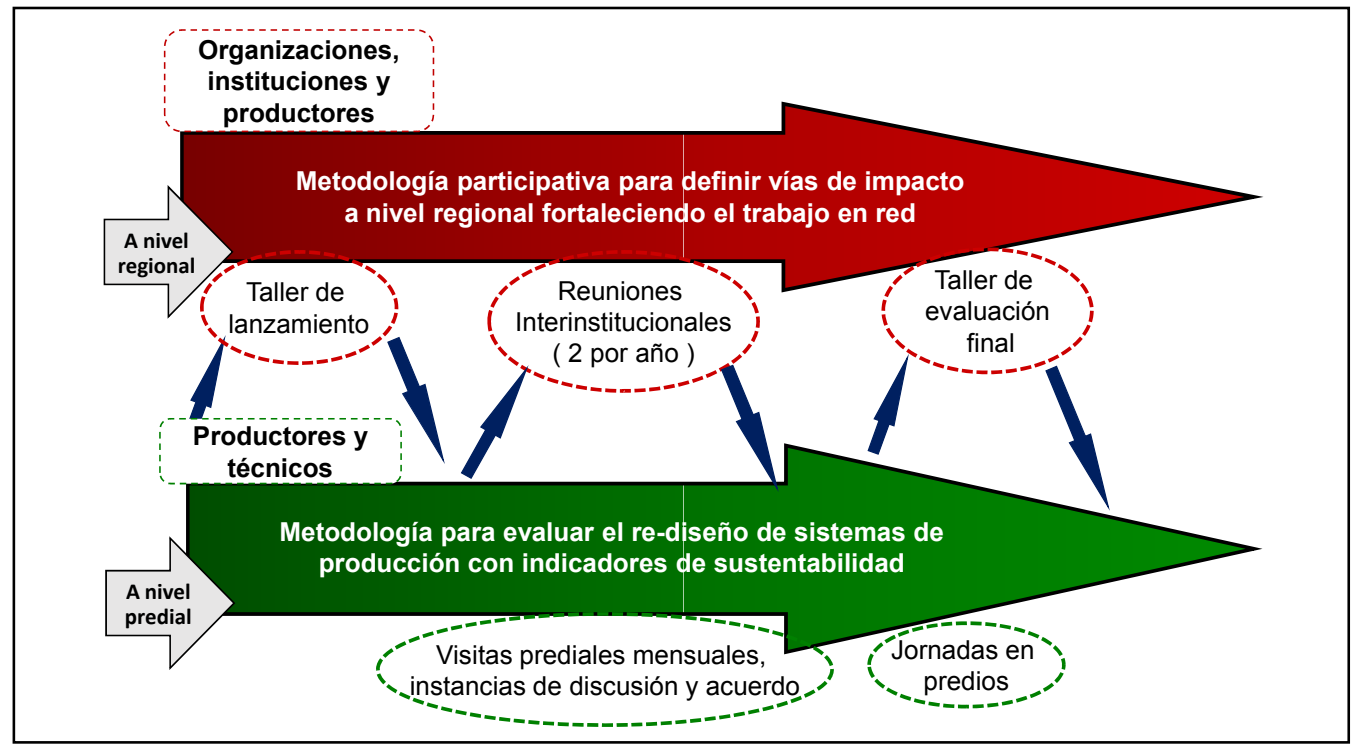

Figura 4. Abordaje metodológico del proyecto.

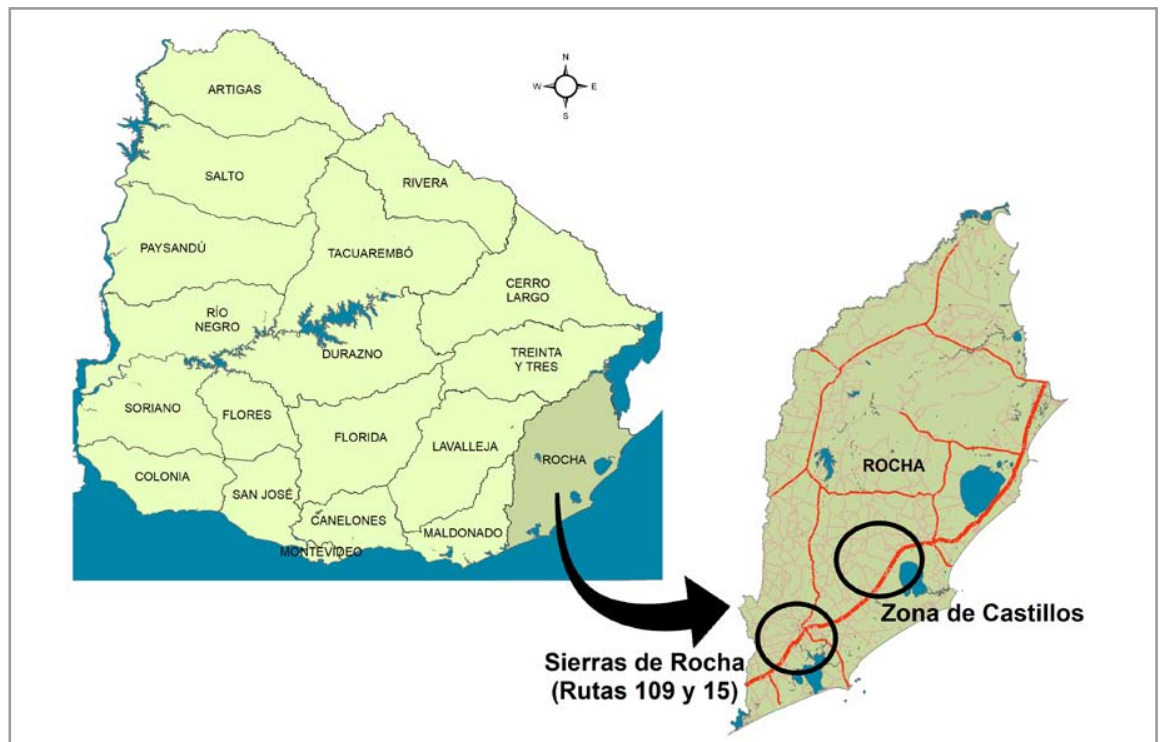

Figura 5. Localización geográfica del trabajo. 
Aplicar el enfoque de co-innovación a nivel predial y regional implicó la formación de un equipo interdisciplinario, integrado por investigadores dispuestos a participar en este tipo de procesos, que incluía especialistas en gestión predial, producción animal, manejo de pasturas, ciencias del suelo, ciencias ambientales y ciencias sociales. El equipo de investigación siguió un proceso de investigación participativa - Participatory Action Research, PAR - que presupone un proceso cíclico de investigación, reflexión y acción (MacDonald, 2012).

Un técnico extensionista cumplió el rol de "técnico de campo", vinculándose directamente con los productores a través de visitas mensuales y acompañando cada una de las etapas de trabajo en los predios. En cada visita, dicho técnico interactuaba con los productores y simultáneamente relevaba datos sobre aspectos económicos, manejo de pasturas y animales y recursos utilizados. También facilitó la conexión entre los productores y los demás miembros del equipo, "técnicos especialistas", que contribuyeron al proceso desde su especialidad y relevaron información del predio para monitorear indicadores. Algunos de los técnicos especialistas también apoyaron y facilitaron el trabajo a nivel regional.

El trabajo en equipo fue un desafío para los participantes y se implementó a partir de reuniones de trabajo entre todos los miembros (al menos dos veces por año), reuniones específicas por grupos disciplinarios y a través del accionar conjunto a lo largo del proceso. Al inicio fue necesario generar una visión y lenguaje común sobre los objetivos de trabajo, acordar las metodologías a implementar y capacitarse en los casos requeridos. Durante el proceso se generaron diversas instancias para reflexionar sobre los avances, discutir resultados parciales y analizar cómo comunicarlos, planificar días de campo y definir los pasos para continuar y mejorar la ejecución del proyecto (Albicette et al., 2017).

\subsection{Metodología a nivel predial}

Se utilizó el método de estudio de casos (Yin, 2013), para el que fueron seleccionados sie- te predios, conjuntamente entre los investigadores del INIA y los equipos técnicos de organizaciones de productores locales (Sociedad de Fomento Rural Ruta 109 y Sociedad de Fomento Rural Castillos) y nacionales (Comisión Nacional de Fomento Rural). Para la selección se tuvieron en cuenta cuatro criterios generales: (i) producción ganadera basada en campo natural como principal fuente de ingresos, (ii) representatividad de los principales sistemas de producción de la región y de la diversidad en el tipo de suelo, tamaño del predio, proporción del área ocupada por campo natural, relación ovino/vacuno, producción ganadera combinada -o no- con producción agrícola, (iii) voluntad y motivación para interactuar con las diferentes actores y para discutir e incorporar a nivel del predio los cambios acordados para mejorar la sustentabilidad, y (iv) socios de la organización local de productores.

Para evaluar la sustentabilidad a nivel predial se utilizó el marco para la evaluación de sistemas de manejo incorporando indicadores de sustentabilidad - MESMIS - desarrollado por Masera et al. (2000). Se trata principalmente de una herramienta de planificación para la mejora de los sistemas hacia la sustentabilidad a través de un proceso, sistemático, sistémico, participativo, flexible e interdisciplinario, basado en indicadores (Speelman et al., 2007; López Ridaura et al., 2005; 2002; Masera et al., 2000). Asimismo, la metodología permite evaluar la sustentabilidad en un predio a lo largo del tiempo y comparar diferentes predios con los mismos indicadores (Masera et al., 2000).

En forma resumida y para describir el proceso de evaluación, el marco MESMIS define atributos básicos de sustentabilidad: productividad, equidad, estabilidad, resiliencia, confiabilidad, adaptabilidad y autodependencia. Considerando dichos atributos propone identificar los puntos críticos, es decir los aspectos y procesos de tipo económico, social, tecnológico o ambiental que limitan o fortalecen la capacidad de los sistemas para sostenerse en el tiempo. Para cada punto crítico plantea seleccionar indicadores que 
permitan describir confiablemente el estado o cambio de condición de dicho aspecto del sistema de manejo. Dada la especificidad de los sistemas de manejo no se puede definir una lista universal de indicadores apropiados para todos los casos. Por el contrario, los indicadores utilizados dependerán de las características del problema bajo estudio, la escala del proyecto, el tipo de acceso y la disponibilidad de datos.
El trabajo con los productores y sus familias se realizó sobre la base de las visitas mensuales del técnico de campo a los predios, siguiendo cuatro etapas (Dogliotti et al., 2014), según se aprecia en el Cuadro 2: (i) caracterización (ii) diagnóstico, (iii) propuesta de re-diseño del sistema de producción; (iv) implementación, monitoreo y evaluación (M\&E) de la evolución de los cambios en el sistema.

Cuadro 2. Etapas del trabajo en los predios. Tomado de Albicette et al. (2016a).

\begin{tabular}{|c|c|c|c|}
\hline $\begin{array}{l}\text { Caracterización } \\
\text { (abr-dic 2012) }\end{array}$ & $\begin{array}{l}\text { Diagnóstico } \\
\text { (nov-dic 2012) }\end{array}$ & $\begin{array}{l}\text { Propuesta de } \\
\text { re-diseño } \\
\text { (jul-dic 2012) }\end{array}$ & $\begin{array}{c}\text { Implementación } \\
\text { monitoreo y evaluación } \\
\text { (ene 2013- jul 2015) }\end{array}$ \\
\hline $\begin{array}{l}\text { 1) Explicitar objetivos } \\
\text { familiares y prediales. }\end{array}$ & & & Implementar el re-diseño: \\
\hline $\begin{array}{l}\text { Consensuar la visión de } \\
\text { futuro - sustentabilidad. }\end{array}$ & & $\begin{array}{l}\text { Consensuar un plan de } \\
\text { mejora: }\end{array}$ & $\begin{array}{l}\text { 1) Acompañar y apoyar la } \\
\text { ejecución. }\end{array}$ \\
\hline $\begin{array}{l}\text { 2) Describir los recursos } \\
\text { y el funcionamiento del } \\
\text { predio. }\end{array}$ & $\begin{array}{l}\text { Acordar las fortalezas y } \\
\text { los aspectos de mejora, } \\
\text { identificando puntos } \\
\text { críticos. }\end{array}$ & $\begin{array}{l}\text { 1) Establecer metas y } \\
\text { cuantificar resultados } \\
\text { esperados. }\end{array}$ & $\begin{array}{l}\text { 2) Monitorear resultados } \\
\text { para apoyar la toma de } \\
\text { decisiones. }\end{array}$ \\
\hline
\end{tabular}

Durante las visitas del técnico de campo al predio se analizaba y discutía con el productor y su familia el manejo realizado desde la visita anterior y el requerido hasta la próxima visita. Cada visita tenía en general dos fases, que variaban su énfasis según la etapa del trabajo en el predio:

a) Recorrida de campo por todo el predio, para observar el estado de los animales, las pasturas y los demás componentes del sistema de producción y analizar la ejecución de las actividades acordadas durante la visita anterior y discutir posibles actividades futuras hasta la siguiente visita. Durante las visitas, los productores y el técnico de campo en conjunto redefinían actividades que no hubiera sido posible ejecutar y acordaban un plan de acción a ejecutar hasta la siguiente visita. b) Registro y análisis de la información, donde el técnico de campo registraba toda la información pertinente y devolvía al productor y su familia, información de monitoreo procesada.

Entre cada visita al predio, el técnico de campo procesaba la información de monitoreo e interactuaba y consultaba con los técnicos especialistas para nutrir el proceso.

Los técnicos especialistas realizaban visitas estratégicas a los predios acompañando al técnico de campo o solos, con el objetivo de interactuar directamente con el productor $y$ su familia y de recopilar la información necesaria para el monitoreo de los indicadores.

A continuación, se describen las cuatro etapas del trabajo en los predios: 


\subsubsection{Etapa 1: Caracterización}

Durante la etapa de caracterización de los predios (abril - diciembre 2012) se describió la estructura y el funcionamiento del sistema de producción, involucrando el subsistema de gestión y el subsistema de producción o biofísico. Para esto se realizaron varias entrevistas al productor y su familia, se estudiaron los registros disponibles de los tres años previos al inicio del proyecto y se realizaron observaciones y mediciones directas en el predio.

Se describió la composición de la familia, la edad de los miembros, el lugar de residencia, la superficie manejada, la tenencia de la tierra, su trayectoria en el campo y la historia laboral, la etapa del ciclo de vida familiar, la sucesión del predio, la existencia o no de trabajo extrapredial y las fuentes de ingresos. El acceso a bienes y servicios básicos para el desarrollo de la vida familiar se caracterizó con el indicador calidad de vida estructural, así como también se valoró la percepción de la propia familia sobre su calidad de vida. Complementariamente se describió la participación previa en proyectos y si contaban con asesoramiento técnico, así como los vínculos con otros productores y organizaciones locales. Considerando el subsistema de gestión se identificaron y describieron las personas que toman decisiones en el predio (equipo de gestión), sus objetivos y las principales ideas que involucraba su concepción de sustentabilidad. También se describió el uso de tecnologías y la valoración y uso de la planificación.

El subsistema de producción fue caracterizado en base a la disponibilidad de recursos, la asignación de los recursos a las actividades de producción y los indicadores de desempeño de las actividades productivas. Complementariamente se analizó el estado de los ecosistemas y su relación con las actividades de producción. En este sentido se realizó una descripción detallada de los recursos humanos, la infraestructura productiva, las actividades de producción desarrolladas (orientación, dimensionamiento, ma- nejo y resultados productivo-económicos), los suelos, las pasturas, el ecosistema en general y la fauna asociada (aves).

\subsubsection{Etapa 2: Diagnóstico}

Para el diagnóstico (noviembre - diciembre 2012), se identificaron y organizaron los puntos críticos según cuatro grupos de atributos de la sustentabilidad (productividad, estabilidad, confiabilidad-adaptabilidad-resiliencia y auto dependencia) y se seleccionaron los indicadores para definir punto de partida o línea de base y evaluar los cambios a nivel predial (monitoreo y evaluación), considerando las tres dimensiones de sustentabilidad: productiva-económica, ambiental y social (Masera et al., 2000).

Complementariamente se elaboró un "árbol de problemas" (AusAID, 2000) del sistema de producción para describir las principales relaciones y el orden jerárquico entre los diversos puntos críticos identificados en el diagnóstico y priorizar los aspectos más relevantes para trabajar en cada predio. Los puntos críticos y el árbol de problemas se discutieron con cada productor y su familia para llegar a un acuerdo sobre las principales limitantes y sus causas, a fin de abordarlos en la etapa de re-diseño.

Para el monitoreo de los indicadores seleccionados fue necesaria la medición de diversas variables del sistema productivo que se detallan metodológicamente a continuación, agrupadas por área. En el caso de los indicadores utilizados para el monitoreo de la sustentabilidad y para poder integrar los resultados obtenidos, se realizó una estandarización de dichos indicadores definiendo un valor deseable o de referencia y expresando luego el valor inicial y final de cada indicador como proporción de ese valor de referencia.

\section{i) Mediciones en el área productivo- económica}

Los indicadores productivo-económicos para los años previos al inicio del proyecto fueron estimados en base a registros que tenían los productores (guías de compra-venta, decla- 
raciones juradas, boletas). Durante la ejecución del proyecto se implementó un sistema de registro de información productivo- económica que permitió el cálculo de estos indicadores. Se registraron fecha, categoría, peso y precio en la compra y venta de animales, junto con los costos de producción.

Producción de carne equivalente por hectárea ( $\mathrm{kg} / \mathrm{ha}$ año). La sumatoria de los kilos de carne vacuna, los kilos de carne ovina y kilos de lana multiplicados por 2,48 (Oficialdegui, 1984), dividido por el área de pastoreo en hectáreas. Se valoró para los ejercicios productivos comprendidos entre 2009/2010 y $2014 / 2015$. El valor de referencia utilizado para la estandarización de este indicador fue de $170 \mathrm{~kg}$ de carne equivalente en base a Carvalho et al., (2008); para la situación inicial se consideró el promedio de los tres años previos al proyecto y para la situación final se consideró el promedio de los tres años de implementación del mismo.

En las vacas de cría se realizó condición corporal (INIA, 2017) y peso vivo previo al entore y condición corporal al destete, durante el período 2012 - 2015.

Las recrías (terneros y terneras y vaquillonas de 1 y 2 años) fueron pesadas en otoño (destete), a fin de su primer invierno, primavera (1 año de vida), en su segundo otoño, a fin de su segundo invierno y a inicio de entore, entre primavera de 2012 e invierno de 2015.

El porcentaje de preñez y porcentaje de procreo por categoría (vacas y vaquillonas), se reconstruyó en base a registros prediales que disponían los productores en los años previos al proyecto y se evaluó por ecografía, al menos 45 días posterior a la retirada de los toros, durante la implementación del proyecto (2012 - 2015).

El diagnóstico de actividad ovárica fue realizado en las vacas de cría a mitad de entore para ajustar el manejo, durante enero de 2013, 2014 y 2015.
La edad a primer entore y los kilos de ternero destetado por vaca entorada fueron valorados para los ejercicios productivos comprendidos entre 2009/2010 y 2014/2015.

En ovinos, la época de encarnerada, el porcentaje de señalada, la producción de lana fueron valorados para los ejercicios productivos comprendidos entre 2009/2010 y $2014 / 2015$.

Ingreso familiar ganadero (U\$S/ha). Fue calculado como la diferencia entre el producto bruto y costos de producción (sin valorizar la mano de obra familiar). Se valoró para los ejercicios productivos comprendidos entre $2009 / 2010$ y $2014 / 2015$. El valor de referencia utilizado para cada caso fue calculado considerando el doble del ingreso medio per cápita, sin valor locativo y sin aguinaldo, para localidades pequeñas y zonas rurales (INE, 2017) multiplicado por el número de integrantes de cada familia y transformado a dólares utilizando la tasa de cambio de dólar billete interbancario del BCU (2015 - 2009) El valor de referencia utilizado en cada caso se presenta en los Anexos 3 a 9. Para la situación inicial se consideró el promedio de los tres años previos al proyecto y para la situación final se consideró el promedio de los tres años de implementación del mismo.

Ingreso neto ganadero (U\$S/ha). Fue calculado como la diferencia entre el producto bruto y costos de producción incluyendo un ficto por la mano de obra familiar, que fue tomado de laudos de consejos de salario del Ministerio de Trabajo y Seguridad Social para el sector. Se valoró para los ejercicios productivos comprendidos entre 2009/2010 y 2014/2015.

Productividad de la mano de obra total aplicada en el predio (U\$S/hora año). Calculado como el ingreso familiar ganadero dividido el tiempo de trabajo (mano de obra familiar más mano de obra contratada permanente) dedicado al manejo de animales y pasturas aumentado en un $20 \%$ para considerar otras tareas realizadas en el predio (mantenimiento, compras-ventas, gestión y 
tareas domésticas). Se calculó en base a la metodología de Balance de Trabajo (Dieguez et al., 2009) para los ejercicios 2011/2012 y 2014/2015. El valor de referencia utilizado para la estandarización fue el valor de la contratación de un peón rural que era de 17 y 22 U\$S/hora para dichos ejercicios (MGAPOPYPA, 2015-2014; 2012-2011).

Número de fuentes de ingresos. Donde las fuentes de ingreso consideradas fueron: producción animal vacunos, producción animal ovinos, producción vegetal, trabajo extrapredial, otras. Toma valores entre 1 y 5 . Fue cuantificado para los ejercicios productivos $2012 / 2013,2013 / 2014$ y $2014 / 2015$. El valor de referencia utilizado para estandarización fue 5. La situación inicial considerada fue el ejercicio productivo 2012/2013 y la situación final el 2014/2015.

Relación deuda/patrimonio, relaciona el valor en dólares de la deuda con la valorización en dólares de la tierra en propiedad. Se valora en una escala de 1 a 5 donde $5=0$; $4=<0,05 ; 3=0,05-0,1 ; 2=0,1-0,15 ; 1=>0,15$. Fue cuantificado para los ejercicios productivos 2012/2013, 2013/2014 y 2014/2015. El valor de referencia utilizado para estandarización fue 5. La situación inicial considerada fue el ejercicio productivo 2012/2013 y la situación final el 2014/2015.

\section{ii) Mediciones en el área de pasturas:}

La altura de forraje (Barthram, 1986) fue medida dos veces por estación en potreros representativos, habiendo muestreado aproximadamente el $80 \%$ del área de cada predio, entre diciembre de 2012 y diciembre de 2015 . El indicador utilizado para evaluar la sustentabilidad fue la altura del campo natural en otoño, por representar el forraje acumulado durante la época de mayor crecimiento del mismo, indicando el estado del sistema previo al inicio del invierno. El valor de referencia utilizado para la estandarización fue de $9 \mathrm{~cm}$ (Soca y Orcasberro, 1992), asignando el valor de $100 \%$ a alturas iguales o mayores a $9 \mathrm{~cm}$. La situación inicial considerada fue el otoño 2013 y la final fue el promedio de otoño 2014 y 2015.
El forraje disponible (Haydock y Shaw, 1975) fue medido dos veces por estación, entre diciembre de 2012 y diciembre de 2015 , en los potreros donde estaban las vacas de cría la mayor parte del año y en potreros con campo natural y mejoramientos que tenían un uso estratégico en los sistemas.

La tasa de acumulación de forraje fue medida mediante el uso de jaulas móviles ('t Mannetje, 1978) dos veces por estación, entre diciembre de 2012 y diciembre de 2015. Fueron colocadas 4 jaulas por predio en el potrero de campo natural donde la cría permanecía la mayor parte del año.

La oferta de forraje definida como los $\mathrm{kg}$ de materia seca por cada kilo de peso vivo (Sollenberger et al., 2005) fue estimada para los tres años previos al inicio del proyecto (2009/2010, 2010/2011, 2011/2012) y calculada durante los tres años de ejecución del mismo (2012/2013, 2013/2014, 2014/2015).

\section{iii) Mediciones en el área ambiental}

Índice de integridad ecosistémica (IIE). Fue especialmente diseñado por el equipo técnico (Blumetto et al., 2016). Este índice evalúa el estado de los ecosistemas de cada potrero, en relación a la mejor condición posible (para ese ambiente y bajo uso productivo), la cual tendría la máxima puntuación. El proceso de obtención del IIE implica la evaluación de distintos atributos agrupados en cuatro dimensiones: estructura de la vegetación, presencia de especies, erosión actual o potencial del suelo y el estado de zonas riparias. Se determinó un valor para cada potrero y luego, en función de la superficie de cada uno, se obtuvo el índice ponderado para todo el establecimiento. La escala va desde 0 (pérdida de todas las funciones ecosistémicas) a 5 (mejor condición). El valor de referencia utilizado para la estandarización fue de 5 . Se realizó una valoración del IIE en primavera 2012 (situación inicial) y en primavera 2015 (situación final). 
Riqueza de especies en campo natural (CN). La riqueza fue medida en transectas a lo largo del potrero de mayor tamaño y/o donde el ganado de cría pasaba más tiempo; dependiendo del tamaño del potrero se relevaron entre 30 a 60 cuadros de 50 x 50 $\mathrm{cm}$ a lo largo de la transecta. La riqueza fue evaluada como el número de especies de campo natural y el aporte de cada una de ellas, considerando todas aquellas con una presencia superior al 5\% (Mueller-Dombois y Ellenberg, 1974). La situación inicial del indicador se valoró en primavera de 2013/2014 y en primavera de 2015 la situación final. El valor de referencia utilizado corresponde al número máximo de especies ( $\mathrm{n}^{\circ}$ max. $\mathrm{sp}$ ) encontradas con este método a escala potrero reportado por Millot et al. (1987), que es de 70 especies para las Sierras del Este.

Riqueza de aves. En cada establecimiento se seleccionaron potreros de referencia que contemplaran los usos de suelo presentes (campo natural, praderas sembradas y cultivos anuales). En esas unidades de muestreo se realizaron transectas lineales de 300 $\mathrm{m}$ de largo con tres repeticiones por unidad (Gibbons y Gregory, 2006), en las cuales se registró la presencia de especies (riqueza) y el número de individuos de cada una (abundancia). El monitoreo se realizó estacionalmente (otoño, invierno, primavera y verano), desde otoño de 2013 a verano de 2015. Para cada productor y año de muestreo se obtuvo la riqueza (número de especies) observada y se calculó la riqueza estimada por extrapolación de curvas de rarefacción según el método descrito por Colwell et al. (2012), para lo cual se utilizó el software Estimates v. 9.1.0 (Colwell, 2013). También se calculó el índice de diversidad de Shannon (Shannon y Weaver, 1949), que contempla la riqueza de especies y abundancia de cada especie en un solo valor. Para la estandarización se tomó como valor de referencia la distribución potencial de aves por ambientes descrita en Brazeiro et al. (2012). Para cada caso se calculó la riqueza potencial en base a los ambientes incluidos o adyacentes a los predios; el valor de referencia para cada caso fue: Caso 1= 117, Caso 2= 118, Caso 3= 139,
Caso $4=133$, Caso 5= 133, Caso 6= 145, Caso $7=150$. La situación inicial los cuatro muestreos estacionales de 2013 y la final es la riqueza total estimada considerando de los cuatro muestreos de 2015.

Estrato alto en CN (\%). La cobertura aérea del estrato superior herbáceo y arbustivo (Mueller-Dombois y Ellenberg, 1974), se estimó en 50 a 100 cuadros de $1 \mathrm{~m}^{2}$, a lo largo de transectas de 100-200 $\mathrm{m}^{2}$, dependiendo del tamaño del potrero. El indicador se valoró en otoño de 2014 (situación inicial) y en primavera de 2015 (situación final), utilizando una escala de 1 a 5 donde $1=0-5$ o $100-82,5 ; 2=5-10$ o $82,5-65 ; 3=10-15$ o $65-$ 47,$5 ; 4=15-20$ o $47,5-30 ; 5=20-30$. El valor de referencia es el valor 5 del indicador, que corresponde a un $20-30 \%$ de acuerdo con Da Trindade et al. (2012).

Carbono orgánico total y particulado. Se evaluó en potreros de campo natural donde estuvo la cría la mayor parte del año, de acuerdo con la metodología de Salvo et al. (2010), con muestreos de suelos en las siguientes profundidades: $0-3 \mathrm{~cm}$; $3-6 \mathrm{~cm}$ y $6-18 \mathrm{~cm}$, en otoño de 2013, 2014 y 2015 . El indicador utilizado para la evaluación de la sustentabilidad fue el porcentaje de carbono orgánico de 0 a $6 \mathrm{~cm}$ de profundidad. El valor de referencia utilizado fue el máximo valor absoluto encontrado en los muestreos para el promedio de 0 a $6 \mathrm{~cm}$ de profundidad, que corresponde a $4,79 \mathrm{~g}$ de carbono cada 100 $\mathrm{g}$ de suelo, el cual representa un potencial constatable y por tanto alcanzable en este tipo de suelos. La situación inicial considerada fue otoño de 2013 y la final 2015.

\section{iii) Mediciones en el área social}

Calidad de vida estructural integrada. Se trata de un índice compuesto cuyo valor varía de $5=$ muy bueno a $1=$ muy malo (Albicette et al., 2016a). Considera el acceso/ calidad de las siguientes variables: vivienda, energía electica, agua potable, conectividad vial, disponibilidad de vehículo, distancia a centros poblados, conectividad digital, salud, nivel educativo formal, capacitación, 
nivel endeudamiento. Se valoró en base a entrevistas con la familia al inicio y al final del proyecto. El valor de referencia utilizado para la estandarización fue de 5.

Calidad de vida subjetiva. Se valoró la percepción de la familia sobre su calidad de vida, en base a una escala que varía de $5=$ muy satisfecho a 1= no satisfecho (Albicette et al., 2016a). Se valoró en base a entrevistas con la familia al inicio y al final del proyecto. El valor de referencia utilizado para la estandarización fue de 5 .

Tiempo disponible luego del trabajo aplicado al manejo de animales y pasturas (horas/año). Se estimó en base a la metodología de Balance de Trabajo (Dieguez et al., 2009) para los ejercicios 2011/2012 y 2014/2015. Para su cálculo, a la mano de obra disponible para trabajo en el predio (familiar y contratada permanente) se le resta el tiempo de trabajo (familiar y contratado permanente) aplicado al manejo de animales y superficie forrajera. El valor de referencia corresponde a la sumatoria de las horas de mano de obra familiar disponibles y las horas mano de obra contratada permanente según cada predio.

Proporción del tiempo de trabajo dedicado al manejo de animales y pasturas provisto por la familia (\%). Se estimó en base a la metodología de Balance de Trabajo (Dieguez et al., 2009) para los ejercicios $2011 / 2012$ y $2014 / 2015$. El valor de referencia utilizado para la estandarización fue de $100 \%$.

Uso de tecnologías propuestas (\%). Para la construcción del indicador se consideraron once tecnologías clave propuestas en el re-diseño: ajuste de carga, adecuación de época de entore, manejo según condición corporal, diagnóstico de actividad ovárica, diagnóstico de gestación para manejo diferencial, control de amamantamiento, destete a los seis meses de edad, manejo preferencial de la recría, entore a los dos años, asignación de potreros según altura y categoría animal y uso de registros. Para su valoración se calculó el porcentaje de las tecnologías utilizadas sobre el total de tecnologías consideradas, de manera que $100 \%$ significa el uso de todas las tecnologías consideradas (Albicette et al., 2016a). El valor de referencia utilizado para la estandarización fue de $100 \%$. Se valoró para los ejercicios 2012/2013 (situación inicial), 2013/2014 y 2014/2015 (situación final).

Valoración y uso de la planificación. Se valoró en base a una escala que varía desde $5=$ valora y usa planificación de largo plazo, a $1=$ no valora ni usa planificación (Albicette et al., 2016a). El valor de referencia utilizado para la estandarización fue de 5 . Se valoró para los ejercicios 2012/2013 (situación inicial), 2013/2014 y 2014/2015 (situación final).

\subsubsection{Etapa 3: Propuesta de re-diseño (planificación estratégica)}

Para la definición de propuestas de re-diseño (planificación estratégica) del sistema de producción (julio - diciembre 2012), el equipo técnico elaboró diferentes alternativas basadas en el enfoque de intensificación ecológica y en los recursos disponibles en el predio. El procedimiento desarrollado y aplicado para esto consistió en las siguientes etapas: (i) definir y dimensionar las actividades de producción incluyendo metas productivas y los productos para vender, (ii) definir el uso del suelo (áreas) considerando pastizales nativos, mejoramientos extensivos y pasturas mejoradas (verdeos y praderas perennes), (iii) definir a través de una presupuestación forrajera, la carga animal a utilizar y la relación ovino/vacuno (en los casos que aplicaba), (iv) definir las tecnologías necesarias a implementar para alcanzar las metas productivas, (v) realizar una evaluación ex-ante de cada propuesta: cuantificar la productividad física y económica esperada, estimar la mano de obra requerida y considerar el impacto potencial sobre los recursos naturales; y comparar los resultados con la situación de partida. 
Las propuestas se discutieron con cada productor y la familia, en un proceso de aprendizaje en el que el conocimiento práctico del productor y el conocimiento científico proporcionado por el equipo de investigación se combinaron, diseñando y acordando una propuesta de re-diseño que cada productor estaba dispuesto a implementar en su predio. Asimismo, se planificaron las metas estratégicas y los pasos a seguir para llegar a la implementación de la propuesta de rediseño generada en conjunto, que se abordarían durante la fase de implementación.

\subsubsection{Etapa 4: Implementación (plani- ficación táctica), monitoreo y evaluación}

La última etapa del proceso fue la implementación de la propuesta de re-diseño acordada (planificación táctica), realizando un monitoreo y evaluación del sistema de producción (enero de 2013 a julio de 2015), para evaluar si mejoraba la sustentabilidad de los predios y cuantificar en qué magnitud. Durante esta fase el equipo de investigación, fundamentalmente el técnico de campo, acompañó y ayudó a los productores a implementar la propuesta acordada. En algunos predios surgieron dificultades inesperadas y por lo tanto se introdujeron modificaciones a la propuesta de re-diseño original, llevándose a cabo varios ciclos de re-diseño e implementación.

El impacto en el sistema fue monitoreado y cuantificado por el equipo de investigación en conjunto con los productores, a través de la medición de los indicadores seleccionados utilizando el marco MESMIS (Masera et al., 2000), lo que se complementó con entrevistas en profundidad y observación participante para evaluar la dimensión social de los cambios y el proceso de aprendizaje.

El equipo de investigación generó varios informes intermedios para describir los principales resultados, discutir con el productor sobre los avances y apoyar la toma de decisiones durante el proceso. También se elaboró un informe final para integrar y evaluar los resultados del proyecto.

\subsection{Metodología a nivel regional}

El objetivo del trabajo a nivel regional fue planificar, monitorear y evaluar el proyecto durante su ejecución, en un proceso participativo entre investigadores, las siete familias y los actores institucionales vinculados a la ganadería familiar de la región de Rocha, para incluir aspectos de mejora del proyecto durante su ejecución y promover un proceso de aprendizaje entre los actores involucrados.

Este nivel de trabajo se orientaba al impacto del proyecto y el propósito era que los participantes mejoraran sus conocimientos y habilidades con relación al proceso que se iba a implementar. Como resultado final se esperaba generar alto interés de los productores, las organizaciones e instituciones por trabajar con este enfoque en un mayor número de predios en la región y de esta manera trascender el trabajo realizado en los 7 predios durante los tres años del proyecto.

Para cumplir con dicho objetivo se utilizó el método Análisis Participativo de Senderos de Impacto - PIPA, sigla por su nombre en inglés - descrito por Álvarez et al. (2010), teniendo en cuenta el enfoque de co-innovación que se quería implementar en el proyecto (descrito en el capítulo 2) y los antecedentes de talleres anuales de evaluación del proyecto de co-innovación con productores ganaderos-hortícolas realizado en Canelones entre 2007 y 2011 (Dogliotti et al., 2012).

El método PIPA (Álvarez et al., 2010) ha sido utilizado en diferentes proyectos de acuerdo con lo mencionado por Douthwaite et al. (2007a; 2007b). Fue diseñado para que los participantes de un proyecto puedan explicitar sus teorías de cambio y su visión del futuro una vez alcanzados los objetivos, construyendo los senderos de impacto y promoviendo el trabajo en red. El método ofrece un marco para la "investigación-acción" en los procesos de cambio (Álvarez et al., 2010; Douthwaite et al., 2008; 2007a) y tiene su base en la teoría de la evaluación de programas, en el análisis de redes sociales y en 
la investigación para entender y fomentar la innovación. Entre sus ventajas se destaca el análisis ex-ante de los impactos esperados del proyecto, lo que ayuda a entender el rol de cada actor en el proceso, que a su vez fomenta la integración y proporciona un marco para el diseño de un sistema de monitoreo y evaluación basado en el aprendizaje (Álvarez et al., 2010; Douthwaite et al., 2008).

Para su implementación en este proyecto el método PIPA fue adaptado considerando la realidad uruguaya y específicamente el contexto de aplicación con ganaderos familiares de Rocha (Albicette et al., 2016c). Se diseñaron seis talleres utilizando técnicas y herramientas participativas, los cuales se desarrollaron entre el 3 de julio de 2012 y el 12 de agosto de 2015. En todos los talleres (Taller I al VI) participaron investigadores, los siete productores y sus familias y los actores institucionales vinculados a la ganadería familiar de la región de Rocha. A partir del Taller I y a efectos de fomentar la participación, se coordinó con los productores y las instituciones, la fecha y el lugar de cada uno de los talleres con una anticipación de al menos un mes. Durante la preparación del mismo se enviaron invitaciones por email a las instituciones y organizaciones de productores y a los productores integrantes del proyecto y sus familias.

Para el diseño de cada taller se elaboró una pauta denominada "guión interno" que establecía claramente para cada sesión del taller qué hacer, cómo hacerlo, con qué recursos, porqué hacerlo, quiénes eran los responsables y comentarios. En el Anexo 1 se presenta como ejemplo el guión del Taller I. Como estructura general cada taller fue pensado con una serie de sesiones:

a) Bienvenida, presentación de objetivos del taller y programa de trabajo: En esta sesión el director de programa y/o la líder del proyecto agradecían la participación y resaltaban la importancia de esas instancias, presentaban el objetivo del taller y el programa de trabajo previsto para ese día (se había mandado con la invitación) con el apoyo visual de papelógrafos. b) "Hilo conductor con el taller anterior": A partir del Taller II y con la idea de traer a la memoria de los asistentes los contenidos y resultados del taller anterior, en plenaria se repasaban las acciones pendientes de realización entre un taller y el otro y las personas involucradas. En la sesión se usaban como insumo las memorias del taller anterior y los productos generados en talleres previos (mapas, diagramas, cuadros, planes de acción, etc.).

c) Sesión informativa del proyecto, el proceso y sus avances: En ella se informaba sobre los avances a nivel de los siete predios, con presentaciones del técnico de campo, de los especialistas por área productiva-económica, ambiental, social, así como con aportes y comentarios de los productores asistentes. Asimismo, se presentaba un resumen de los avances del trabajo a nivel regional.

d) Sesión de trabajo conjunta entre los asistentes: Sesión dedicada a la planificación, monitoreo, evaluación y reflexión conjunta entre los participantes que varió de acuerdo al momento del proyecto.

e) Ronda de novedades institucionales: A partir del Taller II se implementó una sesión para fomentar el intercambio entre los actores, compartiendo los intereses, las agendas y promoviendo la coordinación de actividades entre las instituciones de la región participantes.

f) Elaboración de un plan de acción para el corto plazo: Entre taller y taller se definían actividades a desarrollar y se nombraban los responsables, respondiendo a las preguntas: ¿qué hacer?, ¿quiénes lo hacen? y ¿cuándo?

g) Cierre de camaradería, degustando productos locales: Con la sesión final se fomentaba en intercambio personal entre los participantes.

Los resultados y productos de cada taller fueron sistematizados por parte del equipo técnico, generando un documento con las memorias de cada uno. Las mismas se enviaban a los asistentes por correo electrónico y/o se entregaban impresas al inicio del siguiente taller. 
Los seis talleres implementados tuvieron la estructura descrita y los detalles de cada uno se pueden consultar en Memorias TaIler Interinstitucional I - VI (http://www.inia. uy/Proyectos/Paginas/PF_07.aspx). A continuación, presentamos un resumen de los aspectos particulares más relevantes de la sesión que denominamos "Sesión de trabajo conjunta entre los asistentes": i) Taller I

Los participantes identificaron a los actores relevantes a involucrar en el proyecto. Construyeron con el uso de tarjetas (Figura 6 ), una red de actores regionales vinculados a la ganadería familiar en Rocha y sus relaciones, que se denominó Red de Actores Regionales (RAR) y con la que se trabajó en talleres durante tres años.

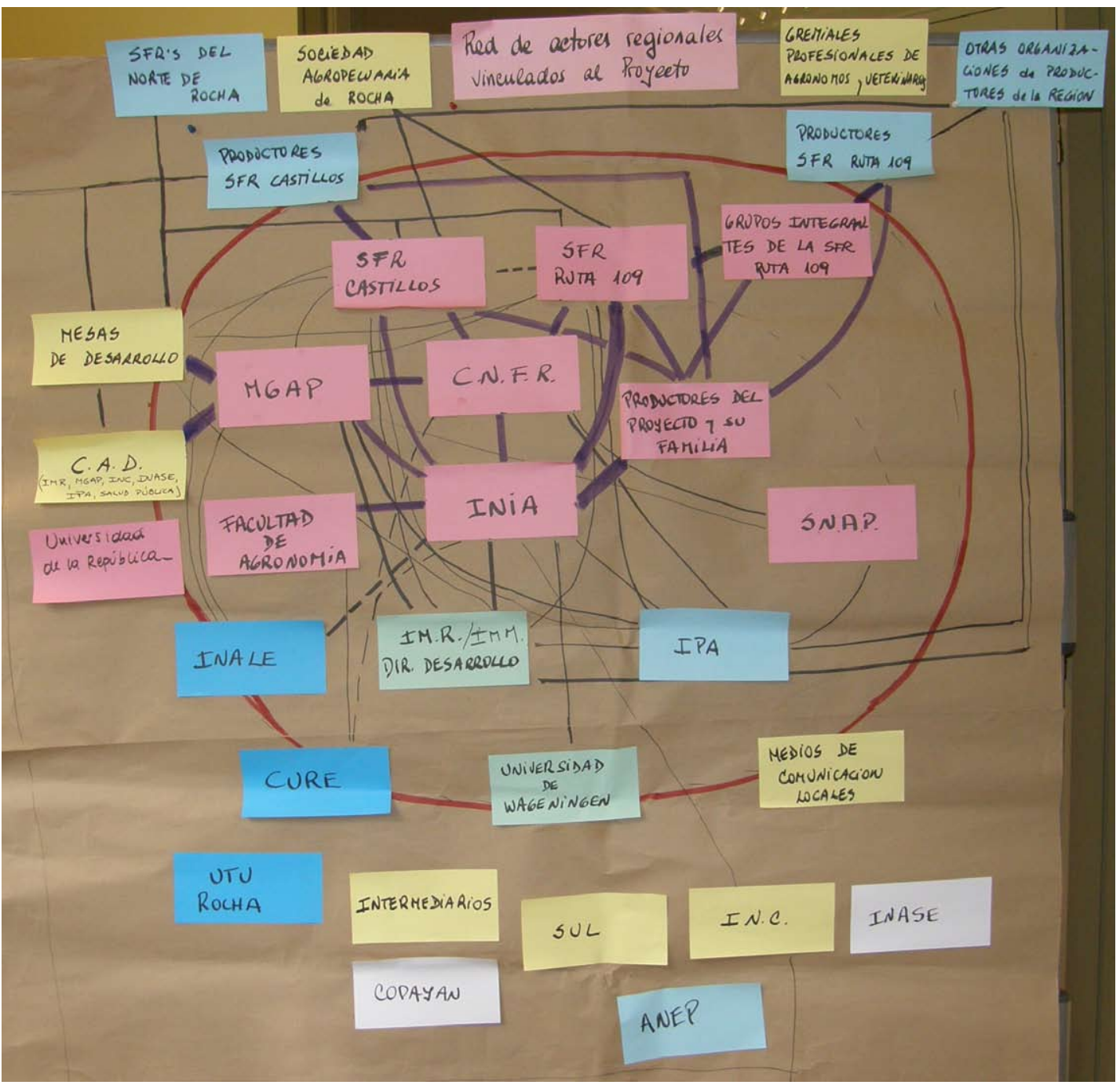

Figura 6. Uso de tarjetas como herramienta para la elaboración de actores regionales.

Asimismo, se elaboró una visión compartida (Senge, 1995) de los resultados esperados del proyecto, como una imagen del futuro que se deseaba crear, que mostraba a dónde se quería ir y cómo sería cuando se llegara allí. Según Senge (1995), la visión es un sueño a largo plazo, es altamente inspiradora, está orientada a la toma de decisiones y sirve como punto de consenso. Para desarrollar este trabajo la consigna uti- 
lizada fue: ¿Qué está pasando en el 2015 luego de finalizado con suceso el proyecto?, pensando en los productores, los técnicos, las organizaciones, las instituciones y sus relaciones. La misma se acompañó de 5 preguntas guía: ¿Qué está siendo diferente ahora?, ¿quién está haciendo qué en forma diferente?, ¿quiénes están interactuando?, ¿Cuáles han sido los cambios en la vida de la gente usando los resultados del proyecto? y ¿cómo se están extendiendo los resultados del proyecto entre los productores y en las instituciones?.

A partir del acuerdo en la visión compartida se elaboraron las vías de impacto del proyecto. El término "vías de impacto" describe la forma en que se espera que las estrategias y actividades de un proyecto provoquen cambios en el conocimiento, actitudes, habilidades y prácticas de los involucrados para lograr los resultados (Douthwaite et al., 2008). Se reflexionó sobre qué actores o grupo de actores se esperaba que cambiaran luego de finalizado el proyecto, y qué actividades se deberían realizar. Se trabajó en base a 4 preguntas: ¿Qué cambio quiero lograr?, ¿qué actores o grupo de actores se espera que cambien?, ¿qué actividades hay que hacer? y ¿quiénes lo van a hacer?.

ii) Taller II al IV

En los talleres II al IV se trabajó siguiendo las pautas generales de cada taller, pero tomando como base lo avanzado en el proceso hasta el momento del taller, generando un espacio de monitoreo, evaluación (M\&E) y planificación participativo, que promoviera la reflexión y análisis conjunto de los avances del proyecto. El fin era que los actores se mantuvieran involucrados con los avances del proyecto y se pudieran generar opiniones para mejorar su implementación. Las preguntas disparadoras utilizadas en cada sesión se detallan en Memorias Taller Interinstitucional I - VI (http://www.inia.uy/Proyectos/Paginas/PF_07.aspx). Como ejemplo, la pregunta realizada en el Taller III fue: "Analizar los principales logros y dificultades del proceso transcurrido desde el inicio del proyecto y realizar sugerencias de mejora para el futuro." La pregunta utilizada en el Taller IV fue: "¿Cómo vamos con el proyecto?, ¿Qué sugerencias de mejora se pueden realizar?". Dependiendo de la pauta y del número de asistentes se trabajaba en plenaria o grupos. En este último caso siempre se incluía una puesta en común en plenaria de los resultados de los grupos, finalizando con una reflexión conjunta.

\section{iii) Taller VI}

En el último taller se realizó una evaluación participativa de diversos aspectos del proyecto, utilizando una encuesta individual escrita (Anexo 2). En el Taller se pusieron en común los resultados, los cuales se sistematizaron en una matriz visible para todos los asistentes (Figura 7), lo que facilitó una mirada global inmediata de los mismos. Esto permitió analizar cada pregunta de la encuesta y reflexionar en conjunto sobre los distintos aspectos de la evaluación. Con posterioridad al taller, los 18 formularios de encuestas completados fueron procesados para el análisis final. 


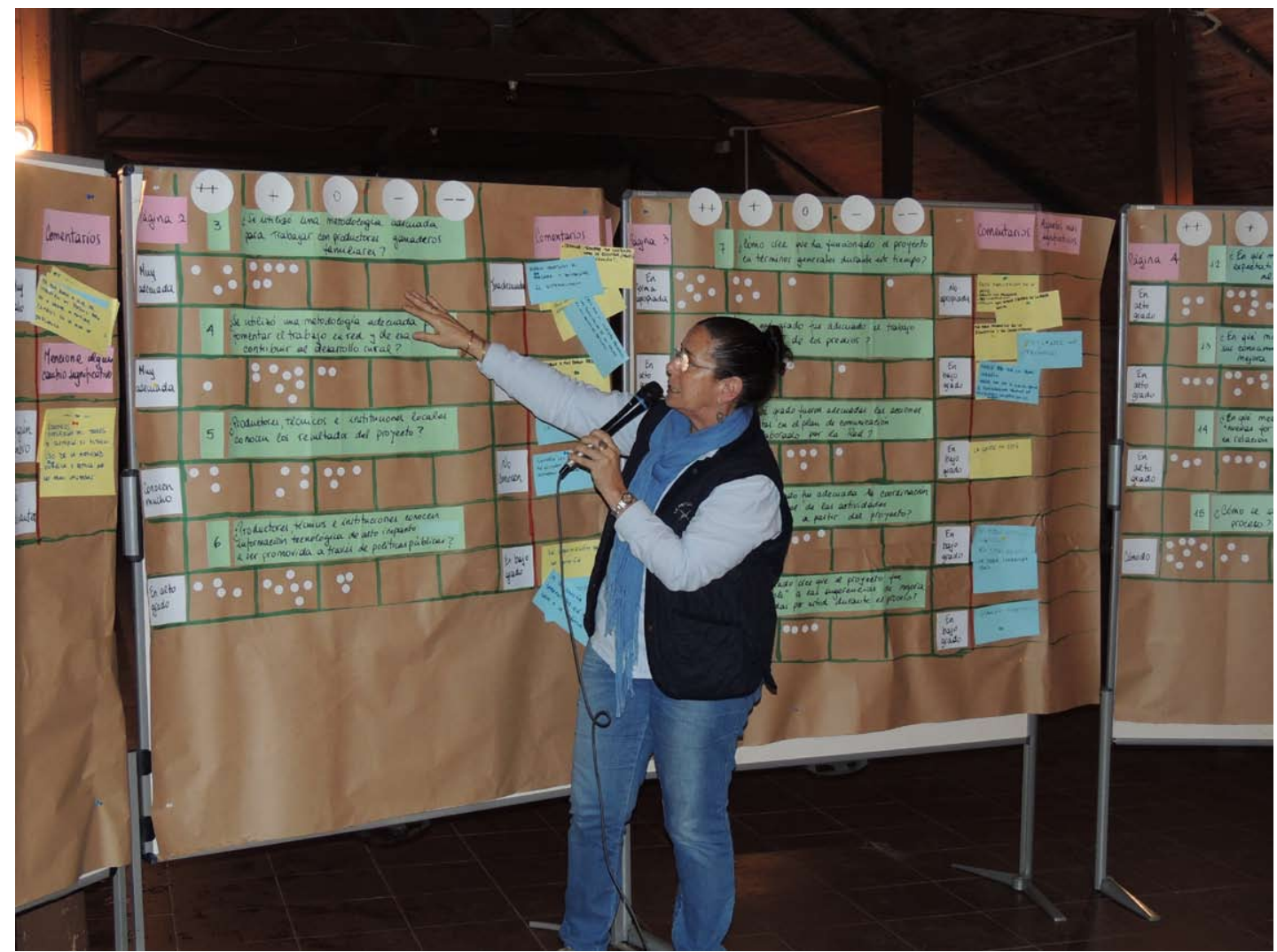

Figura 7. Puesta en común de la evaluación participativa final del proyecto, donde se destaca la matriz empleada para sistematizar los resultados de cada pregunta de la encuesta y reflexionar sobre ellos.

Para finalizar el taller se realizó una ronda con opiniones para planificar las actividades de cierre del proyecto, en particular el día de campo final. 



\subsection{Resultados a nivel predial}

\subsubsection{Etapa 1: Caracterización}

\subsubsection{La familia, sus objetivos y el sistema de gestión}

Las siete familias involucradas en el proyecto eran productores ganaderos familiares, de mediana edad, que vivían en el predio y contaban con larga trayectoria de vida y trabajo en el campo. El sistema de producción predominante era la cría de vacunos y ovinos, con campo natural como principal base forrajera; complementándose en dos de los casos con chacra y apicultura. Mayoritariamente eran propietarios o usufructuaban la tierra de sus padres y manejaban una superficie entre 61 y 364 ha, con índices de productividad de suelo que variaban entre 62 y 116. En dos casos complementaban el ingreso con trabajo extra predial. El tema de la sucesión no fue un problema explícito durante la implementación del proyecto, si bien en seis de los siete casos era un tema que no se había discutido a nivel familiar y en cinco casos se visualizaba como problema en el mediano plazo (Cuadro 3).

Como visión global del concepto de sustentabilidad se presentan a continuación los principales aspectos mencionados por las familias en las entrevistas realizadas, ilustrados con sus frases textuales (en cursiva). Los objetivos de cada familia y su visión particular de futuro-sustentabilidad se detallan en Historia de Innovación Caso 1 - 7 (http://www.inia.uy/ Proyectos/Paginas/PF_07.aspx). Se destaca la fuerte coincidencia entre el concepto de sustentabilidad de las familias entre sí y de éstas con el equipo técnico.

El concepto de sustentabilidad para las siete familias tenía asociadas las siguientes ideas:

- Mejorar los ingresos y estabilizarlos a lo largo de los años:
"Elegir la mejor combinación de los rubros ovino y vacuno que dé más ingresos". "Sacar la mayor productividad, haciendo más y mejor comida sobre la base de campo natural". "Aceptar el desafío de ser un predio chico que debe rendir cada vez más sin destruir los recursos ni nada, cuidando el medio ambiente teniendo sombra, abrigo y agua en los arroyos, pero no a cualquier costo sino afinando la puntería e invirtiendo bien". "Hacer más plata y pagar lo que se debe y preparase para la sucesión". "Producir lo necesario para seguir viviendo bien en el predio $y$ de la producción".

- Mejorar la calidad de vida de la familia y la calidad del trabajo, aumentando el tiempo de descanso y esparcimiento y reduciendo la carga de trabajo:

"Vivir en el campo con más comodidades (ej.: agua corriente en la casa, lavarropas, etc.)". "Criar los hijos chicos como si estuviera en la ciudad, manteniendo la casa en Rocha para ir algún fin de semana". "Trabajar con los vecinos para colocar la luz y tener más comodidades". "Frente a ofertas para vender el campo no la he aceptado, de aquí salgo muerto". "Que la producción del predio permita obtener dinero para estar confortables, tener salud, vivir en el campo". "Tener tiempo libre y más dinero para ir a la playa y salir más". "Mantener momentos de esparcimiento y observar los intereses de la señora". "Reducir la carga de trabajo, trabajar menos, pero a la vez mejorar en la producción". "Mantener el trabajo extra predial y seguir realizando las tareas del predio".

- Mejorar las oportunidades para las nuevas generaciones en cuanto a educación y proceso de sucesión:

"Lograr los objetivos como productor: ser eficiente y generar un buen ingreso". "Que los hijos puedan ir a la escuela de la zona y explorar para que estudien en 
Cuadro 3. Caracterización de los siete casos.

\begin{tabular}{|c|c|c|c|c|c|c|c|}
\hline 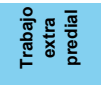 & $\stackrel{2}{z}$ & $\stackrel{0}{z}$ & 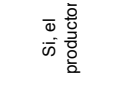 & के & $\stackrel{2}{z}$ & $\stackrel{2}{2}$ & $\stackrel{2}{z}$ \\
\hline 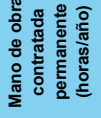 & $\circ$ & 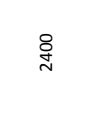 & 。 & 0 & 0 & ○ & o \\
\hline 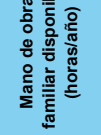 & 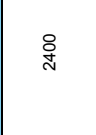 & 京 & 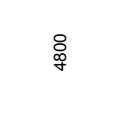 & 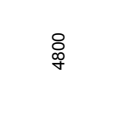 & 㔛 & 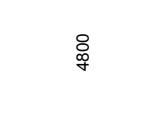 & 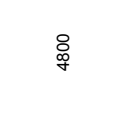 \\
\hline 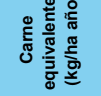 & $\delta$ & 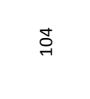 & 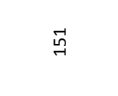 & œ & t & $\infty$ & 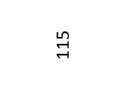 \\
\hline 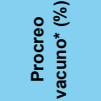 & $\infty$ & $\overrightarrow{0}$ & $\stackrel{\infty}{\oplus}$ & $\approx$ & $\ddot{\iota}$ & $\stackrel{0}{2}$ & 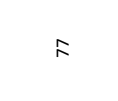 \\
\hline 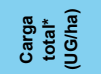 & $\stackrel{\circ}{\circ}$ & $\underset{i}{\vec{i}}$ & 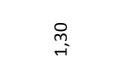 & 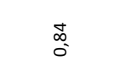 & $\stackrel{\infty}{\stackrel{-}{\sim}}$ & : & ஃ্. \\
\hline 选遶 & \& & $a$ & $\tilde{\nu}$ & $\stackrel{\sim}{ }$ & $\approx$ & $\sigma$ & $\stackrel{\infty}{\sim}$ \\
\hline 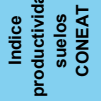 & $\underset{\infty}{+}$ & 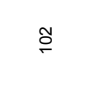 & $\stackrel{\circ}{\circ}$ & $R$ & $\widetilde{0}$ & $\mathscr{\infty}$ & 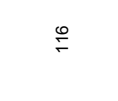 \\
\hline 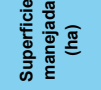 & $\stackrel{\circ}{m}$ & $\frac{m}{m}$ & $\bar{\jmath}$ & $\approx$ & 总 & న్ & $\overline{\stackrel{N}{N}}$ \\
\hline 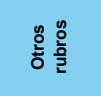 & $\stackrel{\circ}{z}$ & $\stackrel{\circ}{z}$ & $\begin{array}{l}\frac{\pi}{0} \\
\frac{\pi}{0} \\
\frac{\pi}{0}\end{array}$ & 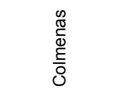 & $\stackrel{\circ}{z}$ & $\stackrel{\circ}{z}$ & $\stackrel{0}{z}$ \\
\hline 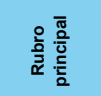 & 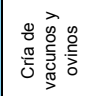 & 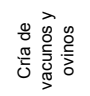 & 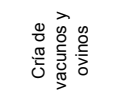 & 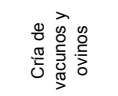 & 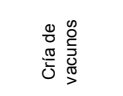 & 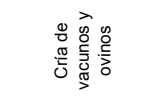 & 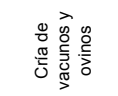 \\
\hline 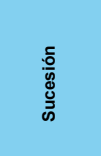 & 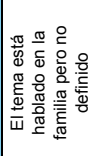 & 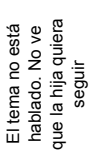 & 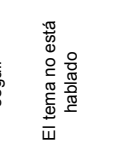 & 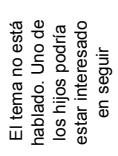 & 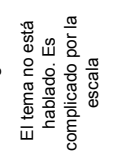 & 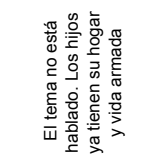 & 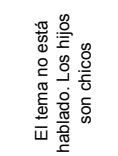 \\
\hline 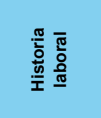 & 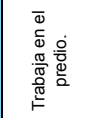 & 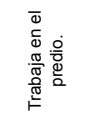 & 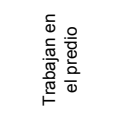 & 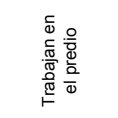 & 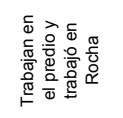 & 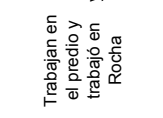 & 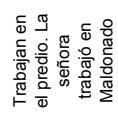 \\
\hline 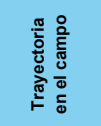 & $\begin{array}{l}\frac{\pi}{5} \\
\frac{\pi}{5} \\
\frac{\pi}{0} \\
\frac{\pi}{\circ}\end{array}$ & $\begin{array}{l}\frac{\pi}{5} \\
\frac{\pi}{5} \\
\frac{\pi}{\sigma} \\
\frac{0}{\circ}\end{array}$ & $\begin{array}{l}\frac{\pi}{0} \\
\frac{\pi}{2} \\
\frac{\pi}{\pi} \\
\frac{\pi}{0} \\
\end{array}$ & $\begin{array}{l}\frac{\pi}{0} \\
\frac{\pi}{2} \\
\frac{\pi}{0} \\
\vdash\end{array}$ & 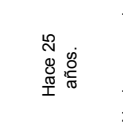 & 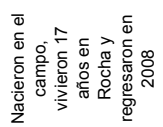 & $\begin{array}{l}\frac{\pi}{0} \\
\frac{\pi}{2} \\
\frac{\pi}{0} \\
\vdash \\
\vdash\end{array}$ \\
\hline 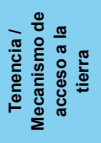 & 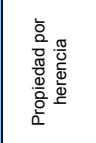 & 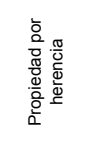 & 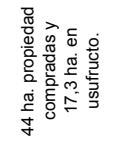 & 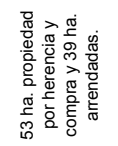 & 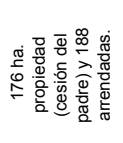 & 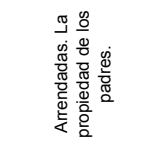 & 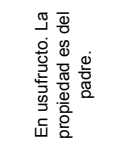 \\
\hline 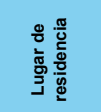 & 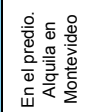 & 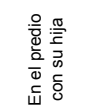 & 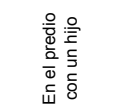 & 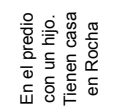 & 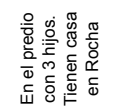 & 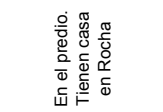 & 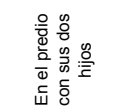 \\
\hline \multirow[t]{2}{*}{ 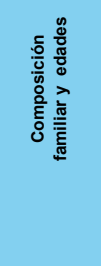 } & 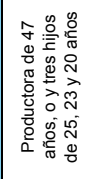 & 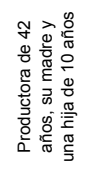 & 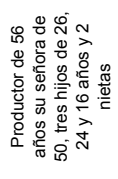 & 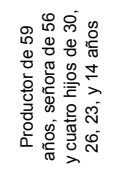 & 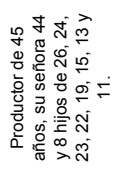 & 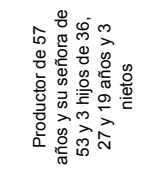 & 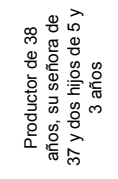 \\
\hline & $\begin{array}{l}\bar{o} \\
\delta \\
0\end{array}$ & 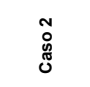 & $\begin{array}{l}n \\
0 \\
0 \\
\tilde{d} \\
0\end{array}$ & $\begin{array}{l}+ \\
0 \\
0 \\
0 \\
0\end{array}$ & $\begin{array}{l}\text { ڤo } \\
0 \\
0 \\
0 \\
0\end{array}$ & $\begin{array}{l}0 \\
: \\
0 \\
0 \\
0\end{array}$ & $\begin{array}{l}\hat{\circ} \\
\text { d } \\
0\end{array}$ \\
\hline
\end{tabular}


otro buen lugar y alguno vuelva al campo pensando en una transición". "Estar acostumbrado a no tener claro si alguno de los hijos seguirá con el predio, ya que las ofertas de trabajo en el medio son más redituables que trabajar hoy en el predio". "Incorporar la huerta como complemento importante y fundamentalmente por el involucramiento de los "chiquilines" para mantenerlos vinculados".

- Mantener o mejorar los recursos naturales: "Cuidar el suelo, mejorar las pasturas y hacer un manejo eficiente de ellas. "Fertilizar considerando que son suelos frágiles y hay que cuidar el tapiz". "Manejar los pajonales y los bañados y mejorar el empotreramiento". "Cuidar los tajamares para aguadas". "Cuidar el medio ambiente para ser más estable frente a los cambios climáticos, el suelo roturarlo lo menos posible".

- Mejorar la planificación y organización predial y apostar a la innovación y el uso de nuevas tecnologías que promuevan la productividad y eficiencia:

"Organizar el predio, plantearse metas y planificar, llevar registros para saber en qué se gasta y ajustar la carga". "Mejorar implica ordenar el predio". "Mejorar la toma de decisiones en conjunto con mi señora para lograr mejores resultados".
"Planificar el predio como una empresa y que la misma dé una buena renta". "Trabajar con el técnico asesor en planes a largo y corto plazo y que mi señora siga llevando los números del predio y anotaciones ya que le gusta, es útil y lo hace muy prolijo".

- Participar en grupos, trabajar con otros y capacitarse:

"Intercambiar ideas con otros (vecinos, grupo, Fomento, Mesa de Desarrollo, proyecto INIA, etc.)". "Estar involucrado en algún grupo de la zona que tenga asesoramiento técnico y gestión transparente y un carácter participativo". "Integrar el grupo de productores para enterarse de las nuevas líneas de crédito y novedades". "En la Fomento hay cierto cansancio ya que cada uno espera por el otro, si bien se espera más de la Fomento y del MGAP". "Relacionarse con los vecinos a través del trabajo en la escuela y en otros ámbitos". "Capacitarse en gestión, nutrición e inseminación y otros temas técnicos y escuchar a los otros que tienen nuevas ideas que le puedan servir al predio".

Las principales ideas asociadas con la visión de futuro - sustentabilidad de las siete familias se presentan en la Figura 8 (Albicette et al., 2016a). Los conceptos más reiterados se visualizan con mayor tamaño de letra.

\section{intercambiar conocimientos}

\section{educación para los hijos}

elegir la mejor combinación de rubros

cuidar los recursos naturales

momentos de esparcimiento vivir en el predio
simplificar y organizar el trabajo familiar

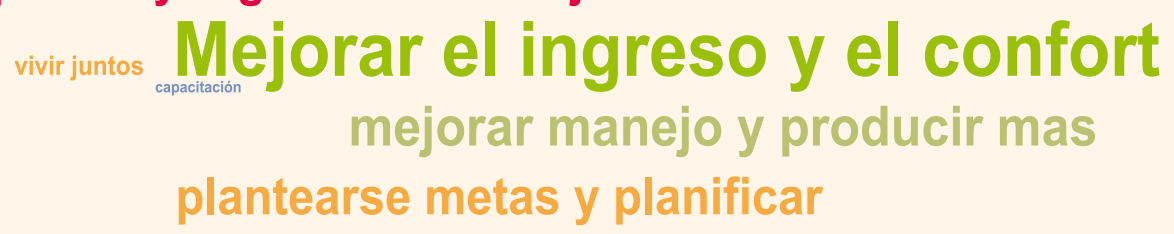

integrar grupos de productores

pensar futuro de hijos y relevo

contar con asesoramiento técnico

Figura 8. Principales ideas asociadas a la visión a futuro - sustentabilidad de las siete familias. 
Al inicio del proyecto en el año 2012 y en términos globales, los productores contaban con los bienes y servicios básicos para desarrollar su vida, lo que se evaluó con el indicador calidad de vida estructural (Cuadro 4). Algunas de las principales limitantes eran la falta de energía eléctrica en tres de los casos, la distancia a centros poblados en dos casos y el nivel educativo con cuatro casos en los que no habían completado secundaria.

Cuadro 4. Calidad de vida estructural integrada para los siete casos.

\begin{tabular}{|c|c|c|c|c|c|c|c|}
\hline Variables consideradas & Caso 1 & Caso 2 & Caso 3 & Caso 4 & Caso 5 & Caso 6 & Caso 7 \\
\hline Vivienda $^{1}$ & 4 & 4 & 3 & 3 & 4 & 4 & 3 \\
\hline Energía eléctrica ${ }^{2}$ & 5 & 0 & 5 & 0 & 0 & 5 & 5 \\
\hline Agua potable $^{3}$ & 5 & 5 & 3 & 3 & 1 & 5 & 5 \\
\hline Conectividad vial $^{4}$ & 5 & 3 & 4 & 3 & 3 & 4 & 4 \\
\hline Disponibilidad de vehículo ${ }^{5}$ & 5 & 3 & 5 & 5 & 3 & 5 & 5 \\
\hline Distancia a centros poblados ${ }^{6}$ & 3 & 5 & 3 & 1 & 1 & 3 & 5 \\
\hline Conectividad digital ${ }^{7}$ & 5 & 5 & 5 & 5 & 3 & 3 & 5 \\
\hline Acceso a salud básica ${ }^{8}$ & 5 & 5 & 5 & 5 & 5 & 5 & 5 \\
\hline Nivel educativo formal $^{9}$ & 4 & 5 & 2 & 2 & 3 & 2 & 4 \\
\hline Acceso a capacitación ${ }^{10}$ & 5 & 5 & 5 & 5 & 5 & 5 & 5 \\
\hline Nivel de endeudamiento ${ }^{11}$ & 4 & 4 & 4 & 4 & 4 & 4 & 4 \\
\hline Puntaje total & 50 & 44 & 44 & 36 & 32 & 45 & 50 \\
\hline $\begin{array}{l}\text { CALIDAD DE VIDA } \\
\text { ESTRUCTURAL INTEGRADA }\end{array}$ & 5 & 4 & 4 & 3 & 3 & 4 & 5 \\
\hline
\end{tabular}

${ }^{1}$ Vivienda: Muy Mala= 1 Rancho de adobe con número de habitaciones insuficiente para los integrantes de la familia y baño fuera de la casa. Mala= 2 Igual a la categoría anterior con mejoras recientes (techos, paredes, pintura, equipamiento y/o otras mejoras) ó vivienda de material precario con número de habitaciones acorde a los integrantes de la familia. Regular= 3 lgual a la categoría anterior con mejoras ó casa de ladrillo y/ó número de habitaciones insuficiente para los integrantes de la familia. Buena= 4 lgual a la categoría anterior con mejoras recientes ó casa de material con revoque en piso y paredes y número de habitaciones acorde para los integrantes de la familia. Muy buena= 5 Igual a la categoría anterior y con mejoras recientes en techos, paredes, pintura, equipamiento y/o otras mejoras.

2 Energía eléctrica: $\mathrm{No}=0, \mathrm{Sí}=5$

${ }^{3}$ Agua potable: Pozo o cachimba fuera de la casa= 1, Pozo o cachimba con ingreso parcial en la casa $=3$, Pozo o cachimba con cañería en toda la casa $=5$

${ }^{4}$ Conectividad vial: Muy Mala $=1$, Mala $=2$, Regular $=3$, Buena $=4$, Muy buena $=5$

${ }^{5}$ Disponibilidad de vehículo: No tiene vehículo $=0$, Tiene moto $=1$, Tiene auto ó camioneta $=3$, Tiene más de 1 vehículo $=5$

${ }^{6}$ Distancia a centros poblados: A mas de de $30 \mathrm{~km}=1$, Entre 30 y $10 \mathrm{~km}=3$, Menos de $10 \mathrm{~km}=5$

${ }^{7}$ Conectividad digital: Ausencia total $=0$, Tiene teléfono fijo $=1$, Tiene teléfono fijo y celular $=3$, Tiene teléfono fijo y/o celular e internet $=5$

${ }^{8}$ Acceso a salud básica: No tienen $=0$; Tiene $=5$

${ }^{9}$ Nivel educativo formal: Primaria incompleta= 1 , Primaria completa $=2$, Secundaria incompleta $=3$, Secundaria completa/ UTU $=4$, Inició nivel terciario $=5$

${ }^{10}$ Acceso a capacitación: No tienen $=0$, Tiene $=5$

${ }^{11}$ Nivel de endeudamiento: Relación nivel de deuda/patrimonio: $>0.15=1$, Entre 0.1 y $0.15=2$, Entre 0.05 y $0.1=3,<0.050>0=4$, No tiene deuda $=5$

CALIDAD DE VIDA ESTRUCTURAL INTEGRADA: Muy mala $<=20$ puntos $=1$, Mala entre 20 y 30 puntos $=2$, Intermedia entre 30 y 40 puntos $=3$, Buena entre 40 y 50 puntos $=4$, Muy buena $>=50$ puntos $=5$ 
La percepción que tenían las familias sobre su propia calidad de vida al inicio del proyecto era muy buena. El valor promedio de este indicador fue de 4,6 , en una escala donde
$5=$ Muy satisfecho y $1=$ Insatisfecho (Cuadro 21). La alta valoración se debe fundamentalmente a que estaban a gusto con su modo de vida, al trabajo de campo y al apego a la naturaleza (Figura 9).

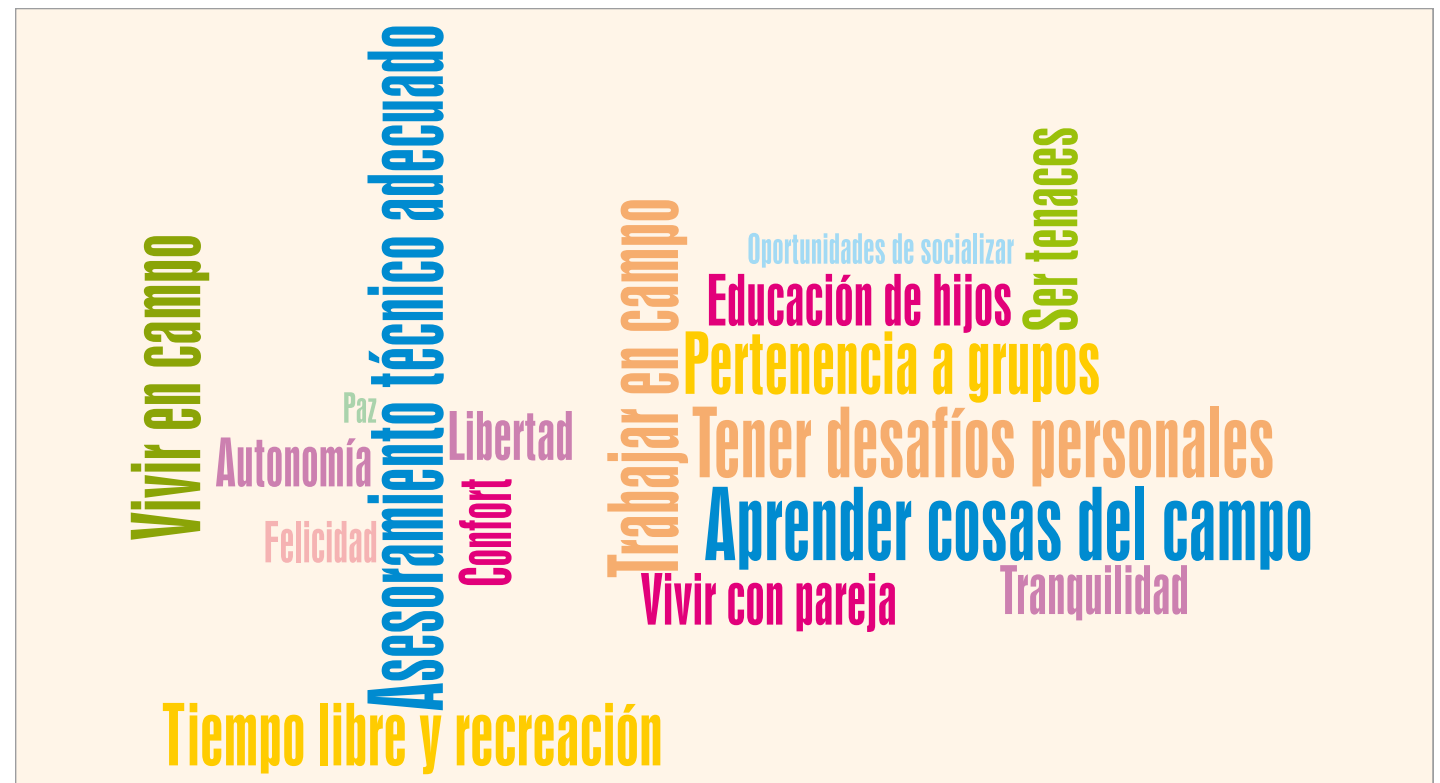

Figura 9. Factores asociados a la calidad de vida subjetiva mencionados por los productores, priorizados de acuerdo con la frecuencia de mención (Albicette et al., 2016a).

En términos generales las decisiones productivas eran tomadas mayoritariamente por quien realizaba el manejo de campo y las decisiones vinculadas al hogar y a la familia eran tomadas mayoritariamente por la mujer. En todos los casos las decisiones estratégicas eran tomadas en familia.

Con relación a la toma de registros productivos y económicos, en tres de los casos no se llevaban registros y en el resto existía algún tipo de registro (guardar boletas, cuadernos de campo, etc.), pero dicha información no se utilizaba para la toma de decisiones.

Con respecto a la valoración y uso de la planificación, al inicio del proyecto ninguna de las familias planificaba a mediano o largo plazo. En general no planificaban y solo en dos de los casos se planificaban algunas áreas o actividades (Cuadro 22).

Todas las familias estaban vinculadas a las organizaciones de productores locales (SFR
Ruta 109 y SFR Castillos) y en seis de los casos integraban algún grupo de productores.

En seis de los casos las familias habían participado de diversos proyectos del MGAP que brindaban asistencia técnica y capacitación (PRONADEGA, Uruguay Rural, Programa Ganadero, PPR, etc.) a través de la organización local de productores.

\subsubsection{Recursos prediales}

\subsection{Recursos humanos}

En seis de los siete casos la mano de obra era provista fundamentalmente por la familia. En el caso restante se contrataba un trabajador asalariado permanente. En todos los predios se contrataba mano de obra zafral para tareas específicas. En dos de los casos algún miembro de la familia realizaba trabajos remunerados fuera del predio. En el Cuadro 5 se detallan estos aspectos, cuantificando la organización del trabajo. 
Cuadro 5. Organización del trabajo en los siete casos.

\begin{tabular}{|c|c|c|c|c|c|c|c|}
\hline & Caso 1 & Caso 2 & Caso 3 & Caso 4 & Caso 5 & Caso 6 & Caso 7 \\
\hline $\begin{array}{l}\text { MOF disponible total }(\mathrm{EH} / \\
\text { año) }\end{array}$ & 1 & 1 & 2 & 2 & 2,25 & 2 & 2 \\
\hline $\begin{array}{l}\text { MOF dedicada al trabajo } \\
\text { extrapredial (EH/año) }\end{array}$ & & & 0,5 & 1,25 & & & \\
\hline $\begin{array}{l}\text { Contratación de MO } \\
\text { permamente (EH/año) }\end{array}$ & No & 1 & No & No & No & No & No \\
\hline $\begin{array}{l}\text { Contratación de MO } \\
\text { zafral (tareas) }\end{array}$ & Maquinaria & $\begin{array}{c}\text { Alambrador } \\
\text { Esquila } \\
\text { Enfardado }\end{array}$ & $\begin{array}{l}\text { Cosecha } \\
\text { maíz } \\
\text { Esquila }\end{array}$ & & Maquinaria & $\begin{array}{l}\text { Esquila } \\
\text { Baño } \\
\text { ovejas } \\
\text { Cosecha } \\
\text { maíz }\end{array}$ & $\begin{array}{l}\text { Maquinaria } \\
\text { Esquila }\end{array}$ \\
\hline $\begin{array}{l}\text { Tiempo de trabajo }{ }^{1} \\
\text { dedicado al manejo de } \\
\text { animales y pasturas (h/ } \\
\text { año) })^{*}\end{array}$ & 1793 & 2134 & 1156 & 789 & 1643 & 2665 & 2074 \\
\hline $\begin{array}{l}\text { Proporción del trabajo } \\
\text { dedicado al manejo del } \\
\text { animales y pasturas } \\
\text { provisto por la familia } \\
(\%)^{*}\end{array}$ & 96 & 14 & 90 & 100 & 96 & 93 & 97 \\
\hline $\begin{array}{l}\text { Productividad de la mano } \\
\text { de obra total aplicada } \\
\text { en tareas productivas } \\
\text { en relación al ingreso } \\
\text { ganadero familiar (U\$S / } \\
\text { hora año) }\end{array}$ & 13 & 8 & 9 & 5 & -2 & 8 & 7 \\
\hline
\end{tabular}

MOF= Mano de obra familiar, $\mathrm{MO}=$ Mano de obra, $\mathrm{EH}=$ Equivalente Hombre $=2400$ horas de trabajo/año, ${ }^{\prime}$ Incluye mano de obra familiar y mano de obra contratada. ${ }^{*}$ Cuantificado en base a la metodología de Balance de Trabajo (Dieguez et al., 2009).

\subsection{Suelos}

Cuatro predios se ubican sobre la unidad Sierra de Polanco de la carta de suelos a escala 1:1.000.000 (MGA-DSF, 1979), que se corresponde con zonas de sierras moderadamente rocosas y pedregosas. Los tres predios restantes se ubican, en distinta proporción, sobre colinas ligeramente rocosas de la unidad José Pedro Varela, y lomadas suaves y fuertes de la unidad Alférez.
Los principales grupos de suelos CONEAT presentes en los establecimientos corresponden a las unidades $2.12,10.7,2.21,2.11$ a y 4.2; con un índice de productividad promedio de 90 . Son suelos de laderas medias y altas asociados a bajos y desagües. En el Cuadro 6 se presenta el índice CONEAT promedio por productor. Por más detalles ver Historia de Innovación Caso 1 - 7 (http://www.inia.uy/ Proyectos/Paginas/PF_07.aspx). 
Cuadro 6. Índice de productividad suelos CONEAT para los siete casos.

\begin{tabular}{ccc} 
Caso & Grupos CONEAT & IC* \\
\hline $\mathbf{1}$ & $10.7,4.2$ & 84 \\
$\mathbf{2}$ & $10.7,2.21,3.31,3.54$ & 102 \\
$\mathbf{3}$ & 2,21 & 105 \\
$\mathbf{4}$ & $2.11 \mathrm{a}, 2.11 \mathrm{~b}, 2.12$ & 70 \\
$\mathbf{5}$ & $2.11 \mathrm{a}, 2.11 \mathrm{~b}, 2.12$ & 62 \\
$\mathbf{6}$ & $2.11 \mathrm{a}, 2.12,2.21$ & 89 \\
$\mathbf{7}$ & $10.7,2.12,2.11 \mathrm{a}, 3.31$ & 116 \\
\hline
\end{tabular}

*IC: Índice CONEAT medio

Se realizó un relevamiento detallado de cada predio a partir del cual se identificaron diferentes unidades cartográficas con grupos de suelos, propiedades y capacidades de uso diferentes. En las laderas medias y altas predominaban unidades donde se agrupaban suelos tipo Brunosoles y Argisoles, asociados a Litosoles; mientras que en zonas bajas que bordean las vías de drenaje dominaban suelos tipo Gleysoles. Las propiedades inferidas variaban según la unidad de suelo (Cuadro 7), pero la mayor proporción de la superficie poseía suelos de fertilidad media, riesgo de sequía media a alto y moderadamente bien drenados. Por más detalles ver Historia de Innovación Caso 1 - 7 (http://www.inia.uy/Proyectos/Paginas/ PF_07.aspx).

Cuadro 7. Porcentaje de suelos según propiedades inferidas en los 7 predios.

\begin{tabular}{cccccc} 
Riesgo de sequía & $\mathbf{( \% )}$ & Fertilidad natural & $\mathbf{( \% )}$ & Drenaje Natural* $^{*}$ & \% \\
\hline Bajo o Nulo & 27 & Baja & 5 & MBD/BD & 9 \\
Bajo-Medio & 8 & Baja-Media & 10 & MBD & 47 \\
Medio & 13 & Media & 48 & MBD/l & 20 \\
Medio-Alto & 45 & Media-Alta & 28 & I & 19 \\
Alto & 7 & Alta & 9 & $\mathrm{P}$ & 5 \\
\hline
\end{tabular}

*MBD = moderadamente bien drenado, $\mathrm{BD}=$ bien drenado, $\mathrm{I}=$ imperfecto; $\mathrm{P}=$ pobre.

En el Cuadro 8 se presenta la proporción del área que ocupaba cada una de las clases de capacidad de uso en los siete establecimientos. Por más detalles ver Historia de Innovación Caso 1 - 7 (http://www.inia.uy/Proyectos/ Paginas/PF_07.aspx). En general todos los predios poseían cerca de un $50 \%$ o más de suelos arables con aptitud agrícola, aunque con limitantes por riesgo de erosión. El resto del área era de buena aptitud pastoril, con restricciones para la agricultura principalmente por presentar hidromorfismo o superficialidad.

Cuadro 8. Área ocupada (\%) por las principales clases de capacidad de uso en cada caso.

\begin{tabular}{ccccccc}
\multicolumn{7}{c}{ \% en las Clases de capacidad de uso* } \\
Caso & II & III & IV & V & VI & VII \\
\hline $\mathbf{1}$ & 15,4 & 60,4 & & 24,2 & & \\
$\mathbf{2}$ & & 69,6 & 1,8 & 16,1 & 12,5 & \\
$\mathbf{3}$ & & 63 & 23,2 & 13,8 & \\
$\mathbf{4}$ & & 63,1 & 21,6 & & 15,3 \\
$\mathbf{5}$ & & 65,3 & 21,7 & 12,4 & 0,5 \\
$\mathbf{6}$ & & & 23,5 & 27 & \\
$\mathbf{7}$ & & 49,5 & & 29,3 & 23,1 & 1,1 \\
\hline
\end{tabular}

*I al IV arables, de I a IV aumentan las limitantes. V al VIII no arables, de V al VIII aumentan las limitantes. 
En cuanto a las propiedades físico-químicas, los suelos presentaban niveles de fósforo bajos, lo que concuerda con la naturaleza de los suelos a nivel nacional, niveles de materia orgánica medios y $\mathrm{pH}(\mathrm{H} 2 \mathrm{O})$ ácido. En el
Cuadro 9 se presenta valores de referencia para el horizonte $A$ de la principal unidad de suelo de cada predio. Por más detalles ver Historia de Innovación Caso 1 - 7 ( http://www. inia.uy/Proyectos/Paginas/PF_07.aspx).

Cuadro 9. Características físico-químicas del horizonte A para los siete casos.

\begin{tabular}{cccccccc} 
Caso & Horizonte & $\begin{array}{c}\text { Profundidad } \\
(\mathrm{cm})\end{array}$ & Clasificación textural & $\begin{array}{c}\mathbf{p H} \\
(\mathrm{H} 2 \mathrm{O})\end{array}$ & $\begin{array}{c}\mathbf{M} . \mathbf{O} . \\
(\%)\end{array}$ & $\begin{array}{c}\text { P Bray I } \\
(\mathrm{ppm})\end{array}$ & $\begin{array}{c}\mathbf{K} \\
(\mathrm{meq} / 100 \mathrm{~g} \text { suelo })\end{array}$ \\
\hline $\mathbf{1}$ & $\mathrm{A}$ & 19 & Franco limosa & 5,7 & 2,74 & $<1$ & 0,63 \\
$\mathbf{2}$ & $\mathrm{A}$ & 18 & Franca & 5,0 & 3,5 & 2 & 0,5 \\
$\mathbf{3}$ & $\mathrm{A} 1$ & 20 & Franco arcillo arenosa & 4,8 & 0,8 & 1,0 & 0,37 \\
$\mathbf{4}$ & $\mathrm{A}$ & 17 & Franco limosa & 6,1 & 4,10 & 2,1 & 0,32 \\
$\mathbf{5}$ & $\mathrm{A}$ & 20 & Franca & 5,4 & 4,14 & 2,4 & 0,52 \\
$\mathbf{6}$ & $\mathrm{A}$ & 27 & Franca & 6,3 & 3,00 & 3,35 & 0,24 \\
$\mathbf{7}$ & $\mathrm{A}$ & 12 & Franca & 6,4 & 4,53 & 3,7 & 0,67 \\
\hline
\end{tabular}

\subsection{Pasturas}

El uso del suelo en los predios era principalmente pastoril (Cuadro 10), con un promedio de los siete predios de $79 \%$ del área utilizada como campo natural, la cual constituía la base forrajera principal en todos los casos. El área mejorada promediaba un $19 \%$ y se componía principalmente de mejoramientos de campo (rincón y maku), verdeos y praderas.

Cuadro 10. Uso de suelo al inicio del proyecto (otoño 2012) para los siete casos.

\begin{tabular}{lccccccc} 
& Caso 1* & Caso 2 & Caso 3 & Caso 4 & Caso 5 & Caso 6 & Caso 7 \\
\hline Superficie total & 316 & 319 & 61 & 92 & 364 & 291 & 234 \\
Superficie pastoreo & 316 & 319 & 59 & 92 & 304 & 291 & 231 \\
Área de Campo Natural (\%) & 55 & 81 & 77 & 75 & 88 & 96 & 82 \\
Área Mejorada (\%) & 45 & 9 & 23 & 25 & 12 & 4 & 18 \\
\hline
\end{tabular}

* Otoño 2013

El diagnóstico inicial sobre el estado de los recursos forrajeros fue realizado en otoño del 2012 y se presenta a continuación.

Campo natural: Si bien el estado inicial del campo natural era diferente en cada uno de los predios (ver Historia de Innovación Caso 1 - 7, http://www.inia.uy/Proyectos/Paginas/ PF_07.aspx), en términos generales se observaron signos de degradación del mismo: suelo desnudo, presencia de algunas hierbas enanas, gramilla, malezas de campo sucio y baja cantidad de forraje en el estrato bajo. En algunos potreros se observó una alta proporción de estrato alto, relacionado con el manejo anterior (alta relación ovino/vacuno).
Composición botánica del campo natural: Al inicio (primavera 2013/2014), se realizó una evaluación de la diversidad de especies de campo natural y el aporte de cada una de ellas, considerando todas aquellas con una presencia superior al $5 \%$ (Mueller-Dombois y Ellenberg, 1974). En promedio, para los siete estudios de caso, fueron identificadas 56 especies, variando desde 43 a 66 (Cuadro 15). De ellas, 15 ocuparon en promedio el $82 \%$ de la superficie y las 5 más importantes representaron el $54 \%$ del total. En la Figura 10 se presentan las especies principales encontradas dentro de las 5 especies principales en cada predio. 


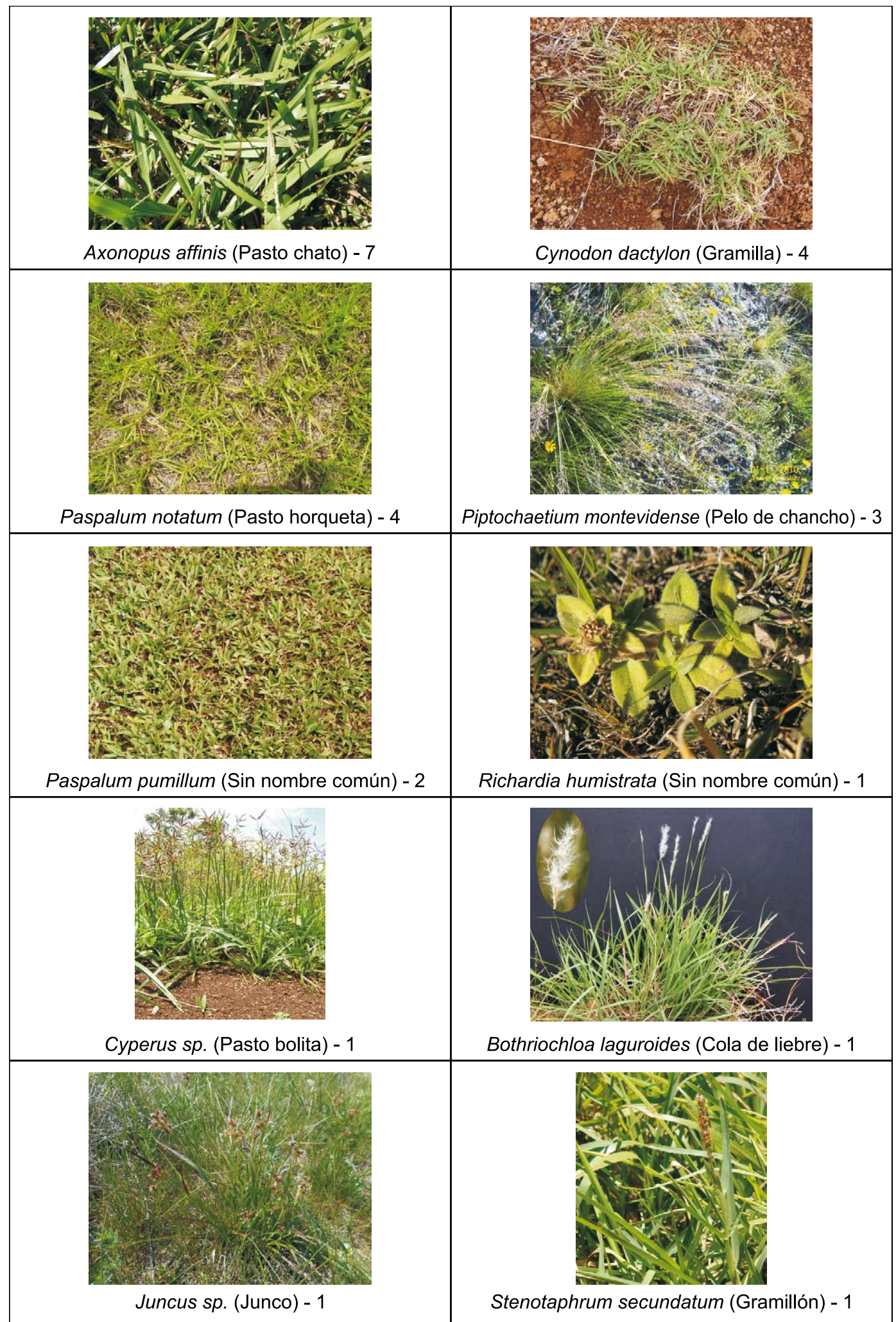

Figura 10. Principales especies del campo natural presentes en los predios, especificando nombre científico y nombre común, e indicando con un número en cuántos predios la especie estuvo presente. 
La presencia de doble estrato en los potreros evaluados era de $9,9 \%$ del área, variando de 3 a 24\%, siendo las principales especies: Cardilla (Eryngium horridum), Paja mansa (Paspalum quadrifarium) y Paja estralladora (Erianthus angustifolius). El nivel de doble estrato promedio encontrado en los potreros no representa en ningún caso un problema importante desde el punto de vista productivo, siendo menor a los 30-35\% reportados como límite (Da Trindade et al., 2012). Desde el punto de vista ambiental dicho componente de la pastura cumple una función central en la biodiversidad.

Praderas y verdeos: En general en los siete predios en las praderas y verdeos se observaron problemas de enmalezamiento. Se identificó una inadecuada selección de especies como mezclas de raigrás y lotus "El Rincón"; sin incorporación de especies de gramíneas perennes, método de laboreo convencional, e inexistencia de una rotación forrajera.

La altura promedio de forraje y el forraje disponible era diferente al inicio (diciembre de 2012) para cada predio. La altura y disponibilidad de forraje promedio para los siete estudios de caso fue de $6,2 \mathrm{~cm}$ y $1307 \mathrm{~kg} \mathrm{MS} / \mathrm{ha}$ respectivamente. Esto fue muy diferente entre predios, variando desde 2,8 a $11,3 \mathrm{~cm}$ y 476 a 2737 kg MS/ha). Ver Figura 19.

La oferta de forraje promedio ( $\mathrm{kg} \mathrm{MS/kg} \mathrm{PV)} \mathrm{fue}$ estimada para los 3 ejercicios anteriores al comienzo del proyecto siendo en promedio para los siete predios de 3,3 kg MS/kg PV. Esto también fue diferente entre predios, variando de 1,2 a 4,6 kg MS/kg PV (Ver Anexos 3 al 10).

\subsection{Infraestructura productiva}

Todos los predios disponían de la infraestructura básica para la cría de ganado, si bien en algunos casos existían espacios de mejora, que ya estaba prevista con el financiamiento de proyectos del MGAP. Por detalles ver Historia de Innovación Caso 1 - 7 (http://www. inia.uy/Proyectos/Paginas/PF_07.aspx).

El número total de potreros por predio variaba entre 10 y 23. En todos los casos permitía un manejo adecuado del rodeo de cría; en tres de los predios, la subdivisión de los potreros más grandes facilitaría el manejo del campo natural, en particular para poder diferir forraje. El estado de los alambrados era bueno en cuatro casos y regular en los tres restantes.

Para el manejo de los animales seis de los predios contaban con mangas propias, tres con embarcadero propio y el resto accedía a uno cercano. Para pesar animales cuatro de los predios contaban o accedían a balanza.

En relación al agua bebida para los animales cinco de los predios disponían de agua de buena calidad, uno de los predios tenía problemas en veranos secos y el restante tenía problemas de calidad de agua (salobre).

Con respecto a disponibilidad de sombra y abrigo para animales, cuatro de los predios disponían de sombra y abrigo sin limitantes, en los tres restantes no tenían acceso a sombra y abrigo en algunos potreros.

\subsubsection{Caracterización ambiental}

\subsection{Integridad ecosistémica}

El Índice de integridad ecosistémica (IIE) promedio de los siete predios obtenido al inicio del proyecto fue de 3,5 . Además del valor global del establecimiento, el IIE también tiene un valor por cada potrero, que puede ser representado gráficamente en una escala visual en el plano del establecimiento como lo muestra la Figura 11. Esta forma de presentación facilita la interpretación de resultados, la detección de puntos o zonas críticas y la toma de decisiones. Los valores iniciales del IIE reflejan una situación ambiental general de los establecimientos que se catalogó como aceptable a buena.

Existían diferentes consideraciones según el caso, pero en todos los establecimientos la mayor proporción de la superficie estaba ocupada por campo natural y el impacto ambiental más importante había sido causado por el sobrepastoreo. Este se traducía en signos de erosión edáfica, pérdida de diversidad botánica 
y estructural, engramillamiento y casi nula presencia de renovales de comunidades leñosas.

En cuanto a las zonas riparias, estaban en buen estado con vegetación natural presente, aunque a veces modificada o interrumpida debido al consumo y pisoteo por el ganado así como a intervenciones de quema con fuego.
Si bien las intervenciones productivas habían afectado los ecosistemas, como el grado de naturalidad era bueno, gran parte de los servicios ecosistémicos se podían mantener. Esto permite plantear que algunos de los elementos afectados podrían revertirse en el mediano plazo, para lograr una mejora en la integridad ecosistémica.
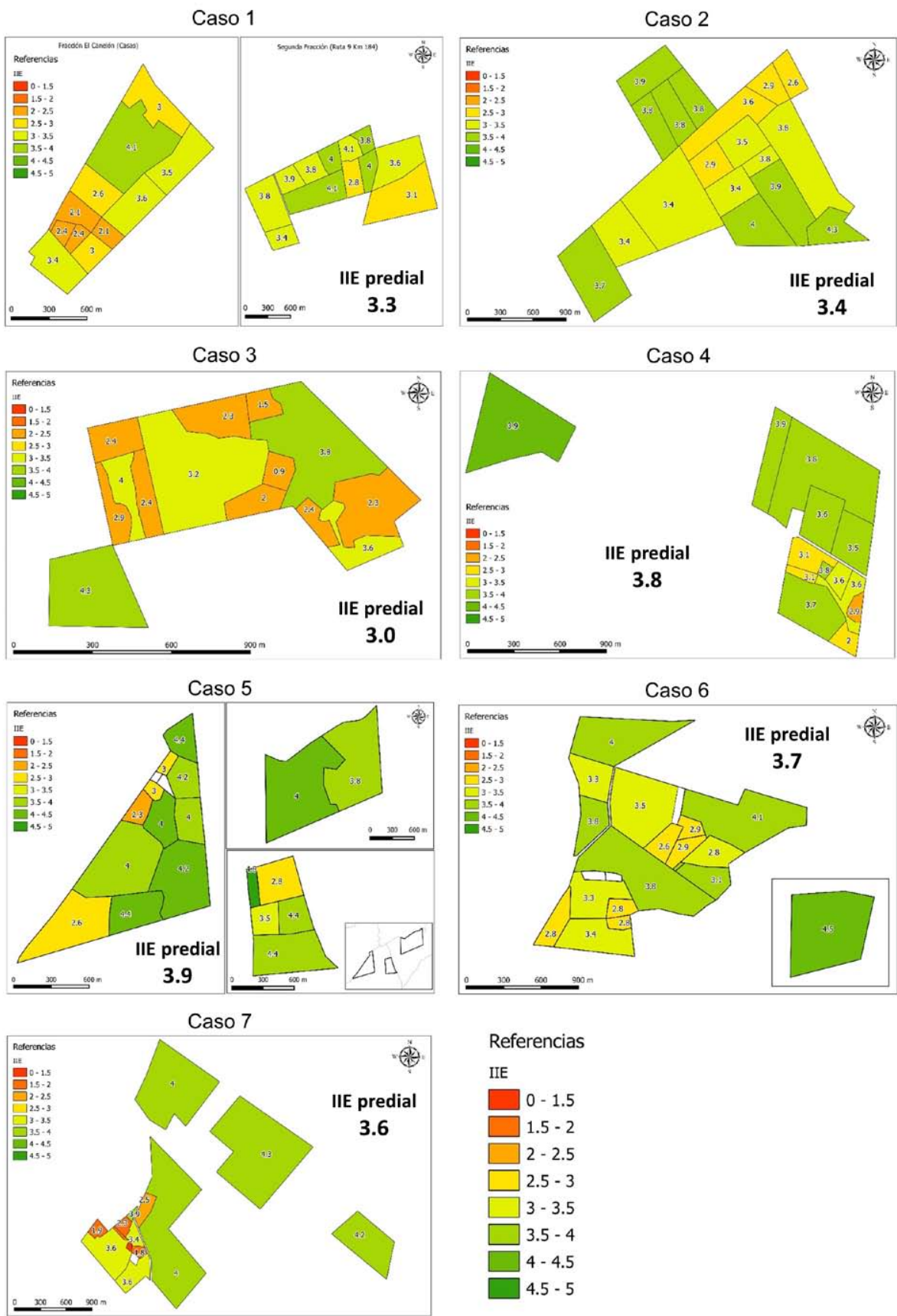

Referencias

IIE

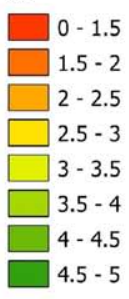

Figura 11. Índice de integridad ecosistémica (IIE) para cada potrero y global para cada caso. 


\subsection{Fauna asociada - aves}

Se utilizó la comunidad de aves como indicadora de la biodiversidad presente en los predios dado que son un grupo de organismos: (i) fácil de detectar; (ii) del que, relativamente, se cuenta con un buen conocimiento general (e.g. taxonómico, biológico, poblacional, biogeográfico); (iii) presenta diversidad de especies y su biología, incluyendo muchos migrantes que son sensibles a diversos cambios ambientales; (iv) presenta especies que se ubican en todo el rango de niveles tróficos y por lo tanto pueden ser sensibles o causantes de cambios a otros niveles de la red trófica; (v) responden rápido a cambios en la estructura física del ambiente; (vi) generan conexión y significado para las personas y sus vidas (Butler et al., 2010; Gregory y van Strien, 2010; Gibbons y Gregory, 2006).

El monitoreo de aves reveló la presencia de 177 especies que, de forma permanente o temporal, utilizaban los ambientes comprendidos dentro de los 7 establecimientos; de ellas, 21 se consideran prioritarias para la conservación en Uruguay (Soutullo et al., 2013) (Cuadro 11). El detalle de los resultados del monitoreo de aves de cada predio se puede profundizar en Guía fotográfica de aves (http://www.inia.uy/Proyectos/Paginas/ PF_07.aspx).

Cuadro 11. Presencia de aves prioritarias para la conservación (Soutullo et al., 2013) en los siete casos.

\begin{tabular}{|c|c|c|c|c|c|c|c|c|}
\hline Nombre Común & Nombre Científico & Caso 1 & Caso 2 & Caso 3 & Caso 4 & Caso 5 & Caso 6 & Caso 7 \\
\hline Carao & Aramus guarauna & & $\sqrt{ }$ & & & & & \\
\hline Batitú & Bartramia longicauda & & $\sqrt{ }$ & & & & & \\
\hline Seriema & Cariama cristata & & & & $\sqrt{ }$ & $\sqrt{ }$ & $\sqrt{ }$ & \\
\hline Gavilán Ceniciento & Circus cinereus & $\sqrt{ }$ & $\sqrt{ }$ & $\sqrt{ }$ & & & & $\sqrt{ }$ \\
\hline Cuervo Cabeza Negra & Coragyps atratus & & & & $\sqrt{ }$ & $\sqrt{ }$ & & $\sqrt{ }$ \\
\hline Monterita Cabeza Gris & Donacospiza albifrons & $\sqrt{ }$ & & $\sqrt{ }$ & $\sqrt{ }$ & $\sqrt{ }$ & $\sqrt{ }$ & $\sqrt{ }$ \\
\hline Aguila Mora & $\begin{array}{l}\text { Geranoaetus } \\
\text { melanoleucus }\end{array}$ & & & & & & $\sqrt{ }$ & $\sqrt{ }$ \\
\hline Mirlo Charrúa & Gnorimopsar chopi & $\sqrt{ }$ & & & & $\sqrt{ }$ & $\sqrt{ }$ & $\sqrt{ }$ \\
\hline Pajonalera Pico Recto & Limnoctites rectirostris & $\sqrt{ }$ & $\sqrt{ }$ & $\sqrt{ }$ & $\sqrt{ }$ & & $\sqrt{ }$ & $\sqrt{ }$ \\
\hline Pajonalera Pico Curvo & Limnornis curvirostris & & $\sqrt{ }$ & & & & $\sqrt{ }$ & \\
\hline Macuquiño & Lochmias nematura & & & & $\sqrt{ }$ & $\sqrt{ }$ & & \\
\hline Perdiz Común & Nothura maculosa & $\sqrt{ }$ & $\sqrt{ }$ & $\sqrt{ }$ & $\sqrt{ }$ & $\sqrt{ }$ & $\sqrt{ }$ & $\sqrt{ }$ \\
\hline Aguatero & $\begin{array}{l}\text { Nycticryphes } \\
\text { semicollaris }\end{array}$ & & & $\sqrt{ }$ & & & & \\
\hline Cardenal Copete Rojo & Paroaria coronata & $\sqrt{ }$ & $\sqrt{ }$ & $\sqrt{ }$ & & & $\sqrt{ }$ & \\
\hline Chorlo Dorado & Pluvialis dominica & & $\sqrt{ }$ & & & & & \\
\hline Ñandú & Rhea americana & $\sqrt{ }$ & $\sqrt{ }$ & & & $\sqrt{ }$ & $\sqrt{ }$ & $\sqrt{ }$ \\
\hline Martineta & Rynchotus rufescens & $\sqrt{ }$ & & & $\sqrt{ }$ & $\sqrt{ }$ & $\sqrt{ }$ & $\sqrt{ }$ \\
\hline Playerito Canela & Tryngites subruficollis & $\sqrt{ }$ & & & & & & \\
\hline Dragón & Xanthopsar flavus & $\sqrt{ }$ & & $\sqrt{ }$ & & & $\sqrt{ }$ & \\
\hline Viudita Blanca Grande & Xolmis dominicanus & $\sqrt{ }$ & & $\sqrt{ }$ & $\sqrt{ }$ & & $\sqrt{ }$ & $\sqrt{ }$ \\
\hline Federal & $\begin{array}{l}\text { Amblyrhamphus } \\
\text { holosericeus }\end{array}$ & & $\sqrt{ }$ & & & & & \\
\hline
\end{tabular}


Entre las especies registradas existían generalistas (viven en varios ambientes) y otras especialistas que viven solo en determinados ambientes, ej.: espejos de agua, montes o vegetación de bañados. Otra forma de clasificar las especies presentes fue por sus hábitos alimenticios, conocidos como gremios
(Figura 12), donde se destacó la presencia de especies en todos los gremios lo cual resultó un buen indicador de salud ambiental y la gran abundancia de especies insectívoras, reforzando el valor de las aves como controladores biológicos de las poblaciones de insectos.

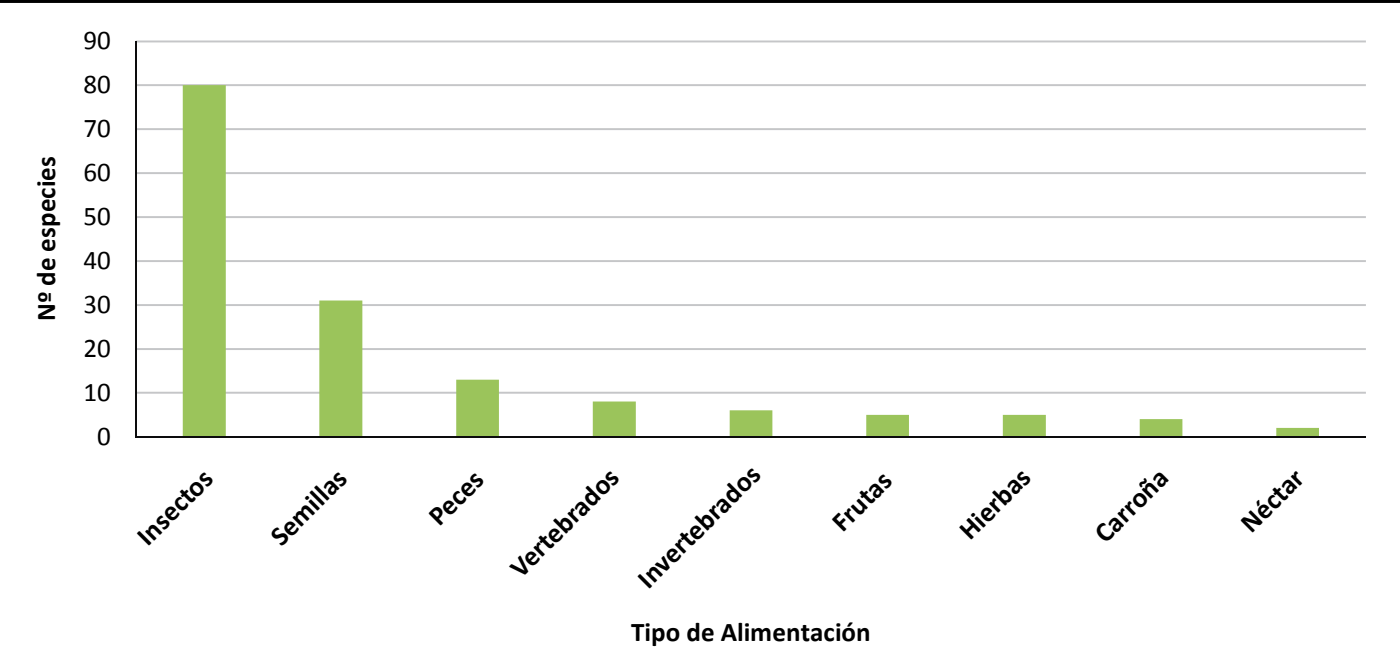

Figura 12. Gremios de alimentación de las especies de aves registradas en los siete casos.

Las 10 especies que aparecieron con mayores registros en los muestreos realizados se muestran en las Figura 13.
En Guía fotográfica de aves (http://www.inia. uy/Proyectos/Paginas/PF_07.aspx), se documentan fotográficamente las especies de aves que fueron registradas en cada uno de los casos. 


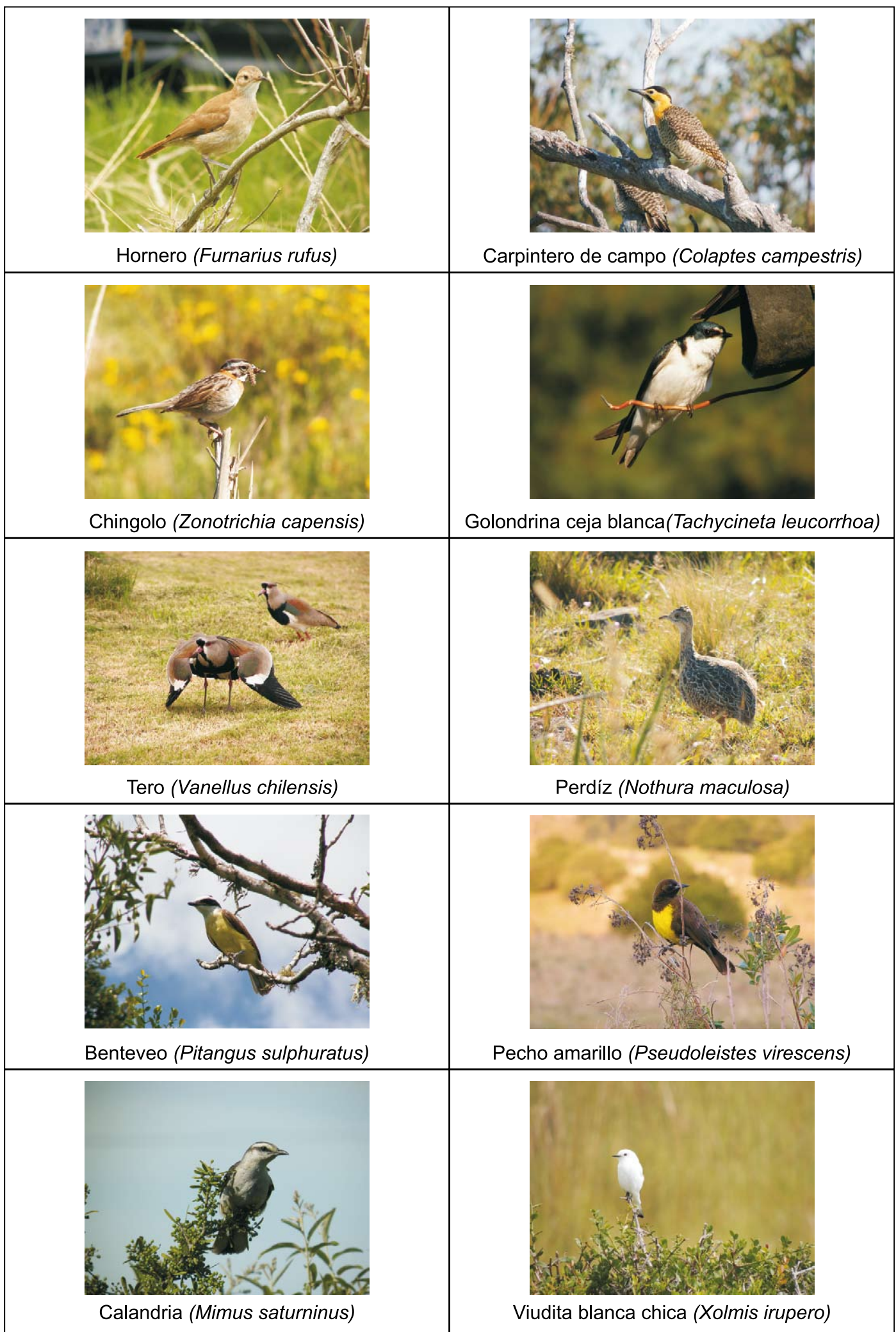

Figura 13. Especies de aves más abundantes en los siete casos. 
El muestreo inicial indica la presencia de una diversidad de especies, con todos los gremios alimenticios representados, lo cual normalmente no ocurre en ecosistemas muy modificados (Codesido et al., 2008). Respecto a las especies prioritarias para la conservación, el caso con menos especies fue de ocho, lo cual es considerado un muy buen nivel del indicador por tratarse de áreas que no están bajo ninguna medida especial de protección. En total se registraron 21 de las 51 especies prioritarias posibles para la bioregión y ambientes considerados.

\subsection{Carbono orgánico total y sus fracciones}

Los valores de carbono orgánico total entre 0 y $18 \mathrm{~cm}$ de profundidad (evaluado como profundidad de exploración radicular de las herbáceas), fueron muy homogéneos, variando entre 2,28 y $2,96 \%$. Tomando como referencia el compendio de suelos (MGAPDGRN, 2001) y considerando que el tipo de suelo tuvo algunas variantes según el caso de estudio, los valores son los esperables para el horizonte $A$, aunque en algún caso podría esperarse valores algo superiores. Los valores observados, se consideran como no limitantes para la productividad del suelo, más allá de que habría oportunidades de enriquecer el contenido en varios casos.

\subsubsection{Actividades de producción}

\subsection{Descripción general y uso de tecnologías}

La principal actividad de producción en los predios era la ganadería mixta (vacuna y ovina), en cinco de los casos y la ganadería vacuna en los dos restantes. En los dos predios de menor escala la producción se complementa con horticultura (chacra: maíz, papa y poroto) en uno y con apicultura en otro. Por detalles ver Historia de Innovación Caso 1 - 7 (http://www.inia.uy/Proyectos/Paginas/PF_07.aspx).
El uso del suelo en los predios era principalmente pastoril (Cuadro 10), con un promedio para los siete predios de $79 \%$ del área utilizada como campo natural, la cual constituía la base forrajera principal en todos los casos.

La especialización productiva en vacunos era la cría con venta de distintos productos según el predio, terneros en otoño (6 predios), terneros de un año en primavera (1 predio), terneras en otoño (4 predios) o vaquillonas (3 predios), vacas de refugo flacas (5 predios) y vacas de refugo gordas (2 predios). En ovinos se realizaba cría con venta de corderos mamones, borregos y ovejas de descarte (4 predios) y ciclo completo con venta de corderos pesados y ovejas de descarte (2 predios). En uno de los predios la producción ganadera se combinaba con chacra, siendo los productos principales maíz, papa y poroto; y con cría de cerdos con venta de lechones.

En relación con el uso de tecnologías propuestas para la cría, al inicio del proyecto había cuatro casos con un nivel de uso muy bajo, un caso con nivel de uso medio y dos casos con muy buen nivel de uso de tecnologías (Cuadro 25).

\subsection{Manejo de los animales}

En esta sección se pretende dar una descripción general del manejo animal en los predios. Un resumen de los principales indicadores de resultados de cada caso y promedio para los siete casos se encuentra en los Anexos 3 a 10. El detalle de cada predio se encuentra en Historia de Innovación Caso 1 - 7 (http://www.inia.uy/Proyectos/Paginasi PF_07.aspx).

\section{i) Vacunos}

Como ya mencionamos, al inicio del proyecto la especialización productiva de los siete predios era la cría. En el Cuadro 12 se presenta el stock vacuno y su correspondencia en unidades ganaderas (UG) para cada caso al inicio del proyecto en otoño de 2012. 
Cuadro 12. Stock vacuno por caso al inicio del proyecto (otoño 2012).

\begin{tabular}{lccccccc} 
& Caso 1* & Caso 2 & Caso 3 & Caso 4 & Caso 5 & Caso 6 & Caso 7 \\
\hline Cabezas vacunas & 226 & 338 & 63 & 42 & 197 & 188 & 178 \\
UG vacunas & 179 & 278 & 47 & 34 & 163 & 150 & 149 \\
UG vacunas/ha & 0,57 & 0,87 & 0,8 & 0,37 & 0,54 & 0,52 & 0,65 \\
\hline
\end{tabular}

* Otoño 2013

Las vacas eran de raza carnicera en todos los casos (Hereford, Angus y sus cruzas) y los toros utilizados eran Aberdeen Angus (3 predios), Red Angus (2 predios), Hereford (2 predios).

El entore era concentrado en primavera-verano en cuatro predios, dos predios tenían entore continuo y uno de los predios tenía doble entore (primavera-verano y otoño). La edad de entore de las vaquillonas era de dos años en seis de los predios y en el restante, gran parte de las vaquillonas se entoraban a los tres años. En ninguno de los predios se realizaba el diagnóstico de actividad ovárica durante el entore.

Medidas de control de amamantamiento, ya fuera destete temporario o precoz, eran utilizadas en tres de los predios. Mientras que el diagnóstico de gestación de forma estructural se realizaba en cinco de los predios y en los dos restantes se hacía en forma ocasional. Sólo en tres casos se tomaban medidas de manejo diferencial de acuerdo al resultado.

El manejo diferencial por condición corporal, vacas de primera cría, y otras categorías que fuera necesario priorizar, se realizaba de forma estructural solo en dos de los predios.

El porcentaje de preñez que lograban los predios, en los tres ejercicios previos era de
$76 \%$ en promedio, pero era variable entre los predios, con un mínimo de $63 \%$ y un máximo de $89 \%$, siendo mejorable en todos los casos (Figura 24 y Anexos 3 al 10).

El porcentaje de procreo vacuno promedio que lograron los predios en los tres ejercicios previos al inicio del proyecto fue de $71 \%$, pero era variable y en la mayoría de los casos muy mejorable (Figura 25 y Anexos 3 al 10).

En general, todos los productores destetaban a las hembras en otoño (mayormente en abril). Al destete pastoreaban principalmente campo natural y durante el invierno en cinco predios pastoreaban mejoramientos de campo o praderas. En cinco de los predios se suplementaban las terneras durante el invierno con ración o granos y en los dos restantes enseñaban a las terneras a comer suplemento. En la mayoría de los casos el proceso de recría tenía amplias posibilidades de mejora.

\section{ii) Ovinos}

La especialización productiva era la cría en cuatro de los predios y el ciclo completo en dos predios, con venta fundamentalmente de corderos mamones o pesados, ovejas de descarte y lana. En el Cuadro 13 se presenta el stock ovino y su correspondencia en unidades ganaderas (UG) para cada caso al inicio del proyecto en otoño de 2012.

Cuadro 13. Stock ovino para cada caso al inicio del proyecto (otoño 2012).

\begin{tabular}{lccccccc} 
& Caso 1* & Caso 2 & Caso 3 & Caso 4 & Caso 5 & Caso 6 & Caso 7 \\
\hline Cabezas ovinas & 117 & 388 & 246 & 263 & --- & 410 & 265 \\
UG Ovinas & 23 & 78 & 44 & 51 & -- & 75 & 51 \\
UG Ovinas/ha & 0,07 & 0,24 & 0,75 & 0,55 & --- & 0,26 & 0,22 \\
\hline
\end{tabular}

* Otoño 2013 
La base de la majada era Corriedale puro o cruza con una raza carnicera (Texel) en cinco de los predios y en el predio restante la majada era Ideal. Los carneros utilizados eran de razas carniceras (Texel o lle de France) en 3 predios, Corriedale en 2 predios e Ideal en 1 predio.

La encarnerada se realizaba fundamentalmente en otoño (abril- mayo), siendo más temprana (febrero-marzo) en los predios que vendían corderos mamones (2). La edad a la primer encarnerada era en todos los casos 2 dientes. En ninguno de los predios se realizaba manejo por condición corporal en la majada.

La esquila era de tipo tradicional (noviembrediciembre) en cuatro de los predios y en los dos restantes se realizaba esquila preparto (agosto).

El porcentaje de procreo logrado en los últimos ejercicios previos al inicio del proyecto eran relativamente bajos o mejorables (Anexos 3 al 10), alcanzando en promedio $77 \%$, con variaciones entre años.

En los dos predios en que se vendían corderos pesados, los corderos se destetaban en enero-febrero, y se engordaban en base a praderas y verdeos durante el invierno y la primavera en un ciclo de unos 9-10 meses de engorde, hasta un peso final de 40-42 $\mathrm{kg}$ de PV. En uno de los casos se vendía al expendio municipal o en feria y en el otro a frigorífico.

\subsection{Comercialización}

La compra y venta de animales y productos generados en el predio se realizaban por canales diversos entre los que se destacan: consignatarios, venta directa, ferias locales, frigorífico y expendio municipal. La valorización de los productos vendidos era un área de mejora relevante en cuatro predios. Asimismo, la compra de insumos y productos sanitarios se realizaban en la ciudad más cercana de acuerdo con la ubicación del predio: Rocha o Castillos. Los suplementos en el caso de los predios cercanos a Castillos eran comprados en la SFR Castillos que contaba con un molino.

\subsection{Carga animal y relación ovino/vacuno}

La carga animal promedio de los siete estudios de caso, en los tres años previos al inicio del proyecto, mostró un valor alto $(0,94$; 0,92 y 0,91 para los ejercicios 2009-2010; 2010-2011 y 2011-2012 respectivamente) y una evolución más o menos estable. En este caso la situación particular de cada predio es de mucha importancia y existieron diferentes evoluciones en cada caso (Figura 16 y Anexos 3 al 10).

La relación ovino/vacuno promedio de los siete estudios de caso para el mismo período, era estable $(2,4 ; 2,9$ y 2,4 para los ejercicios 2009-2010; 2010-2011 y 2011-2012 respectivamente), pero al analizar la situación particular de cada predio se observaban situaciones muy diferentes (Figura $17 \mathrm{y}$ Anexos 3 al 10), destacándose dos predios con relación ovino/vacuno muy altas al inicio (4 y 6 en promedio para dichos ejercicios).

\subsection{Resultados productivos y económicos 2009 - 2012}

Desde el punto de vista productivo-económico los siete casos tenían resultados dispares en los años previos al inicio del proyecto. La producción de carne equivalente era en promedio 99 variando entre 64 y $151 \mathrm{~kg} / \mathrm{ha}$. Estos valores eran similares a los reportados por el Instituto Plan Agropecuario (IPA, 2017) para este período en predios criadores ( $\mathrm{Fi}$ gura 28 y Anexos 3 al 10).

El ingreso familiar ganadero era de $58 \mathrm{U} \$ S / \mathrm{ha}$ en promedio, existiendo una gran variación entre predios, que iba entre - 1 y 139 U\$S/ha (Figura 29 y Anexos 3 al 10).

El ingreso neto ganadero (valorizando la mano de obra familiar) era en promedio para los siete predios de $31 \mathrm{U} \$ \mathrm{~S} / \mathrm{ha}$ para los tres años previos al inicio del proyecto (Figura 30 ), 
siendo valores similares a los reportados para los predios criadores monitoreados por el Instituto Plan Agropecuario, que eran de 36 U\$S/ ha (IPA, 2017).

Estos indicadores económico-productivos eran mejorables en todos los casos. En los Anexos 3 al 10 se detallan para cada caso los componentes de estos indicadores y los precios promedio obtenidos para todos los ejercicios estudiados. Un mayor nivel de detalle para cada caso se encuentra en Historia de Innovación Caso 1 - 7 (http://www.inia.uy/ Proyectos/Paginas/PF_07.aspx).

\subsubsection{Etapa 2: Diagnóstico}

A partir de la información de caracterización relevada y presentada en la sección anterior, se identificaron para cada predio las principales fortalezas y debilidades que fueron organizadas en relación con los atributos de la sustentabilidad, criterios de diagnóstico y puntos críticos de acuerdo al marco MESMIS. Para cada uno de ellos se seleccionaron indicadores específicos para definir el punto de partida o línea de base y evaluar su evolución (Cuadro 14). Por detalles específicos de cada predio ver Historia de Innovación Caso 1 - 7 (http://www.inia.uy/Proyectos/Paginas/PF_07.aspx).

Las principales debilidades o puntos críticos negativos en los siete predios eran: (i) bajo ingreso familiar asociado a baja productividad animal y baja productividad de la mano de obra familiar, (ii) bajo uso de tecnologías disponibles para el manejo de animales y pastura, en conjunto con habilidades de gestión del predio mejorables, (iii) campo natural degradado. Las principales fortalezas o puntos críticos positivos eran: (i) alta satisfacción con el modo de vida, (ii) alta biodiversidad, (iii) bajo nivel de endeudamiento.

Los indicadores seleccionados para evaluar el atributo de productividad fueron: producción de carne equivalente, ingreso familiar ganadero, productividad de la mano de obra aplicada al predio. Para el atributo estabilidad se utilizaron: calidad de vida estructural y calidad de vida subjetiva, tiempo disponible luego del trabajo con animales y superficie forrajera, uso de tecnologías propuestas, índice de integridad ecosistémica, riqueza de especies de $\mathrm{CN}$, riqueza de especies de aves, altura de $\mathrm{CN}$ en otoño, \% estrato alto en $\mathrm{CN}$, \% carbono orgánico total en suelo. Dentro del grupo de atributos confiabilidad, adaptabilidad y resiliencia se utilizaron la proporción del tiempo de trabajo dedicado al manejo de animales y pasturas provisto por la familia (\%) y la diversificación de fuentes de ingreso. Para el atributo autogestión se utilizó la relación deuda/patrimonio y la valoración y uso de la planificación. 
Cuadro 14. Principales puntos críticos de los predios, vinculados a los principales atributos de la sustentabilidad planteados en el marco MESMIS, con los indicadores seleccionados para monitorear su evolución.

\begin{tabular}{|c|c|c|c|}
\hline $\begin{array}{l}\text { Atributo de la } \\
\text { Sustentabilidad }\end{array}$ & $\begin{array}{l}\text { Criterio de } \\
\text { diagnóstico }\end{array}$ & Punto crítico & Indicador \\
\hline \multirow{3}{*}{ Productividad } & $\begin{array}{l}\text { Eficiencia de } \\
\text { producción }\end{array}$ & $\begin{array}{l}\text { Baja / mejorable } \\
\text { productividad }\end{array}$ & $\begin{array}{l}\text { Producción de carne equivalente } \\
\qquad(\mathrm{kg} / \mathrm{ha} \text { año) }\end{array}$ \\
\hline & $\begin{array}{l}\text { Eficiencia } \\
\text { económica }\end{array}$ & $\begin{array}{l}\text { Bajo/mejorable } \\
\text { ingreso familiar }\end{array}$ & $\begin{array}{l}\text { Ingreso familiar ganadero } \\
\text { (U\$S/ha año) }\end{array}$ \\
\hline & $\begin{array}{l}\text { Productividad de la } \\
\text { mano de obra }\end{array}$ & $\begin{array}{l}\text { Baja/mejorable } \\
\text { productividad del } \\
\text { trabajo }\end{array}$ & $\begin{array}{l}\text { Productividad de la mano de obra aplicada } \\
\text { en el predio (U\$S/hora año) }\end{array}$ \\
\hline \multirow{6}{*}{ Estabilidad } & \multirow[t]{2}{*}{ Calidad de vida } & $\begin{array}{l}\text { Alto nivel de } \\
\text { satisfacción con } \\
\text { el modo de vida }\end{array}$ & $\begin{array}{l}\text { Calidad de vida estructural integrada } \\
\text { Calidad de vida subjetiva }\end{array}$ \\
\hline & & $\begin{array}{l}\text { Carga de trabajo } \\
\text { crítica }\end{array}$ & $\begin{array}{l}\text { Tiempo disponible luego del trabajo con } \\
\text { animales y pasturas (horas/año) }\end{array}$ \\
\hline & $\begin{array}{l}\text { Estabilidad } \\
\text { productiva }\end{array}$ & $\begin{array}{l}\text { Bajo uso de } \\
\text { tecnologías } \\
\text { disponibles }\end{array}$ & Uso de tecnologías propuestas (\%) \\
\hline & \multirow{3}{*}{$\begin{array}{l}\text { Provisión de } \\
\text { servicios } \\
\text { ecosistémicos }\end{array}$} & $\begin{array}{l}\text { Alta biodiversidad: } \\
\text { ecosistemas y } \\
\text { especies }\end{array}$ & $\begin{array}{c}\text { Índice de integridad ecosistémica } \\
\text { Riqueza de especies en CN } \\
\text { Riqueza de especies de aves }\end{array}$ \\
\hline & & $\begin{array}{l}\text { Campo Natural } \\
\text { degradado }\end{array}$ & $\begin{array}{c}\text { Altura del CN en otoño }(\mathrm{cm}) \\
\text { Estrato alto en } \mathrm{CN}(\%)\end{array}$ \\
\hline & & Suelo degradados & Carbono orgánico total en el suelo (\%) \\
\hline \multirow{2}{*}{$\begin{array}{l}\text { Confiabilidad/ } \\
\text { Adaptabilidad/ } \\
\text { Resiliencia }\end{array}$} & $\begin{array}{l}\text { Fragilidad del } \\
\text { Sistema }\end{array}$ & $\begin{array}{l}\text { Disponibilidad } \\
\text { de MOF }\end{array}$ & $\begin{array}{l}\text { Proporción del tiempo de trabajo dedicado } \\
\text { al manejo de animales y pasturas provisto } \\
\text { por la familia }(\%)\end{array}$ \\
\hline & Diversificación & $\begin{array}{l}\text { Diversidad de } \\
\text { fuentes de ingresos }\end{array}$ & $\mathrm{N}^{\circ}$ de fuentes de ingresos \\
\hline \multirow[b]{2}{*}{ Autodependencia } & $\begin{array}{l}\text { Dependencia } \\
\text { financiera }\end{array}$ & $\begin{array}{l}\text { Bajo nivel de } \\
\text { endeudamiento }\end{array}$ & Relación deuda/patrimonio \\
\hline & $\begin{array}{l}\text { Toma de } \\
\text { decisiones }\end{array}$ & $\begin{array}{l}\text { Habilidades para la } \\
\text { gestión del predio } \\
\text { mejorables }\end{array}$ & Valoración y uso de la planificación \\
\hline
\end{tabular}

El análisis integrado de los puntos críticos implica una profundización en el estudio de las relaciones causales, las que se presentan como árbol de problemas en la Figura 14. Este árbol permite jerarquizar y conectar los puntos críticos negativos, así como identificar los aspectos clave a trabajar en la etapa de re-diseño. El problema central identificado a nivel de los predios fue de índole productiva y correspondía a un desbalance entre la producción de forraje y los requerimientos animales, lo que resultaba en un espiral de insustentabilidad, en el cual interactúan varios factores.

La principal fuente de forraje en estos sistemas es el campo natural, compuesto principalmente por especies estivales. Históricamente, los campos naturales habían sido manejados manteniendo bajas alturas o disponibilidades de forraje, y consecuentemente con bajos índices de área foliar, 
reduciendo así su capacidad de realizar fotosíntesis. Como resultado, la productividad del campo natural era baja y el riesgo de erosión y pérdida de especies valiosas alto.

Por otro lado, la baja oferta de forraje limitaba el consumo animal lo que traía como consecuencia una baja performance animal, destacando una baja eficiencia reproductiva y bajos pesos de venta; lo que generaba que el ingreso familiar fuera bajo y/o mejorable.

Los factores causales identificados como problema y sobre los cuales se podía trabajar eran la alta carga animal y la relación ovino/vacuno, que son las variables de manejo más importantes ya que determinan la relación entre la oferta de forraje y la demanda animal. Asimismo, se podía ajustar el manejo animal, tanto a nivel de la cría y la recría, el manejo de las pasturas y el manejo de la interacción planta-animal a través de la gestión del pastoreo considerando la gestión espacio-temporal en los sistemas.

Complementariamente al problema central se identificó que los conocimientos, actitudes, habilidades y aspiraciones de los productores eran mejorables y que a través de una metodología de trabajo que fomentara procesos de aprendizaje, se podía trabajar desde la planificación de todo el sistema de producción y la mejora en la gestión y manejo realizados, lo que podía redundar, no solo en la mejora de la productividad del sistema, sino también en una mejor organización de trabajo y mejor calidad de vida.

Desde el punto de vista ambiental, en una visión amplia, se identificó que el manejo inadecuado del pastoreo y la sustitución de campo natural por pasturas sembradas genera la degradación de recursos naturales (fundamentalmente $\mathrm{CN}$ ) y la posible disminución en la provisión de algunos servicios ecosistémicos, en especial relacionado a servicios de regulación. En este sentido el abordaje fundamental para mejorar este aspecto fue promover un aumento de la disponibilidad de forraje en el campo natural a través de una reducción de la intensidad de pastoreo en el predio. La hipótesis era que a nivel del ecosistema se promovería un aumento en la cobertura del suelo, una disminución de la cobertura de especies exóticas (ej.: gramilla) y la diversificación estructural de la vegetación. Esto permitiría la mejora o, al menos, el mantenimiento de los indicadores ambientales como el Índice de integridad ecosistémica y/o la riqueza de aves. Complementariamente se podrían abordar medidas específicas para problemas ambientales concretos, ej: mantenimiento de zonas riparias, recuperación de suelos, restauración de campo natural, recuperación de monte nativo y bañados, etc. Estos aspectos no fueron implementados en el lapso del proyecto, pero son aspectos a considerar en etapas futuras. 


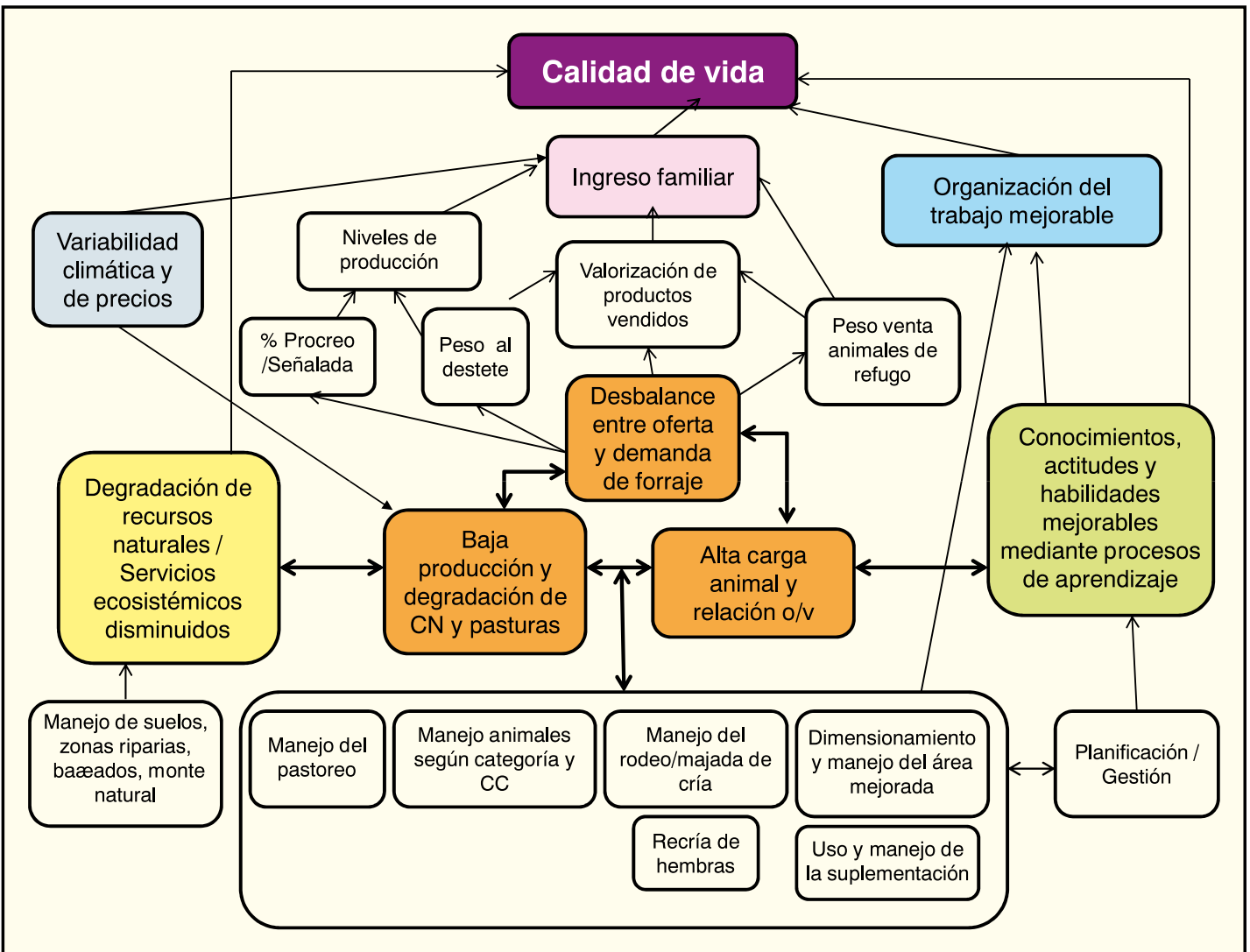

Figura 14. Árbol de problemas y estrategias para abordar los principales problemas identificados, común a todos los predios.

\subsubsection{Etapa 3: Re-diseño}

\subsubsection{Objetivo general}

El objetivo general de las propuestas de re-diseño fue común a todos los predios y consistía en mejorar el ingreso económico y estabilizarlo entre años. Se procuró aumentar la producción de carne en base a medidas de manejo, que no incrementaran los costos, que no degradaran o mejoraran el estado de los recursos naturales, y que no complejizaran el manejo del sistema.

\subsubsection{Objetivos de producción específicos}

El principal objetivo específico, común a todos los predios, fue el de incrementar y estabilizar la producción de forraje (campo natural y áreas mejoradas) y mejorar su gestión para ser más eficientes en la transformación del mismo a producto animal. Para ello se trabajó gestionando el sistema en tiempo y espacio, asignando, según la altura de forraje de los potreros, determinadas categorías animales en diferentes momentos del año.

Paralelamente se trabajó con objetivos específicos complementarios, que variaron en cada predio en función de los resultados que se venían obteniendo y los objetivos del productor y su familia, los que se detallan a continuación:

- Incrementar y mantener entre años la tasa de procreo (Todos menos Caso 1 y Caso 7).

- Reducir costos del manejo de vacas paridas (Caso 7).

- Aumentar el rodeo de cría vacuno manteniendo la tasa de procreo entre años (Caso 1, Caso 3, Caso 4, Caso 7). 
- Estabilizar el número de vacas a entorar de acuerdo con la disponibilidad de alimento (Caso 6).

- Aumentar y homogeneizar el peso al destete de los terneros (Caso 2, Caso3, Caso 4, Casos 5, Caso 6)

- Venta de todos los terneros en el otoño (Caso 2, Caso 3, Caso 4, Caso 5, Caso 6).

- Incrementar el peso de las vacas de refugo a vender (Caso 2, Caso 3, Caso 4, Caso 5, Caso 6).

- Mejorar la genética del rodeo vacuno (recambio toros) (Caso 6, Caso 4).

- Mejorar la recría de las hembras de reposición (Caso 5, Caso 6, Caso 7).

- Recriar vaquillonas de refugo para venta de vaquillonas gordas o preñadas (Caso 1 , Caso 7).

- Reducir la edad de entore a dos años en todas las vaquillonas (Caso 6).

- Reducir la relación ovino/vacuno a partir de una reducción del número de ovejas a encarnerar (Caso 3, Caso 4).

- Definir objetivo productivo en ovinos (Caso 2, Caso 6).

- Incrementar y mantener la tasa de procreo de ovinos (Caso 7).

- Incrementar la producción de carne ovina manteniendo producción de lana (Caso 7).

- Producir de corderos mamones para fin de año (en lugar de cordero pesado) (Caso 4).

- Analizar la posibilidad de incorporar el rubro ovino (Caso 5).

\subsubsection{Herramientas - Medidas de manejo}

\subsection{Medidas generales}

En todos los predios la herramienta fundamental fue la planificación a 2-3 años, incluyendo medidas de manejo por mes y/o estación, la proyección de stock, compra-venta de animales y el flujo financiero.

Asimismo, se implementó un sistema de monitoreo del sistema de producción, conjunto entre los productores y los técnicos, que se utilizaba para tomar decisiones.

\subsection{Manejo de pasturas y animales}

En todos los casos la principal medida propuesta fue mejorar el manejo de la interacción pastura - animal, optimizando la producción de forraje y la de carne.

Para ello se realizaron las siguientes medidas de manejo:

- Ajuste de la carga animal y/o de la relación ovino/vacuno (disminución de la intensidad de pastoreo), lo que llevó a un aumento de la altura y oferta de forraje.

- Asignación diferencial de pasturas a categorías críticas en distintos momentos del año en función de la altura de la pastura y de los requerimientos animales (gestión espacio-temporal).

- Manejo preferencial en algunas categorías: rodeo de cría (vacas primera cría en invierno, pre y posparto, vacas preñadas en otoño, vacas en baja condición corporal); recría (terneras y vaquillonas en invierno, vaquillonas a entorar en salida de invierno, terneros/as al destete).

- Remoción de restos secos a fin de verano, reserva de potreros para uso estratégico.

\subsection{Manejo de vacunos}

Las herramientas de manejo vacuno propuestas en los predios variaron según los diferentes objetivos específicos y las prácticas que usaban previamente. A continuación, se explicitan el conjunto de medidas de manejo planteadas, aclarando entre paréntesis los casos en que las mismas fueron propuestas:

- Ajuste de época de entore: diciembre a febrero (Caso 2, Caso 3, Caso 4, Caso 5, Caso 6).

- Eliminar doble entore (Caso 2).

- Destete temporario a inicio del entore (Caso 2, Caso 3, Caso 4, Caso 5, Caso 6).

- Diagnóstico de ciclicidad ovárica a mitad de entore (medidas tácticas en función de los resultados obtenidos, por ejemplo: 
destete precoz a vacas en anestro profundo) (Todos los Casos).

- Destete definitivo en marzo-abril ( Caso 2, Caso 3, Caso 4, Caso 5, Caso 6).

- Diagnóstico de gestación en otoño (clasificación de preñeces tempranas y tardías) (Todos menos Caso 1 y Caso 7).

- Manejo diferencial de vacas preñadas (según condición corporal) y falladas (Todos menos Caso 1 y Caso 7).

- Manejo de vacas según condición corporal (Todos menos Caso 1 y Caso 7).

- Venta de terneros machos y hembras de refugo en otoño (Caso 3).

- Suplementación estratégica invernal a terneras (y vaquillonas) con concentrado o verdeos, praderas y mejoramientos (Caso 2, Caso 4, Caso 5, Caso 6).

- Recría de todas las terneras (Caso 1, Caso 7).

- Venta de vacas de refugo gordas (Caso 2, Caso 3, Caso 4).

- Revisación de toros (Todos menos Caso 1 y Caso 7).

- Recambio de toros (Caso 6).

- Plan sanitario (Todos los Casos).

\subsection{Manejo de ovinos}

Las herramientas de manejo ovino propuestas en los predios variaron según los diferentes objetivos específicos y las prácticas que usaban previamente. A continuación se explicitan el conjunto de medidas de manejo planteadas, aclarando entre paréntesis los casos en que las mismas fueron propuestas:

- Mantener una majada para consumo (Caso 3).

- Ajuste de época de encarnerada según momento de venta de corderos (Caso 2, Caso 4, Caso 6, Caso 7).

- Flushing pre-encarnerada (Caso 2, Caso 4, Caso 6).

- Revisación de carneros (Caso 2, Caso 4, Caso 6, Caso 7).

- Mantener el uso de carneros de razas carniceras (Caso 6).

- Cambio de raza (Caso 2, Caso 7).

- Esquila pre-parto (Caso 2, Caso 7).
- Destete al menos 60 días antes de encarnerada (Caso 2, Caso 4).

- Definición de área para manejo de la majada parida (Caso 4).

- Plan sanitario (antiparasitarios, vacunas, etc.) (Caso 2, Caso 3, Caso 6).

\subsection{Manejo de pasturas}

Las herramientas de manejo de pasturas propuestas fueron comunes a todos los predios y consistieron en:

- Campo natural: manejo considerando altura de forraje, manejo estacional, reservas y alivios.

- Mejoramientos de campo: siembra o resiembra, ajuste de fertilización, cierres estratégicos, limpieza o renovación en otoño, etc.

- Pasturas sembradas: estabilizar rotación forrajera (verdeos - pradera con gramínea perenne), siembra directa, ajuste de fertilización, manejo en función de altura de forraje, manejo estacional, etc.

En términos generales se buscó que todas las medidas tendieran a mejorar el estado y la producción del principal recurso, el campo natural. Respecto al resto de los recursos forrajeros, las medidas tendieron a estabilizar la producción evitando destinar áreas de campo natural en buen estado a la siembra de pasturas, y trabajando fundamentalmente sobre las zonas ya intervenidas, promoviendo la perennización de las pasturas.

\subsubsection{Opciones evaluadas}

Considerando los objetivos de producción y las herramientas de manejo planteadas, se diseñaron diferentes alternativas de rediseño para cada predio. En todos los casos se discutieron las ventajas y desventajas de cada una de las posibilidades, e incluso se replantearon algunas propuestas de acuerdo con el análisis realizado junto con la familia. A principios de 2013 se acordó en una propuesta de re-diseño para proceder a su implementación. El detalle de las opciones evaluadas y de la propuesta acordada en 
cada predio se presentan en Historia de Innovación Caso 1 - 7 (http://www.inia.uy/Proyectos/Paginas/PF_07.aspx).

\subsubsection{Etapa 4: Implementación y monitoreo}

\subsubsection{Implementación del plan de re-diseño}

\subsection{Manejo general}

La principal estrategia discutida y acordada fue la de incrementar los niveles de producción de carne por hectárea, a partir de mejorar la eficiencia y productividad individual de los animales en base a un aumento de la oferta de forraje. A partir del manejo del pastoreo -en particular del campo natural-, del ajuste de la carga animal y del empleo de medidas de manejo de bajo costo y alto impacto productivo, se esperaba una mejora en la tasa de destete y en el peso de venta de los animales (terneros, corderos, vacas). Los detalles específicos de la implementación de la propuesta de re-diseño en cada predio se pueden consultar en Historia de Innovación Caso 1 - 7 (http://www.inia.uy/Proyectos/Paginas/PF_07.aspx).

\subsection{Vacunos}

Una vez acordado el objetivo inicial se procuró llegar al número de vacas a entorar definido para cada predio. Respecto al manejo del rodeo de cría, se mantuvieron medidas de manejo que ya se venían realizando en los predios y se incorporaron nuevas, de manera de asegurar la utilización de todas las medidas propuestas en el re-diseño (Cuadro 25). Una de las medidas incorporadas en todos los predios fue el diagnóstico de actividad ovárica a mitad de entore, como herramienta para evaluar la necesidad de tomar medidas de manejo (destete temporario o precoz, alimentación preferencial de vacas) en los animales que estuvieran en anestro a fin de incrementar el porcentaje de preñez del rodeo y de ajustar los costos. Respecto a la recría, se procuró mejorar el proceso en las vaquillonas para lograr entorar su totalidad y con un buen peso a los 2 años, lo que también minimiza los problemas al segundo entore. Se puso especial énfasis en evitar pérdidas de peso durante el primer invierno, a partir del uso de suplemento (ración) o pastoreo de praderas y mejoramientos de Lotus. A partir del inicio de primavera, se procuró maximizar las ganancias de peso pastoreando campo natural con buena disponibilidad de forraje.

\subsection{Ovinos}

En los predios donde había ovinos, una vez acordado el objetivo productivo, se definió el número de ovejas a encarnerar para cada predio. Asimismo, se ajustó el manejo considerando aspectos como genética, momento de encarnerada, momento de esquila, entre otros.

Tanto para ovinos como para vacunos, estaba previsto formular un plan sanitario. Si bien, se ajustaron los principales aspectos del manejo de sanidad, no quedó establecido como plan. Desde el proyecto no se pudo contar con apoyo específico de un técnico veterinario.

\subsection{Pasturas}

En relación al manejo del campo natural, el primer objetivo buscado fue incrementar gradualmente la altura de forraje de todo el predio. El principal cambio en el manejo fue asignar los distintos potreros según la altura de forraje y la categoría animal. Se puso especial énfasis en el alivio de potreros con menor altura de forraje, lográndose paulatinamente la recuperación de las áreas con mayores síntomas de sobrepastoreo. Esto permitía también estar mejor preparados en caso de que se presentara una seca. En todos los casos se trabajó en la planificación para los meses siguientes de la asignación de animales por potrero y la reserva de potreros para períodos críticos y categorías demandantes, como por ejemplo para terneras y vaquillonas durante el invierno, vacas a parir en primavera, etc. 
Cuando la doble estructura de la pastura era un problema, se puso énfasis en el ajuste en la relación ovino/vacuno y en el control de la misma a partir del manejo de la carga instantánea, en aquellos potreros en los cuales su tamaño y la infraestructura de alambrados lo permitían. Se realizaban pastoreos con vacunos adultos de forma estratégica en algunos momentos del año para controlar parte de las maciegas, complementando esto con el corte con rotativa.

En las áreas sembradas se definió una rotación forrajera de verdeos y pradera con siembra directa, con el objetivo de limpiar las chacras de malezas para lograr implantar una pradera en base a Festuca, que pudiera persistir por 4 años o más, lo que también permitía mejorar la cobertura de suelo, evitando erosión. Se intentó optimizar el manejo del pastoreo a partir del ajuste de la altura remanente pos pastoreo y el alivio estratégico durante parte del verano. En situaciones con alto grado de enmalezamiento se emplearon además herbicidas selectivos en momentos estratégicos.

En las áreas de campo mejorado se intentó optimizar el manejo de los mejoramientos existentes en los predios. Las principales medidas de manejo fueron el ajuste del pastoreo, evitando el sobrepastoreo, realizando cierres estratégicos y fertilizando con fósforo en otoño (cuidando el balance leguminosacampo natural).

\subsection{Ambiente}

Desde el área ambiental se concurrió al establecimiento periódicamente (una vez por estación). Además de realizar los muestreos correspondientes, estas visitas generaron un espacio de diálogo entre productores y técnicos del equipo ambiental que permitió, entre otras cosas, discutir conceptos relacionados a los impactos de la actividad productiva sobre distintos componentes del ecosistema. A su vez, se discutieron aspectos que pueden considerarse en la toma de decisiones y sus posibles consecuencias sobre el ambiente. Todos los productores mostraron interés en esta área, con distintos énfasis.
Se discutió la importancia que tenía cada uno de los ambientes presentes en el establecimiento como sitios de alimentación, refugio y nidificación de diferentes especies de aves. Se habló sobre la relevancia de no impactar esas áreas ya que presentaban una gran diversidad de aves. Este concepto se reforzó con el registro de especies prioritarias para la conservación que se encuentran amenazadas.

A continuación, se presentan las oportunidades de mejora identificadas en el proceso, especificando entre paréntesis los casos en que corresponde:

- Restauración de campo natural degradado (Caso 3).

- Manejar el engramillamiento de algunos potreros con el fin de reducirlo y mejorar el estado del campo natural (Caso 2, Caso 6, Caso 7).

- Regeneración de campo natural en potreros que fueron utilizados para la instalación de pasturas perennes hace algunos años (actualmente hay recuperación no dirigida) (Caso 1).

- Procurar la búsqueda de alternativas de pasturas perennes en sustitución de los verdeos (Caso 3, Caso 5).

- Protección de la vegetación de cañadas y arroyos incluyendo conservación de pastizales, no uso de herbicidas en desagües y zonas sensibles y la recuperación de monte nativo en las zonas riparias (Caso 2, Caso 3, Caso 4, Caso 5, Caso 7).

- Cambiar la modalidad de laboreo de suelos a siembra directa (Caso 2, Caso 3, Caso 5, Caso 6, Caso 7).

- Manejo de zonas bajas ricas en biodiversidad y pastizales húmedos. Se destaca el valor de los caraguatales y pastizales de los bajos, responsables del mantenimiento de la calidad de agua (Caso 1, Caso 2, Caso 3).

- Manejo de la renovación de la vegetación leñosas en zonas de monte serrano (Caso 4, Caso 5, Caso 6, Caso 7).

- Evitar uso de quemas para el control de especies indeseadas (Caso 3, Caso 4, Caso 5, Caso 6). 
- Intentar la regeneración del palmar, el cual está en retroceso (Caso 2, Caso 3).

- Ajustar el manejo de los mejoramientos con Lotus ya que hay sobre-dominancia de la leguminosa en algunos casos y aumenta el riesgo de desplazamiento de las especies de campo natural con el consecuente riesgo de invasión de gramilla (Caso 4).

\subsection{Gestión predial}

En el marco del proyecto se trabajó con las siete familias en la proyección de animales a entorar y encarnerar para los años siguientes, estimando la cantidad de animales a vender por año. Durante cada visita mensual se planificaba el manejo de las diferentes categorías de animales y los distintos potreros para los siguientes meses.

En todos los casos, con la información relevada y los productores de cada predio se procesó la información de ejercicios anteriores, calculando y analizando indicadores, tanto de los ejercicios anteriores como los de implementación del proyecto, como forma de apoyar la toma de decisiones. Dos de los predios ya llevaban los registros necesarios, otros dos predios si bien llevaban algunos registros de pesadas y/o compra-venta de animales, incorporaron desde junio de 2012 el registro mensual detallado de gastos y en uno de los predios se incorporó el registro por parte del productor de ingresos y egresos mensuales del predio.

\subsubsection{Evolución de resultados en los predios}

\subsection{Carga animal y relación ovino/vacuno}

En términos generales, la carga animal promedio para los siete estudios de caso se redujo durante todo el proceso, pasando de $0,92 \mathrm{UG} / \mathrm{ha}$ promedio en los tres ejercicios previos al proyecto a $0,85 \mathrm{UG} / \mathrm{ha}$ promedio durante los tres años de implementación. Asimismo, la relación ovino/vacuno se redujo de 2,6 a 1,5 (Figura 15 y Anexo 10), en promedio para los siete casos.

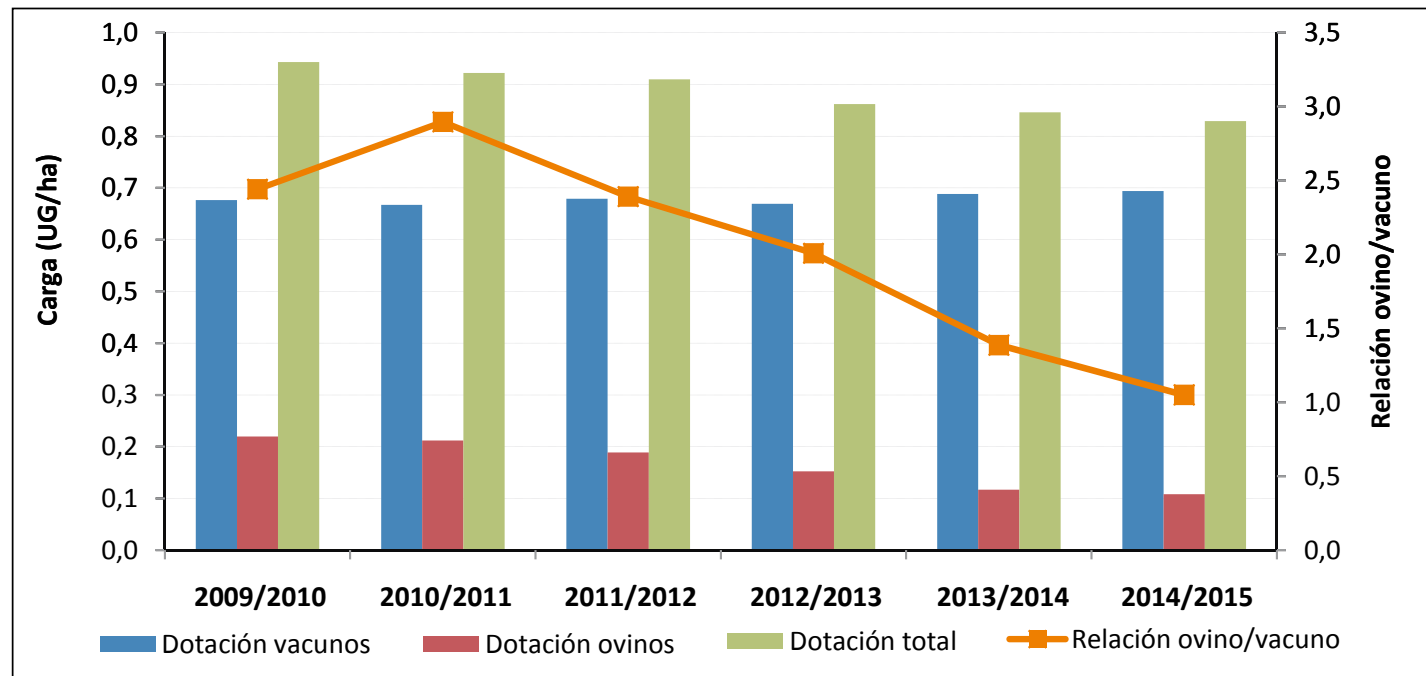

Figura 15. Evolución de la carga vacuna, ovina, total y de la relación ovino/vacuno promedio de los siete casos según ejercicio. 
Sin embargo, debemos destacar que la evolución de la carga animal fue variable en cada predio, con predios que tuvieron un leve incremento de carga y otros que tuvieron una leve reducción en la misma, como se detalla en la Figura 16 y en los Anexos 3 al 9. Lo mismo sucedió con la relación ovino/vacuno, que también fue variable entre predios, dependiendo de la situación de partida de cada uno y de la estrategia acordada (Figura 17 y Anexos 3 al 9).
El ajuste de la carga y/o de la relación ovino/ vacuno requirió una estrategia específica en cada predio, dependiendo de su situación de partida y de los objetivos acordados. El análisis conjunto de las Figuras 15 y 16 muestra que entre las opciones manejadas por cada sistema, algunos sustituyeron carga ovina por carga vacuna para mantener o incluso aumentar la carga total, mientras que otros redujeron la carga total principalmente con una reducción de la carga ovina.

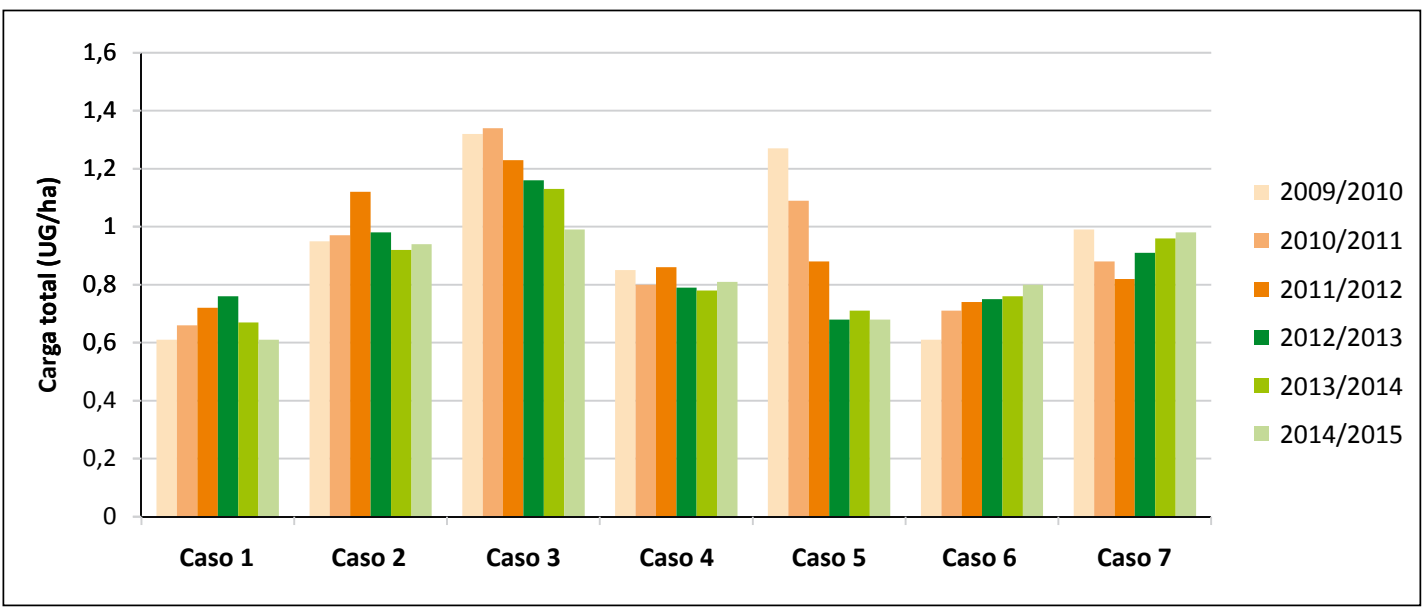

Figura 16. Evolución de carga total (UG/ha) por caso para los tres ejercicios previos al inicio del proyecto (2009/2010; 2010/2011 y 2012/2013) y para los tres ejercicios de implementación del mismo (2012/2013; 2013/2014 y 2014/2015).

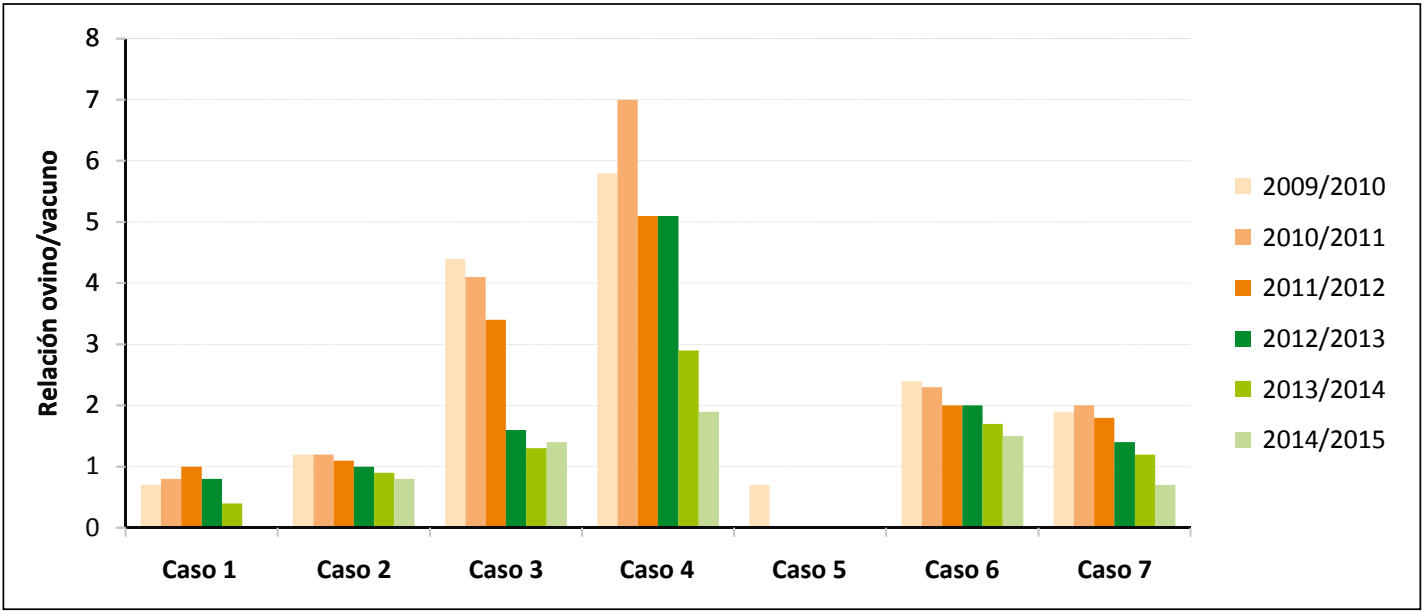

Figura 17. Evolución de la relación ovino/vacuno por caso para los tres ejercicios previos al inicio del proyecto (2009/2010; 2010/2011 y 2012/2013) y para los tres ejercicios de implementación del mismo (2012/2013; 2013/2014 y 2014/2015). 


\subsection{Altura promedio de las pasturas}

Los valores de altura de forraje en los siete predios mejoraron notoriamente durante la implementación del proyecto. Si tomamos como referencia el valor de altura sugerido por Soca y Orcasberro (1992) para lograr una buena performance del rodeo de cría, podemos observar que cuando se comenzó a medir la altura de forraje en los predios se registraron valores muy por debajo de lo sugerido como adecuado (verano y otoño 2013), y que dichos valores fueron mejorando notoriamente a partir del invierno de 2013 (Figura 18).

Paralelamente, el monitoreo de pasturas realizado por el proyecto permite afirmar que en esta región cada centímetro de pasto equivale, en promedio, a $300 \mathrm{~kg} \mathrm{MS} / \mathrm{ha}$, lo que coincide con Do Carmo et al. (2015). Teniendo en cuenta que la evolución de altura promedio de todos los predios fue mejorando a lo largo del proceso, podemos afirmar que trabajaron con mayor cantidad de pasto en cada estación. Por otro lado, debemos tener en cuenta que el trabajar con más pasto permite producir más pasto (Nabinger, 1998), y esto se ve reflejado también en la biomasa de raíces (Ansín et al.,1998), aportando ambas cosas a estar mejor preparados para los períodos de déficit de lluvia.

Durante los tres años de implementación del proyecto se recabaron datos de precipitaciones en cada predio. En los dos primeros años (verano 2013 y verano 2014) los registros de lluvia fueron buenos (413 y $539 \mathrm{~mm}$ respectivamente), superando el valor promedio calculado en base a registros históricos (INIA-GRAS, 2011-1991) para verano en esta región $(398 \mathrm{~mm})$. En el tercer año (2015) se registraron valores de lluvia por debajo de los promedios históricos principalmente en verano $(273 \mathrm{~mm})$ y en otoño (142 $\mathrm{mm}$ ), siendo la media histórica de otoño 411 $\mathrm{mm}$. Sin embargo, como se venía trabajando con valores de altura de forraje dentro de lo sugerido, se pudo mantener el resultado productivo en la mayoría de los casos (Figura 28). Esto se logró por una muy buena gestión del forraje, sin necesidad de incorporar suplementación frente a eventos de sequía.

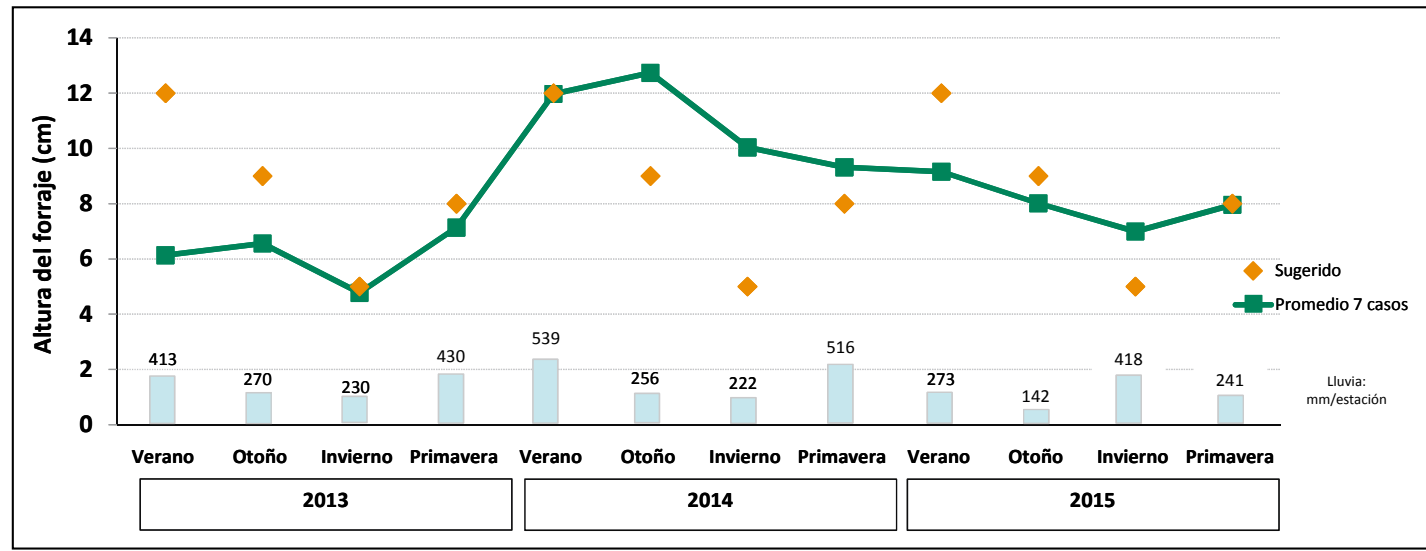

Figura 18. Evolución de la altura promedio del forraje para los siete casos durante los tres años de implementación del proyecto y el valor de referencia sugerido por la literatura (Soca y Orcasberro, 1992). Se incluye también el registro promedio de lluvia por estación (mm acumulados).

La evolución de altura de forraje para cada uno de los predios fue diferente en cada caso (Figura 19), explicado en parte por el manejo anterior de cada predio, fundamentalmente por la carga y relación ovino/vacuno que se manejaron, y por el manejo durante los tres años de implementación. Los sistemas que se venían manejando con carga y relación ovino/vacuno muy elevadas, y por lo tanto con alturas de forraje muy bajas, presentaron una respuesta más lenta en la recuperación de la altura del forraje que los sistemas que 
venían con cargas y/o relación ovino/vacuno más adecuadas. El detalle de la evolución de cada predio acompañado de los datos de precipitaciones registradas en cada uno se observa en Historia de Innovación Caso
1 - 7 (http://www.inia.uy/Proyectos/Paginasi PF 07.aspx). De cualquier forma todos los sistemas lograron incrementar la altura y la cantidad de pasto hacia el verano 2014, capitalizando las condiciones climáticas.

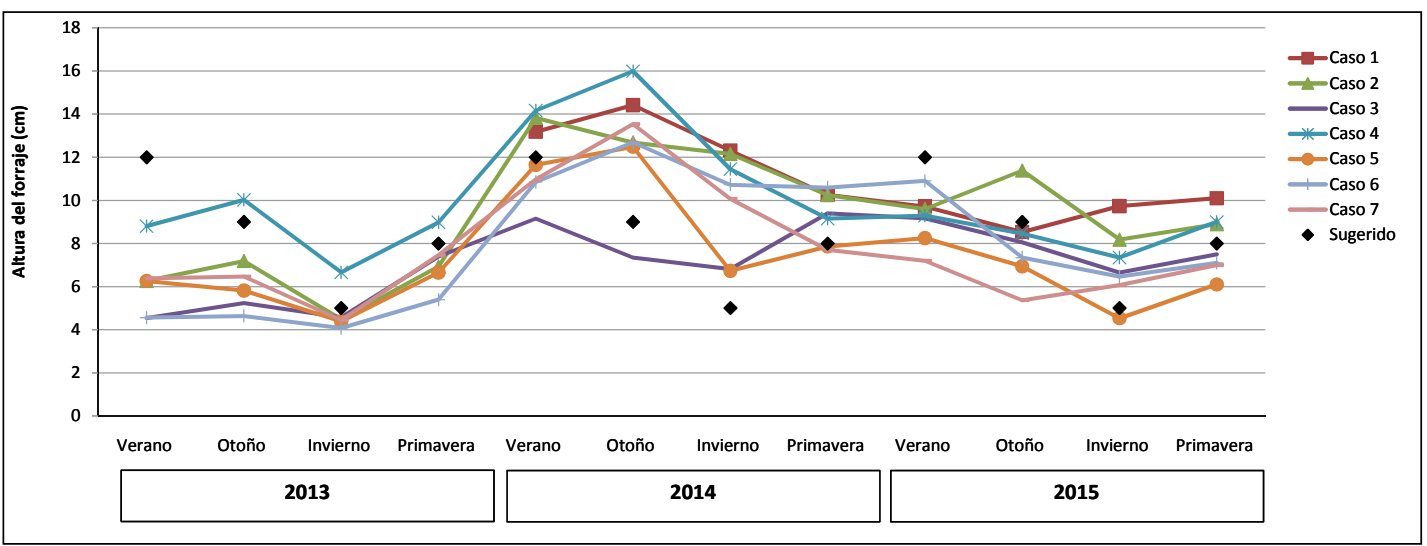

Figura 19. Evolución de la altura de pasto promedio del predio para cada caso durante los tres años de implementación del proyecto y valor de referencia sugerido por Soca y Orcasberro (1992).

La oferta de forraje promedio (kg MS/kg PV) aumentó durante la implementación del proyecto, pasando en promedio para los siete predios de 3,3 kg MS/kg PV (estimada para los 3 ejercicios previos al proyecto) a $5,6 \mathrm{~kg}$ $\mathrm{MS} / \mathrm{kg} \mathrm{PV}$ (calculada para los 3 ejercicios de implementación del proyecto). Los valores obtenidos durante la implementación fueron diferentes entre predios, variando de 3,2 a $7,5 \mathrm{~kg} \mathrm{MS} / \mathrm{kg}$ PV (Anexo 3 al 10).

\subsection{Producción de forraje del predio}

El campo natural es la base de los sistemas estudiados y representó en promedio, el $76 \%$ del total de forraje producido. El resto fue producido por campo natural mejorado, praderas y verdeos anuales.

Los campos naturales produjeron en promedio $4219 \mathrm{~kg} \mathrm{MS} / \mathrm{ha}$ año durante el ejercicio 2013/2014 y $3690 \mathrm{~kg} \mathrm{MS/ha} \mathrm{año} \mathrm{durante} \mathrm{el}$ ejercicio 2014/2015, lo que muestra las posibilidades de mejora que tienen estos campos, ya que dichos valores son superiores a los reportados para la unidad de suelo "Sierra de Polanco", con 1394 (+/-584) kg MS/ ha año (Mas et al., 1997) y dentro de los rango reportados para la unidad de suelos "Alférez", con 3425 (+/-1055) kg MS/ha año
(Bermúdez y Ayala, 2005). En Historia de Innovación Caso 1 - 7 (http://www.inia.uy/Proyectos/Paginas/PF_07.aspx) se presenta la producción de forraje por productor para los dos años en que se evaluó.

\subsection{Composición botánica del campo natural y doble estructura}

Se identificaron en el total de los sitios evaluados más de 150 especies, pero la riqueza individual estuvo entre 35 a 67 especies, dependiendo del potrero y del tiempo. La riqueza media de las especies fue de 56 y 51 para el inicio y final respectivamente, mientras que el índice de Shannon $(H)$ (Shannon y Weaver, 1949) varió entre 2,42 a 3,31, observándose en promedio una reducción de 0,08 entre las evaluaciones (Cuadro 15). Estos valores de riqueza de especies y el Índice de Shannon están dentro de los rangos citados por otros estudios sobre pastizales de campos en Uruguay y la región (Jaurena et al., 2016; Millot et al., 1987). Es importante señalar que la extensión del proyecto ( 3 años), el periodo entre muestreos y la alta dependencia a las condiciones climáticas, son limitantes para explicar que los cambios en este indicador se deban los cambios de manejo. 
Cuadro 15. Evolución de especies en el campo natural para los siete casos, valorada como Riqueza (número de especies) e Índice de Shannon $(\mathrm{H})$.

\begin{tabular}{|c|c|c|c|c|c|c|}
\hline \multirow[b]{3}{*}{ Caso } & \multicolumn{6}{|c|}{ Especies en el campo natural } \\
\hline & \multicolumn{3}{|c|}{ Riqueza ( $\mathbf{N}^{\circ}$ ) } & \multicolumn{3}{|c|}{ Índice de Shannon (H) } \\
\hline & Inicial & Final & Variación & Inicial & Final & Variación \\
\hline 1 & 58 & 52 & -6 & 3,15 & 3,07 & $-0,08$ \\
\hline 2 & 47 & 35 & -12 & 2,72 & 2,42 & $-0,30$ \\
\hline 3 & 55 & 39 & -16 & 3,10 & 2,86 & $-0,24$ \\
\hline 4 & 43 & 54 & 11 & 2,70 & 3,04 & 0,34 \\
\hline 5 & 61 & 56 & -5 & 3,25 & 2,93 & $-0,32$ \\
\hline 6 & 66 & 67 & 1 & 3,28 & 3,31 & 0,03 \\
\hline 7 & 65 & 56 & -9 & 3,06 & 3,06 & 0,00 \\
\hline Promedio & 56 & 51 & -5 & 3,04 & 2,96 & $-0,08$ \\
\hline
\end{tabular}

Dentro de las especies de campo natural que aumentaron su contribución a lo largo del proyecto (Figura 20) podemos destacar en primer lugar Axonopus affinis, una gramínea postrada y muy asociada a condiciones de mayor humedad, como lo fueron esos años, con un incremento promedio para los 7 predios de $5,5 \%$. En menor proporción, también asociado a mayores condiciones de humedad, se destacan el incremento de las ciperáceas y del Paspalum pumilus con 2,6 y $1,9 \%$ respectivamente. El resto de las especies que crecieron en términos porcentuales en el promedio de los 7 predios corresponden a gramíneas perennes estivales de los géneros Paspalum y Coelorachis, varias de alto valor forrajero, que en buena medida componen la estructura basal del campo natural.
Con respecto a las especies de campo natural que disminuyeron a lo largo del proyecto (Figura 20) se destaca en primer lugar a Piptochaetium montevidense, gramínea perenne invernal de nuestros campos, con $-2,7 \%$. También se redujo durante el proyecto la gramilla (Cynodon dactylon), en un $1,9 \%$, aspecto interesante por tratarse de una especie invasora de gran colonización. Por último, hay un conjunto de especies importantes, presentes en todos los predios, que no se modificaron sustancialmente a lo largo del proyecto, como las juncáceas, Richardia humisatrata o Danthonia rhizomata. La evolución detallada de las especies de campo natural en cada predio puede ser consultada en Historia de Innovación Caso 1 - 7 (http://www.inia.uy/Proyectos/Paginas/ PF_07.aspx). 


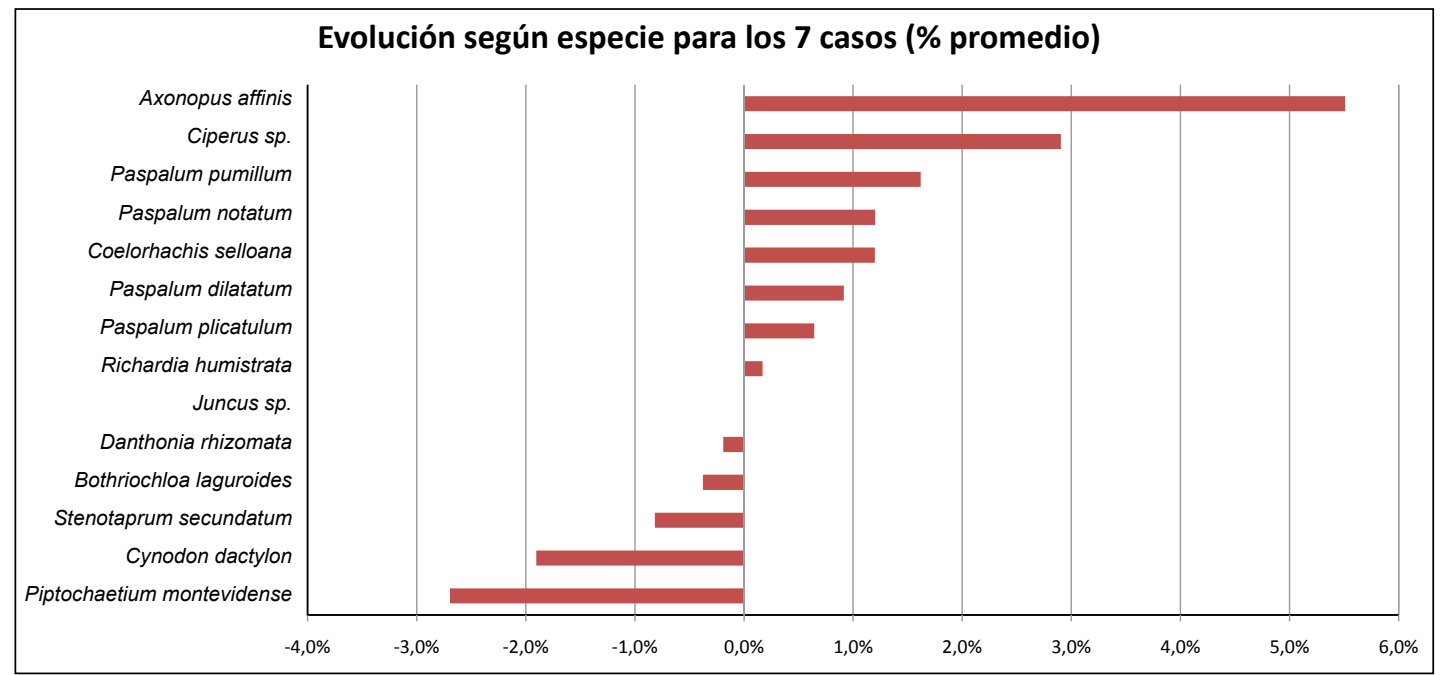

Figura 20. Cambio en el peso porcentual según especie, para el promedio de los siete casos.

El área de doble estrato en los potreros evaluados dentro de los establecimientos (Cuadro 16) ocupaba inicialmente en promedio un $9,9 \%$ del área total, con situaciones muy diferentes según potrero (de 3 a 19\%), mientras que hacia fines del proyecto se pudo observar un leve aumento a $15,3 \%$. A pesar de que el punto de partida fue variado en el porcentaje del estrato alto y en las especies que lo conforman según potrero y productor, el manejo diferencial explica que la evolución haya sido muy diferente entre ellos, pasando desde incrementos importantes de hasta $21 \%$, hasta situaciones de mantenimiento o leve reducción. Pero en ningún caso se sobrepasaron los niveles críticos de
$30-35 \%$ reportados a partir de los cuales se comienza a alterar el comportamiento animal y a afectar la producción (Da Trindade et al., 2012). Las pajas y otros componentes de la doble estructura representan una fuente de alimento de relevancia en momentos de crisis forrajeras, como sequías.

Desde un punto de vista ambiental la doble estructura es central para aumentar la heterogeneidad estructural e incrementar la biodiversidad, generando la posibilidad de más hábitat para diferentes animales. También los componentes más altos de la pastura cumplen un rol central en el ciclado de nutrientes y en la generación de microclimas diferentes.

Cuadro 16. Evolución del doble estrato en campo natural para los siete casos al inicio y fin del proyecto.

\begin{tabular}{cccccc} 
& \multicolumn{3}{c}{} & \multicolumn{2}{c}{ Doble estrato } \\
Caso & Inicial & Final & Variación & \multicolumn{2}{c}{ Escala de $\mathbf{1}$ a $\mathbf{5}^{*}$} \\
$\mathbf{1}$ & 4 & 10 & 6 & Inicial & Final \\
$\mathbf{2}$ & 6 & 27 & 21 & 1 & 3 \\
$\mathbf{3}$ & 3 & 3 & 0 & 2 & 5 \\
$\mathbf{4}$ & 11 & 15 & 4 & 1 & 1 \\
$\mathbf{5}$ & 19 & 24 & 5 & 3 & 4 \\
$\mathbf{6}$ & 16 & 15 & -1 & 4 & 5 \\
$\mathbf{7}$ & 10 & 13 & 3 & 4 & 4 \\
\hline Promedio & $\mathbf{9 , 9}$ & $\mathbf{1 5 , 3}$ & $\mathbf{5 , 4}$ & 3 & 3 \\
\hline
\end{tabular}

* Escala de 1 a 5 en relación al \% del área de pastoreo que ocupa el doble estrato, donde 1= 0-5\% o 100-82,5\%; 2= 5-10\% o 82,5$65 \% ; 3=10-15 \%$ o $65-47,5 \% ; 4=15-20 \%$ o $47,5-30 \% ; 5=20-30 \%$ 
La composición del estrato superior se puede agrupar en tres grandes grupos de plantas: sub-arbustivas, rosetas y pajas. El incremento de cada uno de estos tipos de plantas depende fundamentalmente del punto de partida y del manejo de los animales, favoreciendo su consumo fundamentalmente para el caso de las pajas o manteniendo el tapiz competitivo, evitando la instalación o expansión de las ya presentes. A modo de ejemplo se muestra la evolución de dos potreros bien diferentes tanto desde el punto de partida como de su evolución (Figura 21). Mientras en el primer caso las rosetas representaban el componente principal con el tiempo bajaron su presencia fuertemente y las pajas y sub-arbustos se incrementan para llegar a igualarse hacia el final del periodo. Por su parte, en el segundo caso las pajas fueron el componente de mayor peso, que junto con las rosetas tuvieron un incremento para luego descender y terminar en los niveles iniciales.
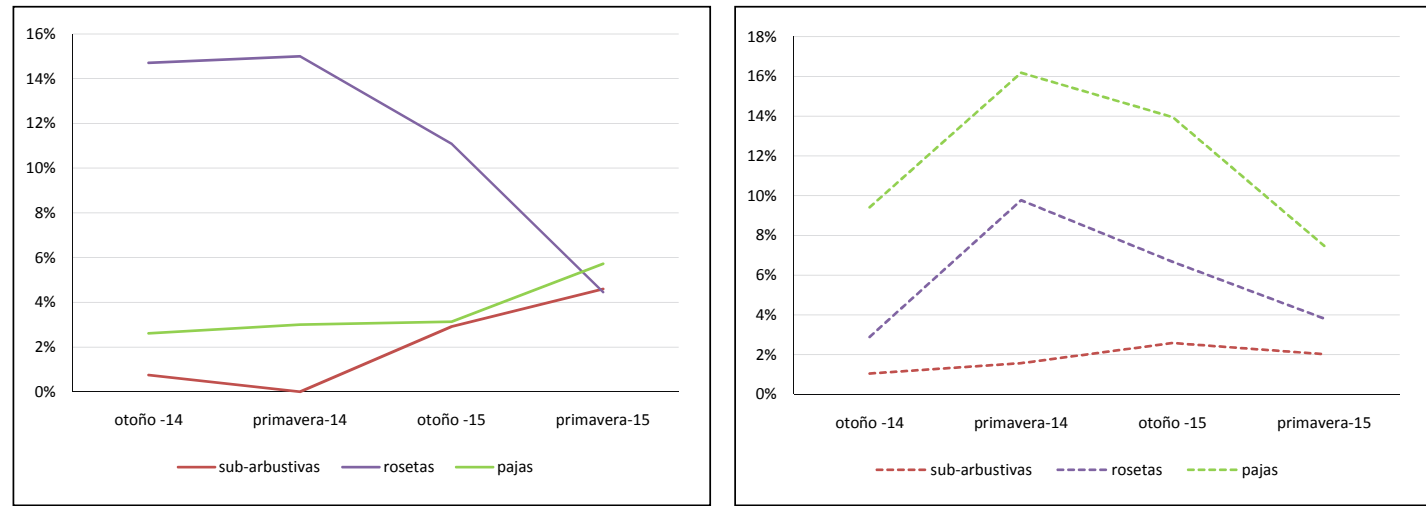

Figura 21. Evolución del estrato alto (\%) según tipo de especie, para dos potreros diferentes estudiados.

\subsection{Evolución de peso de hembras de recría}

La evolución del peso de la recría fue positiva en todos los predios, mejorando los pesos al año y a los dos años (entore) (Figura 22). Los datos de cada predio se pueden consultar en Historia de Innovación Caso 1 - 7 (http://www.inia.uy/Proyectos/Paginas/ PF_07.aspx). A modo de ejemplo si se compara el peso promedio a los 12 meses de edad en las hembras de recría, se observa claramente que los pesos alcanzados res- pecto al inicio del proyecto fueron en aumento, pasando en promedio de $211 \mathrm{~kg}$ al inicio del proyecto a $255 \mathrm{~kg}$ al final del mismo. Las hembras al entore (dos años) también mejoraron su peso, pasando de $330 \mathrm{~kg}$ al inicio a $368 \mathrm{~kg}$ hacia el final del proyecto. La mejora de la recría era uno de ejes importantes de las propuestas, con el objetivo de lograr el entore a los dos años de todas las vaquillonas, un buen porcentaje de preñez en los animales de segunda cría y un buen rodeo de cría en general. 


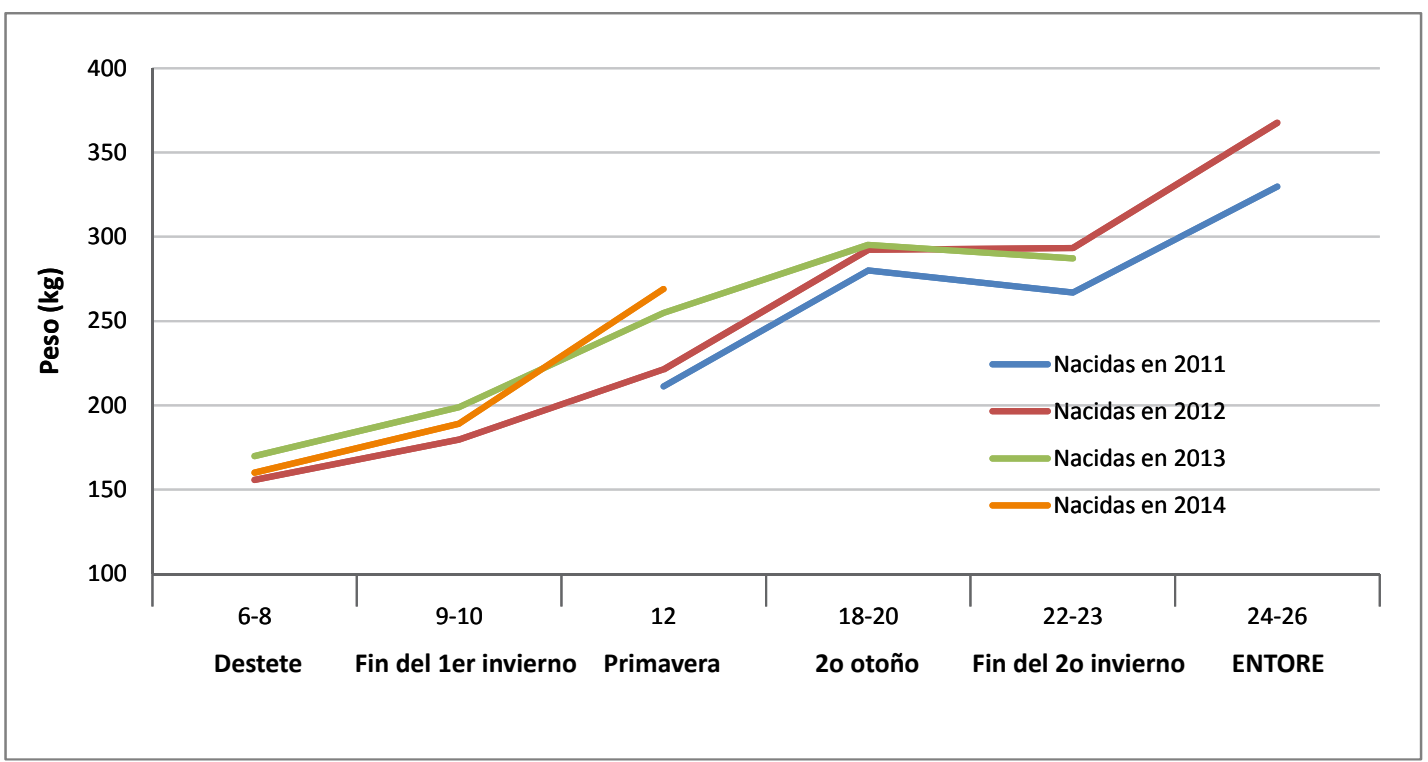

Figura 22. Evolución de pesos de las hembras de recría $(\mathrm{kg})$ para el promedio de los siete casos según el año de nacimiento.

\subsection{Resumen de manejos durante el entore y resultados de preñez}

En todos los predios se trabajó para concentrar el entore entre diciembre y febrero y en particular en uno de los predios se trabajó para eliminar el doble entore.

El manejo general durante el entore, para los siete predios, fue similar y consistió en: (i) evaluar condición corporal en las vacas de cría al inicio del entore y definir medidas de manejo en función de los resultados, (ii) realizar un destete temporario, todos los años, a todas las vacas de cría con ternero al pie a inicio del entore, (iii) realizar un diagnóstico de actividad ovárica a todo el rodeo, a mitad de entore y, en función de los resultados (animales ciclando, en anes- tro superficial o en anestro profundo) y las condiciones de cada predio, definir medidas de manejo (otro destete temporario o destete precoz, etc.), (iv) realizar diagnóstico de gestación a todo el rodeo en otoño y definir medidas de manejo en función de los resultados.

En la Figura 23 se esquematizan las principales medidas de manejo tomadas sobre los animales durante el período de entore para cada año del proyecto y sus resultados, tomando como ejemplo uno de los casos. Lo más importante en todos los casos fue el uso de la información para la toma de decisiones sobre bases seguras. El detalle del manejo de entore para cada uno de los predios se presenta en Historia de Innovación Caso 1 - 7 (http://www. inia.uy/Proyectos/Paginas/PF_07.aspx). 
Manejo del entore 2012/2013

Dic/12 INICIO ENTORE

Condición corporal:

Vacas 1er cría: 4

Vacas adultas: 3,9

\section{PROBABILIDAD \\ PREÑEZ: $72 \%$}

\section{Destete temporaric} Manejo por CC
Ene/13

\begin{tabular}{|c|}
\hline $\begin{array}{c}\text { Monitoreo actividad } \\
\text { ovárica }\end{array}$ \\
\hline Preñadas o ciclando: 19
\end{tabular}

Anestro superficial: 10

Anestro profundo: 7

PROBABILIDAD

PREÑEZ: $79 \%$
Mar/13

May/13

FIN ENTORE

PREÑEZ TOTAL: $92 \%$

(incluyendo vaquillonas y

vacas $\sin$ ternero)

\section{Manejo del entore 2013/2014}

Dic/13

INICIO ENTORE

Condición corporal:

Vacas 1er cría: 3,9

Vacas adultas: 3,8

PROBABILIDAD

PREÑEZ: $68 \%$

Destete temporario

Manejo por CC

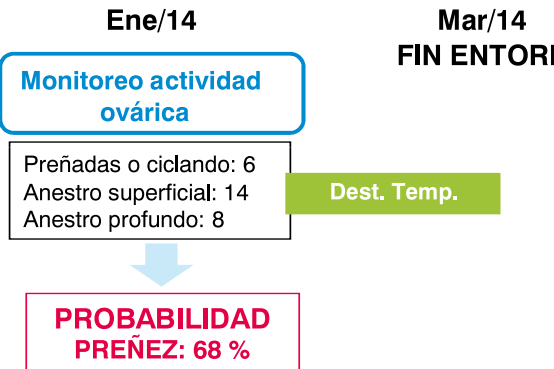

Mar/14
FIN ENTOR

May/14

Diagnóstico preñez

PREÑEZ: $96 \%$

PREÑEZ TOTAL: $98 \%$

(incluyendo vaquillonas)

Manejo del entore 2014/2015

Dic/14 INICIO ENTORE

Condición corporal:

Vacas 1er cría: 4,2

Vacas adultas: 4,0

\section{PROBABILIDAD}

PREÑEZ:7 $6 \%$

Destete temporario

Manejo por CC

\section{Ene/15}

\section{Monitoreo actividad ovárica}

Preñadas o ciclando: 13

Anestro superficial: 20

Anestro profundo: 7

\section{PROBABILIDAD \\ PREÑEZ: $75 \%$}

Mar/15

FIN ENTORE

May/15

Diagnóstico preñez

PREÑEZ: $93 \%$

PREÑEZ TOTAL:9 $4 \%$

(incluyendo vaquillonas)

Figura 23. Esquema de las medidas de manejo realizadas para cada año durante el período de entore y los resultados de probabilidad de preñez (estimada en función de la condición corporal de cada categoría y la preñez esperada para dicha condición), la preñez obtenida en las vacas con ternero al pie y la preñez total (incluye vaquillonas y vacas falladas), tomando como ejemplo uno de los casos del proyecto. 
La preñez del ganado pasó de $76 \%$ (promedio en los tres años previos al proyecto y de los siete predios) a $91 \%$ (promedio de los años de implementación de proyecto y de los siete predios) (Figura 24). Los datos de evolución de preñez por categoría y número de vientres entorados por predio se presentan en Historia de Innovación Caso 1 - 7 (http://www.inia.uy/Proyectos/Paginasi PF_07.aspx).

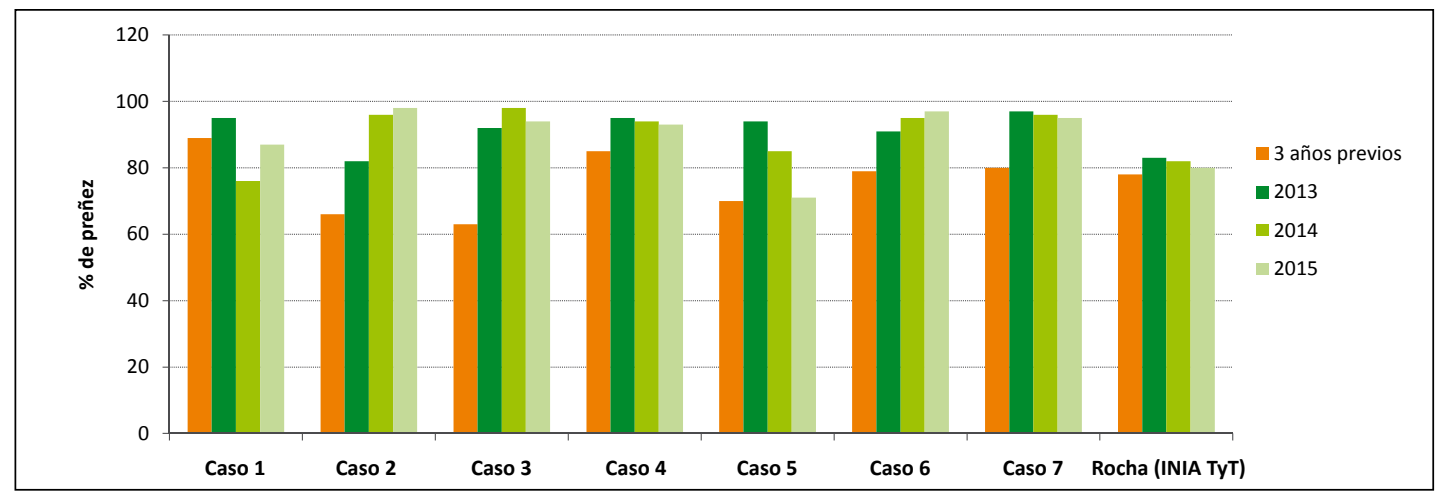

Figura 24. Evolución del porcentaje de preñez para cada caso del proyecto y de los resultados de los talleres de evaluación de los diagnósticos de gestación vacuna para Rocha (INIA, 2015-2010) para el promedio de los 3 años previos al inicio del proyecto y para cada año de implementación del mismo.

El procreo aumentó en todos los casos salvo en el caso 1 (Figura 25), pasando de un promedio de $71 \%$ previo al inicio del proyecto a un $84 \%$ durante la implementación del mismo.

En algunos predios ya se venían obteniendo buenos resultados de preñez y procreo previo al inicio del proyecto, pero en base a medidas de manejo que implicaban mayores costos como el destete precoz estructural. Con la incorporación del diagnóstico de actividad ovárica a mitad de entore, fue posible identificar claramente a los animales que requerían de esta medida de manejo y reducir así el número de animales que recibían este tratamiento o incluso suprimiendo esta medida de manejo, manteniendo los buenos resultados productivos y reduciendo los costos y el tiempo de trabajo.

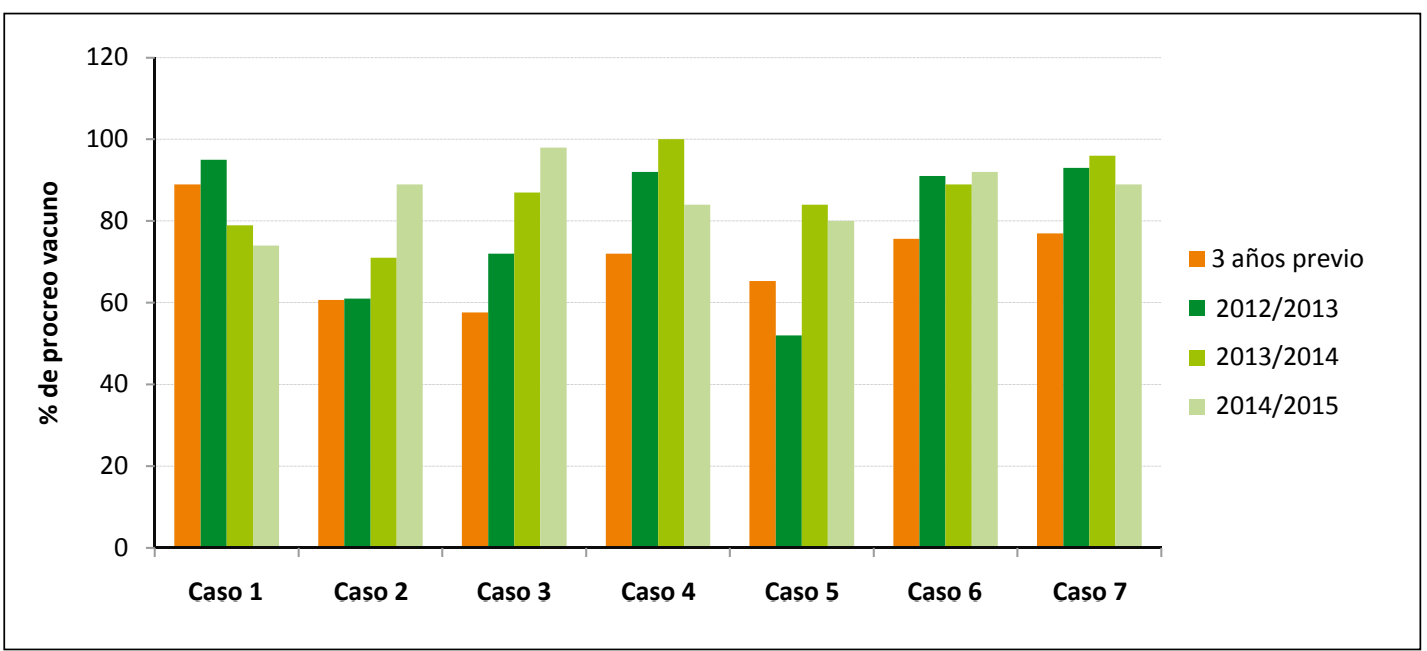

Figura 25. Porcentaje de procreo promedio por caso, para el promedio de los 3 años previos al proyecto y para cada año de implementación del mismo. 


\subsection{Kilos de ternero destetado por vaca entorada}

Los kilos de ternero destetado por vaca entorada se incrementaron en los años de implementación del proyecto en todos los predios respecto al promedio de los 3 años previos al mismo (Figura 26). Este indicador nos permite integrar además de la eficiencia reproductiva del rodeo, el peso final de los terneros. Durante la implementación del proyecto no solo se logró tener más terneros (por un aumento de la preñez y en algunos casos número de vacas entoradas) sino que cada ternero tuvo mejor peso (Figura 27).

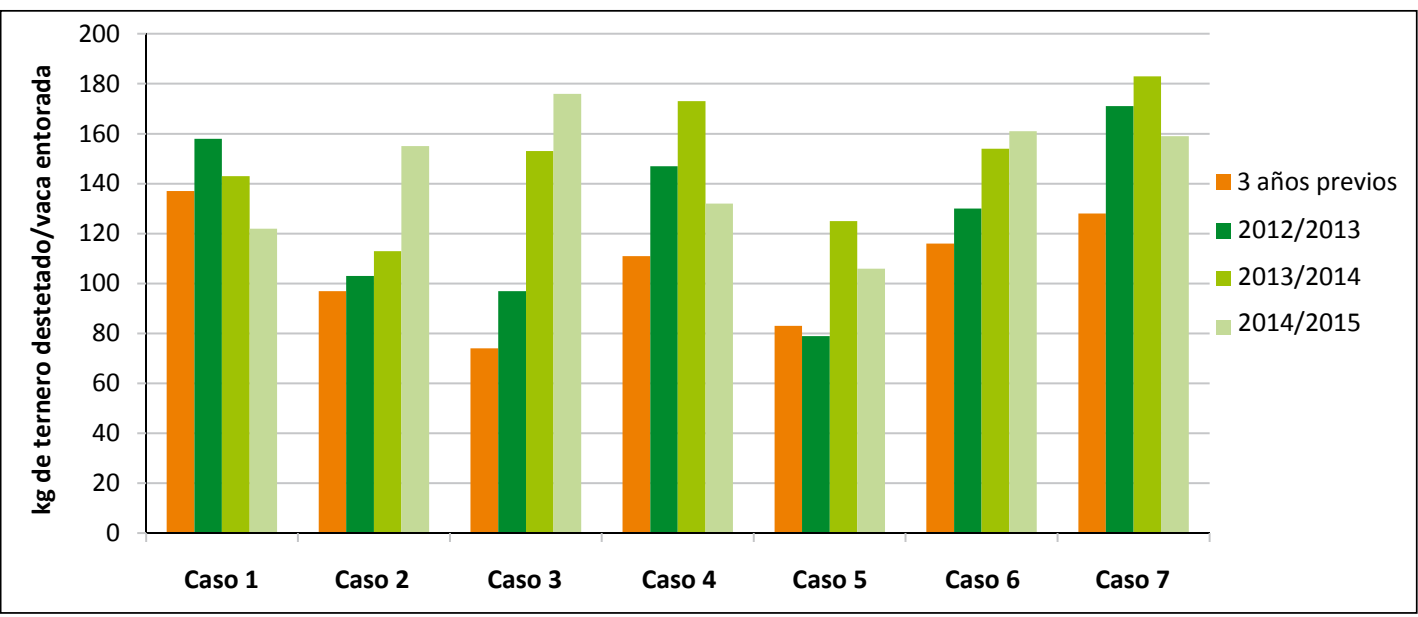

Figura 26. Kilos de ternero destetado por vaca entorada por caso, para el promedio de los 3 años previos al inicio del proyecto y los 3 años de ejecución.

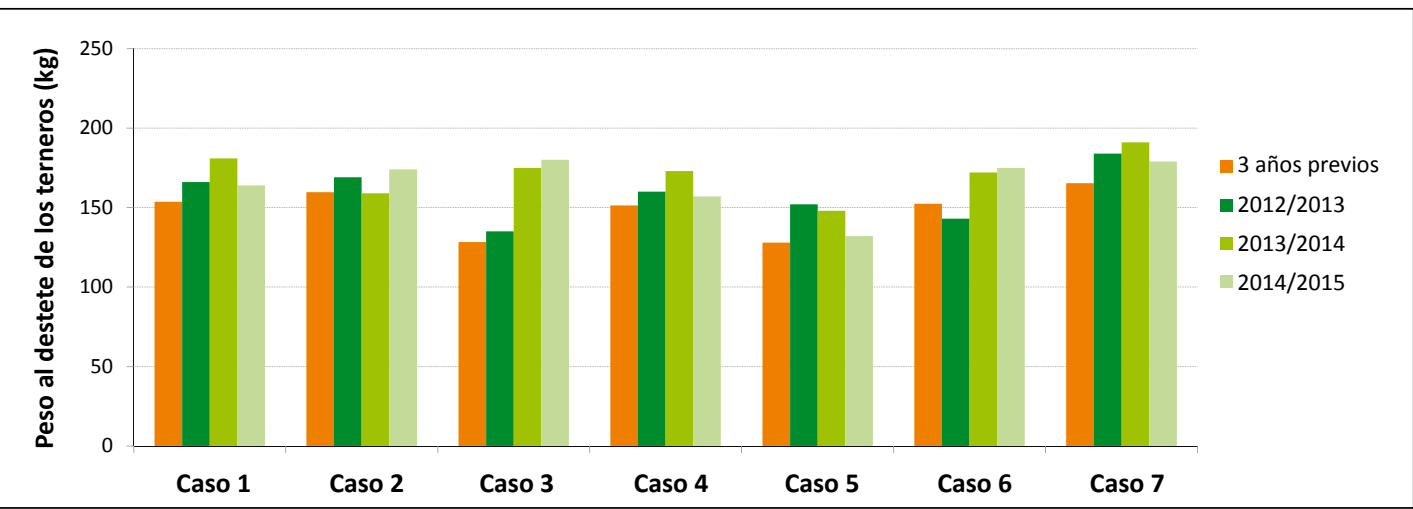

Figura 27. Evolución del peso de terneros al destete $(\mathrm{kg})$ por caso para el promedio de los 3 años previos al inicio del proyecto y los 3 años de ejecución. 


\subsection{Producción de carne equivalente por hectárea}

La producción de carne promedio de los siete predios aumentó de $99 \mathrm{~kg}$ carne equivalente/ha (promedio de los tres años previos al inicio del proyecto) a $121 \mathrm{~kg}$ de carne equivalente/ha (promedio de los 3 años de implementación del proyecto); lo que significa un incremento promedio de 22\% (Anexo 10). En seis de los casos se registra un aumento entre los tres años previos al inicio del proyecto y los tres años de implementación, mientras que en el caso 1 se mantuvo
(Figura 28 y Anexos 3 al 9). Si comparamos los resultados obtenidos en los predios del proyecto con los obtenidos en predios criadores monitoreados por el IPA (2017) observamos que la producción de carne en los años previos al inicio del proyecto era similar en ambos casos ( 99 vs 97 kg carne equivalente/ha, respectivamente), mientras que durante la implementación del proyecto la producción de carne promedio de los predios del proyecto fue superior a la obtenida por en los predios criadores monitoreados por IPA (2017) (121 vs 101 kg carne equivalente/ha respectivamente).

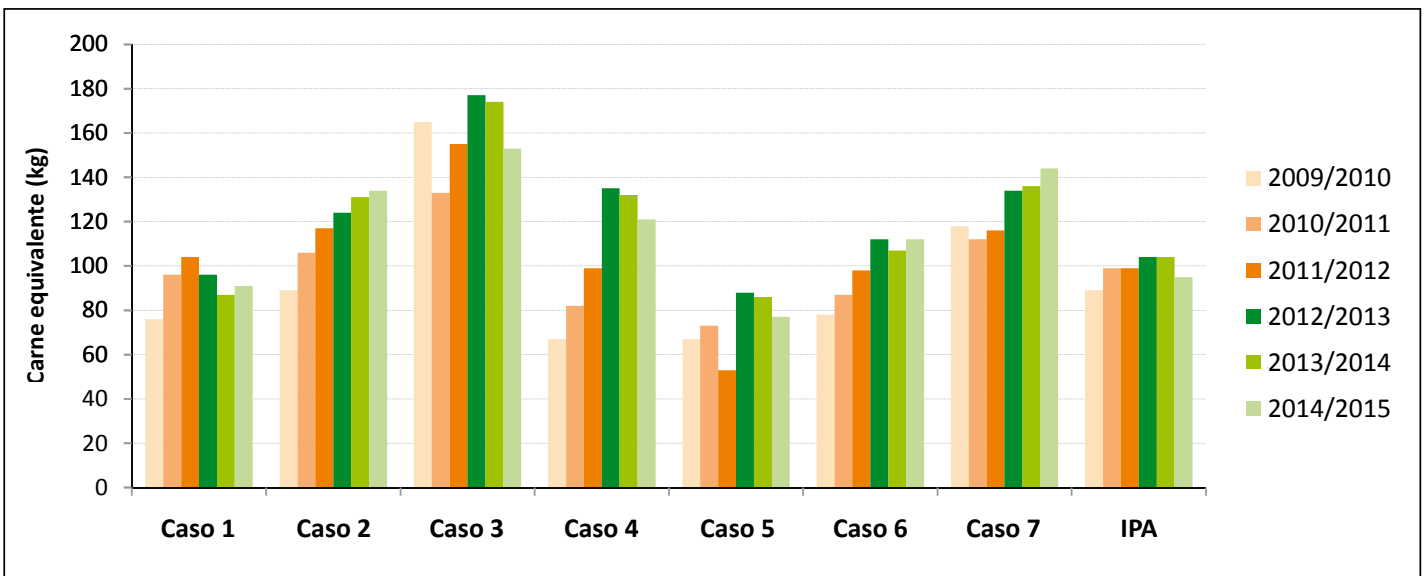

Figura 28. Evolución de la producción de carne equivalente $(\mathrm{kg} / \mathrm{ha})$ por caso, para los 3 ejercicios previos al inicio del proyecto (2009/2010; 2010/2011 y 2011/2012) y los 3 años de implementación (2012/2013; 2013/2014 y $2014 / 2015)$, y resultados de los predios criadores monitoreados por el IPA (2017) para los respectivos ejercicios.

\subsection{Resultado económico en ganadería}

El producto bruto y el ingreso ganadero familiar aumentó en todos los casos considerando los 3 años previos al inicio del proyecto y los 3 años de implementación (140 a 191 U\$S/ha y 58 a 90 U\$S/ha; promedio para todos los casos respectivamente). El costo (sin valorizar mano de obra familiar) por kilo de carne producido se mantuvo estable considerando los 3 años previos al inicio del proyecto y los 3 años de implementación $(0,88$ vs 0,85 U\$S/kg; promedio para todos los casos). Sin embargo, los costos totales (sin valorizar mano de obra familiar) considerando los 3 años previos al inicio del proyecto y los 3 años de implementación pasaron de 83 a 101 U\$S/ha (promedio para todos los casos) lo que implica un $22 \%$ de aumento, que se debe al aumento en la producción de carne. Los resultados económicos de los siete estudios de caso para el promedio de los tres años previos al inicio del proyecto y el promedio de los 3 años de implementación del proyecto se presentan en la Figura 29 y en el Anexo 10. Los resultados por año para cada predio se presentan en los Anexos 3 al 9. 


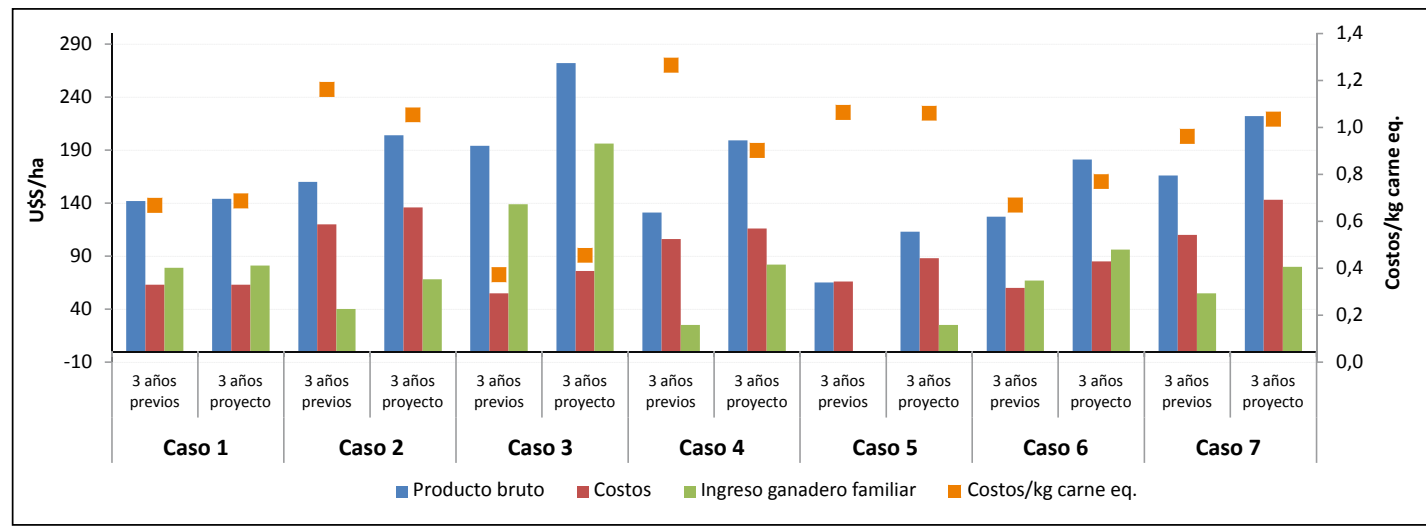

Figura 29. Evolución para cada caso del producto bruto, costos e ingreso ganadero familiar promedio de los 3 años previos al inicio del proyecto (ejercicios 2009/2010; 2010/2011 y 2011/2012) y de los 3 años de implementación (ejercicios 2012/2013; 2013/2014 y 2014/2015).

Para poder comparar los resultados con datos nacionales se calculó el ingreso neto ganadero de cada predio, valorizando la mano de obra familiar. Si comparamos los resultados obtenidos en los predios del proyecto (Figura 30, Anexos 3 a 10) con los obtenidos en los predios criadores monitoreados por el IPA (2017), observamos que el ingreso ganadero neto pro- medio en los años previos al inicio del proyecto era similar en ambos casos (31 y 36 U\$S/ha respectivamente), mientras que durante la implementación del proyecto el ingreso ganadero neto promedio de los predios del proyecto fue superior a la obtenida en los predios criadores monitoreados por IPA (59 vs 35 U\$S/ha respectivamente).

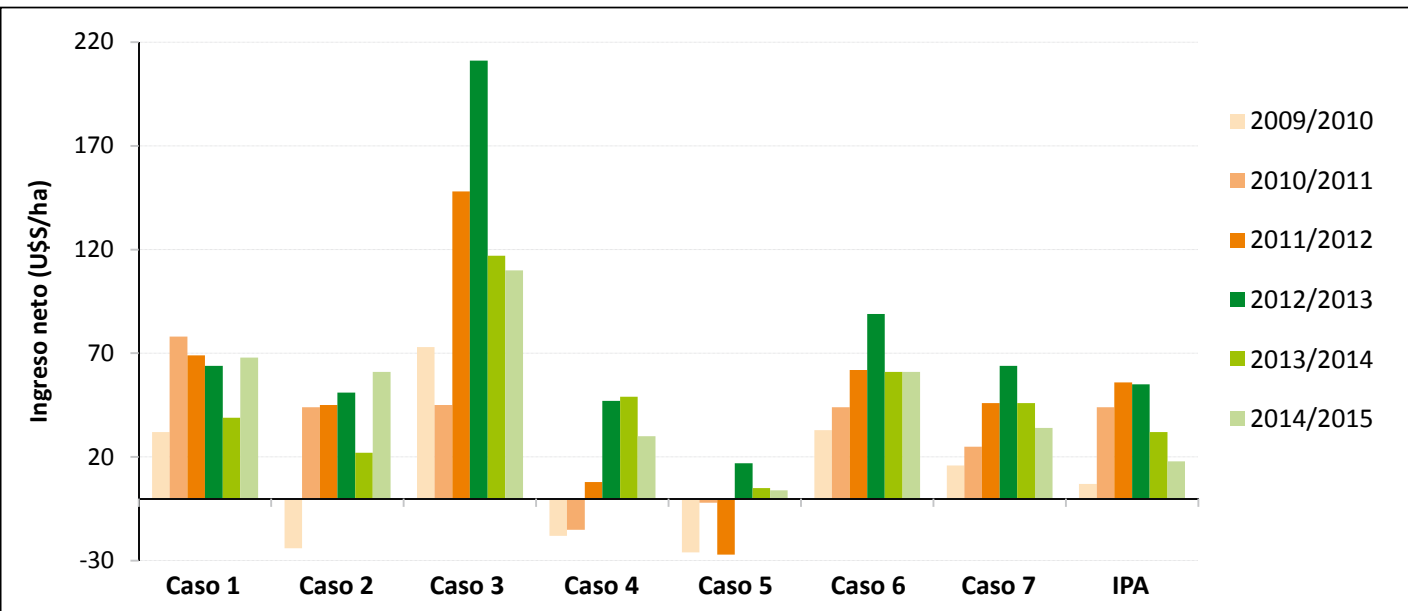

Figura 30. Ingreso neto ganadero (U\$S/ha) de los siete casos para los 3 ejercicios previos al inicio del proyecto (2009/2010; 2010/2011 y 2011/2012) y los 3 ejercicios de implementación (2012/2013; 2013/2014 y 2014/2015), y resultados obtenidos en los predios monitoreados por el IPA (2017).

El detalle de los resultados económico-procios estudiados se presenta en los Anexos ductivos de los siete casos para los ejerci3 al 10. 


\subsection{0 Índice de integridad ecosistémica}

El valor global del Índice de integridad ecosistémica (IIE) promedio para los siete casos tuvo una leve mejora pasando de 3,6 en
2013 a 3,7 en 2015; si analizamos los casos observamos que, salvo en un caso, el índice se mantuvo o mejoró (Cuadro 17). Este valor se mantiene en promedio por encima de 3,5, valor considerado aceptable para este tipo de sistemas.

Cuadro 17. Variación del Índice de integridad ecosistémica (IIE) para cada caso.

\begin{tabular}{cccc} 
Caso & IIE inicial & IIE final & Cambio \\
\hline $\mathbf{1}$ & 3,3 & 3,5 & $(+) 0.2$ \\
$\mathbf{2}$ & 3,4 & 3,6 & $(+) 0.2$ \\
$\mathbf{3}$ & 3 & 3,2 & $(+) 0.2$ \\
$\mathbf{4}$ & 3,8 & 3,7 & $(-) 0.2$ \\
$\mathbf{5}$ & 3,9 & 3,9 & 0 \\
$\mathbf{6}$ & 3,7 & 4 & $(+) 0.2$ \\
$\mathbf{7}$ & 3,6 & 3,7 & $(+) 0.1$ \\
\hline Promedio & $\mathbf{3 , 6}$ & $\mathbf{3 , 7}$ & $\mathbf{0 , 1}$
\end{tabular}

Al observar la calificación de los potreros individuales (Figura 31), puede apreciarse que hubo variaciones tanto al alza como a la baja. Los descensos se produjeron en zonas donde se modificó el uso del suelo con la siembra de cultivos anuales o se realizaron quemas de la vegetación natural. Por otro lado, las mejoras se observaron principalmente en potreros de campo natural que mejoraron aspectos estructurales como el doble estrato herbáceo y arbustos, así como en áreas de cultivos anuales que pasaron a ser praderas perennes multi específicas.

Dentro de los establecimientos donde el IIE aumentó existen algunos potreros en los que el índice disminuyó; esto se explica por la mejora de la integridad en el resto de los potreros. Esta situación demuestra que, concentrando manejos intensivos en ciertas zonas del predio, con menor IIE, lo cual eventualmente produce una reducción de los valores del IIE para estos potreros, puede ayudar a mejorar el estado del ecosistema del resto de los potreros. Por ejemplo, generando un alivio de la carga ganadera o evitando la sustitución de la vegetación en áreas mayores, que generalmente corresponden a potreros de campo natural. Esto se convierte en una estrategia deseable que permitiría mejorar la integridad ecosistémica global del establecimiento e incrementar la provisión de servicios ecosistémicos. 


\section{Caso 1}

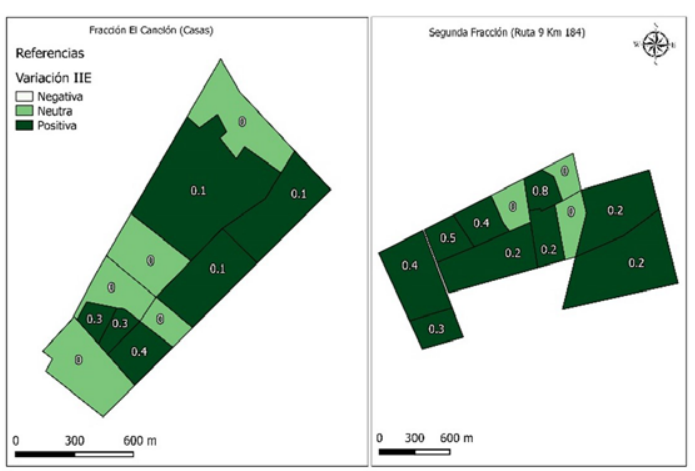

Caso 3

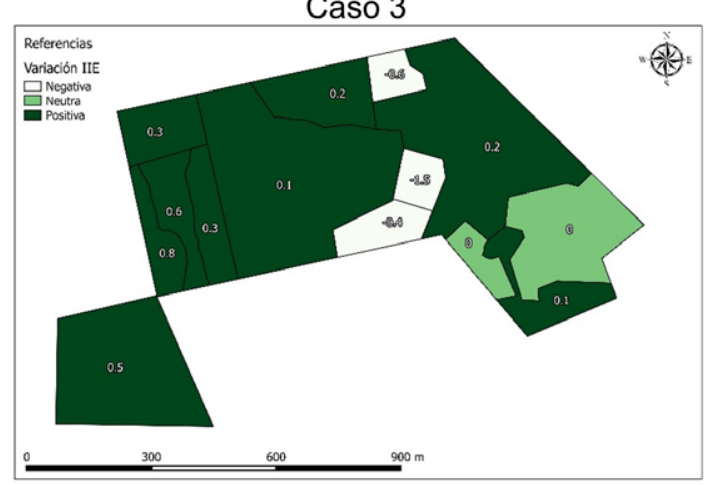

Caso 5

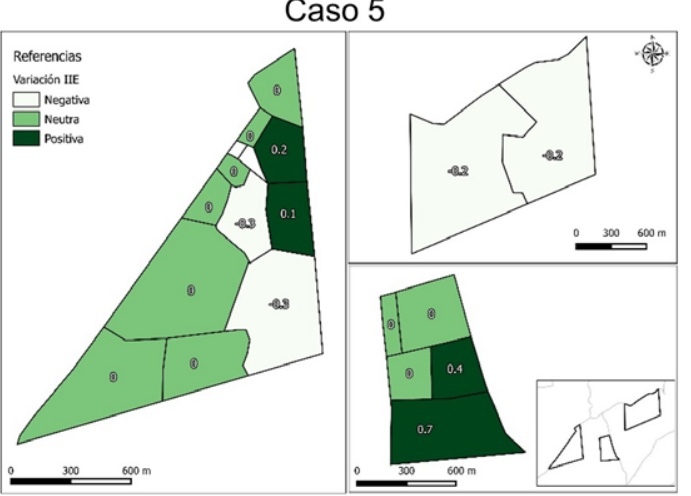

\section{Caso 7}

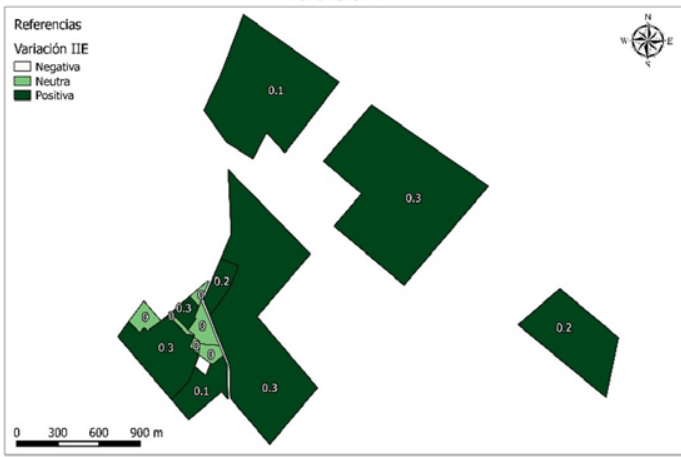

Caso 2

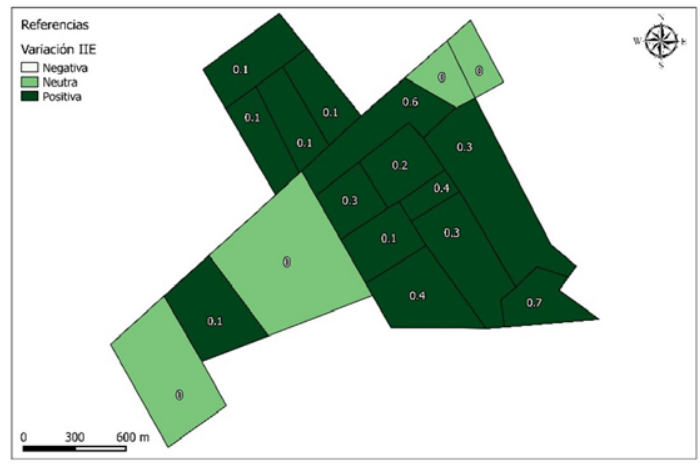

Caso 4

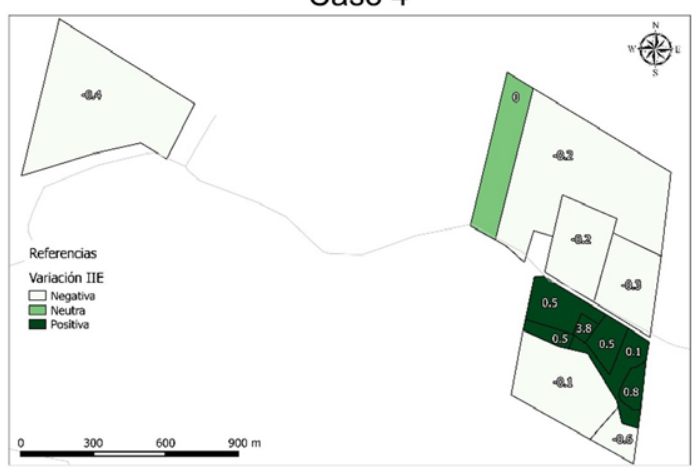

Caso 6

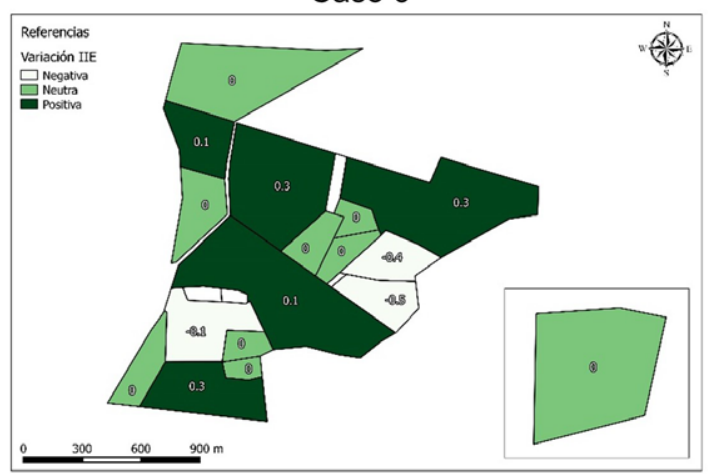

Referencias

Variación IIE

$\square$ Negativa

Neutra

Positiva

Figura 31. Variación del IIE entre el inicio y el final del proyecto para cada potrero en cada caso. 
Los resultados del análisis de correlación entre los valores obtenidos de IIE y otras variables ambientales y productivas monitoreadas y medidas en el proyecto se presentan en el Cuadro 18. El IIE tuvo una correlación positiva con la riqueza de especies y la diversidad de pastos y aves. Estas variables no integran directamente el índice, aunque se incluyen algunas apreciaciones de las comunidades herbáceas. Los valores de IIE también tuvieron una correlación positiva con el contenido de carbono orgánico del suelo en 0 a $3 \mathrm{~cm}$ y 3 a $6 \mathrm{~cm}$ de profundidad. Esta correlación positiva ratifica el criterio de las dimensiones evaluadas en el índice y su influencia sobre varios aspectos ambientales.

Cuadro 18. Coeficiente de correlación de Pearson entre el Índice de integridad ecosistémica y otras variables ambientales.

\begin{tabular}{ccccccc} 
Variable & $\begin{array}{c}\text { Riqueza } \\
\text { aves }\end{array}$ & $\begin{array}{c}\text { Índice de } \\
\text { Shannon } \\
\text { aves }\end{array}$ & $\begin{array}{c}\text { Riqueza } \\
\text { herbáceas }\end{array}$ & $\begin{array}{c}\text { Índice de } \\
\text { Shannon } \\
\text { herbáceas }\end{array}$ & $\begin{array}{c}\text { Carbono } \\
\text { Orgánico } \\
\mathbf{0}-\mathbf{3} \mathbf{~ c m} \\
\text { profundidad }\end{array}$ & $\begin{array}{c}\text { Carbono } \\
\text { Orgánico } \\
\mathbf{3} \mathbf{- 6} \mathbf{~ c m} \\
\text { profundidad }\end{array}$ \\
\hline $\begin{array}{c}\text { Pearson IIE } \\
\mathbf{p}\end{array}$ & 0,81 & 0,77 & 0,76 & 0,82 & 0,74 & 0,57 \\
\hline
\end{tabular}

\subsection{Fauna asociada - aves}

A lo largo del proyecto la riqueza de aves (número total de especies) observada en transectas y la riqueza estimada, no tuvieron grandes variaciones o se incrementaron en relación con la situación inicial según el caso (Cuadro 19). Este resultado probablemente esté implicando un efecto neutro o positivo del manejo productivo realizado en los últimos años. Dentro de cada establecimiento los resultados fueron diferentes según el uso del suelo presente en cada potrero muestreado. En campo natural $(\mathrm{CN})$ se registró un mayor número de especies de aves, seguido de los sitios con praderas sembradas (PS) y cultivos anuales (CA). Esto se refleja en el valor de diversidad medido a través del índice de Shannon (Shannon y Weaver, 1949), que fue de 3,92 para $\mathrm{CN}, 3,27$ para $\mathrm{PS}, \mathrm{y}$
3,04 para CA. Cabe destacar la presencia de árboles, así como de vegetación de bañado (caraguatales y pajonales) que son elementos que favorecieron la ocurrencia de algunas especies en los potreros, aumentando su diversidad. En cuanto al valor de diversidad global de los siete predios este índice aumentó en cinco casos comparando el inicio y final del proyecto.

Si bien el incremento, tanto de la riqueza como de la diversidad medida a través del Índice de Shannon, podría no deberse exclusivamente a cambios producidos dentro de cada establecimiento; dado el conocimiento de la biología de las nuevas especies registradas en el período final del proyecto, puede ser asociado al cambio estructural de la vegetación que provocó la reducción de la intensidad de pastoreo en los potreros de referencia.

Cuadro 19. Riqueza de aves observada, estimada e índice de Shannon para cada caso para el año inicial (2013) y final (2015) del muestreo.

\begin{tabular}{ccccccc}
\multicolumn{3}{c}{ Año 2013 } & \multicolumn{3}{c}{ Año 2015 } \\
\hline \multirow{2}{*}{ CASO } & $\begin{array}{c}\text { Riqueza } \\
\text { observada }\end{array}$ & $\begin{array}{c}\text { Riqueza } \\
\text { estimada }\end{array}$ & $\begin{array}{c}\text { Índice de } \\
\text { Shannon }\end{array}$ & $\begin{array}{c}\text { Riqueza } \\
\text { observada }\end{array}$ & $\begin{array}{c}\text { Riqueza } \\
\text { estimada }\end{array}$ & $\begin{array}{c}\text { Índice de } \\
\text { Shannon }\end{array}$ \\
\hline $\mathbf{1}$ & 38 & 53 & 3,1 & 51 & 63 & 3,0 \\
$\mathbf{2}$ & 41 & 63 & 2,9 & 50 & 63 & 3,2 \\
$\mathbf{3}$ & 43 & 60 & 3,2 & 67 & 82 & 3,7 \\
$\mathbf{4}$ & 55 & 68 & 3,3 & 60 & 81 & 3,6 \\
$\mathbf{5}$ & 68 & 83 & 3,5 & 71 & 83 & 3,5 \\
$\mathbf{6}$ & 52 & 61 & 2,9 & 63 & 76 & 3,5 \\
$\mathbf{7}$ & 68 & 83 & 3,3 & 66 & 78 & 3,4 \\
\hline
\end{tabular}




\subsection{Carbono orgánico total y sus fracciones}

Debido a que no era esperable encontrar cambios en el carbono orgánico total (\%) dentro del período de implementación del proyecto, para evaluar cambios en la evolución de carbono orgánico se monitoreó la evolución de sus fracciones $(\mathrm{g} / 100 \mathrm{~g})$, en campo natural a una profundidad de 0 a 6 $\mathrm{cm}$, información que se presenta en el Cuadro 20. Si bien existe una tendencia incremental en el carbono del suelo en las frac- ciones más lábiles, dada la variabilidad de contenidos de las muestras, no fue posible obtener diferencias significativas a excepción de dos casos (2 y 5). Es claro que fenómenos como la incorporación de carbono al suelo con una gran complejidad biológica y muy variables entre micrositios requieren de plazos mayores a los disponibles en el proyecto. No obstante, la tendencia general indica que es altamente probable que se pueda incrementar el stock de carbono si se continúa trabajando con promedios altos de biomasa disponible.

Cuadro 20. Carbono orgánico total (\%) y sus fracciones $(\mathrm{g} / 100 \mathrm{~g})$ para los campos naturales de 0 a $6 \mathrm{~cm}$ de profundidad, por caso, para los años 2013 y 2015.

\begin{tabular}{|c|c|c|c|c|c|c|c|c|}
\hline \multirow[b]{2}{*}{ Caso } & \multicolumn{2}{|c|}{$\begin{array}{c}\text { C total (\%) } \\
0-6 \mathrm{~cm}\end{array}$} & \multicolumn{2}{|c|}{$\begin{array}{c}\text { C-POM }(\mathrm{g} / 100 \mathrm{~g}) \\
212 \mu \mathrm{m}\end{array}$} & \multicolumn{2}{|c|}{$\begin{array}{c}\text { C-POM }(g / 100 \mathrm{~g}) \\
53 \mu \mathrm{m}\end{array}$} & \multicolumn{2}{|c|}{$\begin{array}{c}\text { C-POM }(\mathrm{g} / 100 \mathrm{~g}) \\
<53 \mu \mathrm{m}\end{array}$} \\
\hline & 2013 & 2015 & 2013 & 2015 & 2013 & 2015 & 2013 & 2015 \\
\hline 1 & $\mathrm{~s} / \mathrm{d}$ & 2,3 & $\mathrm{~s} / \mathrm{d}$ & $s / d$ & $\mathrm{~s} / \mathrm{d}$ & $\mathrm{s} / \mathrm{d}$ & $\mathrm{s} / \mathrm{d}$ & $\mathrm{s} / \mathrm{d}$ \\
\hline 2 & 3,73 & 3,3 & $0,52 a$ & $1,21 b$ & 0,46 & 0,77 & 2,75 & 2,24 \\
\hline 3 & 3,48 & $\mathrm{~s} / \mathrm{d}$ & 0,55 & $s / d$ & 0,46 & $\mathrm{~s} / \mathrm{d}$ & 2,47 & $\mathrm{~s} / \mathrm{d}$ \\
\hline 4 & 3,88 & 3,58 & 0,42 & 0,78 & 0,37 & 0,42 & 3,09 & 2,39 \\
\hline 5 & 4,08 & 3,76 & $0,61 a$ & $0,97 b$ & 0,36 & 0,49 & 3,11 & 2,3 \\
\hline 6 & 2,58 & 2,72 & 0,65 & 0,57 & 0,61 & 0,4 & 1,33 & 1,75 \\
\hline 7 & 3,25 & 3,3 & 0,33 & 0,49 & 0,48 & 0,3 & 2,48 & 2,5 \\
\hline
\end{tabular}

Letras diferentes corresponden a diferencias significativas con $p=0,01$. $s / d=\sin$ dato

\subsection{Calidad de vida}

Los valores de calidad de vida estructural integrada en promedio no tuvieron cambios significativos (Cuadro 21). Las diferencias en este indicador se deben a que: (i) dos predios accedieron a la luz y mejoraron su conectividad digital, pero no directamente por el proyecto, (ii) en uno de los predios se mejoró el estado de la vivienda por la mejora de ingresos durante el proyecto, (iii) en dos predios los productores quedaron sin vehículos (uno por rotura y otro por separación de bienes).
La percepción que tenían las familias de su propia calidad de vida (calidad de vida subjetiva) se mantuvo en muy buenos niveles (Cuadro 21). Dos de las familias elevaron su percepción de calidad de vida, una al haber tomado una decisión personal importante que afectó positivamente tanto la unidad productiva como la unidad familiar y otra porque reafirmó la decisión de no mudarse a la ciudad y abandonar la producción, a partir de los logros obtenidos con el proyecto. 
Cuadro 21. Valoración de la calidad de vida para los siete casos.

\begin{tabular}{ccccc} 
& $\begin{array}{c}\text { Calidad de vida estructural integrada } \\
\text { 2012 }\end{array}$ & $\mathbf{2 0 1 5}$ & \multicolumn{2}{c}{ Calidad de vida subjetiva } \\
\hline Caso 1 & 5 & 4 & $\mathbf{2 0 1 2}$ & $\mathbf{2 0 1 5}$ \\
Caso 2 & 5 & 4 & 4 & 5 \\
Caso 3 & 4 & 4 & 5 & 5 \\
Caso 4 & 3 & 3 & 4 & 5 \\
Caso 5 & 3 & 3 & 5 & 5 \\
Caso 6 & 4 & 4 & 4 & 4 \\
Caso 7 & 5 & 5 & 5 & 5 \\
\hline Promedio & $\mathbf{4 , 1}$ & $\mathbf{3 , 9}$ & 5 & 5 \\
\hline
\end{tabular}

Calidad de vida estructural integrada: $5=$ Muy buena; $4=$ Buena; $3=$ Intermedia; $2=$ Mala; $1=$ Muy mala.

Calidad de vida subjetiva: $5=$ Muy satisfecho; $4=$ Medianamente satisfecho; $3=$ Satisfecho; $2=$ Poco satisfecho; $1=$ Insatisfecho

\subsection{Planificación predial y organización del trabajo}

Una de las bases principales para lograr los resultados descritos anteriormente fue la mejora en la planificación y organización del predio. En el entendido que si bien el re-diseño implica realizar diversos ajustes en el manejo del sistema, para que los mismos pudieran ser implementados con éxito debían ser pensados en el contexto de funcionamiento de todo el predio y con un horizonte temporal de largo plazo.

Esta organización distinta a la que venían teniendo los productores fue identificada por ellos y el equipo de investigación y cuantificada con el indicador "Valoración y uso de la planificación" para los siete casos, cuya evolución desde el inicio al final del proyecto se presenta en el Cuadro 22.

Cuadro 22. Valoración y uso de la planificación para los siete casos.

\begin{tabular}{cccc} 
& \multicolumn{3}{c}{ Valoración y uso de la planificación* } \\
& $\mathbf{2 0 1 3}$ & $\mathbf{2 0 1 4}$ & $\mathbf{2 0 1 5}$ \\
\hline Caso 1 & 3 & 5 & 5 \\
Caso 2 & 2 & 3 & 4 \\
Caso 3 & 1 & 3 & 4 \\
Caso 4 & 2 & 3 & 3 \\
Caso 5 & 2 & 4 & 4 \\
Caso 6 & 2 & 4 & 4 \\
Caso 7 & 3 & 5 & 5 \\
\hline Promedio & $\mathbf{2 , 1}$ & $\mathbf{3 , 9}$ & $\mathbf{4 , 1}$ \\
\hline
\end{tabular}

* $5=$ valora la planificación y tiene planes de largo plazo. 4= valora la planificación y tiene planes de mediano plazo $3=$ valora la planificación y tiene algunas áreas con planificación. $2=$ valora la planificación pero no usa planes. 1= ni valora ni usa planes 
Las siguientes frases reflejan cómo percibieron los productores esa evolución: "Aprendimos a planificar de manera objetiva, cada una de las cosas. Que no todo se mejora con dinero. La planificación y el orden tienen su lugar. Nos hemos concientizado. Planificación y manejo". "Por ejemplo: Clasificar las vacas por peso, por estado corporal. Tener una carga adecuada". "Hacer un entore racional concentrando sin que sea menos eficiente". "Planificar las pasturas, manejo y rotación. Son procesos largos".

La planificación incorporada en el predio tuvo como consecuencia una reducción en la cantidad de trabajo y una mayor disponibilidad de tiempo para realizar otras actividades. Esto fue un aspecto emergente que destacaron los mismos productores como ejemplifica la siguiente frase: "Noto que estamos más organizados. Y de pronto tenemos organización significa que se trabaja más cómodo, pasas menos trabajo en situaciones de invierno que antes era más complicado, pero como tenemos más comida... mejor preparados. Incluso hasta pasamos menos trabajo. Tendríamos más tiempo para hacer otras cosas".

La cuantificación de este aspecto con la metodología del Balance de Trabajo (Dieguez et al., 2009) permitió demostrar que el tiempo de trabajo dedicado al manejo de animales y pasturas se redujo en términos promedio un $25 \%$, sin modificar la proporción del trabajo que era aportado por mano de obra familiar. Las principales tareas que se simplifican y reducen el tiempo de trabajo son las tareas de recorrida por el campo, ya que al tener animales en buen estado disminuyen mucho los problemas de animales caídos y débiles, hay mucho menos complicaciones al momento de la parición; además en algunos casos se dejó de hacer destete precoz o de suplementar categorías en invierno, lo cual también redujo el tiempo de trabajo. Asimismo, estos cambios determinaron un aumento promedio de $97 \%$ en la productividad en U\$S/año (de ingreso familiar ganadero) de la mano de obra aplicada en el predio (Cuadro 23).

Como consecuencia de lo anterior se aumentó en un $29 \%$ en promedio el tiempo disponible, o margen de maniobra, para realizar otro tipo de tareas que no son directamente con animales y/o pasturas, como ser actividades de mantenimiento, compra y venta de insumos y productos, trámites, gestión, tareas domésticas, o bien trabajo extrapredial. Paralelamente se dispuso de mayor tiempo para realizar actividades sociales, participar en jornadas y actividades de capacitación, así como de mayor tiempo libre o de recreación. En todos los predios se dispuso de un buen margen de maniobra o tiempo disponible para actividades que no son en el predio, lo cual se asocia a una buena calidad de vida. Los casos 3 y 4 , los de menor escala, presentaron un nivel muy alto de tiempo disponible luego del manejo de animales y pasturas. Esa disponibilidad de tiempo permite que en dichos casos se incorpore el trabajo extrapredial, e incluso en el caso 3 se realice horticultura como rubro complementario, como estrategia para aumentar el ingreso familiar. 
Cuadro 23. Evolución de la cantidad de trabajo y de la productividad del trabajo familiar en los siete casos.

\begin{tabular}{|c|c|c|c|c|c|c|c|}
\hline & \multicolumn{3}{|c|}{$\begin{array}{l}\text { Tiempo de trabajo sobre los } \\
\text { animales y la superficie forrajera } \\
\text { (horas/año) }{ }^{1}\end{array}$} & \multicolumn{3}{|c|}{$\begin{array}{l}\text { Tiempo disponible luego del } \\
\text { trabajo con animales y superficie } \\
\text { forrajera (horas/año) }\end{array}$} & \multirow[t]{2}{*}{$\begin{array}{l}\text { Mano de obra } \\
\text { disponible } \\
\text { en el predio } \\
\text { (MOF+MOCP) } \\
\text { (horas/año) }\end{array}$} \\
\hline & $2011 / 2012$ & $2014 / 2015$ & $\begin{array}{c}\text { Variación } \\
(\%)^{2}\end{array}$ & 2011/2012 & $2014 / 2015$ & $\begin{array}{c}\text { Variación } \\
(\%)^{2}\end{array}$ & \\
\hline Caso 1 & 1793 & 921 & -49 & 607 & 1479 & 144 & 2400 \\
\hline Caso 2 & 2134 & 1867 & -13 & 2666 & 2933 & 10 & 4800 \\
\hline Caso 3 & 1156 & 617 & -47 & 3644 & 4183 & 15 & 4800 \\
\hline Caso 4 & 789 & 649 & -18 & 4011 & 4151 & 3 & 4800 \\
\hline Caso 5 & 1643 & 1319 & -20 & 3757 & 4081 & 9 & 5400 \\
\hline Caso 6 & 2665 & 2545 & -5 & 2135 & 2255 & 6 & 4800 \\
\hline Caso 7 & 2074 & 1625 & -22 & 2726 & 3175 & 16 & 4800 \\
\hline Promedio & & & -24 & & & 29 & \\
\hline
\end{tabular}

\begin{tabular}{|c|c|c|c|c|c|c|}
\hline & \multicolumn{3}{|c|}{$\begin{array}{l}\text { Proporción del trabajo sobre los animales } \\
\text { y superficie forrajera provisto por la familia } \\
\qquad(\%)^{1}\end{array}$} & \multicolumn{3}{|c|}{$\begin{array}{l}\text { Productividad de la mano de obra aplicada } \\
\text { en el predio (U\$S/hora año) }\end{array}$} \\
\hline & 2011/2012 & $2014 / 2015$ & Variación $(\%)^{2}$ & 2011/2012 & $2014 / 2015$ & Variación $(\%)^{2}$ \\
\hline Caso 1 & 96 & 93 & -3 & 13 & 26 & 95 \\
\hline Caso 2 & 14 & 15 & 7 & 8 & 12 & 41 \\
\hline Caso 3 & 90 & 90 & 0 & 9 & 19 & 104 \\
\hline Caso 4 & 100 & 98 & -2 & 5 & 8 & 83 \\
\hline Caso 5 & 96 & 92 & -4 & -2 & 5 & 340 \\
\hline Caso 6 & 93 & 95 & 2 & 8 & 8 & 5 \\
\hline Caso 7 & 97 & 97 & 0 & 7 & 8 & 10 \\
\hline Promedio & & & 0 & & & 97 \\
\hline
\end{tabular}

${ }^{1}$ Cuantificado con la metodología de Balance de Trabajo (Dieguez et al., 2009). ${ }^{2}$ Final//Inicial ${ }^{*} 100$ - 100.

MOF: Mano de obra familiar. MOCP: Mano de obra contratada permanente.

\subsection{Aprendizajes y cambios relevantes identificados por los productores}

Los aprendizajes y cambios más relevantes identificados por los productores a partir de entrevistas se presentan en el Cuadro 24, discriminando en cambios en los predios y cambios en los productores. Los cambios generados en el manejo del predio no fueron solamente cambios en las prácticas, sino que tuvieron un sustento en nuevos conoci- mientos, habilidades, actitudes y aspiraciones - KASA, por su sigla en inglés - en los productores. La valoración de la creación de capacidades a través del análisis KASA (Rockwell y Bennett, 2004) muestra que los cambios en los predios se sustentan fundamentalmente en mayor conocimiento sobre manejo de animales y pasturas, cambios en rutinas y prácticas productivas y de gestión, así como cambios personales en confianza y autoestima y cambios de actitud hacia la conservación de recursos naturales. 
Cuadro 24. Aprendizajes y cambios más relevantes para los siete casos.

\begin{tabular}{|c|c|c|}
\hline & Cambios en los predios & Cambios en los productores ${ }^{1}$ \\
\hline Caso 3 & $\begin{array}{l}\text { Más pasto } \\
\text { Mejor producción } \\
\text { Más fácil el trabajo, menos } \\
\text { complicaciones } \\
\text { Llevar un control para tomar } \\
\text { decisiones. } \\
\text { Más tiempo para arreglar cosas y para } \\
\text { el trabajo extrapredial }\end{array}$ & $\begin{array}{l}\text { "Con menos se hace más” } \\
\text { Conocer nuevas pautas de manejo } \\
\text { Saber cómo trabajar con más pasto } \\
\text { Ahora con más pasto hay espacio para pensar mucho y } \\
\text { usar el manejo } \\
\text { Cambios en rutinas y prácticas productivas** } \\
\text { Cambios en rutinas y prácticas de gestión*** } \\
\text { El ver los números es fundamental, se pueden hacer } \\
\text { comparaciones } \\
\text { Ver otros predios, aprender de otros y asumir riesgo } \\
\text { Cambio de actitud positivo hacia el cuidado de los recursos } \\
\text { naturales }\end{array}$ \\
\hline Caso 4 & $\begin{array}{l}\text { Más pasto } \\
\text { Más mejoramientos } \\
\text { Mayor empotreramiento } \\
\text { Menor dotación y relación ovino/ } \\
\text { vacuno } \\
\text { Acortar el entore } \\
\text { Mejor condición corporal de animales } \\
\text { No quemar campo } \\
\text { Dentro del campo es mucho más fácil } \\
\text { y menor el trabajo } \\
\text { Al aumentar el pie de cría vacuno } \\
\text { reteniendo hembras se venden menos } \\
\text { animales } \\
\text { Fue necesario más trabajo } \\
\text { extrapredial para compensar }\end{array}$ & $\begin{array}{l}\text { Saber cómo trabajar con más pasto } \\
\text { Conocer sobre manejo de animales y pasturas } \\
\text { Conocer cuánto produce el predio } \\
\text { Cambios en rutinas y prácticas productivas** } \\
\text { Estar más organizados y más centrados (metas) } \\
\text { Cambios en rutinas y prácticas de gestión*** } \\
\text { Cambio de actitud hacia conservación de recursos } \\
\text { naturales } \\
\text { Aspiración de mantener la forma de trabajo }\end{array}$ \\
\hline
\end{tabular}

${ }^{1}$ Cambios en conocimientos, habilidades, actitudes y aspiraciones (KASA).

${ }^{* *}$ Se vincula al cambio en el \% de uso del conjunto de tecnologías de producción propuestas en el re-diseño.

${ }^{* * *}$ Se vincula al cambio en la valoración y uso de la planificación. 
Cuadro 24. Aprendizajes y cambios más relevantes para los siete casos.

\begin{tabular}{|c|c|c|}
\hline & Cambios en los predios & Cambios en los productores ${ }^{1}$ \\
\hline Caso 5 & $\begin{array}{l}\text { Más pasto } \\
\text { Mejor condición corporal de animales } \\
\text { Líneas estratégicas y objetivos claros } \\
\text { Llevar registros } \\
\text { Planificación, antes era más a ciegas } \\
\text { Tareas más sencillas } \\
\text { Más tiempo en la casa }\end{array}$ & $\begin{array}{l}\text { Saber cómo trabajar con más pasto } \\
\text { Cambios en rutinas y prácticas productivas }{ }^{* *} \\
\text { Cambios en rutinas y prácticas de gestión }{ }^{* * *} \\
\text { Cambio de mentalidad, más abierto a intercambiar con } \\
\text { otros y consultar técnicos } \\
\text { Aspiración de mantener la forma de trabajo e incertidumbre } \\
\text { sobre poder hacerlo sin el apoyo técnico }\end{array}$ \\
\hline Caso 6 & $\begin{array}{l}\text { Mejores ingresos } \\
\text { Más pasto } \\
\text { Mejores animales y más terneros } \\
\text { Clasificar vacas en base a condición } \\
\text { corporal } \\
\text { Carga adecuada } \\
\text { Entore racional, concentrado } \\
\text { Planificación y organización } \\
\text { Simplificación del trabajo }\end{array}$ & $\begin{array}{l}\text { Conocer sobre manejo de animales y pasturas } \\
\text { Conocer nuevas pautas de manejo. } \\
\text { "No todo se mejora con dinero" } \\
\text { "No importa tener muchos animales sino cuánto se } \\
\text { produce" } \\
\text { Cambios en rutinas y prácticas productivas"** } \\
\text { Cambios en rutinas y prácticas de gestión"*** } \\
\text { Tratar de mantener esta forma de trabajo }\end{array}$ \\
\hline Caso 7 & $\begin{array}{l}\text { "Agrandé el predio porteras hacia } \\
\text { adentro" } \\
\text { Mejoramientos con festuca } \\
\text { Uso de tecnologías de bajo costo } \\
\text { Llevamos mejor los números } \\
\text { Más visitados que nunca } \\
\text { Muestra para otros productores }\end{array}$ & $\begin{array}{l}\text { Conocer sobre manejo de animales y pasturas } \\
\text { Aplicación de técnicas de bajo costo } \\
\text { Cambios en rutinas y prácticas productivas }{ }^{* *} \\
\text { Cambios en rutinas y prácticas de gestión } \\
\text { Cambio de actitud hacia los recursos naturales y a mirar el } \\
\text { entorno } \\
\text { "Ver cosas que no veíamos antes" (especies forrajeras y } \\
\text { fauna) } \\
\text { Confianza en seguir caminando solo } \\
\text { Contar los resultados para impulsar el cambio en otros } \\
\text { productores }\end{array}$ \\
\hline
\end{tabular}

${ }^{1}$ Cambios en conocimientos, habilidades, actitudes y aspiraciones (KASA).

**Se vincula al cambio en el \% de uso del conjunto de tecnologías de producción propuestas en el re-diseño.

***Se vincula al cambio en la valoración y uso de la planificación.

\subsection{Uso de tecnologías}

Durante el primer año del proyecto del conjunto de técnicas propuestas, el promedio de los predios utilizaba el $39 \%$ y al final del proyecto el promedio de los predios pasó a utilizar el $97 \%$ de las técnicas, lo que demuestra un aumento muy importan- te y el uso integral de todas las tecnologías propuestas (Cuadro 25). Asimismo, es de destacar que a un año de comenzado el proyecto los productores utilizaban en promedio el $95 \%$ de las técnicas. Esto demuestra que el proceso de co-innovación fue muy eficiente y rápido en promover innovaciones. 
Cuadro 25. Nivel de uso de técnicas sugeridas para ganadería al inicio, medio término y final del proyecto para los siete casos.

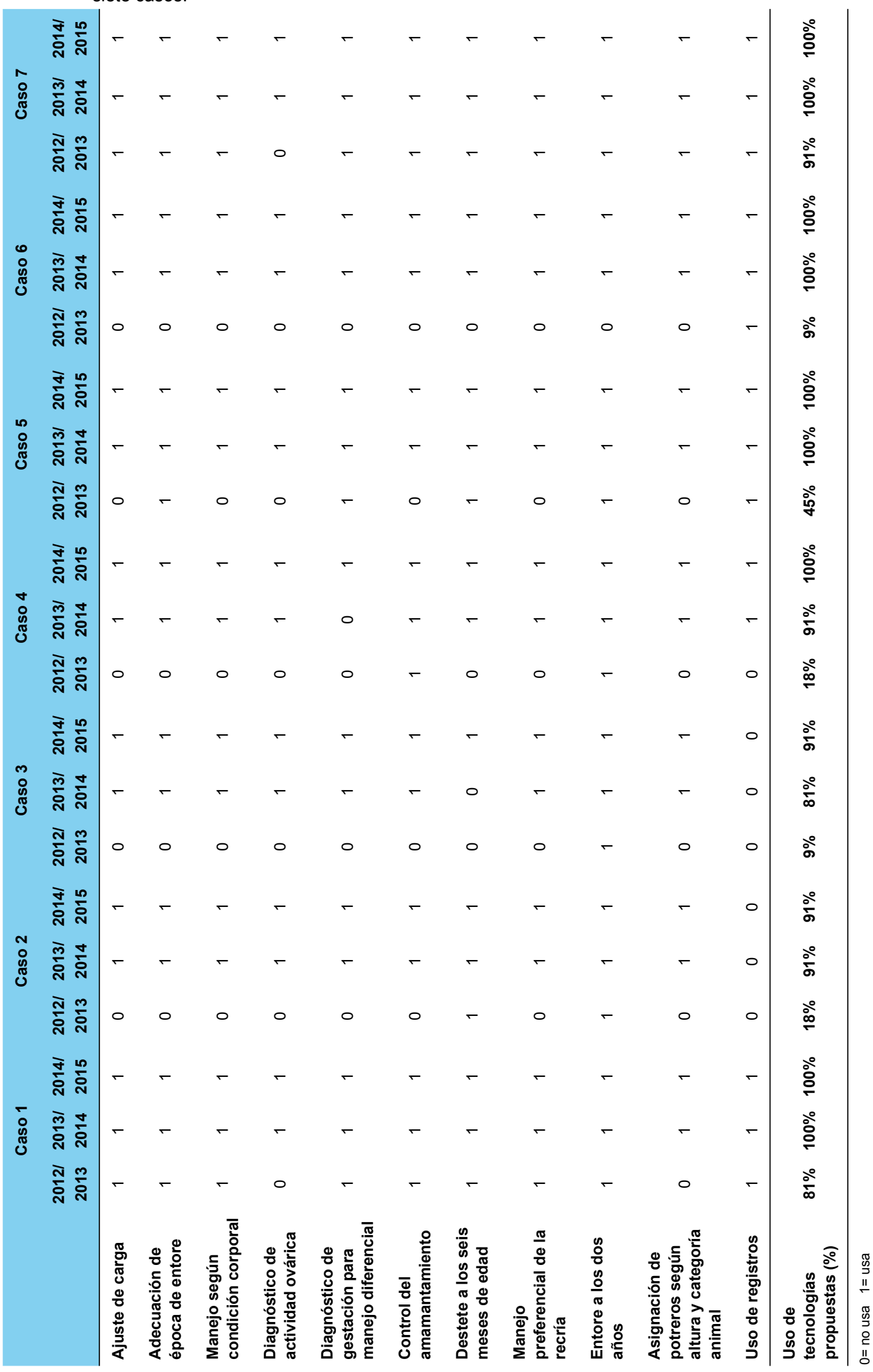




\subsubsection{Integración de resultados a nivel predial}

Una mirada global de los resultados obtenidos en todos los casos (Figuras 32 a 39) nos permite puntualizar que:

- En el área productivo-económica y en términos generales, para la mayoría de los indicadores y casos se observaron mejoras en relación al valor de referencia $(100 \%)$ si comparamos la situación inicial con la final, a excepción del caso 1. La producción de carne aumentó en todos los predios, salvo el caso 1, llegando a un valor promedio de $71 \%$ con 5 predios que superan el $65 \%$ del valor de referencia $(170 \mathrm{~kg} / \mathrm{ha})$. Es de destacar en la mayoría de los casos, el bajo valor del ingreso familiar ganadero con relación al valor de referencia, lo que en parte está explicado porque se utilizó un valor de referencia "ambicioso", duplicando el ingreso promedio per cápita de localidades pequeñas y zonas rurales. En los casos 3 y 4 la producción de carne por hectárea aumentó a niveles adecuados, pero la escala de los predios es muy baja, lo que explica los bajos ingresos. Es en estos casos donde la producción ganadera se complementa con trabajo extrapredial para mejorar el ingreso familiar global. En el caso 5 la producción de carne es muy baja, y por más que la escala del predio es significativamente mayor a los casos anteriormente mencionados, esto no al- canza para tener valores adecuados de ingreso familiar ganadero. En dos de los casos (1 y 3) se destaca un aumento importante en la productividad del trabajo predial, debida a reducciones muy importantes $(50 \%)$ del tiempo de trabajo. Una debilidad en general dentro de esta área es la diversificación de fuentes de ingresos, a excepción de los casos donde existe el trabajo extrapredial y/o otros rubros de producción. Por otro lado, existe una fortaleza que es el bajo o nulo nivel de endeudamiento.

- En el área ambiental en todos los casos se observan aumentos muy relevantes en la altura del forraje en campo natural, con excepción de los predios que ya se manejaban con más disponibilidad de forraje (casos 1 y 4). En el resto de los indicadores, se destaca el mantenimiento o una leve mejoría en los valores observados.

- En el área social se destacan mejoras muy relevantes en el uso de tecnologías propuestas, así como en la valoración y uso de la planificación, que constituyen la base para la mejora del resto de los indicadores. En los casos 1, 3, 5 y 7 se observan mejoras en el tiempo disponible de las personas debido fundamentalmente a la disminución del tiempo de trabajo con animales y pasturas en el predio. Por otro lado la proporción del trabajo aportada por la familia no fue afectada en ninguno de los casos y la calidad de vida se mantuvo en niveles altos. 


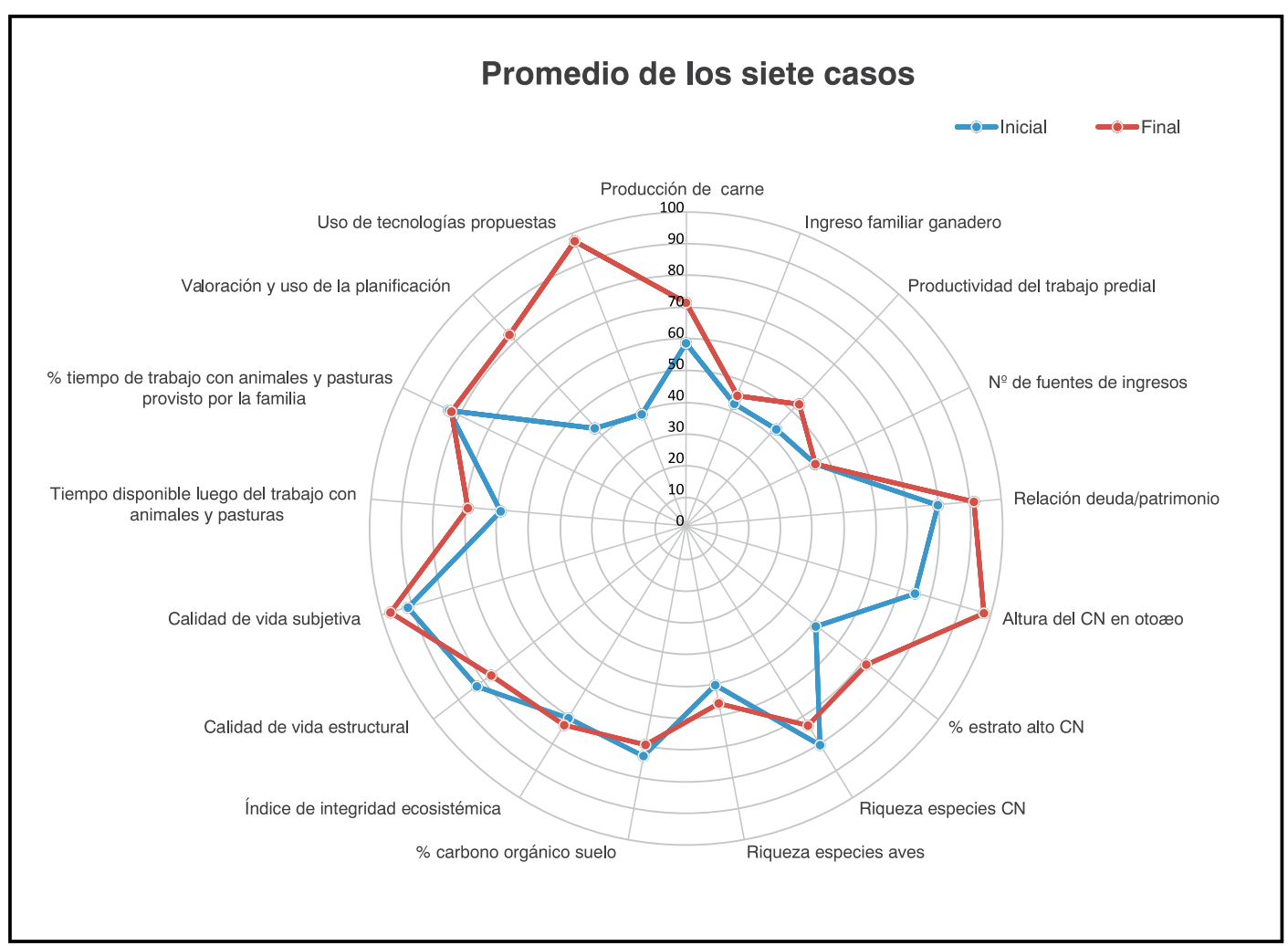

Figura 32. Resultados integrados promedio de los siete casos.

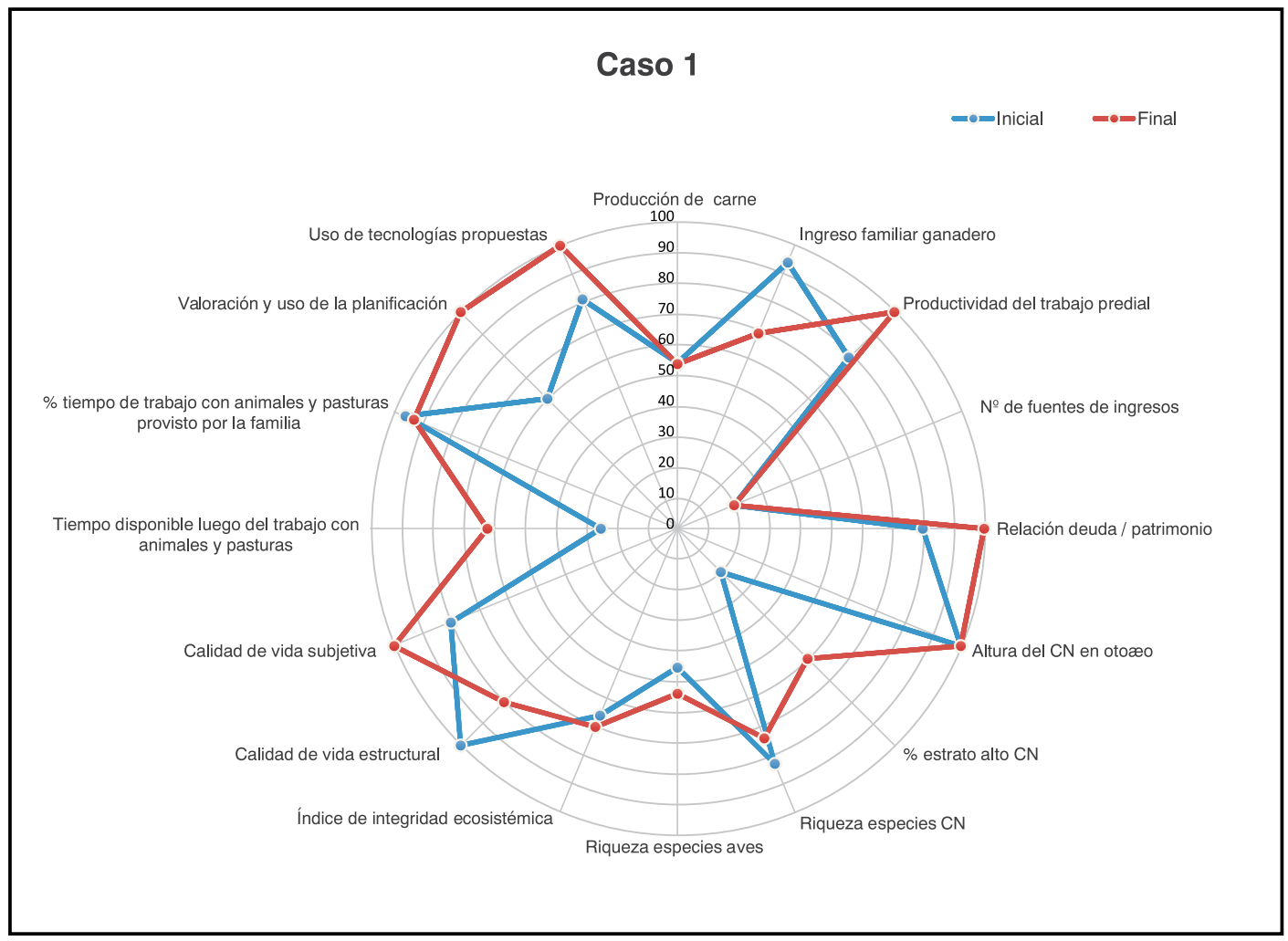

Figura 33. Resultados integrados Caso 1. 


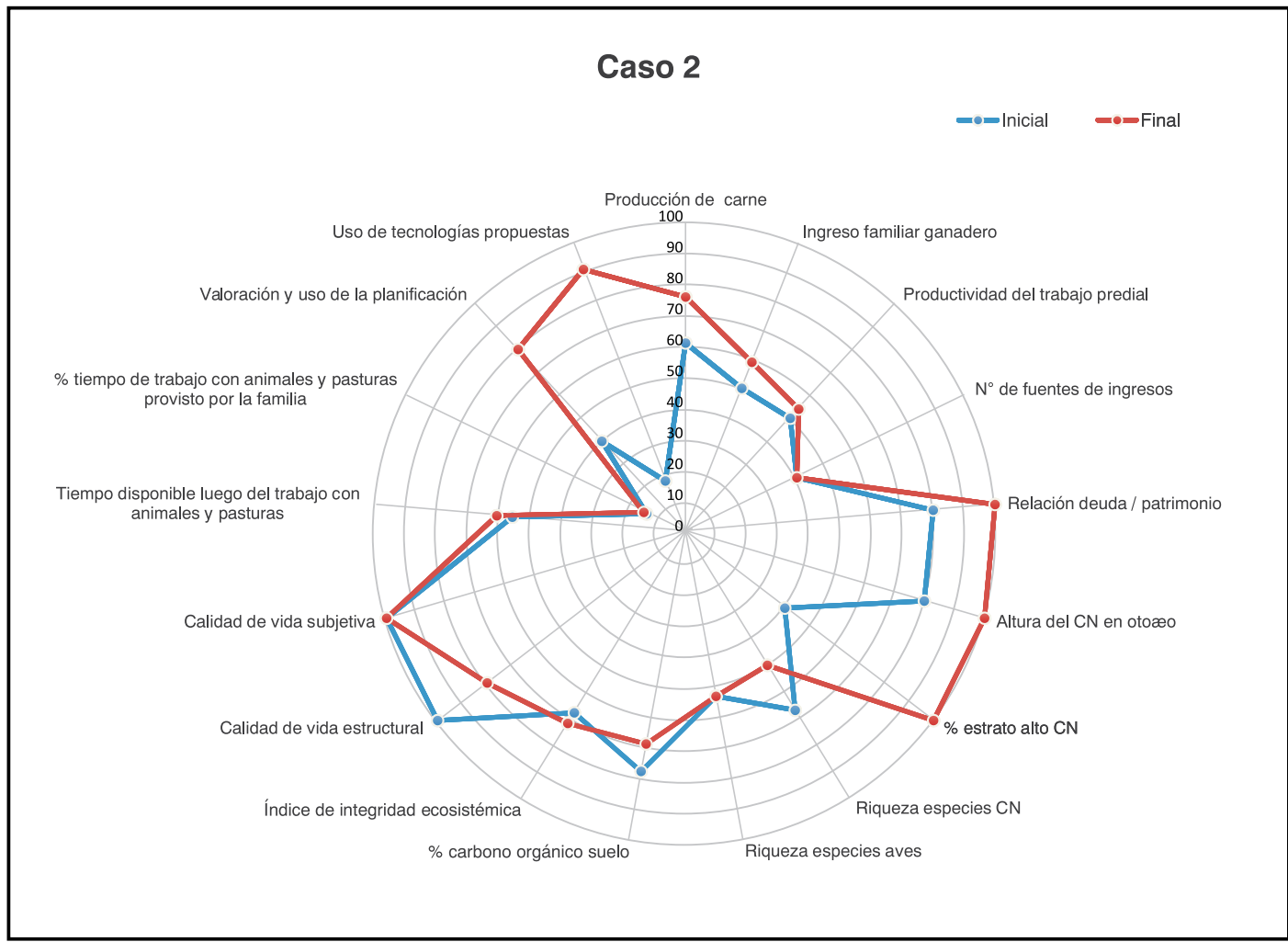

Figura 34. Resultados integrados Caso 2.

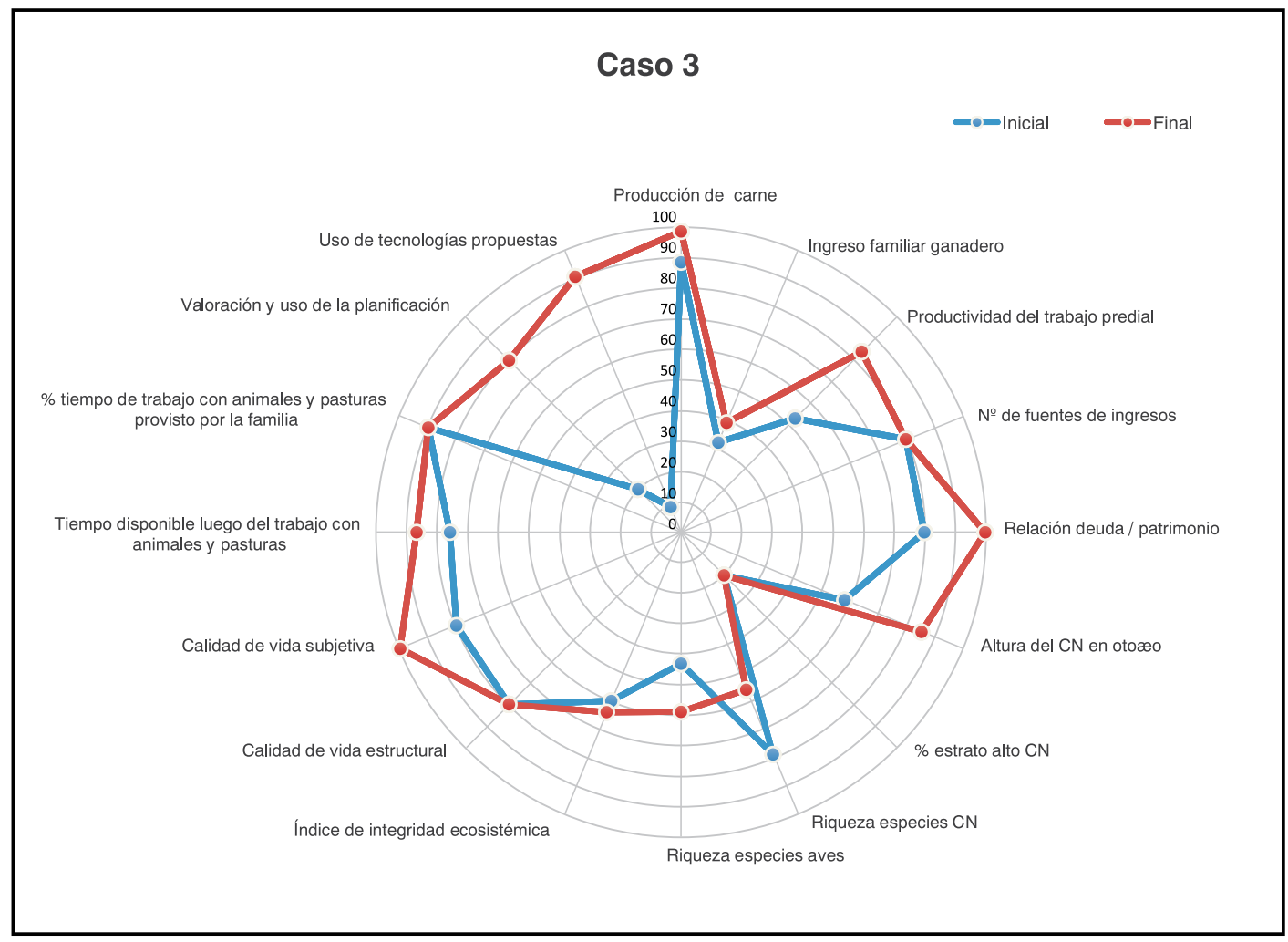

Figura 35. Resultados integrados Caso 3. 


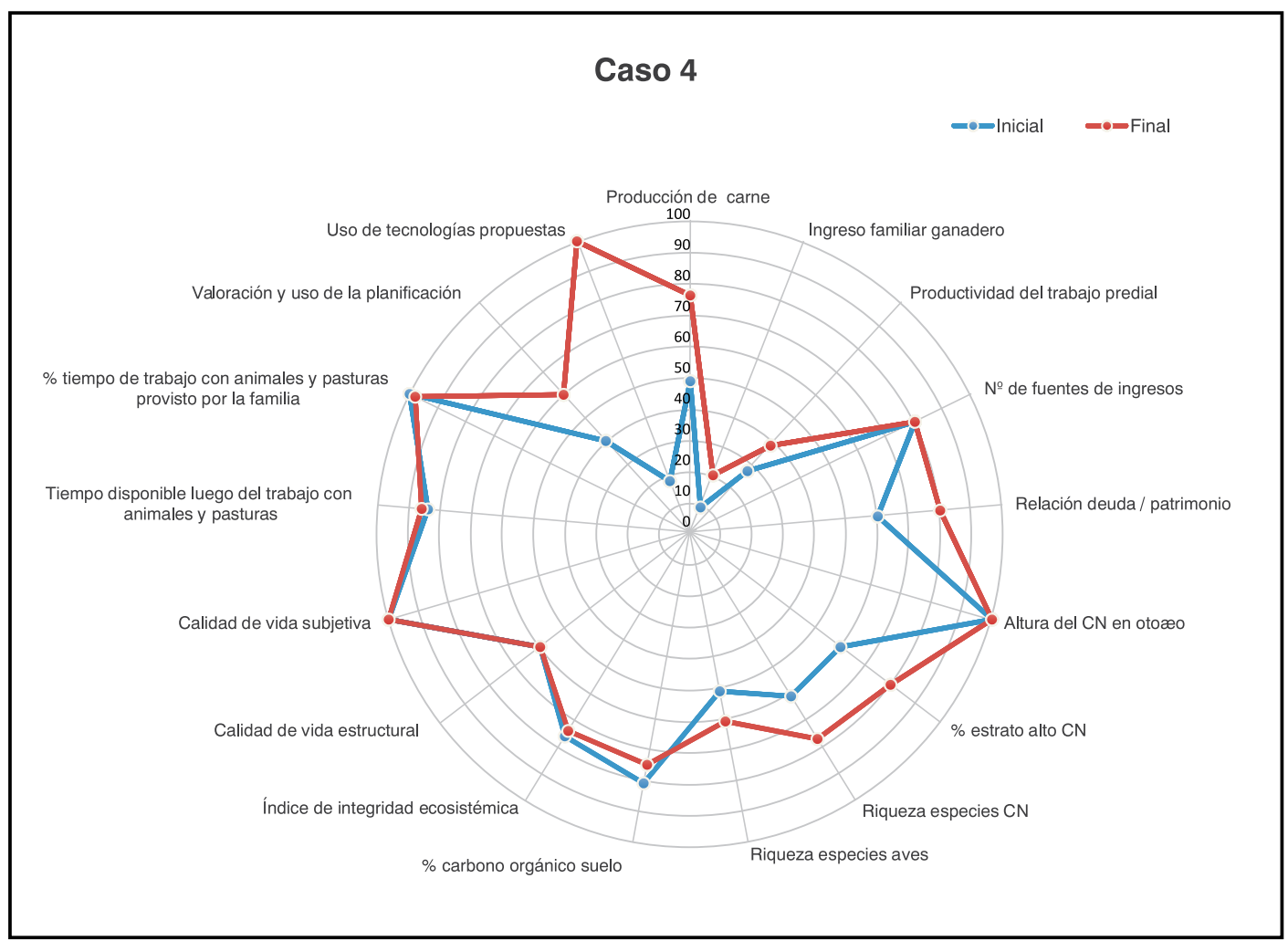

Figura 36. Resultados integrados Caso 4.

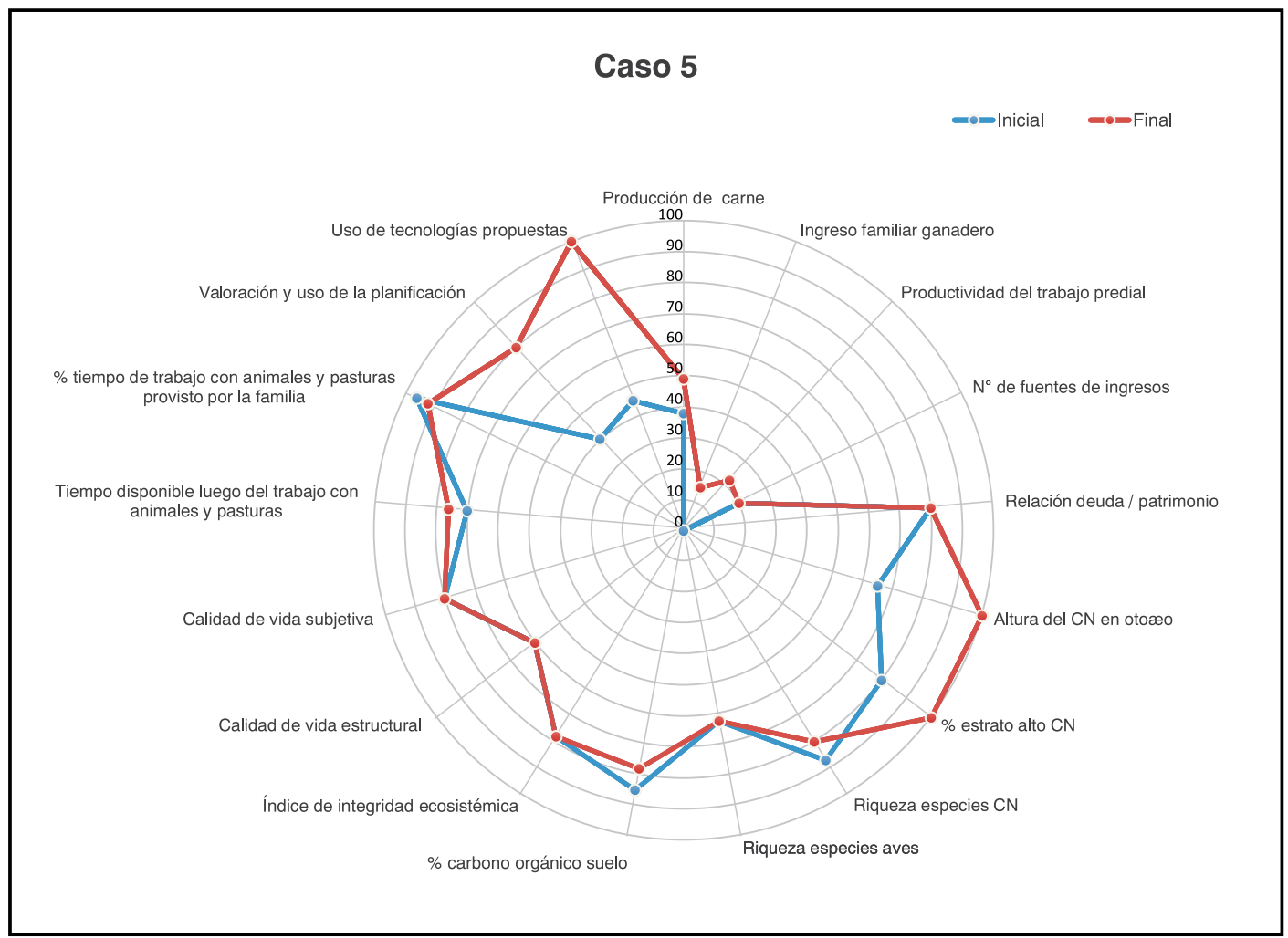

Figura 37. Resultados integrados Caso 5. 


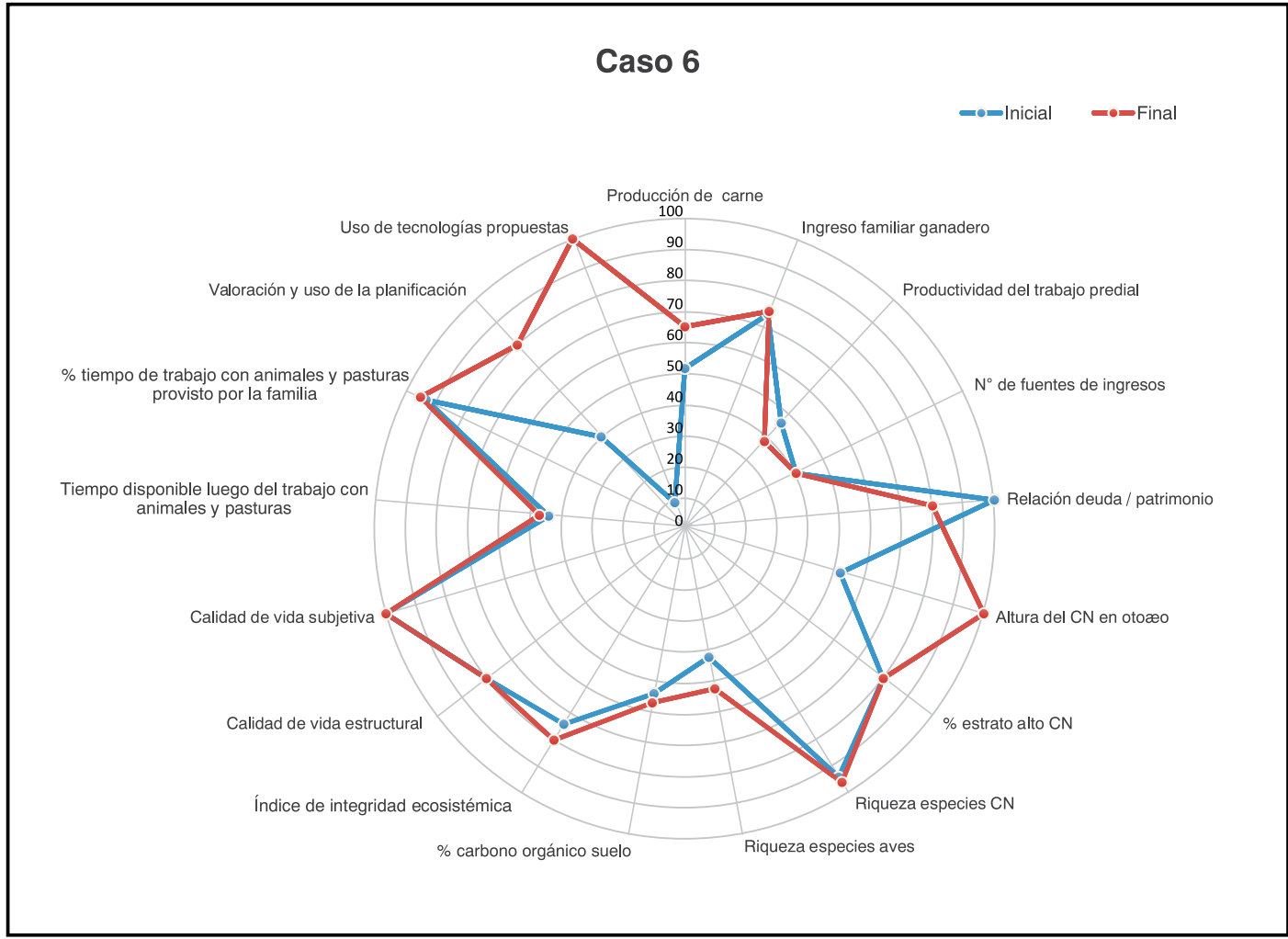

Figura 38. Resultados integrados Caso 6.

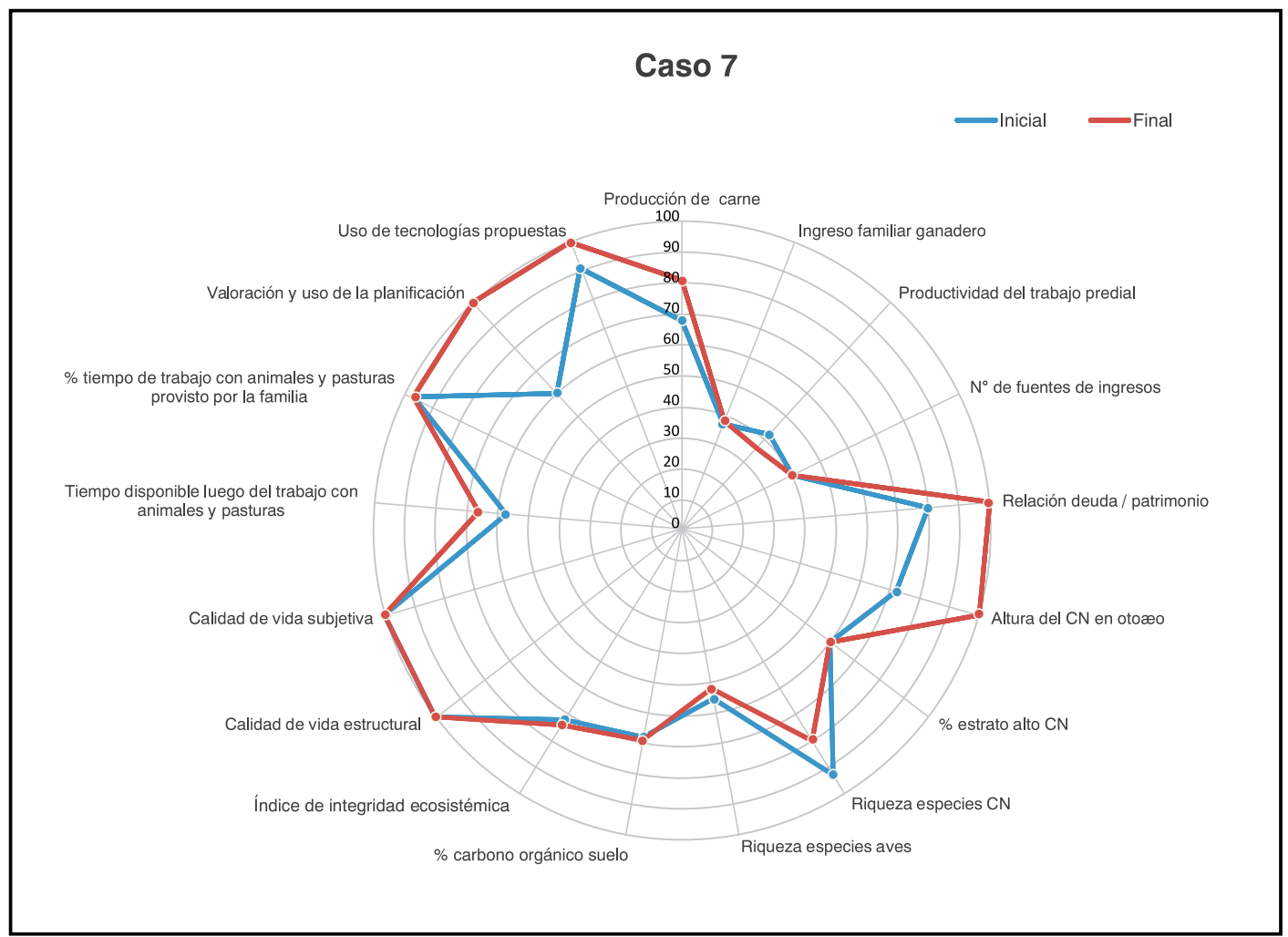

Figura 39. Resultados integrados Caso 7. 


\subsubsection{Valoración de la forma de trabajo y vínculo productor-técnico}

Los productores diferenciaron claramente la forma de trabajo y vínculo con el técnico de este proyecto con respecto a sus experiencias previas (Cuadro 26). Sobre ese tema mencionaron en las entrevistas y en la evaluación final:

"El técnico viene todos los meses, es continuado, es algo que lo tienes todo el año. El control es más frecuente. Un seguimiento..."

"Es un técnico que agarra muchas cosas. Desde la parte social. Valora todo y no es alguien que te venga a obligar. Hasta el momento todo lo que hemos hecho ha sido en consenso. Lo que me parece bueno".

"Tal cosa la tienes que hacer así a rajatabla el técnico nunca me ha dicho y me parece bueno porque ahí es cuando el productor se va dando cuenta y se va involucrando en el proyecto y se va dando cuenta que las cosas son así. Todo el equipo técnico..."

"Ellos con mucha paciencia y con una parte personal muy especial, porque jamás nos han impuesto nada, sino que nos han mostrado los números. Yo en muchas oportunidades les he dicho que no estoy dispuesto a esos cambios. Me ha costado procesar esos cambios. No ha sido de un día para otro. No ha sido fácil para ellos ni para nosotros este proceso. O sea que ellos nos han tenido que mostrar cómo se debe hacer el cambio y después han tenido que jugar la otra parte, más difícil que ha sido el convencimiento nuestro. Cómo han tenido que jugar ellos para convencernos y de la forma que lo han hecho. De forma amena, sin imponernos. Por eso digo que ha sido una labor muy destacada para hacerlo así. Tomándose su tiempo. Y saliéndose con la de ellos porque ellos han estado con los números claros".

Cuadro 26. Factores destacados por caso de la relación productor-técnico, que la diferencian de experiencias anteriores.

Factores destacados de la relación productor-técnico

\begin{tabular}{|c|c|}
\hline & Factores destacados de la relación productor-técnico \\
\hline Caso 1 & $\begin{array}{l}\text { Frecuencia y regularidad, apoyo constante y acompañamiento, abiertos, sociables, confianza, } \\
\text { visión sistémica. }\end{array}$ \\
\hline Caso 2 & Proceso iterativo negociado y en simetría (paciencia). \\
\hline \multirow[t]{2}{*}{ Caso 3} & $\begin{array}{l}\text { Visión sistémica e integradora, confianza, proceso iterativo negociado y en simetría, discutir en } \\
\text { base a números. }\end{array}$ \\
\hline & Profundidad del trabajo, apoyo siempre. \\
\hline Caso 4 & $\begin{array}{l}\text { Cercanía y confianza (calidad de vínculo), regularidad y frecuencia de las visitas, proceso iterativo, } \\
\text { negociado y en simetría. }\end{array}$ \\
\hline Caso 5 & $\begin{array}{l}\text { Visión sistémica, proceso iterativo negociado y en simetría (consenso), regularidad y frecuencia } \\
\text { (que incluso podría ser mayor). }\end{array}$ \\
\hline Caso 6 & $\begin{array}{l}\text { Sin experiencia previa de asesoramiento técnico. Valora proceso iterativo, negociado y en simetría } \\
\text { (psicólogo). }\end{array}$ \\
\hline Caso 7 & $\begin{array}{l}\text { Regularidad, todo el año, seguimiento, visión sistémica, proceso iterativo, negociado y en } \\
\text { simetría. }\end{array}$ \\
\hline
\end{tabular}




\subsection{Resultados a nivel regional}

\subsubsection{Una red interinstitucional que acompañó el proceso predial}

La implementación de seis talleres regionales, así como diversas reuniones locales, favorecieron la consolidación de una Red de Actores Regionales (RAR). Los integrantes de la misma se involucraron en la implementación del proyecto, participando activamente en su planificación, monitoreo y evaluación, lo que permitió la incorporación de mejoras en tiempo real, generando resultados del proyecto más orientados hacia el impacto.
La RAR estuvo integrada por los siete productores del proyecto y sus familias, el equipo técnico de INIA y los representantes de instituciones de investigación y educación, del gobierno y de organizaciones de la sociedad civil, los cuales mantuvieron su participación a lo largo de todo el proceso. En el Cuadro 27 se presentan los grupos de actores según la clasificación de Schut et al. (2015), un detalle de cada uno de los actores y la participación de cada uno en los seis talleres. La asistencia a los seis talleres varió entre 28 y 39 personas, siendo el promedio 30 personas, lo que demuestra el alto nivel de involucramiento de los participantes en el proceso.

Cuadro 27. Grupos de actores y su participación en los seis talleres de la Red de Actores Regionales (RAR).

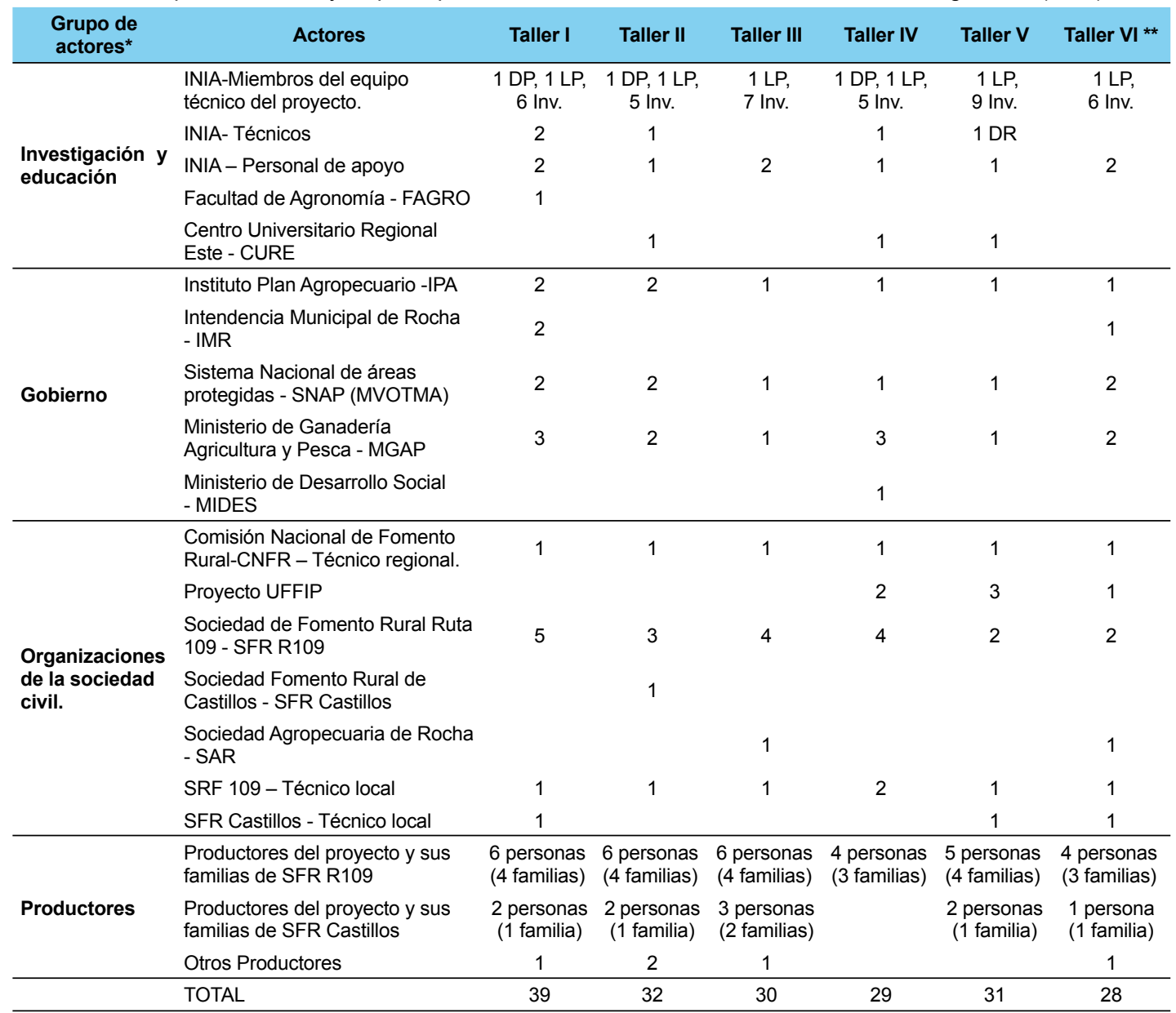

* Basado en Schutt et al. (2015)

** El día del taller final hubo una fuerte tormenta y algunos productores no pudieron participar.

DP: Director de Programa, LP Líder de Programa, Inv.: Investigador DR: Director Regional 


\subsubsection{La visión compartida y las vías de impacto consensuadas}

El trabajo realizado por los participantes durante los Talleres I y II ( ver Memorias Taller Interinstitucional I - II, http://www.inia.uy/Proyectos/Paginas/PF_07.aspx) permitió avanzar en la definición de una visión compartida del proyecto, es decir el "sueño" común de los resultados esperados del proyecto, que contenía las siguientes ideas fuerza:

- Se ha mejorado la sustentabilidad de los predios del proyecto y de la región en forma considerable, con la aplicación de tecnología "sustentable" en la región, que ha redundado en una mejora en la conservación de los recursos naturales y un mejor nivel social (educación, trabajo y salud), existiendo un espacio de trabajo para abordar la problemática de la educación de los jóvenes.

- Los productores adoptan una forma de trabajo grupal e interactúan con los predios de referencia y entre sí. Tienen mejores ingresos y la capacidad de financiar gradualmente los equipos técnicos. Adquirieron conocimientos y habilidades en técnicas específicas y en el manejo de los recursos. Un grupo de gente tiene argumentos para dialogar con el poder público con relación a la producción familiar.

- Las instituciones están involucradas con la mejora de la producción familiar, destacándose las Sociedades de Fomento
Rural (SFR), Instituto Nacional de Investigación Agropecuaria (INIA), Instituto Plan Agropecuario (IPA), Ministerio de Ganadería Agricultura y Pesca - Dirección General de Desarrollo Rural (MGAP-DGDR) e Intendencia Municipal de Rocha - Dirección de Desarrollo (IMR-DD), junto a la Comisión Nacional de Fomento Rural (CNFR). Todas trabajan en Red y abordan un estudio para generar nuevos proyectos que complementan las cadenas productivas.

- Los técnicos y productores de las instituciones y organizaciones están muy vinculados entre sí y con todos los actores de la región, siendo capaces de planificar proyectos a largo plazo.

- Los conocimientos adquiridos se extienden en forma grupal con charlas técnicas y jornadas entre productores y técnicos, talleres en escuelas, universidades y sociedades de fomento, con difusión por la prensa y una revista, y con el uso eficiente de herramientas de comunicación de las instituciones de la Red.

Considerando la visión compartida, los participantes desarrollaron las vías de impacto del proyecto usando un modelo de resultados que describía qué cambios se querían lograr y la forma en que los actores tenían que interactuar. Se definieron actividades y responsables para contribuir a realizar el sueño de la visión (Cuadro 28). Este modelo fue usado como base para el monitoreo y evaluación del proceso. 
Cuadro 28. Vías de impacto-Modelo de resultados acordadas entre los actores de la Red de Actores Regionales (RAR).

\begin{tabular}{|c|c|c|c|c|}
\hline $\begin{array}{l}\text { ¿Qué cambio } \\
\text { quiero lograr? }\end{array}$ & $\begin{array}{l}\text { Actores o grupo } \\
\text { de actores que se } \\
\text { espera que cambien }\end{array}$ & $\begin{array}{c}\text { ¿Qué se necesita? } \\
\text { (Resultados intermedios) }\end{array}$ & Actividades & ¿Quiénes lo van a hacer? \\
\hline $\begin{array}{l}\text { Ha mejorado la } \\
\text { sustentabilidad } \\
\text { de los predios del } \\
\text { Proyecto. }\end{array}$ & $\begin{array}{l}\text { Productores de los } \\
\text { predios y técnicos } \\
\text { del proyecto } \\
\text { estrechamente } \\
\text { vinculados. }\end{array}$ & $\begin{array}{l}\text { Trabajo cotidiano en los } \\
\text { predios y en las visitas, } \\
\text { con discusiones y acuerdos } \\
\text { que generan aprendizajes y } \\
\text { cambios. } \\
\text { Lograr un compromiso } \\
\text { sostenido de técnicos y } \\
\text { productores que permita dar } \\
\text { valor a la interacción técnico- } \\
\text { productor. }\end{array}$ & $\begin{array}{l}\text { Trabajo en los } \\
\text { predios. }\end{array}$ & $\begin{array}{l}\text { Productor y familia, técnicos } \\
\text { INIA con acompañamiento } \\
\text { de técnicos de las } \\
\text { Instituciones involucradas } \\
\text { en instancias específicas. } \\
\text { Equipo amplio del Proyecto } \\
\text { (productores participantes, } \\
\text { técnicos de INIA y técnicos } \\
\text { de las Instituciones } \\
\text { involucradas). }\end{array}$ \\
\hline \multirow{6}{*}{$\begin{array}{l}\text { Productores de la } \\
\text { región conocen } \\
\text { la tecnología } \\
\text { "sustentable" } \\
\text { aplicada en el } \\
\text { proyecto. }\end{array}$} & $\begin{array}{l}\text { Productores de los } \\
\text { predios piloto. }\end{array}$ & $\begin{array}{l}\text { Productores de los predios } \\
\text { piloto Interactúan con sus } \\
\text { grupos de referencia. }\end{array}$ & $\begin{array}{l}\text { Reuniones de grupo } \\
\text { (estratégicas). }\end{array}$ & \\
\hline & $\begin{array}{l}\text { Productores socios } \\
\text { de las Fomento. }\end{array}$ & $\begin{array}{l}\text { Productores socios de las } \\
\text { Fomento interactúan con los } \\
\text { productores de los predios } \\
\text { piloto. }\end{array}$ & $\begin{array}{c}\text { Reuniones de } \\
\text { presentación e } \\
\text { intercambio una vez } \\
\text { al año. } \\
\text { Diversas actividades } \\
\text { (presenciales, con } \\
\text { medios, escritas, } \\
\text { web) establecidas } \\
\text { en el plan de } \\
\text { comunicación. } \\
\end{array}$ & $\begin{array}{l}\text { Equipo amplio del Proyecto } \\
\text { (productores, técnicos } \\
\text { de INIA y técnicos de las } \\
\text { Instituciones involucradas). }\end{array}$ \\
\hline & $\begin{array}{l}\text { Técnicos de } \\
\text { las Instituciones } \\
\text { directamente } \\
\text { vinculadas al } \\
\text { proyecto. }\end{array}$ & $\begin{array}{l}\text { Interacción de técnicos de las } \\
\text { Instituciones participantes del } \\
\text { proyecto con predios piloto. } \\
\text { Interacción entre equipos } \\
\text { técnicos de las Instituciones } \\
\text { participantes del proyecto. }\end{array}$ & $\begin{array}{c}\text { Reuniones } \\
\text { estratégicas entre } \\
\text { equipos técnicos. } \\
\text { Diversas } \\
\text { actividades } \\
\text { (presenciales, con } \\
\text { medios, escritas, } \\
\text { web) establecidas } \\
\text { en el plan de } \\
\text { comunicación. }\end{array}$ & $\begin{array}{l}\text { Equipo amplio del Proyecto } \\
\text { (productores, técnicos } \\
\text { de INIA y técnicos de las } \\
\text { Instituciones involucradas). }\end{array}$ \\
\hline & \multirow{3}{*}{ Instituciones. } & Fomentar el trabajo en Red. & $\begin{array}{l}\text { Predicar con el } \\
\text { ejemplo. }\end{array}$ & $\begin{array}{l}\text { Equipo amplio del Proyecto } \\
\text { (productores, técnicos } \\
\text { de INIA y técnicos de las } \\
\text { Instituciones involucradas). }\end{array}$ \\
\hline & & $\begin{array}{l}\text { Canalizar temas e inquietudes } \\
\text { que surjan en el marco del } \\
\text { proyecto y el trabajo en red } \\
\text { a los ámbitos Institucionales } \\
\text { que correspondan } \\
\text { (educación, trabajo, salud, } \\
\text { comercialización, sistemas de } \\
\text { apoyo a la producción). }\end{array}$ & $\begin{array}{l}\text { Un delegado de la } \\
\text { Red actúa como } \\
\text { emisario de las } \\
\text { ideas que emerjan } \\
\text { y se consensuen } \\
\text { en los espacios } \\
\text { participativos de la } \\
\text { Red. }\end{array}$ & $\begin{array}{l}\text { El delegado es designado } \\
\text { por consenso de acuerdo } \\
\text { al tema. }\end{array}$ \\
\hline & & $\begin{array}{c}\text { Fomentar en las Instituciones } \\
\text { un enfoque técnico adecuado } \\
\text { para trabajar con PF. }\end{array}$ & $\begin{array}{c}\text { Talleres de } \\
\text { sensibilización } \\
\text { con instituciones/ } \\
\text { decisores políticos. }\end{array}$ & $\begin{array}{l}\text { Equipo amplio del Proyecto } \\
\text { (productores, técnicos } \\
\text { de INIA y técnicos de las } \\
\text { Instituciones involucradas). }\end{array}$ \\
\hline
\end{tabular}




\subsubsection{Un plan de comunicación para trascender el trabajo en los predios}

El plan de comunicación surgió como necesidad de planificar las actividades de divulgación del proyecto en el primer taller de la RAR y sirvió de herramienta para darle contenido y definiendo actividades durante la implementación del mismo. Entre el primer taller y el segundo, un subgrupo de actores designados en el primer taller elaboró una propuesta de estrategia para la comunicación que se validó en el segundo taller, donde se definieron actividades concretas para el primer plan de comunicación (2013). Un segundo plan de comunicación se elaboró para el periodo 2014-2015. Los planes de comunicación incluían una serie actividades de divulgación, que permitieron compartir el conocimiento generado a lo largo del proyecto considerando tres públicos objetivo: productores, técnicos e instituciones y tres niveles de acción: (i) los más cercanos y directamente vinculados al proyecto, (ii) los vecinos y técnicos de la zona, (iii) los actores regionales. Un resumen de las actividades implementadas a lo largo del proyecto se presenta en el Cuadro 29 que presenta un detalle de las actividades de divulgación para diversos públicos y en el Cuadro 30 que presenta un detalle de las actividades científico-tecnológicas. 
Cuadro 29. Resumen de las actividades de divulgación implementadas en base a los dos planes de comunicación elaborados por la Red de Actores Regionales (RAR).

\begin{tabular}{|c|c|c|c|c|}
\hline Actividad & Objetivo & $\begin{array}{l}\text { ¿Quién fue } \\
\text { invitado? }\end{array}$ & $\begin{array}{l}\text { Canales utilizados } \\
\text { para la invitación }\end{array}$ & $\begin{array}{l}\text { No Actividades / } \\
\text { Participantes }\end{array}$ \\
\hline $\begin{array}{l}\text { Reuniones en los } \\
\text { predios }\end{array}$ & $\begin{array}{l}\text { Compartir y discutir la } \\
\text { implementación y los } \\
\text { resultados del proyecto a } \\
\text { nivel predial }\end{array}$ & $\begin{array}{l}\text { Grupos de los } \\
\text { PP, su técnico } \\
\text { y vecinos }\end{array}$ & $\begin{array}{l}\text { Invitación } \\
\text { personal, SMS }\end{array}$ & $\begin{array}{l}9 \text { reuniones, } \\
100 \text { participantes }\end{array}$ \\
\hline $\begin{array}{l}\text { Actividades } \\
\text { locales }\end{array}$ & $\begin{array}{l}\text { Intercambio de información } \\
\text { sobre temas tecnológicos } \\
\text { específicos (ej. escala de } \\
\text { condición corporal, manejo } \\
\text { de pasturas, diagnóstico de } \\
\text { actividad ovárica) }\end{array}$ & $\begin{array}{l}\text { Miembros de } \\
\text { la RAR }\end{array}$ & SMS & $\begin{array}{c}3 \text { actividades en los } \\
\text { predios, } \\
90 \text { participantes }\end{array}$ \\
\hline $\begin{array}{l}\text { Actividades } \\
\text { de divulgación } \\
\text { demandadas por } \\
\text { las organizaciones } \\
\text { de productores } \\
\text { locales. }\end{array}$ & $\begin{array}{l}\text { Intercambio de información } \\
\text { en temas tecnológicos } \\
\text { (manejo de toros y vacas } \\
\text { para el entore, manejo del } \\
\text { rodeo de cría en condiciones } \\
\text { de sequía) }\end{array}$ & $\begin{array}{l}\text { Socios de las } \\
\text { SFR y } \\
\text { productores } \\
\text { de la región }\end{array}$ & $\begin{array}{l}\text { SMS, } \\
\text { Promoción en } \\
\text { medios de } \\
\text { comunicación } \\
\text { locales }\end{array}$ & $\begin{array}{l}2 \text { actividades, } \\
70 \text { participantes }\end{array}$ \\
\hline $\begin{array}{c}\text { Talleres } \\
\text { interinstitucionales }\end{array}$ & $\begin{array}{l}\text { Planificación, Monitoreo y } \\
\text { Evaluación del proceso }\end{array}$ & $\begin{array}{l}\text { Miembros de } \\
\text { la RAR }\end{array}$ & E-mail y SMS & $\begin{array}{c}6 \text { Talleres, } \\
180 \text { participantes }\end{array}$ \\
\hline $\begin{array}{l}\text { Seminarios para } \\
\text { profesionales } \\
\text { vinculados al } \\
\text { desarrollo rural }\end{array}$ & $\begin{array}{l}\text { Discusiones técnicas (temas } \\
\text { Sociales y Ambientales) }\end{array}$ & Profesionales & E-mail & $\begin{array}{l}2 \text { Seminarios, } \\
90 \text { participantes }\end{array}$ \\
\hline $\begin{array}{l}\text { Días de campo } \\
\text { en predios de } \\
\text { productores del } \\
\text { proyecto }\end{array}$ & $\begin{array}{l}\text { Compartir resultados del } \\
\text { proyecto y avances del } \\
\text { proceso }\end{array}$ & $\begin{array}{l}\text { Invitación, } \\
\text { abierta }\end{array}$ & $\begin{array}{c}\text { Invitaciones } \\
\text { personales, } \\
\text { Newsletter INIA, } \\
\text { Twitter, SMS, } \\
\text { Promoción } \\
\text { en medios de } \\
\text { comunicación, Web, } \\
\text { afiches }\end{array}$ & $\begin{array}{l}5 \text { días de campo, } \\
600 \text { participantes }\end{array}$ \\
\hline $\begin{array}{l}\text { Participación en } \\
\text { medios masivos } \\
\text { de comunicación }\end{array}$ & $\begin{array}{l}\text { Divulgación de actividades } \\
\text { del proyecto y resultados }\end{array}$ & $\begin{array}{l}\text { Equipo de } \\
\text { investigación }\end{array}$ & & $\begin{array}{c}2 \text { artículos en prensa } \\
\text { nacional, } 1 \text { artículo } \\
\text { en el Boletín de la } \\
\text { FAO, } 3 \text { artículos en } \\
\text { la Revista INIA, } 3 \\
\text { artículos en revistas } \\
\text { agropecuarias }\end{array}$ \\
\hline
\end{tabular}

SMS: Mensaje de texto. 
Cuadro 30. Registro de actividades de comunicación técnico-científicas para divulgar resultados en eventos nacionales e internacionales 2012-2016.

\begin{tabular}{|c|c|c|}
\hline & Objetivo & $\begin{array}{l}\mathrm{N}^{\circ} \text { de actividades y total de } \\
\text { participantes }\end{array}$ \\
\hline \multirow[t]{2}{*}{ Congresos } & \multirow[t]{2}{*}{$\begin{array}{l}\text { Diseminar actividades y resultados del } \\
\text { proyecto }\end{array}$} & $\begin{array}{l}4 \text { actividades nacionales con } 5 \text { artículos y } 1 \\
\text { poster; } 7 \text { actividades internacionales con } 12 \\
\text { artículos }\end{array}$ \\
\hline & & 2000 participantes \\
\hline \multirow{3}{*}{$\begin{array}{l}\text { Reuniones } \\
\text { Nacionales }\end{array}$} & \multirow{3}{*}{$\begin{array}{l}\text { Compartir el proceso con organizaciones } \\
\text { nacionales }\end{array}$} & $\begin{array}{l}8 \text { actividades con diferentes actores: } \\
\cdot 2 \text { con MGAP } \\
\cdot 1 \text { con IPA }\end{array}$ \\
\hline & & $\begin{array}{l}\cdot 2 \text { con organizaciones de productores } \\
\cdot 1 \text { con FAGRO } \\
\cdot 2 \text { con grupos de productores de otras } \\
\text { regiones }\end{array}$ \\
\hline & & 170 participantes \\
\hline \multirow{2}{*}{$\begin{array}{l}\text { Reuniones } \\
\text { internacionales }\end{array}$} & \multirow{2}{*}{$\begin{array}{l}\text { Compartir el proceso con organizaciones } \\
\text { internacionales }\end{array}$} & 10 actividades \\
\hline & & 450 participantes \\
\hline \multirow{3}{*}{$\begin{array}{l}\text { Reuniones } \\
\text { interinstitucionales }\end{array}$} & \multirow{3}{*}{$\begin{array}{l}\text { Discutir el enfoque de co-innovación con } \\
\text { foco en el desarrollo de políticas públicas } \\
\text { para el desarrollo de la producción } \\
\text { familiar }\end{array}$} & 6 actividades con representantes de: \\
\hline & & $\begin{array}{l}\text { SNAP } \\
\text { - Ganaderos Familiares y Cambio Climático. } \\
\text { Proyecto GFCC (MGAP) } \\
\text { Desarrollo y Adaptación al Cambio } \\
\text { Climático. Proyecto- DACC (MGAP) - } 2 \\
\text { actividades } \\
\text { - Programa Nacional de Transferencia para } \\
\text { Ganaderos Familiares } \\
\text { - Simposio Co-innovación-Proyecto UFFIP }\end{array}$ \\
\hline & & 180 participantes \\
\hline $\begin{array}{l}\text { Publicaciones en } \\
\text { revistas científicas }\end{array}$ & $\begin{array}{l}\text { Compartir resultados con la comunidad } \\
\text { científica }\end{array}$ & 2 artículos publicados \\
\hline
\end{tabular}

Los días de campo fueron muy bien valorados y cumplieron los objetivos para los que fueron diseñados. Lograron focalizar en el proceso de trabajo y en sus resultados, combinando la participación directa de los productores quienes contaban su experiencia y la presentación de información del monitoreo de indicadores por parte de los técnicos. El sistema utilizado alimentó un intercambio relevante y fluido entre los participantes.

El 8 de diciembre de 2015, 200 personas asistieron al día de campo donde se presentaron los resultados finales del proyecto. La hoja de evaluación de la actividad fue respondida por 98 participantes: el $93 \%$ consideró la actividad como excelente o muy buena. Además, el $83 \%$ de las respuestas indicaron que las tecnologías propuestas presentadas durante el día de campo eran factibles de implementar en sus propios predios. Al final de ese día, siete autoridades nacionales subrayaron la importancia del enfoque y los resultados de los proyectos en relación con: i) mejorar la sostenibilidad de las explotaciones mediante un proceso de intensificación y adaptación al cambio climático; ii) mejorar los conocimientos y las aptitudes de los productores; iii) promover la creación de redes regionales; iv) generación de datos con rigor científico para respaldar las políticas para la producción familiar. Finalmente, el proceso se destacó como una innovación metodológica para el INIA, como "una forma de trabajar que piensa en qué (...) y cómo se hacen las cosas". En la pagina Web de INIA 
se encuentra información de las jornadas de 2014 (Ver Jornada Anual - 2014, http://www. inia.uy/Proyectos/Paginas/PF_07.aspx).

y de 2015 (Ver Jornada Final, http://www. inia.uy/Proyectos/Paginas/PF_07.aspx).

El Director de Desarrollo Rural del MGAP destacó al final del día de campo: "Los resultados del proyecto han demostrado que en ganadería familiar es posible hacer un proceso de intensificación productiva con sostenibilidad y adaptación al cambio climático". "Este proyecto es innovador en la construcción del conocimiento que tiene la base en el bienestar de las familias rurales". Mientras tanto, un miembro de la Junta Directiva de INIA mencionó: "Hay confianza en el INIA con esta forma de trabajar: además de pensar en" qué ", pensar en "cómo" hacer las cosas. Este proyecto es un muy buen punto de partida para esto". Un Profesor Titular Grado 5 de Facultad de Agronomía y Director de la Agencia Nacional de Innovación e Investigación también señaló: "Tres razones explican el éxito del proyecto: 1) Un enfoque sólido de sistemas que demostró una comprensión profunda de los cuales son" los hilos "para mover la ganadería familiar y cuáles son las mejores alternativas para hacer cambios.

2) Se utilizaron metodologías útiles para trabajar en los predios y en la región. Para las familias que hacen cambios en sus campos es necesario un proceso de aprendizaje que requiere un método y tiempo para aprender. 3) El trabajo interdisciplinario y la integración con las instituciones locales mostraron que había un espacio de integración y eso no es menor en un país pequeño como Uruguay".

Estos resultados se explican en parte por un fuerte trabajo de planificación y preparación de las actividades, el alto involucramiento principalmente de los productores y de los actores de la RAR en este proceso, así como por los excelentes resultados obtenidos a nivel predial.

\subsubsection{Monitoreo y Evaluación (M\&E), reflexión e incorporación de sugerencias}

En los talleres se realizaron diferentes instancias de monitoreo y evaluación, tomando como base las vías de impacto, el modelo de resultados y los planes de comunicación. Esto permitió fortalecer el compromiso y fomentar la confianza, obteniendo sugerencias de mejoras para la implementación del proyecto, que en la medida de lo posible fueron incorporadas por el equipo técnico. Como ejemplo de la profundidad de las reflexiones desarrolladas, se presenta un resumen de logros, dificultades y sugerencias de mejora del proyecto, planteadas durante los talleres III y IV (Cuadro 31). Los principales logros se relacionan con los buenos y rápidos resultados obtenidos y la eficiente metodología utilizada a nivel predial, así como la consolidación de una red que permitió un mayor vínculo entre las instituciones de la región. Las principales dificultades estuvieron relacionadas con la falta de un abordaje específico del tema de sanidad animal a nivel predial y la coordinación principalmente al inicio del proceso a nivel regional. Las principales sugerencias de mejora a nivel predial se orientaban a fortalecer el trabajo en salud animal, lo que no fue posible de implementar en el proyecto. A nivel regional las sugerencias se relacionaban con enfatizar la divulgación de los resultados y del proceso, llegar a más productores y profundizar la coordinación con otros actores, lo cual fue incorporado en los planes de comunicación elaborados por la RAR. 
Cuadro 31. Principales logros, dificultades y sugerencias de mejora planteados en instancias de reflexión realizadas en los Talleres III y IV de la RAR

\section{Principales logros:}

- Se tomó conciencia y se logró trabajar de otra forma

- Algunos productores cambiaron su forma de pensar y actuar ("hicimos el Click").

- El proyecto promovió nuevos conocimientos y aprendizajes.

- Se incorporaron nuevas técnicas de producción.

- Sorprendió la rapidez con que se aumentó la producción de carne en los predios.

- Se logró disponer de información en todos los predios a través de diversas formas de registro.

- Se avanzó en una aproximación a la caracterización de recursos.

- Se incorporó la planificación en todos los predios.

- Se logró mayor vínculo entre las instituciones de la región.

- Se dispone de una metodología generada en interacción con el productor y eficiente en resultados.

- Se usaron los predios para mostrar a otros el proceso y los resultados.

- Se realizaron días de campo "muy buenos".

\section{Principales dificultades:}

- No se abordó específicamente el tema de sanidad animal con especialistas en el área.

- La coordinación del aterrizaje del proyecto con las instituciones locales.

- El equipo técnico no tenía residencia en la zona.

- Falta de claridad para que los resultados trasciendan a los predios.

- Integración de otros productores de la región al proceso.

- Hubo dificultad de seguir el proceso.

- Existía cierto egoísmo por compartir

- Problemas de comunicación entre los productores y las instituciones locales.

\section{Sugerencias de mejora:}

- Incorporar un técnico veterinario y definir un plan sanitario en los predios.

- Hacer hincapié en el proceso con otros productores, los más alejados.

- Hacer más jornadas con determinados temas, ej.: condición corporal, pasturas.

- Mayor difusión para transmitir lo aprendido.

- Mayor intercambio sobre aspectos técnicos (metodológicos):

- Entre productores de grupo y otros.

- Entre técnicos.

- Productor-técnico, incluso de temas específicos (disciplinas).

- Filmación del proceso.

- Profundizar coordinación con actores para volcar resultados .

- Mayor participación en la discusión técnica, incorporando a técnicos de la región.

- Tener más presencia del equipo técnico en la zona.

- Acordar un manejo ganadero sustentable (enfoque y tecnología) entre las instituciones.

- Divulgar metodología de seguimiento del sistema de producción a la red de técnicos institucionales.

- Coordinar con el MGAP y buscar la forma de asociarse, para pensar cómo sostener los aprendizajes del proyecto en el tiempo. 


\subsubsection{Evaluación final}

Los resultados de la evaluación final luego de procesados los 18 formularios recibidos se presentan en el Cuadro 32, en forma integrada. El detalle de las preguntas realizadas se presenta en el Anexo 2 y mayor detalle sobre las respuestas se presenta en Memorias Taller Interinstitucional VI (http://www. inia.uy/Proyectos/Paginas/PF_07.aspx).

Un análisis cuantitativo de las respuestas permite destacar que la performance general del proyecto fue valorada positivamente, ya que todas las respuestas fueron calificadas con un valor promedio por encima de 3 en una escala de 1 a 5 . Las respuestas que figuran con valor 1 fueron realizadas por la misma persona.

Particularmente la valoración global del proyecto fue altamente calificada con un promedio de 4,22. Con relación al cumplimiento de objetivos se destacan los cambios en los predios $(4,17)$ y su relevancia $(4,28)$, la metodología utilizada a nivel predial $(4,44)$ y su performance $(4,44)$. Con relación al funcionamiento del proyecto, que fue bien valorado en forma general con un promedio de 4,44, los evaluadores destacaron que fue mejorando con el tiempo a partir de una mayor presencia e interacción con la realidad local. En este grupo de preguntas se destacó especialmente el trabajo a nivel de los predios $(4,44)$, el sentimiento positivo por haber participado en el proyecto $(4,39)$, así como también la permeabilidad del proyecto a las sugerencias de mejora durante el proceso $(4,17)$ y el cumplimiento de las expectativas de los participantes (4.06). Los aspectos calificados con menor valor tuvieron relación con el conocimiento que en ese momento los productores, técnicos e instituciones locales tenían sobre los resultados del proyecto $(3,61)$ y con la posibilidad de que los resultados generados puedan impactar en la región a futuro $(3,44)$. 
Cuadro 32. Resultados de la evaluación participativa final del proyecto. Se presenta el número de respuestas que evalúa en cada nivel (Excelente a Muy malo) y el valor promedio ponderado obtenido para cada aspecto evaluado.

\begin{tabular}{|c|c|c|c|c|c|c|c|}
\hline & & $\begin{array}{l}\text { Excelente } I \\
\text { En alto grado }\end{array}$ & $\begin{array}{l}\text { Muy Bien / } \\
\text { Muy bueno }\end{array}$ & $\begin{array}{l}\text { Bien } / \\
\text { Bueno }\end{array}$ & $\begin{array}{l}\text { Malo / } \\
\text { Bajo }\end{array}$ & $\begin{array}{l}\text { Muy malo } \\
\text { /Muy bajo }\end{array}$ & \\
\hline & Aspecto evaluado / Valoración & 5 & 4 & 3 & 2 & 1 & $\begin{array}{l}\text { Promedio } \\
\text { Ponderado }\end{array}$ \\
\hline GLOBAL & Valoración global del proyecto & 6 & 11 & 0 & 1 & 0 & 4,22 \\
\hline \multirow{6}{*}{$\begin{array}{l}\text { CUMPLIMIENTO } \\
\text { DE OBJETIVOS }\end{array}$} & $\begin{array}{l}\text { Cantidad de cambios en los } \\
\text { predios que mejoraron la } \\
\text { sustentabilidad }\end{array}$ & 8 & 8 & 1 & 0 & 0 & 4,17 \\
\hline & $\begin{array}{l}\text { Relevancia de los cambios a nivel } \\
\text { predial }\end{array}$ & 9 & 8 & 0 & 0 & 0 & 4,28 \\
\hline & $\begin{array}{l}\text { Metodología para trabajar con } \\
\text { productores familiares }\end{array}$ & 10 & 7 & 0 & 1 & 0 & 4,44 \\
\hline & $\begin{array}{l}\text { Metodología para fomentar el } \\
\text { trabajo en red y contribuir al } \\
\text { desarrollo }\end{array}$ & 3 & 10 & 3 & 1 & 0 & 3,67 \\
\hline & $\begin{array}{l}\text { Los productores, técnicos e } \\
\text { instituciones locales conocen los } \\
\text { resultados del proyecto }\end{array}$ & 3 & 8 & 6 & 0 & 0 & 3,61 \\
\hline & $\begin{array}{l}\text { Los productores, técnicos e } \\
\text { instituciones conocen información } \\
\text { tecnológica a ser promovida } \\
\text { a través de políticas públicas } \\
\text { dirigidas a la producción familiar }\end{array}$ & 6 & 8 & 3 & 1 & 0 & 4,06 \\
\hline \multirow{5}{*}{$\begin{array}{l}\text { FUNCIONAMIENTO } \\
\text { DEL PROYECTO }\end{array}$} & $\begin{array}{l}\text { Funcionamiento del proyecto en } \\
\text { términos generales }\end{array}$ & 12 & 4 & 1 & 0 & 1 & 4,44 \\
\hline & $\begin{array}{l}\text { Trabajo adecuado a nivel de los } \\
\text { predios }\end{array}$ & 11 & 5 & 1 & 1 & 0 & 4,44 \\
\hline & $\begin{array}{l}\text { Acciones de divulgación } \\
\text { adecuadas diseñadas previstas } \\
\text { en el plan de comunicación }\end{array}$ & 4 & 10 & 3 & 1 & 0 & 3,94 \\
\hline & $\begin{array}{l}\text { Coordinación institucional } \\
\text { adecuada de las actividades } \\
\text { desarrolladas a partir del proyecto }\end{array}$ & 5 & 11 & 2 & 0 & 0 & 4,17 \\
\hline & $\begin{array}{l}\text { Permeabilidad del proyecto a } \\
\text { incorporar sugerencias de mejora } \\
\text { durante la implementación }\end{array}$ & 8 & 7 & 2 & 0 & 1 & 4,17 \\
\hline \multirow{4}{*}{ OTROS TEMAS } & $\begin{array}{l}\text { Cumplimiento de expectativas } \\
\text { que tenía cada participante del } \\
\text { proyecto }\end{array}$ & 8 & 7 & 0 & 2 & 1 & 4,06 \\
\hline & $\begin{array}{l}\text { Se mejoraron los conocimientos } \\
\text { sobre estrategias de mejora para } \\
\text { la ganadería familiar }\end{array}$ & 8 & 6 & 2 & 0 & 1 & 3,94 \\
\hline & $\begin{array}{l}\text { Se tienen "nuevas formas de } \\
\text { hacer las cosas" en relación a la } \\
\text { ganadería familiar }\end{array}$ & 9 & 4 & 2 & 0 & 0 & 3,72 \\
\hline & $\begin{array}{l}\text { Sentimiento sobre la participación } \\
\text { en el proceso }\end{array}$ & 13 & 3 & 0 & 1 & 0 & 4,39 \\
\hline PARA EL FUTURO & $\begin{array}{l}\text { Los resultados generados en el } \\
\text { proyecto pueden impactar en la } \\
\text { región }\end{array}$ & 3 & 10 & 1 & 2 & 0 & 3,44 \\
\hline
\end{tabular}


Con relación a la posibilidad de que los resultados generados puedan impactar en la región a futuro, la evaluación incluía preguntas abiertas que buscaban rescatar elementos para trabajar luego de finalizado el proyecto. En este sentido y con relación a aspectos que facilitarían el impacto en la región en base a los resultados generados en el proyecto se presentan los aspectos mencionados más relevantes:

- La convicción de los productores participantes de los buenos resultados.

- El compromiso de las instituciones locales por continuar.

- La posibilidad de acceder a nuevos proyectos/herramientas para darle continuidad.

- Mayor difusión en medios locales. Mayor vinculación con generadores de políticas para la producción familiar.

- Toma de conciencia de los productores que estos proyectos ayudan a una mejor producción.

- No discontinuar con el proyecto y acercar la información a más productores explicando paso a paso lo ocurrido en el proyecto (con frecuencia y regularidad). Seguir con otros predios.

- En la medida en que los productores participen en las distintas actividades desarrolladas por la institución.

- Difusión de los resultados para técnicos y para productores por separado desde el inicio.

Con relación a los aspectos que limitan el impacto en la región en base a los resultados generados en el proyecto se presentan los aspectos más relevantes mencionados:

- Bajo involucramiento de los productores en general a participar activamente de los proyectos.

- Que los productores cambien su manera de pensar y estén dispuestos a escuchar.

- La voluntad de los técnicos/productores por seguir el proceso.

- El compromiso de las instituciones por continuar divulgando e implementando estas herramientas.
- Los plazos cortos de los proyectos que apoyan estas medidas (GFCC, etc.).

- Inserción a la Red considerando la complejidad institucional.

- Poca participación de los productores en las jornadas. Pocos técnicos capacitados para tomar decisiones a nivel predial (fuera del proyecto).

- Poca participación de instituciones. A nivel de la región no ha trascendido.

- Idiosincrasia local para la participación. ¿Voluntad de iniciar procesos de cambio?

Algunos de los principales comentarios realizados en el espacio abierto posterior a cada pregunta se presentan en frases textuales tomadas de las respuestas a la evaluación y sirven para complementar los resultados del Cuadro 32.

Opiniones sobre el proyecto en general:

- "El proyecto ha sido una experiencia positiva en función que ha mejorado su impacto en el tiempo. Es muy valiosa la metodología de co-innovación para abordar el cambio técnico en sistemas ganaderos familiares".

- "Surgen insumos muy valiosos a nivel predial, a nivel de coordinación institucional que deben ser tenidos en cuenta en la agenda nacional".

- "Creo que fue bueno a nivel de impacto en los predios pero no en llegar a motivar cambios en la zona de influencia".

Comentarios sobre los principales cambios en los predios:

- "Tomar conciencia de donde se estaba, desde donde se partía y luego tomar las decisiones hacia la meta a obtener. Llevar registros".

- "Ajuste de carga, asignación de potreros por altura, diagnóstico de gestación y uso de registros".

- "Los cambios están sujetos a la forma en que se encuentra el predio al comienzo del proyecto". 
Comentarios sobre la metodología de trabajo en predios:

- "Se entiende que la metodología de coinnovación parece adecuada para el perfil de productor familiar (diagnóstico-rediseño-implementación)".

- "El vínculo técnico-productor fue muy bueno".

- "Hubiera pretendido más participación de los grupos en las decisiones prediales".

- "Quiero destacar que siempre nos consultaban antes de tomar alguna medida para implementar en el predio. ;Que nunca nos obligaron a hacer cosas que nos impusieran! La decisión fue personal".

Comentarios sobre la metodología de trabajo en red:

- "Se fue mejorando con el tiempo. Al principio fue más difícil, pero con la presencia y el tiempo se fue adecuando en función de la realidad local".

- "Me parece que esto habría que mejorarlo, justamente para llegar a más gente".

- "Foco en el predio, apoyo al grupo, énfasis en la Fomento y en la RED".

Comentarios sobre el plan de comunicación elaborado por la Red de Actores Regionales:

- "El plan de comunicación es un punto que pudo haber sido mejor y tuvo que ver con las dificultades iniciales de coordinación y con las debilidades de las instituciones involucradas"

Sobre el grado en que el proyecto fue permeable a las sugerencias de mejora recibidas, la reflexión fue la siguiente:

- "Se reconoce la receptividad ante los planteos que fueron hechos en el proceso y que en su mayor parte fueron aceptados e implementados".

Considerando que uno de los objetivos específicos del proyecto era generar información tecnológica de alto impacto a ser promovida a través de políticas públicas dirigidas a la producción familiar, la evaluación final recabó en una pregunta abierta sugerencias de los evaluadores hacia los decisores políticos para definir políticas públicas orientadas a la producción familiar. En este sentido se presentan a continuación, en frases textuales, las principales sugerencias relevadas:

- "Fortalecimiento de las organizaciones de productores".

- "Necesidad de profundizar en la articulación institucional. No sumar más ámbitos. Trabajar en la red social".

- "Proyectos de intervención predial (metodología de co-innovación) deberían ser integrales y de largo plazo (5 años)".

- "Crear equipos técnicos extensionistas comprometidos en llevar adelante los cambios en la ganadería familiar. Dejar los escritorios (técnicos públicos) y llegar a los predios".

- "Mayor énfasis en trabajar con más pasto, demasiado riesgo productivo y ambiental cuando esto no se realiza".

- "El proyecto arroja suficientes resultados a nivel predial y regional como para tomarse como insumos en políticas en la temática. No es dar dinero por dar dinero. Este tipo de proyecto enseñó a trabajar a los productores sin tener que dar los subsidios, sino en base a un buen relevamiento del predio. Hay que dar asistencia técnica permanente (no dinero), asistencia técnica para grupos y no necesariamente subsidiada".

\subsubsection{Emergentes a partir del proyecto}

Durante la implementación del proyecto los resultados fueron compartidos en días de campo y otras actividades específicas organizadas en las que participaron directamente alrededor de 1000 personas. Sin embargo, y como resultado del proceso de aprendizaje promovido, el impacto más importante fue generar una demanda de diferentes actores para trabajar con la metodología de co-innovación. En este sentido se destaca: 
- La Comisión Nacional de Fomento Rural (CNFR) presentó un proyecto a ser financiado por el Fondo de Promoción de Tecnología Agropecuaria (FPTA) de INIA basado en la metodología implementada en el proyecto, que -si era aprobado- le hubiera permitido obtener fondos para trabajar con productores ganaderos familiares de otra región del país utilizando el enfoque de co-innovación.

- El Fondo de Promoción de Tecnología Agropecuaria (FPTA) de INIA financió en su último llamado (ejecución 2017-2020) dos proyectos de transferencia de tecnología que aplican el enfoque de co-innovación.

- Por su parte el equipo técnico de este proyecto ha tenido intercambios y realizado aportes sobre aspectos metodológicos a otros proyectos de investigación de INIA y con otros espacios institucionales como PROCISUR e IICA.

- El FONTAGRO ha financiado el proyecto "Plataforma de innovación para la Sustentabilidad de Sistemas Ganaderos Familiares en Uruguay y Argentina" a ser ejecutado entre 2017 y 2020 , el cual toma como base metodológica el enfoque de co-innovación y los resultados de este proyecto. El proyecto incluye implementar el enfoque de co-innovación en predios ganaderos familiares de ambos países, para lo cual se seleccionaron en Uruguay 30 predios de referencia entre los cuales se encuentran cuatro de los casos estudiados en este proyecto. La idea al incluirlos fue darle continuidad al proceso de co-innovación y poder tener registros del uso del enfoque luego de su aplicación a más largo plazo.

- En diferentes ámbitos del MGAP se han tomado resultados del proyecto tanto del enfoque de co-innovación como de la propuesta técnica evaluada, que han sido considerados en la formulación de futuras políticas públicas. En particular se mencionan:

(i) El proyecto "Ganaderos Familiares y Cambio Climático" en acuerdo con Facultad de Agronomía lleva adelante una intervención en ganadería familiar que pretende extender la forma de trabajo que se implementó en este proyecto a 30 productores ganaderos familiares de basalto y la Región Este del país.

(ii) El proyecto "Ganadería clima-inteligente y restauración en pastizales" cuya elaboración está siendo financiada con donación del Fondo Mundial del Medio Ambiente (GEF) y que cuenta la colaboración de organizaciones de productores (FUCREA y CNFR) y de técnicos de INIA y FAGRO toma al proyecto como base para su propuesta .

(iii) El documento de Propuesta para el Programa Nacional de Transferencia de Tecnología Ganadera, elaborado por un grupo de trabajo en el que participaron técnicos de cinco instituciones: MGAP - INAC - INIA - IPA - SUL y entregado al Ministro. 

El objetivo del proyecto "Co-innovando para el desarrollo sostenible de sistemas de producción familiar de Rocha-Uruguay" fue contribuir a la mejora de la sustentabilidad de sistemas ganaderos familiares. Para ello implementó el enfoque de co-innovación desde un instituto de investigación, donde trabajaron conjuntamente investigadores, productores y actores regionales relevantes para la ganadería familiar.

\section{1 ¿Es posible innovar en sistemas de producción familiar?}

Confirmamos la principal hipótesis de trabajo del proyecto en sistemas ganaderos familiares: "es posible mejorar los resultados productivos y económicos manteniendo o mejorando el estado de los recursos naturales, desarrollando un proceso participativo hacia el re-diseño de los sistemas de producción, sin incorporar capital externo y promoviendo procesos de aprendizaje entre productores, técnicos e instituciones". En todos los casos se transitó un proceso de innovación efectivo basado en la intensificación ecológica como paradigma del cambio técnico, que permitió generar información relevante para comprender y cuantificar los cambios ocurridos en sistemas de producción reales. Dichos cambios consistieron principalmente en implementar tecnologías de procesos, a partir de los recursos disponibles en las unidades de producción, diseñando soluciones adaptadas y aceptables para cada situación particular a través de un proceso de aprendizaje de los productores y demás actores involucrados en el proyecto. En los siete casos estudiados se obtuvieron mejoras en la mayoría de los atributos de sustentabilidad evaluados a través de los indicadores definidos a partir del diagnóstico en base al marco MESMIS (ver Capítulo. 4.1., Cuadro 14, Figuras 32 a 38).
En el área productivo-económica, el principal impacto fue el aumento de la productividad de carne por hectárea manteniendo los costos controlados, lo que permitió duplicar el ingreso neto por hectárea. El aumento en productividad de carne se debe por un lado al aumento de los kilos de ternero destetado por vaca entorada (Figura 26), los cuales se explican por un incremento en el porcentaje de preñez y en los kilos de terneros al destete (Figuras 24 y 27 ); y por otro al mayor peso de los animales de recría y de refugo (Figura 22). Si comparamos la productividad de carne y el ingreso neto ganadero de los siete casos estudiados con los resultados obtenidos en empresas ganaderas criadoras monitoreadas por el Instituto Plan Agropecuario (IPA) con la herramienta de registro Carpeta Verde (IPA, 2017), para los tres años previos al inicio del proyecto, no se observaron diferencias en producción de carne equivalente por hectárea ni en ingreso neto por unidad de superficie. Sin embargo, durante los tres años de implementación del proyecto, la producción de carne equivalente promedio de los siete predios participantes del proyecto fue $22 \%$ superior y el ingreso neto fue el doble respecto de las empresas criadoras monitoreadas por IPA (Figuras 28 y 30). Dado que los predios del proyecto y los predios monitoreados por IPA estuvieron sometidos a las mismas condiciones de precios y clima, estas diferencias se podrían explicar principalmente por la propuesta técnica enmarcada en la estrategia de intensificación ecológica (Tittonel, 2014) y por la propuesta metodológica de intervención en los predios a través del proceso de co-innovación implementado (Albicette et al., 2017; 2016b).

El ajuste de la carga animal, como principal medida de manejo en el sistema para controlar el balance energético en los animales y la producción de forraje (Bransby et al., 2000), sumado al ajuste de la relación ovino/vacuno, permitieron aumentar la disponibilidad y 
la oferta de forraje. La disponibilidad aumentó de 7,7 cm de altura en campo natural en el primer otoño a $9,9 \mathrm{~cm}$ en los dos otoños siguientes (Figura 19) mientras que la oferta de forraje pasó de 3,5 kg MS/kg PV previo al inicio a 5,6 kg MS/kg PV durante la ejecución del proyecto.

El control de la intensidad de pastoreo mediante manejo por oferta de forraje considerando categoría animal y disponibilidad de forraje en los potreros contribuyó a incrementar la disponibilidad del campo natural (sección 4.1.4.2.2 y Figura 19). Los cambios implementados permitieron aumentar la disponibilidad de forraje en el primer año y amortiguar los impactos negativos debidos al déficit hídrico experimentado en el último año del proyecto, contribuyendo así a mejorar la resiliencia de los sistemas ganadero pastoriles (Figuras 18 y 19) (Nabinger et al., 2011; Soca et al., 2007). Lo anterior, sumado a la aplicación de tecnologías de bajo costo para la cría (Cuadro 25) (Quintans et al., 2013; Soca et al., 2013; Soca y Orcasberro 1992) contribuyó a mejorar la productividad global sin modificar los costos de producción (Figuras 28 y 29).

La mejora en la recría también fue clave en incrementar la eficiencia productiva global de los sistemas. En los siete casos se alcanzó la meta de preñar las vaquillonas a los dos años. Esto se logró aumentando los pesos de los animales en recría, tanto en las terneras al año como en las de dos años (Figura 22), lo cual fue posible por una priorización en la alimentación de las terneras durante su primer invierno, asignando forraje de campo natural y suplementación al $1 \%$ del peso vivo o forraje de mejoramientos de campo natural mayor a $5 \mathrm{~kg} \mathrm{MS} / 100 \mathrm{~kg}$ PV (Quintans et al., $2008 \mathrm{~b}$ ), realizando un uso estratégico de las tecnologías de insumos.

Durante el primer año de implementación de las propuestas se vieron resultados positivos y relevantes en la productividad de carne. La rápida respuesta de los sistemas se explica en parte por el aumento de los pesos de los animales al destete (Figura 27) y al refugo en el primer año, que se complementó con un aumento del porcentaje de procreo al segundo año (Figura 25), debido a que se "trabajó con más pasto" (mayor disponibilidad de forraje) y se lo gestionó de manera adecuada. No obstante, los resultados de producción de carne equivalente por hectárea obtenidos en este trabajo todavía mantienen una brecha relevante con el valor de referencia de producción de carne equivalente de $170 \mathrm{~kg} / \mathrm{ha}$ definido en base a Carvalho et al. (2008), lo que marca la relevancia de continuar trabajando en esta línea.

En el área ambiental los resultados demuestran que es posible "ganar-ganar" en productividad y calidad ambiental dentro de los niveles de producción de carne equivalente que se lograron en los predios del proyecto $(180 \mathrm{~kg} / \mathrm{ha}$, Figura 28$)$, contrariamente al planteo de que el aumento de la productividad conlleva un detrimento de la calidad ambiental (Ran et al., 2013; Herrero et al., 2009). Esto fue posible mediante el aumento de la biomasa aérea promedio manejando el sistema con una visión integral en el espacio y en tiempo, de acuerdo a los principios de la intensificación ecológica.

El Índice de integridad ecosistémica (IIE) como indicador global mantuvo o incrementó levemente sus valores (Cuadro 17) Los resultados respecto al IIE responden principalmente a la recuperación estructural de la vegetación, tanto horizontal como vertical, debido a la reducción de la intensidad de pastoreo en los sistemas de producción, (Dias et al., 2017; Fuhlendorf et al., 2006). En términos numéricos el cambio estructural se refleja en el $5 \%$ de aumento promedio de la doble estructura herbácea como se muestra en el Cuadro 16. Este aspecto estructural suele ser una de las preocupaciones de los productores que consideran que pierden área de pastoreo, sin embargo, esto es una condición normal de la reducción de la intensidad de pastoreo y un aporte importante a la diversificación de hábitats.

Entre otros efectos, los cambios en la estructura de la vegetación permiten que la fauna 
asociada al agro-ecosistema estudiado, en particular las aves, encuentre ambientes adecuados a sus necesidades (Garden et al., 2007; Di Giulio et al., 2001). En nuestro estudio la riqueza y diversidad de aves se mantuvo y en algunos casos se constató un incremento (Cuadro 19) con una buena representación de los gremios alimenticios (Figura 12), lo cual implica especies ocupando diversos niveles tróficos.

Otra consecuencia de la reducción de la intensidad de pastoreo podría ser la reducción el número de especies herbáceas del estrato bajo (Cuadro 15) debido al cambio en las condiciones de competencia lo que ya ha sido reportado (Hickman et al., 2004), no obstante, ello puede tener causas en la mayor pluviosidad promedio, factor que interactúa claramente con la intensidad de pastoreo (Milchunas et al., 1988).

Ante un escenario de elevar aún más la biomasa aérea promedio de los sistemas de producción mediante la disminución de la intensidad de pastoreo, es posible esperar incrementos en la productividad primaria neta y en las tasas de secuestro de carbono (Parton et al.,1987), mayor captura de nutrientes que no irán a cursos de agua (Urgeghe, 2010), mejora en la diversidad estructural y renovación de las comunidades leñosas naturales (Hester et al., 1996; Lunt et al., 2007) en estos agro-ecosistemas. Aquí radica el próximo desafío de la investigación ambiental en sistemas ganaderos sobre campo natural.

En el área social se destacan cambios muy significativos en los conocimientos, habilidades y actitudes de los productores con relación a la gestión de sus predios. A partir del diagnóstico y de la elaboración conjunta de una propuesta de re-diseño de los sistemas de producción, se incorporó la planificación de metas y actividades a mediano y largo plazo (Cuadro 22). La implementación del re-diseño implicó la incorporación de tecnologías, destacándose el uso conjunto del $97 \%$ de las tecnologías propuestas al tercer año del proyecto (Cuadro 25), superior al $81 \%$ obtenido en sistemas hortícolas-gana- deros familiares en Uruguay, empleando una metodología similar (Dogliotti et al., 2014). El uso integral de las tecnologías propuestas fue esencial para lograr la mejora en los resultados económico-productivos y ambientales de cada sistema de producción.

Los cambios en la organización del trabajo emergieron a partir de la planificación y el uso de tecnologías. Se redujo un $25 \%$ las horas de trabajo dedicadas al manejo de animales y pasturas y se aumentó un $97 \%$ la productividad de la mano de obra empleada en el predio (Cuadro 23). Estos cambios son relevantes para los productores ganaderos familiares, fundamentalmente si se considera el envejecimiento de la población rural, la falta de involucramiento de las nuevas generaciones, el trabajo extra-predial y la dificultad para contratar mano de obra asalariada (Capra et al., 2009; Dieguez et al., 2009). Asimismo, dado que la organización del trabajo afecta la toma de decisiones en relación con el cambio técnico en los predios (Molina y Álvarez, 2009), este resultado refuerza lo adecuado de las propuestas de re-diseño a las necesidades de los productores, que permitieron producir más, trabajando menos y cuidando el ambiente.

Los resultados obtenidos en los sistemas de producción familiar estudiados se deben a cambios en conocimientos, actitudes, habilidades y aspiraciones - KASA, por su sigla en inglés - (Rockwell y Bennett, 2004) de los productores y sus familias (Cuadro 24). Vale resaltar que las innovaciones son tanto sociales como tecnológicas y que requieren de aprendizaje social (Bock, 2012), por lo cual los cambios en los KASA son un pre-requisito para la innovación (Drechsel et al., 2001).

El desafío para la investigación en el área social radica en profundizar en la evaluación de los aprendizajes y la capacidad de los productores para sostener los cambios, así como profundizar en aspectos clave del vínculo productor-técico e identificar el tipo de apoyo técnico necesario para continuar el proceso de mejora. 


\section{2 ¿Cómo innovamos en sistemas de producción familiar?}

La co-innovación combinada con la intensificación ecológica como estrategia de intervención a partir del trabajo conjunto entre productores, investigadores y actores regionales, fue efectiva para el desarrollo de sistemas de producción ganaderos familiares más sostenibles (Akpo et al., 2015; Dogliotti et al., 2012). Este enfoque permitió el desarrollo de ciclos continuos de planificación, monitoreo y evaluación para el aprendizaje, donde diversos actores trabajaron juntos para abordar temas vinculados a la sostenibilidad de sistemas ganaderos familiares y el desarrollo rural, estableciendo una plataforma para la innovación (Leeuwis et al., 2014).

El enfoque de co-innovación aplicado a nivel predial facilitó los procesos de innovación en los cuales las soluciones a los problemas tecnológicos fueron co-generadas por diversos actores en un proceso interactivo de aprendizaje, como señalan Botha et al. (2017b) y Coutts et al. (2017). La clave para lograr esto fue la metodología de trabajo que se utilizó, principalmente en base a visitas mensuales del técnico de campo a los predios, siguiendo cuatro etapas: caracterización - diagnóstico - re-diseño - implementación, monitoreo y evaluación (Cuadro 2), y las herramientas principales fueron la definición de una visión de futuro - sustentabilidad para cada familia y el uso del MESMIS complementado con construcción de árboles de problemas. Esto permitió implementar e integrar los tres pilares del enfoque de co-innovación: la visión de sistemas adaptativos complejos, el monitoreo y evaluación dinámicos y el aprendizaje social (Figura 1).

El desafío de mejorar la sustentabilidad no puede ser abordado con ajustes o modificaciones en algunos componentes aislados del sistema (Dogliotti et al., 2014; IAASTD, 2009; Chia et al., 2003), por lo cual se incorporó la visión de sistemas adaptativos complejos (Rossing et al., 2010). Esto incluye los objetivos y metas familiares, lo que se denominó "visión de futuro - sustentabilidad", y una concepción amplia de la sustentabilidad a partir del marco MESMIS (Masera et al., 2000). La visión de futurosustentabilidad de cada una de las familias se constituyó en el gran objetivo del proceso a nivel predial, incorporando el componente humano como parte esencial del sistema (Sorensen y Kristensen, 1992), donde no sólo se realizan actividades de producción, sino que también se dan procesos de vida familiar y de relación con actores externos. Complementariamente, la visión desde los atributos básicos de la sustentabilidad y de los aspectos económicos, sociales, tecnológicos y ambientales que plantea el MESMIS (Masera et al., 2000), permitió ampliar la mirada y realizar un análisis mucho más abarcativo y sistémico de los sistemas de producción. Además, la construcción de árboles de problemas permitió establecer el orden jerárquico entre los diversos puntos críticos identificados en el diagnóstico y priorizar los aspectos más relevantes para trabajar en cada predio y definir propuestas adecuadas a cada caso (Fresco y Westphal, 1988; Dogliotti et al., 2014).

Las propuestas de re-diseño se generaron combinando los conocimientos de los productores y del equipo de investigación, especialmente del técnico de campo, sobre los sistemas de producción y aprendiendo juntos, priorizando las tecnologías de proceso sobre las de insumos. La participación activa de los productores en el proceso de identificación de los problemas y alternativas de mejora facilita la implementación de las mismas (Akpo et al., 2015; Dogliotti et al., 2012; Leeuwis et al., 2002). La innovación ya no se concibe como proviniendo de fuentes externas, sino que ésta se desarrolla y diseña en su contexto de aplicación y con la participación activa de quienes manejan los sistemas y toman las decisiones (Leeuwis y Van der Ban, 2004; Gibbons et al., 1997).

El monitoreo y evaluación dinámico del proceso de innovación en los predios fue implementado mediante el marco MESMIS (Masera et al., 2000). En el proyecto se 
emplearon un conjunto de indicadores económico-productivos, ambientales y sociales (Cuadro 14) para evaluar la sustentabilidad de los sistemas ganaderos familiares acordes al contexto de los mismos. El monitoreo de indicadores de sustentabilidad reafirmó la importancia de los indicadores económicoproductivos (Astier et al., 2011) y requirió del desarrollo de nuevos indicadores para el área ambiental (Blumetto et al., 2016) y social (Albicette et al., 2016a). Esto fue posible debido al trabajo del equipo técnico interdisciplinario y su vínculo con los productores, logrando así una integración y entendimiento de los aspectos involucrados en la sostenibilidad de los siete casos estudiados.

El aprendizaje social se promovió mediante la metodología de trabajo (Cuadro 2, sección 3.1). Se resalta la medición de indicadores, su análisis en forma conjunta y el uso de dicha información en la toma de decisiones durante la ejecución del proyecto (Rossing et al., 2010; Douthwaite et al., 2003). A lo largo del proceso, el vínculo entre el productor/ familia y el equipo de investigación, más precisamente el vínculo entre el productor y el técnico de campo, emergió como la piedra angular y se constituyó en el vehículo para generar cambios hacia situaciones de mayor sostenibilidad en los predios (Albicette et al., 2016a). El mismo fue esencial para generar los cambios en KASA (Rockwell y Bennett, 2004) en los productores y sus familias e innovar (Klerkx et al., 2012). Por ejemplo, los nuevos conocimientos y habilidades adquiridas los habilitó a tomar nuevas decisiones e implementar las propuestas de re-diseño tendientes a mejorar la productividad cuidando el ambiente (Albicette et al., 2016a). El vínculo productor-técnico de campo fue muy valorado por los productores y diferenciado de sus experiencias previas de trabajo con técnicos asesores (Albicette et al., 2016a). Se destacó el acompañamiento frecuente y regular que dio lugar a un proceso iterativo, negociado y en paridad, con una visión sistémica e integradora, trabajando en base a consensos y discutiendo en base a información cuantitativa del predio (Cuadro 26), lo que coincide con los elementos clave de la relación productor-técnico que plantea Arango (2006). La generación de confianza fue esencial para establecer dicho vínculo (Rossi, 2011), la cual se construyó en base a las visitas mensuales del técnico de campo al predio, la metodología de trabajo (Cuadro 2 y capítulo 3.1) y la solidez del asesoramiento del técnico de campo con soporte del equipo de investigación. En este proceso fue fundamental iniciar el trabajo con una o dos recomendaciones tecnológicas tácticas, que quizás no fueran las más significativas, pero que permitieron generar confianza en el técnico de campo, para continuar con la planificación estratégica a más largo plazo.

El enfoque de co-innovación aplicado a nivel regional permitió que la metodología y resultados del proyecto no solo fuese conocida, sino que inspiró a miembros del gobierno y actores políticos nacionales y locales, instituciones de investigación, organizaciones de productores y técnicos extensionistas en el diseño de líneas de trabajo vinculadas a la promoción de la sostenibilidad de los sistemas ganaderos familiares (ver sección 4.2.6.). Esto fue posible debido a la fuerte base territorial del proyecto, la amplia participación de actores locales y a la implementación de la metodología PIPA para la planificación, monitoreo y evaluación de actividades.

La aplicación del método PIPA promovió la co-innovación a nivel regional fomentando el aprendizaje social a partir de la creación de un espacio común para el trabajo en red, la planificación, monitoreo y evaluación participativa (Albicette et al., 2016c). Los actores locales, los siete productores y sus familias con el equipo de investigación generaron una red interinstitucional de actores regionales (RAR), que fue capaz de diseñar una visión común de lo que se esperaba del proyecto, así como planificar y actuar para generar esos cambios (Albicette et al., 2016c, Alvarez et al., 2010). El plan de comunicación fue el medio que permitió compartir la experiencia (Cuadros 29 y 30 ).

La flexibilidad es un aspecto fundamental en los procesos de co-innovación para permitir 
la convergencia de los actores en determinados temas, así como para generar un espacio de aprendizaje (Botha et al., 2017b). La estrategia del proyecto y las actividades definidas se modificaron y ajustaron a lo largo de los tres años de su implementación en base a las reflexiones mantenidas en los seis talleres (Sección 3.2.). De esta manera, a medida que el proceso avanzaba y se iban produciendo cambios, se informaba sobre avances y resultados del proyecto y se incorporaban las lecciones aprendidas en tiempo real (Dogliotti et al., 2012, Douthwaite et al., 2003). La actuación de un facilitador y de un "reflexive monitor" (van Mierlo et al., 2010), es clave para diseñar un sistema de monitoreo y evaluación dinámicos (Akpo et al., 2015). Ello permite implementar un método de trabajo que incluya espacios de reflexión y facilite la identificación de metas para transitar las vías de impacto necesarias para alcanzar la visión acordada por la RAR (Cuadro 28). La RAR se estableció en base a un fuerte involucramiento de los actores desde el inicio del proceso, generando fuertes vínculos de confianza (Akpo et al., 2015). Para consolidar una red de actores locales, además, es necesario: (i) definir los objetivos claros y una agenda de trabajo, (ii) permitir la negociación y facilitación, (iii) sistematizar y mantener la continuidad y coherencia entre los espacios de intercambio y reflexión, de acuerdo a la cultura local (Klerkx et al., 2012).

Una red consolidada en la región se constituye en una plataforma para la innovación, donde las lecciones aprendidas pueden ser escaladas mientras que se construyen nuevas maneras de trabajar y de aprender juntos (Leeuwis et al, 2014; Crawford et al., 2007). Considerando que la innovación no es lineal, sino que es un proceso de aprendizaje que resulta de redes colaborativas (Klerkx et al., 2012; Knickel et al., 2009), el desarrollo de una plataforma de innovación utilizando la metodología de este proyecto podría ser efectiva para promover la sostenibilidad de la ganadería familiar del país. 
Los sistemas de generación y transferencia de tecnología lineales están siendo reemplazados por los Sistemas de Innovación Agrícola - AIS, por su sigla en inglés - (Klerkx et al., 2012; Moschitz et al., 2015). La coinnovación como una de las opciones de AIS (Coutts et al., 2016) se está consolidando como un enfoque para resolver problemas en sistemas complejos, tanto en sistemas familiares como en cadenas agroindustriales y de manejo de cuencas (Botha et al., 2017a).

En este trabajo la contribución al re-diseño de sistemas de producción ganaderos familiares en Rocha-Uruguay se logró aplicando un enfoque de co-innovación. El proceso implementado durante tres años conjuntamente por productores, investigadores y miembros de una red interinstitucional consistió en: (i) trabajar con una visión sistémica dirigida a resolver problemas reales de los productores; (ii) combinar el trabajo a nivel predial y regional; (iii) considerar un período de tiempo adecuado para permitir cambios y su evaluación; (iv) promover el monitoreo y evaluación participativo; y $(v)$ tener flexibilidad para incorporar las lecciones aprendidas y hacer ajustes durante la implementación.

Los resultados presentados demuestran que el enfoque de co-innovación fue eficaz para mejorar la sostenibilidad de los predios familiares ganaderos y hacer un aporte al desarrollo rural. Los primeros pasos en el proceso de cambio implicaron principalmente el uso de tecnologías de proceso, que incluían el manejo espacio-temporal del pastoreo y la sincronización de la demanda energética animal con la producción de pasto; sin realizar inversiones ni incorporar insumos significativos. En etapas más avanzadas del proceso de cambio, se pueden incorporar tecnologías que mejoren la performance del sistema a través de la incorporación de insumos y algunas inversiones (fertilización, suplementación y aumento de área mejorada). Este proceso de aprendizaje necesita de continuidad para reafirmar los procesos de cambio iniciados y de nuevos casos para validar el enfoque con otros sistemas de producción y realidades regionales.

Este nuevo paradigma, que permite abordar la complejidad de los sistemas de la agricultura familiar, es un desafío para para el diseño de políticas públicas y para todos los actores involucrados. A nivel de productores es necesario seguir profundizando en la evaluación de los aprendizajes y la capacidad de los productores para sostener los cambios, así como en el tipo de apoyo técnico necesario para continuar el proceso de mejora. $\mathrm{Pa}$ ralelamente es necesario diseñar estrategias para involucrar a más productores que estén motivados para participar en estos procesos, de la mano del fortalecimiento de las organizaciones que los nuclean. A nivel de investigadores es necesario promover el enfoque de sistemas complejos al momento de analizar los problemas y las oportunidades de los sistemas de producción y de realizar propuestas de mejora. La construcción y fortalecimiento de equipos transdisciplinarios (productores, actores regionales, investigadores) es clave en este sentido. A nivel de técnicos extensionistas es necesario promover su capacitación para desarrollar los conocimientos y habilidades que les permita implementar esta forma de trabajo con productores y conformar equipos técnicos regionales que apoyen su actividad. A nivel de los actores regionales se requiere la incorporación y valoración en las instituciones y organizaciones de este enfoque de innovación. En términos generales se plantea el desafío de generar nuevas capacidades para diseñar, implementar y sostener estos procesos de co-innovación a nivel de técnicos de campo, técnicos para trabajar en las plataformas de innovación y facilitadores de los procesos. 
Para escalar los resultados a nivel nacional y para que la innovación sea una actividad permanente a nivel de la ganadería familiar, se requiere del desarrollo de un sistema de extensión basado en el enfoque de co-innovación. El MGAP ha dado pasos concretos y el sistema está en vías de construcción. En base a la experiencia generada en este proyecto y a la discusión y reflexión de un equipo de trabajo de INIA y Facultad de Agronomía vinculado a experiencias de co-innovación, desarrollamos a continuación algunas ideas clave para ser consideradas en el diseño del mismo.

La puesta en marcha de un sistema de extensión para productores ganaderos familiares debe ser un proceso proyectado a largo plazo e implementado en forma gradual. Esto implica comenzar a trabajar con experiencias piloto, que permitan ir capitalizando aprendizajes y aumentar paulatinamente el número de productores.

En este sentido es relevante considerar que los productores involucrados estén interesados y motivados y que compartan esta filosofía de trabajo. Asimismo, los técnicos involucrados deben estar capacitados en la aplicación de este enfoque, motivados y tener vocación de trabajo en equipo. Para la construcción de un vínculo efectivo entre productor y técnico es necesario generar confianza y asignar un tiempo técnico adecuado por productor. La implementación de la forma de trabajo en los predios por parte del técnico de campo requiere de 11 jornadas técnicas por productor por año durante el primer año y 9 jornadas por productor los siguientes dos años. Esto implica que un técnico puede trabajar como máximo con 20 productores durante el primer año y con 25 productores en los dos años siguientes. Es fundamental la estabilidad del técnico de campo a lo largo de todo el proceso de cambio. La co-financiación progresiva del apoyo técnico por parte de los productores participantes debería ser una estrategia planificada desde el inicio del proyecto, como forma de asegurar su sostenibilidad en el tiempo.

Es importante generar un marco de apoyo a la actividad de los grupos de productores y sus técnicos extensionistas, inserto en las organizaciones locales de productores y con el apoyo de las instituciones de investigación y formación de recursos humanos (INIA, Universidad de la República).

Consideramos que un sistema privado con financiación público - privada y que promueva la articulación interinstitucional sería una opción viable para considerar. 
Akpo, E., Crane, T. A., Vissoh, P. V., Tossou, R. C. 2015. Co-production of knowledge in multi-stakeholder processes: Analyzing joint experimentation as social learning. Journal of Agricultural Education and Extension 21 (4): 369-388.

Albicette, M. M., Leoni, C., Ruggia, A., Scarlato, S., Blumetto, O., Albín, A., Aguerre, V. 2017. Co-innovation in family-farming livestock systems in Rocha, Uruguay: A 3-year learning process. Outlook on Agriculture 46 (2): 92-98.

Albicette, M. M., Bortagaray, I., Scarlato, S., Aguerre, V. 2016a. Co-innovación para promover sistemas ganaderos familiares más sostenibles en Uruguay. Análisis de tres años de cambios en la dimensión social de la sostenibilidad. Revista Latinoamericana de Estudios Rurales I (2): 105-136.

Albicette, M. M., Leoni, C., Ruggia, A., Scarlato, S., Albín, A., Aguerre, V. 2016b. A co-innovation approach in family-farming livestock systems in Rocha - Uruguay: A threeyear learning process. En: EUROPEAN IFSA SYMPOSIUM, 12th., "Social and technological transformation of farming systems: Diverging and converging pathways", Symposium Handbook, Harper Adams University, UK, 12-15 July 2016.

Albicette, M. M., Leoni, C., Ruggia, A., Bortagaray, I., Scarlato, M., Scarlato, S., Blumetto, O., Albín, A., Aguerre, V. 2016c. Applying the Participatory Impact Pathway Analysis (PIPA) approach to enhance coinnovation for sustainability within livestock family farming in Uruguay. En: EUROPEAN IFSA SYMPOSIUM, 12th., "Social and technological transformation of farming systems: Diverging and converging pathways", Symposium Handbook, Harper Adams University, UK, 12-15 July 2016.
Albicette, M. M. 2010. Sistematización y evaluación del proceso de una experiencia de investigación participativa (IP). Tesis de Maestría. Universidad de la República (Uruguay). Facultad de Agronomía. 185 p.

Altesor, A., Ayala, W., Paruelo, J. 2011. Bases ecológicas y tecnológicas para el manejo de pastizales. Montevideo (UY): INIA. 2011. 234 p. (Serie FPTA-INIA; 26). Proyecto FPTA-175.

Alvarez, S., Douthwaite, B., Thiele, G., Mackay, R., Córdoba, D., Tehele, K. 2010. Participatory Impact Pathways Analysis: a practical method for project planning and evaluation. Development in Practice 20 (8): 946-958.

Ansín, O. E., Oyhamburu, E. M., Hoffmann, E. A., Vecchio, M. C., Ferragine, M. C. 1998. Distribución de raíces en pastizales naturales y pasturas cultivadas de La Pampa Deprimida Bonaerense y su relación con la biomasa forrajera. Revista de la Facultad de Agronomía, La Plata 103 (2): 141-148.

Arango, H. 2006. Una herramienta digital para la planificación predial participativa. LEISA Revista de Agroecología 22 (1): 19.

Astier, M., Speelman, E., López-Ridaura, S., Masera, O., Gonzalez-Esquivel, C. 2011. Sustainability indicators, alternative strategies and trade-offs in peasant agroecosystems: Analysing 15 case studies from Latin America. International Journal of Agricultural Sustainability 9 (3): 409-422.

AusAID. 2000. AusGuideline "The Logical Framework Approach". [Archivo PDF]. Último acceso, Febrero 2017.

http://portals.wi.wur.nl/files/docs/ppme/ausguidelines-logical\%20framework\%20approach.pdf

Axelrod, R., Cohen, M., 2000. Harnessing Complexity: Organizational Implications of a Scientific Frontier. 208 p. 
Barthram, G. T. 1986. Experimental techniques: the HFRO sward stick. Biennial Report. Hill Farming Research Organization 1984-85. pp. 29-30.

BCU (Banco Central del Uruguay). 20152009. Estadísticas y estudios/Cotizaciones/ Más monedas e información histórica. [Base de datos]. Último acceso, Noviembre 2017. http://www.bcu.gub.uy/Estadisticas-e-Indicadores/Paginas/Cotizaciones.aspx

Bermúdez, R., Ayala, W. 2005. Producción de forraje de un campo natural de la zona de lomadas del este. En: Seminario de actualización técnica en manejo de campo natural. Montevideo (UY): INIA. pp. 33-29. (Serie Técnica; 151).

Bertol, I., Gomes, K.E., Denardin, R.B.N., Machado, L.A.Z., Maraschin, G.E. 1998. Propriedades físicas do solo relacionadas a diferentes níveis de oferta de forragem numa pastagem natural. Pesquisa Agropecuária Brasileira 33 (5): 779-786.

Bervejillo, J., Tambler, A. 2014. Comportamiento del sector carne vacuna. En: Anuario 2014. Montevideo (UY): MGAP, OPYPA. pp. 39-59.

Blumetto, O., Castagna, A., Cardozo, G., Ruggia, A., Scarlato, S., Tiscornia, G., García, F. 2016. Ecosystem Integrity Index: A new tool for ecosystem services evaluation in livestock production systems. En: Proceedings of the 10th International Rangeland Congress, Saskatoon. Canadá. pp. 448-449.

Bock, B. 2012. Social innovation and sustainability; how to disentangle the buzzword and its application in the field of agriculture and rural development. Studies in Agricultural Economics 114 (2): 57-63.

Boggiano, P. 2003. Manejo Integrado de Pradera - Componente "Manejo y Conservación de la Diversidad Biológica". Proyecto Combinado GEF/IBRD "Manejo Integrado de los Recursos Naturales y de la Diversidad Biológica", Uruguay. $71 \mathrm{p}$.
Botha, N., Turner, J., Fielke, S., Klerkx, L, 2017a. Using a co-innovation approach to support innovation and learning: Cross-cutting observations from different settings and emergent issues. Outlook on Agriculture 46 (2): 87-91.

Botha, N., Coutts, J., Turner, J., White, T., Williams, T. 2017b. Evaluating for learning and accountability in system innovation: Incorporating reflexivity in a logical framework. Outlook on Agriculture 45 (2): 154-160.

Botha, N., Coutts, J., Turner, J.A., White, T., Williams, T. 2016. Evaluating for learning and accountability in system innovation: Incorporating reflexivity in a logical framework. En: EUROPEAN IFSA SYMPOSIUM, 12th., "Social and technological transformation of farming systems: Diverging and converging pathways", Symposium Handbook, Harper Adams University, UK, 12-15 July 2016.

Botha, N., Klerkx, L., Small, B., Turner, J.A. 2014. Lessons on transdisciplinary research in a co-innovation programme in the New Zealand agricultural sector. Outlook on Agriculture 43 (3): 219-223.

Bransby, D. I., Maclaurin, A. R., 't Mannetje, L., Jones, R. M. 2000. Designing animal production studies En: 't Mannetje, L., Jones, R.M. (Eds). Field and Laboratory Methods for Grassland and Animal Production Research. Wallingford, UK: CAB International. Wageningen University, Wageningen, The Netherlands. p. 327-352.

Brazeiro, A., Achkar, M., Bartesaghi, L., Ceroni, M., Aldabe, J., Carreira, S., Duarte, A., González, E., Haretche, F., Loureiro, M., Martínez, J.A., Maneyro, R., Serra. S., Zarucki, M. 2012. Distribución potencial de especies de Uruguay: vertebrados y leñosas. Informe Técnico. Convenio MGAP/PPR - Facultad de Ciencias/Vida Silvestre/Sociedad Zoológica del Uruguay. CIEDUR. 47p. 
Bremm, C., Laca, E. A., Fonseca, L., Mezzalira, J. C., Elejalde, D. A. G., Gonda, H. L., de Faccio Carvalho, P. C. 2012. Foraging behaviour of beef heifers and ewes in natural grasslands with distinct proportions of tussocks. Applied Animal Behaviour Science 141(3): 108-116.

Bucher, E.H., Huszar, P.C. 1999. Sustainable management of the Grand Chaco of South America: Ecological promise and economic constraints. Journal of Environmental Management 57: 99-108.

Butler, S. J., Boccaccio, L., Gregory, R. D., Vorisek, P. y Norris, K. 2010. Quantifying the impact of land-use change to European farmland bird populations. Agriculture. Ecosystems \& Environment 137(3-4): 348-357.

Capra, G., Albin, A., Ruggia, A., García, F., Aguerre, V., Vilaró, F., Gilsanz, J.C., Arboleya, J., Rachetti, M. 2009. Tecnología para la producción familiar del departamento de Rocha: avances del acuerdo de trabajo INIA-CNFR. Revista INIA Uruguay N 18. pp. 40-44.

Carámbula, M. 2001. Manejo de Lotus Maku para producción de forraje. En: Risso, D., Albicette, M. (Eds.). Lotus Maku: manejo, utilización y producción de semillas. Montevideo (UY): INIA. pp. 11-21 (Serie Técnica; 119).

Carriquiry, M., Espasandin, A.C., Astessiano, A.L., Casal, A., Claramunt, M., Do Carmo, M., Genro, C., Gutierrez, V., Laporta, J., López-Mazz, C., Meikle, A., Olmos, F., Pérez Clariget, R., Scarlato, S., Trujillo, A.I., Viñoles, C., Soca, P. 2012. La cría vacuna sobre campo nativo: Un enfoque de investigación jerárquico para mejorar su productividad y sostenibilidad. Veterinaria 48 (1): 41- 48.

Carvalho, P. C. F., Batello, C., de Faccio Carvalho, P. C. 2009a. Access to land, livestock production and ecosystem conservation in the Brazilian Campos biome: the natural grasslands dilema. Livestock Science 120: 158-62.
Carvalho, P. C. F., Nabinger, C., Lemaire, G., Genro, T. C. M. 2009b Challenges and opportunities for livestock production in natural pastures: the case of Brazilian Pampa Biome. En: International Rangeland Congress. Diverse Rangelands for a Sustainable Society. Plenary. pp. 9-15.

Carvalho, P. C. F., Paruelo, J., Ayala, W. 2008. La intensificación productiva en los pastizales del Río de la Plata: tendencias y consecuencias ecosistémicas. En: XXII Reunión del Grupo Técnico en Forrajeras del Cono Sur. Bioma Campos. Innovando para mantener su sustentabilidad y competitividad. pp. 29-40.

Chambers, R., Pacey, A., Thrupp, L. A. 1989. Farmer First: Farmer innovation and agricultural research. London, Intermediate Technology Publications. 219 p.

Colwell, R.K. 2013. EstimateS: Statistical estimation of species richness and shared species from samples. Version 9 and earlier. User's Guide and application. Último acceso, Febrero 2017 http://purl.oclc.org/estimates

Colwell, R. K., Chao, A., Gotelli, N.J., Lin, S.-Y., Mao, C.X., Chazdon, R.L., Longino., J. T. 2012. Models and estimators linking individual-based and sample-based rarefaction, extrapolation, and comparison of assemblages. Journal of Plant Ecology 5: 3-21.

Conant, R.T., Cerri, C.E.P., Osborne, B.B., Paustian, K. 2017. Grassland management impacts on soil carbon stocks: a new synthesis. Ecological Applications 27: 662-668.

Codesido, M,, González Fischer C., Bilenca, D. 2008. Asociaciones entre diferentes patrones de uso de la tierra y ensambles de aves en agroecosistemas de la región pampeana, Argentina. Ornitologia Neotropical 19 (Suppl.): 575-585.

Coutts, J., White, T., Blackett, P., 2017. Evaluating a space for co-innovation: Practical application of nine principles for co-innovation in five innovation projects. Outlook on Agriculture 45 (2): 99-107. 
Coutts, J., White, T., Blackett, P., Rijswijk, K., Bewsell, D., Park, N., Turner, J.A., Botha, N. 2016. Evaluating a space for co-innovation: The practical application of nine principles for co-innovation in five innovation projects. En: EUROPEAN IFSA SYMPOSIUM, 12th., "Social and technological transformation of farming systems: Diverging and converging pathways", Symposium Handbook, Harper Adams University, UK, 12-15 July 2016.

Coutts, J., Botha, N., Turner, J. 2014. Evaluating a Co-innovation Policy Initiative in New Zealand. En: Proceedings of Farming Systems Facing Global Challenges. 11th European International Farming Systems Symposium. Berlin. $11 \mathrm{p}$.

Cramb, R. 2006. Replanteando el desarrollo, la difusión y adopción de tecnologías agrícolas. En: Gonsalves et al. (Eds.) Investigación y desarrollo participativo para la agricultura y el manejo sostenible de recursos naturales. Volumen 1: Comprendiendo. Investigación y desarrollo participativo. Perspectivas de los usuarios con la investigación y el desarrollo agrícola. Filipinas y Canadá. CIP e IDRC. pp.168-174.

Crawford, A., Nettle, R., Paine, M., Kabore, C. 2007. Farms and Learning Partnerships in Farming Systems Projects: A Response to the Challenges of Complexity in Agricultural Innovation. Journal of Agricultural Education and Extension 13 (3): 191-207.

Chia, E., Téstut, M., Figari, M., Rossi, V. 2003. Comprender, dialogar, coproducir: Reflexiones sobre el asesoramiento en el sector agropecuario. Agrociencia 7 (1): 77-91.

Da Trindade, J. K., Pinto, C. E., Neves, F. P., Mezzalira, J. C., Bremm, C., Genro, T. C. M., Tischler, M. R., Nabinger, C., Gonda, H. L., Carvalho, P. C. F. 2012. Forage allowance as a target of grazing management: implications on grazing time and forage searching. Rangeland Ecology \& Management 65 (4): 382-393.
Dias, R.A., Gianuca, A.T., Vizentin-Bugoni, J., Gonçalves, M.S.S., Bencke, G.A., Bastazini, V.A.G. 2017. Livestock disturbance in Brazilian grasslands influences avian species diversity via turnover. Biodiversity Conservation 26: 2473-2490.

DIEA-MGAP 2011. Censo General Agropecuario 2011: Resultados Definitivos. [Archivo PDF]. Último acceso, Febrero 2017.

http://www.mgap.gub.uy/sites/default/files/ multimedia/censo2011.pdf

Dieguez F., Saravia, A., Duarte, E. 2009. El trabajo en las explotaciones ganaderas. En: Familias y Campo. Rescatando estrategias de adaptación. Ed.: Morales, H., Dieguez, F. Instituto Plan Agropecuario. Uruguay. V. 1ra, p.: 49- 62.

Di Giulio, M., Edwards, P. J., Meister, E. 2001. Enhancing insect diversity in agricultural grasslands: the roles of management and landscape structure. Journal of Applied Ecology 38 (2): 310-319.

Do Carmo, M., Claramunt, M., Soca, P. 2016. Animal energetics in extensive grazing systems: Rationality and results of research models to improve energy efficiency of beef cow-calf grazing Campos systems. Journal of Animal Science 94 (6): 84-92.

Do Carmo, M., Cardozo, G., Soca, P. 2015. Measurement of campos rangelands herbage mass by simple methods. [Resumen]. Annual Meeting of the Society for Range Management, SRM, 68., Sacramento, USA.

Do Carmo, M., Carriquiry, M., Espasandín, A. C., Soca. P. 2014. Ecosystem energy efficiency affected by forage allowance and cow genotype in Campos grassland. Proc. 1st Intl. Symp. Nutr. Herb. and Int Symp Rumin. Physiol., Canberra, Australia. 
Dogliotti, S., García, M.C., Peluffo, S. Dieste, J.P., Pedemonte, A.J., Bacigalupe, G.F., Scarlato, M., Alliaume, F., Álvarez, J., Chiappe, M., Rossing, W.A.H. 2014. Coinnovation of family farm systems: A systems approach to sustainable agriculture. Agricultural Systems 126: 76-86.

Dogliotti, S., Abedala, C., V. Aguerre, V., Albín, A., Alliaume, F. Álvarez, J., Bacigalupe, G. F, Barreto, M., Chiappe, M., Corral, J., Dieste, J. P., García de Souza, M. C, Guerra, S., Leoni, C., Malán, I., Mancassola, V., Pedemonte, A., Peluffo, S., Pombo, C. Salvo, G., Scarlato, M. 2012. Desarrollo sostenible de sistemas de producción hortícolas y hortícola-ganaderos familiares: una experiencia de co-innovación. Montevideo (UY): INIA. 112 p. (Serie FPTA-INIA; 33). Proyecto FPTA-209. Douthwaite, B. Alvarez, S., Thiele, G., Mackay, R. 2008. Participatory Impact Pathways Analysis: A practical method for project planning and evaluation. ILAC Brief 17.

Douthwaite, B., Alvarez, S., Cook, S., Davies, R., George, P., Howell, J., Mackay, R., Rubiano, J. 2007a. Participatory Impact Pathways Analysis: A Practical Application of Program Theory En: Research-For-Development. The Canadian Journal of Program Evaluation 22 (2): 127-159.

Douthwaite, B., Schulz, S., Olanrewaju, A., Ellis-Jones, J. 2007b. Impact pathway evaluation of an integrated Striga hermonthica control project in Northern Nigeria. Agricultural Systems 92: 201-222.

Douthwaite, B., Kuby, T., van de Fliert, E., Schulz, S. 2003. Impact pathway evaluation: an approach for achieving and attributing impact in complex systems. Agricultural Systems 78: 243-265.

Douthwaite, B., Keatinge, J. D. H., Park, J. R. 2002. Learning selection: An evolutionary model for understanding, implementing and evaluating participatory technology development. Agricultural Systems 72: 109-131.
Douthwaite, B., de Haan, N.C., Manyong, V., Keatinge, D. 2001. Blending "hard" and "soft" science: the "follow-the-technology" approach to catalyzing and evaluating technology change. Conservation Ecology 5 (2): 13.

Drechsel, P., Gyiele, L., Asante-Mensah, S. 2001. Assessing human capacity building and the potential of technology adoption via KASA analysis. [Archivo PDF]. Último acceso, Febrero 2017.

http://www.ruaf.org/sites/default/files/ econf2_backgroundpaper_drechsel_gyiele_ asantemensah.doc

Duru, M., Hubert, B. 2003. Management of grazing systems: from decision and biophysical models to principles for action. Agronomie 23 (8): 689-703.

Fedrigo, J. K. 2015. Recuperação de pastagens naturais degradadas por sobrepastejo, por meio do diferimento. Tesis de Doctorado. Universidad Federal dou Rio Grande Do Sul. Brasil.134 p.

Fedrigo, J. K. 2011. Diferimento e fertilização de pastagem natural em neossolo de basalto na Campanha do Rio Grande do Sul. Tesis de Maestrado. Universidade Federal do Rio Grande Do Sul. Brasil. 83p.

Formoso, D., Pereira, D. 2008. Efecto del Pastoreo Mixto sobre la Vegetación del Campo Natural en Cristalino Central (Región Centro-Sur). Producción Ovina (20): 5-20.

Fresco L. y Westphal E., 1988. A hierarchical classification of farm systems. Expl. Agric. (1988), 24:399-419.

Fuhlendorf, S. D., Harrell, W. C., Engle, D. M, Hamilton, R.G., Davis, C. A., Leslie Jr., D. M. 2006. Should heterogeneity be the basis for conservation? Grassland bird response to fire and grazing. Ecological Applications 16 (5): $1706-1716$. 
Garden, J. G., Mcalpine, C. A., Possingham, H. P., Jones, D. N. 2007. Habitat structure is more important than vegetation composition for local-level management of native terrestrial reptile and small mammal species living in urban remnants: A case study from Brisbane, Australia. Austral Ecology 32 (6): 669-685.

Gibbons, D.W., Gregory, R.D. 2006. Birds En: Sutherland, W.J. (Eds.). Ecological census techniques. 2nd Edition, Cambridge University Press, Cambridge. pp. 308-350.

Gibbons, M., Limoges, C., Nowotny, H., Schwartzman, S., Scott, P., Trow, M. 1997. La nueva producción del conocimiento. Ediciones Pomares-Corredor, S.A., Barcelona, España, 225 p.

Gómez Miller, R. Saravia, H. 2016. Tecnología en sistemas ganaderos criadores de Sierras del Este: oferta disponible y toma de decisiones tecnológicas en el predio. Agrociencia 20 (1): 113-122.

Gonçalves, E. N., Carvalho, P. C. D. F., Kunrath, T. R., Carassai, I. J., Bremm, C. Fischer, V. 2009. Relações planta-animal em ambiente pastoril heterogêneo: processo de ingestão de forragem. Revista Brasileira de Zootecnia 38 (9): 1655-1662.

Gregory, R. D., van Strien, A. 2010. Wild Bird Indicators: Using Composite Population Trends of Birds as Measures of Environmental Health. Ornithological Science 9 (1): 3-22.

Guterres, D.B., Bayer, C., Castilhos, Z.M.S., Nabinger, C. 2006. Carbono orgânico em Chernossolo sob pastagem nativa no RS. En: 16 Reunião Anual da Sociedade Brasileira de Ciência do Solo. UFSE/SBSC, São Cristóvão, pp. sn.

Hall, A., Janssen, W., Riikkaet, R. 2006. Enhancing Agricultural Innovation: How to go beyond the strengthening of research systems. The World Bank. [Archivo PDF]. Último acceso, Febrero 2017

http://siteresources.worldbank.org/lntard/ Resources/Enhancing_Ag_Innovation.pdf
Hall, A., Mytelka, L., Oyeyinka, B. 2005 Innovation systems: Implications for agricultural policy and practice. Maastricht, CGIAR. ILAC Brief 2. 4 p.

Haydock, K. P., Shaw, N. H. 1975. The comparative yield method for estimating dry matter yield of pasture. Australian Journal of Experimental Agriculture and Animal Husbandry 15: 663-670.

Heitschmidt, R. K., Taylor, Jr., C. A. 1991 Livestock production. En: Heitschmidt, R., K., Stuth, J. W. (Eds.). Grazing management: an ecological perspective. Oregon: timber Press, p. 259.

Hellin, J. 2012. Agricultural Extension, Collective Action and Innovation Systems: Lessons on Network Brokering from Peru and Mexico. Journal of Agricultural Education and Extension 18 (2): 141-159.

Herrero, M., Thornton, P. K., Gerber, P., Reid, R. S. 2009. Livestock, livelihoods and the environment: understanding the tradeoffs. Current Opinion in Environmental Sustainability 1 (2): 111-120.

Hester, A. J., Mitchell, F. J. G., Kirby, K. J. 1996. Effects of season and intensity of sheep grazing on tree regeneration in a British upland woodland. Forest Ecology and Management 88(1): 99-106.

Hickman, K. R., Hartnett, D. C., Cochran, R. C., Owensby, C. E. 2004. Grazing management effects on plant species diversity in tallgrass prairie. Journal of Range Management 57: 58-65.

Holling, C.S. 2000. Theories for sustainable futures. Conservation Ecology.4 (2): 7. 
Horne, P. M., Stür, W. W. 2006. Desarrollando soluciones agrícolas con los pequeños agricultores: ¿Cómo empezar con enfoques participativos? En: Gonsalves et al. (Eds.) Investigación y desarrollo participativo para la agricultura y el manejo sostenible de recursos naturales. Volumen 1: Comprendiendo. Investigación y desarrollo participativo. Perspectivas de los usuarios con la investigación y el desarrollo agrícola. Filipinas y Canadá. CIP e IDRC. pp. 200-209.

IAASTD. International Assessment of Agricultural Knowledge, Science and Technology for Development. 2009. Executive summary of the synthesis report. Washington, Island Press. IAASTD. pp. 1-23.

INE (Instituto Nacional de Estadísticas). 2015-2009. Demografías y estadísticas sociales/condiciones de vida/ingreso de las personas y los hogares/por área geográfica/ ingreso medio per cápita. [Base de datos]. Último acceso, Noviembre 2017.

http://www.ine.gub.uy/c/document_library/ get_file?uuid=ca57dafa-8091-4c2f-8df8-

7 b8445859b93\&groupld=10181

INIA (Instituto Nacional de Investigación Agropecuaria). 2017. Estado corporal vacuno para carne. INIA. Montevideo, Uruguay. Cartilla 14. 2 p.

INIA. 2015. Cuadro resumen de los resultados del Taller: Rocha. En: XIII Taller de Evaluación de los Diagnósticos de Gestación Vacuna. Último acceso, Noviembre 2017.

http://www.inia.uy/estaciones-experimentales/ direcciones-regionales/inia-treinta-y-tres/ xiii-taller-de-evaluaci\%C3\%B3n-de-losdiagn\%C3\%B3sticos-de-gestaci\%C3\%B3nvacuna

INIA. 2014. Cuadro resumen de los porcentajes de preñez 2014: Rocha. En: XII Taller de Evaluación de los Diagnósticos de Gestación Vacuna. Último acceso, Noviembre 2017. http://www.inia.uy/estaciones-experimentales/ direcciones-regionales/inia-treinta-y-tres/ xii-taller-de-evaluaci\%C3\%B3n-de-losdiagn $\%$ C3\%B3sticos-de-gestaci\%C3\%B3nvacuna
INIA. 2013. Cuadro resumen de los resultados presentados: Rocha. En: Ciclo Destacados INIA 2013. Cría vacuna: mucho más que terneros. Último acceso, Noviembre 2017. http://destacados.inia.org.uy/images/pres/ c91h0psqtgzori6ggm03.pdf

INIA. 2012. Cuadro resumen de los resultados presentados: Rocha. En: X Taller de Evaluación de Diagnósticos de Gestación Vacuna. Último acceso, Noviembre 2017. http://www.inia.uy/estaciones-experimentales/ direcciones-regionales/inia-treinta-y-tres/actividad-2012-213

INIA. 2011. Cuadro resumen de los resultados presentados: Rocha. En: IX Taller de evaluación de los diagnósticos de gestación vacuna. Último acceso, Noviembre 2017. http://www.inia.uy/estaciones-experimentales/ direcciones-regionales/inia-treinta-y-tres/ actividad-2011-153

INIA. 2010. Cuadro resumen de los resultados presentados: Rocha. En: VIII Taller de Evaluación de los Diagnósticos de Gestación Vacuna. Último acceso, Noviembre 2017. http://www.inia.uy/estaciones-experimentales/ direcciones-regionales/inia-treinta-y-tres/ actividad-2010-180

INIA-GRAS. 2011-1991. Banco de datos agroclimático. [Base de datos]. Último acceso, Noviembre 2017.

http://www.inia.uy/gras/Clima/Banco-datosagroclimatico

IPA (Instituto Plan Agropecuario). 2017. Programa de Monitoreo de Empresas Ganaderas-Carpetas Verdes. Montevideo, Uruguay. [Base de datos]. Último acceso, Febrero 2017.

https://www.planagropecuario.org.uy/web/

monitoreo-de-empresas-ganaderas.html

Jaurena, M., Lezama, F., Salvo, L., Cardozo, G., Ayala, W., Terra, J., Nabinger, C. 2016. The Dilemma of Improving Native Grasslands by Overseeding Legumes: Production Intensification or Diversity Conservation. Rangeland Ecology \& Management 69: 35-42. 
Klerkx, L., Van Mierlo, B., Leeuwis, C. 2012. Evolution of Systems Approaches to Agricultural Innovation: Concepts, Analysis and Interventions. En: Darnhofer, I., Gibbon, D., Dedieu, B. (Eds.): Farming Systems Research into the 21st Century: The New Dynamic. pp. 457-483.

Klerkx, L., Aarts, N., Leeuwis, C. 2010. Adaptive management in agricultural innovation systems: The interactions between innovation networks and their environment. Agricultural Systems 103: 390-400.

Knickel, K., Brunori, G., Rand, S., Proost, J. 2009. Towards a better conceptual framework for innovation processes in agriculture and rural development: From linear models to systemic approaches. Journal of Agricultural Education and Extension 15 (2): 131-146.

Lee, S., Olson, D., Trimi, S. 2012. Co-innovation: convergenomics, collaboration, and co-creation for organizational values. Management Decision 50 (5): 817-831.

Leeuwis, C., Schut, M., Waters-Bayer, A., Mur, R., Atta-Krah, K., Douthwaite, B. 2014. Capacity to innovate from a system CGIAR research program perspective. Penang, Malaysia: CGIAR Research Program on Aquatic Agricultural Systems. Program Brief: AAS-2014-29. [Archivo PDF]. Último acceso, Febrero 2017.

http://drylandsystems.cgiar.org/sites/default/files/ Systems $\% 20$ perspective_capacity $\% 20$ to $\% 20$ innovate.pdf

Leeuwis, C., Aarts, N. 2011. Rethinking Communication in Innovation Processes: Creating Space for Change in Complex Systems. Journal of Agricultural Education and Extension 17 (1): 21-36.

Leeuwis, C., Van den Ban, A. 2004. Communication for rural innovation: Rethinking agricultural extension. Oxford, Blackwell Science. 412 p.

Leeuwis, C., Pyburn, R., Röling, N. 2002. Wheelbarrows full of frogs: social learning in rural resource management: international research and reflections. Koninklijke Van Gorcum. 479 p.
López-Ridaura, S., M. K. van Ittersum, O. R. Masera, P., Leffelaar, A., Astier, M., van Keulen, H. 2005. Sustainability evaluation. Applying ecological principles and tools to natural resource management systems. En: Maples, A. D. (Eds.) Sustainable development: New research. NovaScience, Hauppauge, New York, USA. pp. 139-167.

López-Ridaura, S., Masera, O., Astier. M. 2002. Evaluating the sustainability of complex socio-environmental systems. The MESMIS framework. Ecological Indicators 2: 135-148.

Lunt, I.D., Eldridge, D.J., Morgan, J.W., Witt, G.B. 2007. A framework to predict the effects of livestock grazing and grazing exclusion on conservation values in natural ecosystems in Australia. Australian Journal of Botany 55: 401-415.

MacDonald, C. 2012. Understanding participatory action research: a qualitative research methodology option. Canadian Journal of Action Research 13 (2): 34-50.

Mas, C., Bermúdez, R., Ayala, W. 1997. Crecimiento de las pasturas naturales en dos suelos de la Región Este 2a. ed. En: Carámbula, M.; Vaz Martins, D.; Indarte, E. (Eds.). Pasturas y producción animal en áreas de ganadería extensiva. 2a. reimpresión. Montevideo (UY): INIA. pp. 59-67. (Serie Técnica; 13).

Masera, O., Astier, M., López-Ridaura, S. 2000. Sustainability and natural resource management. The MESMIS Evaluation Framework. Working Document D36. México: Grupo Interdisciplinario de Tecnología Rural Apropiada.

MGA-DSF. Ministerio de Ganadería y Agricultura. Dirección de Suelos y Fertilizantes, Uruguay. 1979. Carta de reconocimiento de suelos del Uruguay. Tomo III. Clasificación de suelos. Descripción de las unidades de suelos. Montevideo. 452 p. 
MGAP-OPYPA. 2015-2014， 2012-2011. Anuarios de Precios. [Base de datos]. Último acceso Noviembre 2017.

http://www.mgap.gub.uy/unidad-ejecutora/oficinade-programacion-y-politicas-agropecuarias/ precios-indicadores-costos/indicadores-delsector-agropecuario/anuarios-de-precios

MGAP-DGRN. 2001. Compendio Actualizado de Información de Suelos del Uruguay. En: Dirección General de Recursos Naturales, Ministerio de Ganadería, Agricultura y Pesca. MGAP/ DGRN. Último acceso Noviembre 2017.

http://www.mgap.gub.uy/unidad-ejecutora/ direccion-general-de-recursos-naturales/tramitesy-servicios/biblioteca-digital/compendio-desuelos-del-uruguay

Milchunas, D. G., Sala, O. E., Lauenroth, W. K. 1988. A generalized model of effects of grazing by large herbivores on grassland community structure. The American Naturalist 132: 87-106.

Millot, J., Risso, D., Methol R. 1987. Relevamiento de pasturas naturales y mejoramientos extensivos en áreas ganaderas del Uruguay. Consultora FUCREA-CHPA.

Molina, C., Álvarez, J. 2009. Identificación de factores incidentes en las decisiones de adopción de tecnología en productores ganaderos criadores familiares. Agrociencia 8 (2): 70-83.

Moschitz, H., Roep, D., Brunori, G., Tisenkopfs, T. 2015. Learning and innovation networks for sustainable agriculture: Processes of co-evolution, joint reflection and facilitation. Journal of Agricultural Education and Extension 21 (1): 1-11.

Mueller-Dombois, D., Ellenberg, H., 1974. Aims and methods of vegetation ecology. Wiley, New York, NY. 547p.

Nabinger, C. 1998. Princípios de manejo e produtividade de pastagens: manejo e utilização sustentável de pastagens. En: Anais III Ciclo de Palestras em Produção e Manejo de Bovinos de Corte. Universidad de Luterano do Brasil - ULBRA, Porto Alegre. pp. 54-107.
Nabinger, C., De Faccio Calvalho, P.C., Cassiano Pinto, E., Messalira, J.C., Martins Brambilla, D., Boggiano, P. 2011. Ecosystems services from natural grasslands: It's possible to enhance them with more productivity? Archivos Latinoamericanos de Producción Animal 19 (3-4): 27-34.

Nolan, T. 1996. Perspective: Animal vegetation relations which optimise production, utilisation and protection of natural resources: An African experience. African Journal of Range and Forage Science 13 (1): 42-48.

Oficialdegui, R. 1984. Carne equivalente: los riesgos de la simplificación. Montevideo (UY): SUL. pp. 53-62. (Boletín Técnico; 13).

Okali, C., Sumberg, J., Farrington, J. 1994. Farmer participatory research. Rhetoric and reality. London, ODI. 159 p.

Parton, W.J., Schimel, D.S., Cole, C.V., Ojima, D.S. 1987. Analysis of factors controlling soil organic matter levels in Great Plains grasslands. Soil Science Society of America Journal 51 (5): 1173-1179.

Pereira, G. 2003. La ganadería en Uruguay. Contribución a su conocimiento. DIEAMGAP. Último acceso Noviembre 2017.

http://www.mgap.gub.uy/portal/agxppdwn.aspx?7 ,5,296,O,S, 0,355\%3BS\%3B9\%3B120

Pretty, J. 1995. Participatory learning for sustainable agriculture. World Development 23 (8): 1247-1263.

Probst, K., Hagmann, J. 2006. Enfoques prototípicos para el desarrollo de innovaciones. En: Gonsalves et al. (Eds.) Investigación y desarrollo participativo para la agricultura y el manejo sostenible de recursos naturales. Volumen 1: Comprendiendo. Investigación y desarrollo participativo. Perspectivas de los usuarios con la investigación y el desarrollo agrícola. Filipinas y Canadá. CIP e IDRC. pp. 18-26. 
Probst, K., Hagmann, J. 2003. Understanding participatory research in the context of natural resource management-paradigms, approaches and typologies. London, ODI. AgREN Network Paper $n^{\circ} 130.16$ p.

Quintans, G., Scarsi, A. 2013. Seminario de actualización técnica: Cría Vacuna. Montevideo (UY): INIA. 264 p. (Serie Técnica; 208).

Quintans, G., Velazco, J.I., Roig, G. 2008a. Seminario de actualización técnica: cría vacuna. Montevideo (UY): INIA. 199 p. (Serie Técnica; 174).

Quintans, G., Banchero, G., Carriquiry, M., López, C., Baldi, F., 2008b. Efecto de la condición corporal y la restricción del amamantamiento con y sin presencia del ternero sobre la producción de leche, anestro posparto y crecimiento de los terneros: En: Quintans, G., Velazco, J.I., Roig, G. (Eds.). Seminario de actualización técnica: cría vacuna. Montevideo (UY): INIA. pp. 172-181. (Serie Técnica; 174).

Ran, Y., Deutsch, L., Lannerstad, M., Heinke, J. 2013. Rapidly Intensified Beef Production in Uruguay: Impacts on Water-related Ecosystem Services. Aquatic Procedia 1: 77-87.

Rockwell, K., \& Bennett, C. 2004. Targeting Outcomes of Programs: A Hierarchy for Targeting Outcomes and Evaluating Their Achievement. Faculty Publications: Agricultural Leadership, Education \& Communication Department. Paper 48. [Archivo PDF]. Último acceso, Febrero 2017

http://digitalcommons.unl.edu/cgi/viewcontent.cgi ?article $=1047 \&$ context=aglecfacpub

Rogers, E. M. 1995. Diffusion of innovations. 5th ed. New York, Free Press. 543 p.

Röling, N. 2006. Conceptual and Methodological Developments in Innovation. Keynote for Innovation Africa Symposium, Kampala. [Archivo PDF]. Último acceso, Febrero 2017 http://ciat-library.ciat.cgiar.org:8080/jspui/ bitstream/123456789/2195/2/Key_note_address. pdf
Röling, N., Engel, P. 1991. The development of the concept of agricultural knowledge information Systems (AKIS): Implications for extension. En: Rivera, W. y Gustafson, D. (Eds.). Agricultural Extension: Worldwide institutional evolution and forces for change. Amsterdam, Elsevier. pp. 125-137.

Rossi, V. 2011. Aportes metodológicos para el asesoramiento técnico y la extensión rural. Cangüé 31: 51-60.

Rossing, W.A.H., Dogliotti, S., Bacigalupe, G.F., Cittadini, E., Mundet, C., Mariscal Aguayo, V., Douthwaite, B., Alvarez, S., Cordoba, D., Lundy, M., Tehelen, K. Almekinders, C. 2010. Project design and management based on a co-innovation framework. En: Building Sustainable Rural Futures: The Added Value of Systems Approaches in Times of Change and Uncertainty-IFSA 2010, Viena. Austria. pp. 402412.

Rovira, J. 1996. Manejo nutritivo de los rodeos de cría en pastoreo. Montevideo (UY): Hemisferio Sur. $288 p$

Salvo, L., Hernández, J., Ernst, O. 2010. Distribution of soil organic carbon in different size fractions, under pasture and crop rotations with conventional tillage and no-till systems. Soil Tillage Research 109: 116-122.

Santos, D. T. dos, Pilau, A., Aguinaga, A. A. Q., Nabinger, C. 2008. Redes de Referência: produtividade e rentabilidade ao alcance do produtor. En: Marcantonio, Getúlio. (Org.). Exemplos de propriedades rentáveis pela produtividade. 1 ed. Porto Alegre, RS, v. 1, pp. 129-146.

Scarlato, S., Carriquiry, M., Do Carmo, M., Faber, M. M. A., Genro, T. C. M., Laca E. A, Soca, P. 2012. Foraging behavior of beef cows grazing native grassland: Effect of herbage allowance on temporal and spatial grazing patterns. Journal of Animal Science 90 (3): 502. 
Scoones, I., Thompson, J. 1994. Beyond farmer first. Rural people's knowledge, agricultural research and extension practice. London, Intermediate Technology Publications. 301 p.

Shannon, C., Weaver, W., 1949. The mathematical theory of communication. University of Illinois Press, Urbana, IL, USA.

Scheuermeier, U., Katz, E., Heiland, S. 2004. Finding new things and ways that work. A manual for introducing participatory innovation development (PID). Lindau, LBL. 244 p.

Schönhuth, M., Kievelitz, U. 1994. Diagnóstico rural rápido. Diagnóstico rural participativo. Métodos participativos de diagnóstico y planificación en la cooperación al desarrollo. Una introducción comentada. Eschborn, GTZ. 137 p.

Schut, M., Klerkx, L., Rodenburg, J., Kayeke, J., Hinnou, L.C., Raboanarielina, C.M., Adegbola,P.Y., van Ast, A., Bastiaans, L. 2015. RAAIS: Rapid Appraisal of Agricultural Innovation Systems (Part I). A diagnostic tool for integrated analysis of complex problems and innovation capacity. Agricultural Systems 132: 1-11.

Senge, P. 1995. La quinta disciplina en la práctica. Granica Ediciones S.A. 594 p.

Serageldin, I. 2003. Nurturing and nourishing the world's poor: Important roles of horticulture in sustainable development. Chronica Horticulturae 43: 4-10.

Soca, P., Espasandín, A., Carriquiry, M. 2013. Efecto de la oferta de forraje y grupo genético de las vacas sobre la productividad y sostenibilidad de la cría vacuna en campo natural. Montevideo (UY): INIA. 86 p. (Serie FPTA-INIA; 48). Proyecto FPTA-242.

Soca, P., Do Carmo, M., Claramunt, M. 2007. Sistemas de cría vacuna en ganadería pastoril sobre campo nativo sin subsidios: propuesta tecnológica para estabilizar la producción de terneros con intervenciones de bajo costo y de fácil implementación. Avances en Producción Animal 32 (1-2): 3-26.
Soca, P., Orcasberro, R. 1992. Propuesta de Manejo del Rodeo de Cría en base a Estado Corporal, Altura del Pasto y Aplicación del Destete Temporario En: Evaluación Física y Económica de Alternativas Tecnológicas en Predios Ganaderos. Estación Experimental M. A. Cassinoni. Facultad de Agronomía. Universidad de la República.

Sollenberger, L.E., Moore, J.E., Allen, V.G., Pedreira, C.G.S. 2005. Reporting forage allowance in grazing experiments. Crop Science 45: 896-900.

Sorensen, J.T., Kristensen, E.S. 1992. Systemic Modelling: $A$ research methodology in livestock farming. En: Gibon, A., Mathron, G., Vissac, B. (Eds.). Global Appraisal of Livestock Farming Systems and Study on their Organizational Level: Concepts, Methodology and Results. Commission of the European Communities.

Soutullo, A., Clavijo, C., Martínez-Lanfranco, J.A. (Eds.). 2013. Especies prioritarias para la conservación en Uruguay. Vertebrados, moluscos continentales y plantas vasculares. SNAP/ DINAMA/MVOTMA, Montevideo. 222 p.

Speelman, E.N., López-Ridaura, S., Colomer, N.A., Astier, M., Masera, O.R. 2007. Ten years of sustainability evaluation using the MESMIS framework: Lessons learned from its application in 28 Latin American case studies. International Journal of Sustainable Development \& World Ecology 14: 345-361.

Srinivasan, M.S., Bewsell, D., Jongmans, C., Elley, G. 2016. Just in case to justified irrigation: Applying co-innovation principles to irrigation water management. En: EUROPEAN IFSA SYMPOSIUM, 12th., "Social and technological transformation of farming systems: Diverging and converging pathways", Symposium Handbook, Harper Adams University, UK, 12-15 July 2016.

Tittonell, P. 2014. Ecological intensification of agriculture - sustainable by nature. Current Opinion in Environmental Sustainability 8: 53-61. 
Tittonell, P., De Grazia, J. 2011. Un marco conceptual para la identificación y evaluación de alternativas agroecológicas en investigación. Revista Brasilera de Agroecologia 6 (2): 3-12.

T Mannetje, L. 1978. Measuring quantity of grassland vegetation. En: Measurement of Grassland Vegetation and Animal Production. Commonwealth Bureau of Pastures and Field Crops, Hurley, Berkshire, England. C.A.B. Bulletin \#52.

Tommasino, H., Cortelezzi, A., Mondelli, M., Bervejillo, J., Carrazzone, S. 2014. Tipología de productores agropecuarios: caracterización a partir del Censo Agropecuario 2011. En: Anuario 2014. OPYPA. Uruguay. pp. 491-508.

Tripp, R. 1991. The farming system research movement and on-farm research. En: Tripp, R. (Eds.) Planned change in farming systems: Progress in on-farm research. The Trinity Press. England. pp. 3-16.

Turner, J.A., Williams, T., Nicholas, G., Foote, J., Rijswijk, K., Barnard, T., Beechener, S., Horita, A. 2016. Triggering system innovation in agricultural innovation systems: Initial insights from a Community for Change in New Zealand. En: EUROPEAN IFSA SYMPOSIUM, 12th., "Social and technological transformation of farming systems: Diverging and converging pathways", Symposium Handbook, Harper Adams University, UK, 12-15 July 2016.

Urgeghe, A.M., Breshears, D.D., Martens, S.N., Beeson P.C. 2010. Redistribution of runoff among vegetation patch types: on ecohydrological optimality of herbaceous capture of run-on. Rangeland Ecology and Management 63: 497-504.

Van Huis, A. 2006. New paradigms for the generation and access to agricultural research results. En: GFAR-FAO (Eds.). Reorienting agricultural research to meet the millennium development goals. Italy, GFAR Secretariat. pp. 111-123.
Van Mierlo, B., Regeer, B., Van Amstel, M., Arkesteijn, M., Beekman, V., Bunders, J., de Cock Buning, T., Elzen, B., Hoes, A., Leeuwis, C. 2010. Reflexive monitoring in action: A guide for monitoring system innovation projects. Oisterwijk, The Netherlands: Boxpress.

Van Veldhuizen, L., Waters-Bayer, A., Wettasinha, Ch. 2006. Desarrollo participativo de tecnologías donde no hay investigadores. En: Gonsalves et al. (Eds.). Investigación y desarrollo participativo para la agricultura y el manejo sostenible de recursos naturales. Volumen 1: Comprendiendo. Investigación y desarrollo participativo. Perspectivas de los usuarios con la investigación y el desarrollo agrícola. Filipinas y Canadá. CIP e IDRC. pp. 192-199.

Vereijssen, J., Srinivasan, M.S., Dirks, S., Fielke, S.J., Jongmans, C., Agnew, N.M., Klerkx, L., Pinxterhuis, J.B., Moore, J., Edwards, P., Brazendale, R., Botha, N., Turner, J.A. 2016. Addressing complex challenges using a co-innovation approach: lessons from five case studies in the New Zealand primary sector. En: EUROPEAN IFSA SYMPOSIUM, 12th., "Social and technological transformation of farming systems: Diverging and converging pathways", Symposium Handbook, Harper Adams University, UK, 12-15 July 2016.

Waters-Bayer, A., Bayer, W. 2005. The social dimensions in agricultural R\&D: How civil society fosters partnerships to promote local innovation by rural communities. En: EFARD Conference. Zurich. 8 p.

Wheeler, J.L., Burns, J.C., Mochrie, R.D., Gross, H.D. 1973. The choice of fixed or variable stocking rates in grazing experiments. Experimental Agriculture 9: 289-302.

Yin, R. 2013. Case Study Research: Design and Methods. SAGE Publications. Fifth Edition. $312 \mathrm{p}$. 
Anexo 1 - Guión interno para talleres

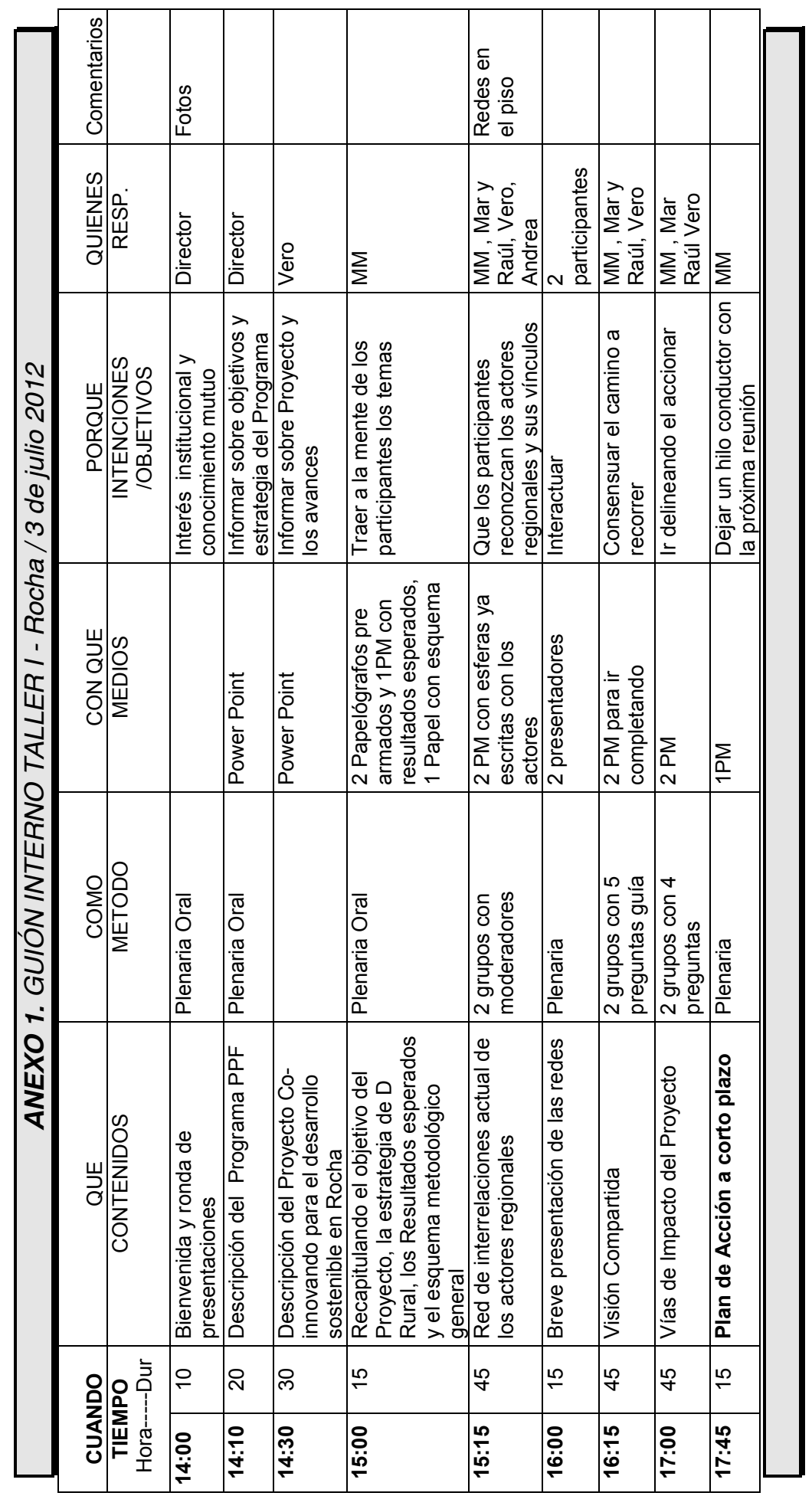




\section{Anexo 2}

Proyecto "Co-innovando para el desarrollo sostenible de sistemas de producción familiar en Rocha-Uruguay"

12 de agosto de 2015

\section{EVALUACIÓN DEL PROYECTO}

Insumos:

- Presentación general de resultados a nivel predial.

- Video con entrevistas de monitoreo.

- Presentación general de resultados a nivel regional.

- Vivencia personal.

Para contestar las siguientes preguntas hay cinco alternativas:
$(++)$
$(+)$
(0)
$(-)$
$(--)$

Por favor, indique con $(X)$ lo que mejor refleja su opinión.

\section{GLOBAL:}

1) ¿Cómo valora en forma global el proyecto?

Excelente ( ) ( ) ( ) ( ) ( ) Muy malo

\section{Comentarios:}

\section{CUMPLIMIENTO DE OBJETIVOS:}

Considerando los objetivos del proyecto y la visión compartida generada por la red, valore los siguientes aspectos:

2) ¿Se implementaron cambios en los 7 predios del proyecto que mejoraron su sustentabilidad?

$\begin{aligned} & \text { Muchos } \\ & \text { cambios }\end{aligned}$
$\begin{aligned} & \text { Muy } \\ & \text { relevantes }\end{aligned}$

Por favor, indique los cambios más significativos para Ud.:

3) ¿Se utilizó una metodología adecuada para trabajar con productores ganaderos familiares?

Muy adecuada ( ) $\quad(\quad) \quad(\quad) \quad(\quad) \quad(\quad)$ Inadecuada

\section{Comentarios:}


4) ¿Se utilizó una metodología adecuada para fomentar el trabajo en red y de esa forma contribuir al desarrollo regional?

Muy adecuada $(\quad) \quad(\quad) \quad(\quad) \quad(\quad) \quad(\quad)$ Inadecuada

\section{Comentarios:}

5) ¿Los productores, técnicos e instituciones locales conocen los resultados del proyecto? Conocen mucho $\quad(\quad) \quad(\quad) \quad(\quad) \quad(\quad) \quad(\quad)$ No conocen.

\section{Comentarios:}

6) ¿Los productores, técnicos e instituciones conocen información tecnológica de alto impacto a ser promovida a través de políticas públicas dirigidas a la producción familiar?

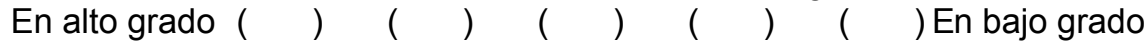

\section{Comentarios:}

\section{FUNCIONAMIENTO DEL PROYECTO}

7) ¿Cómo cree que ha funcionado el proyecto en términos generales durante este tiempo? En forma apropiada ( ) $\quad\left(\begin{array}{llllll} & \end{array}\right) \quad(\quad)$ No apropiada

Por favor, indique los aspectos más significativos para Ud.:

8) ¿En qué grado fue adecuado el trabajo a nivel de los predios?

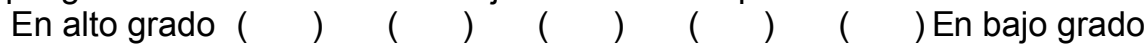

9) ¿En qué grado fueron adecuadas las acciones previstas en el plan de comunicación elaborado por la red interinstitucional?

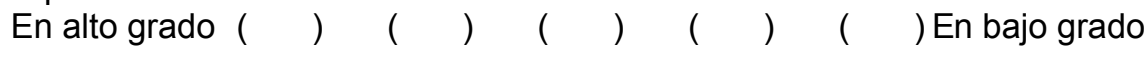

\section{Comentarios:}

10) ¿En qué grado fue adecuada la coordinación institucional de las actividades desarrolladas a partir del proyecto?

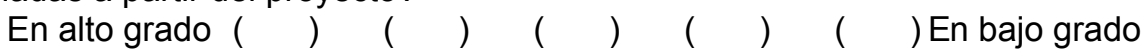

\section{Comentarios:}


11) ¿En qué grado cree que el proyecto fue "permeable" a las sugerencias de mejora realizadas por usted durante el proceso?

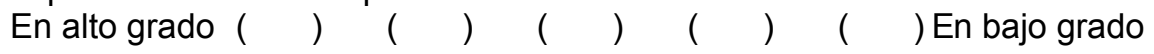

\section{Comentarios:}

\section{OTROS TEMAS}

12 ¿En qué medida se cumplieron las expectativas que tenía Ud. respecto al proyecto?

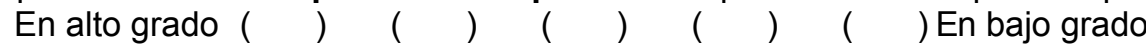

\section{Comentarios:}

13) ¿En qué medida cree Ud. que mejoraron sus conocimientos sobre estrategias de mejora para la ganadería familiar?
En alto grado
(1)

Por favor, indique los aspectos más significativos para Ud:

14) ¿En qué medida cree Ud. que tiene "nuevas formas de hacer las cosas" en relación a su trabajo en ganadería familiar?
En alto grado

(1)

Por favor, indique los aspectos más significativos para Ud.:

15) ¿Cómo se sintió participando de este proceso?

Cómodo ( ) ( ) ( ) ( ) ( ) Incómodo

\section{Comentarios:}

\section{AFUTURO}

16) ¿En qué medida cree Ud. que los resultados generados en el proyecto pueden impactar en la región?

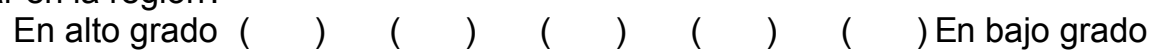

Por favor, indique tres aspectos que faciliten este proceso:

Por favor, indique tres aspectos que limiten este proceso: 
17) En base a la experiencia y aprendizajes generados en el marco de este proyecto, qué sugerencias le haría a los decisores políticos a la hora de definir políticas públicas para la producción familiar?

Mencione tres aspectos o políticas que considera fundamentales para apoyar la ganadería familiar en Uruguay:

\section{ADEMÁS ME GUSTARÍA COMENTAR:}

\section{CARACTERIZACIÓN INDIVIDUAL}

¿Es usted?

Marque con una X la/s opción/es que correspondan

(i) ¿Productor integrante del proyecto?

(ii) ¿Productor representante de una SFR?

Si representa a una SFR indique cual es

(iii) Técnico?

Si es técnico, a qué institución pertenece?

MUCHAS GRACIAS. 


\section{Anexo 3}

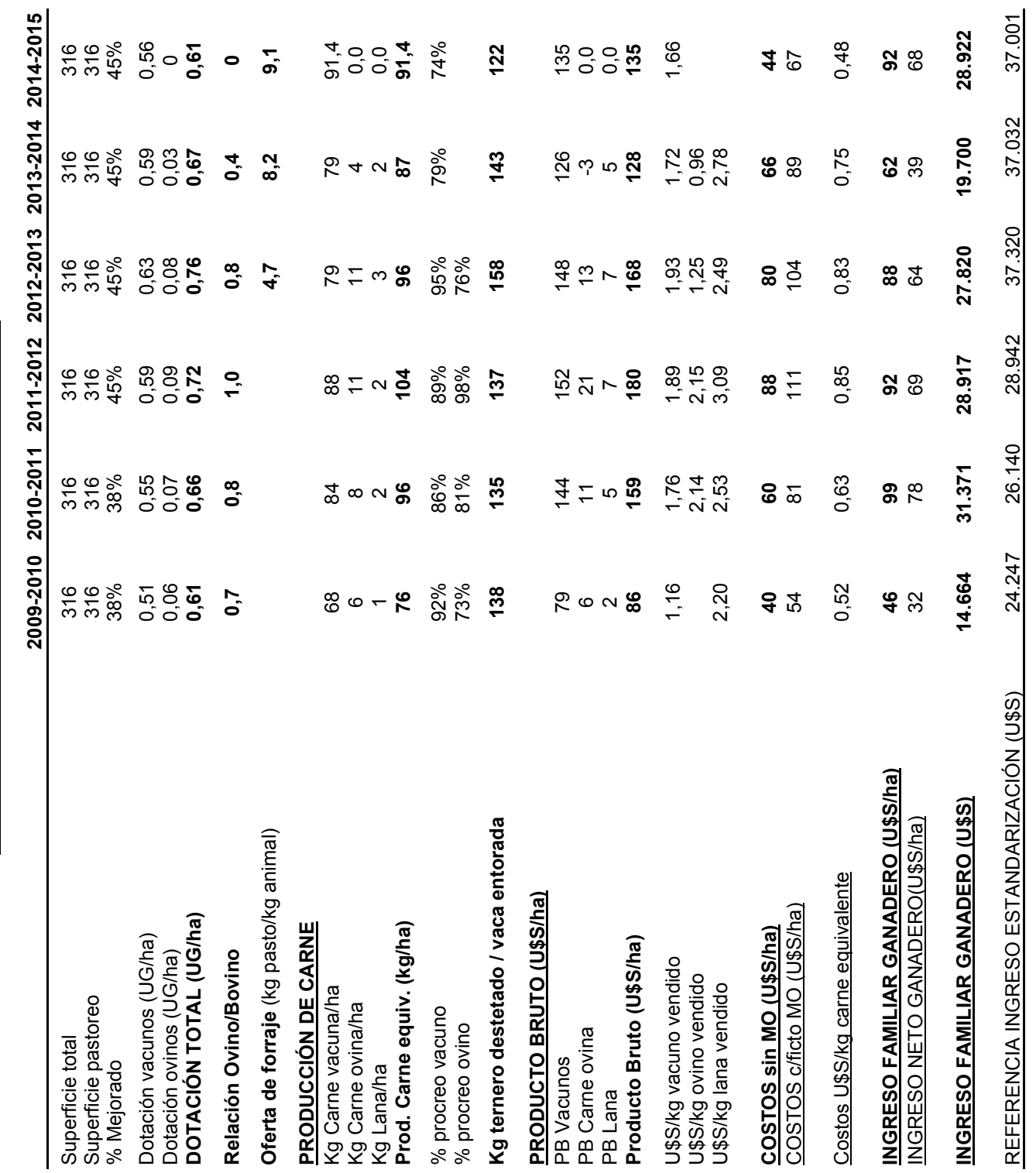


Anexo 4

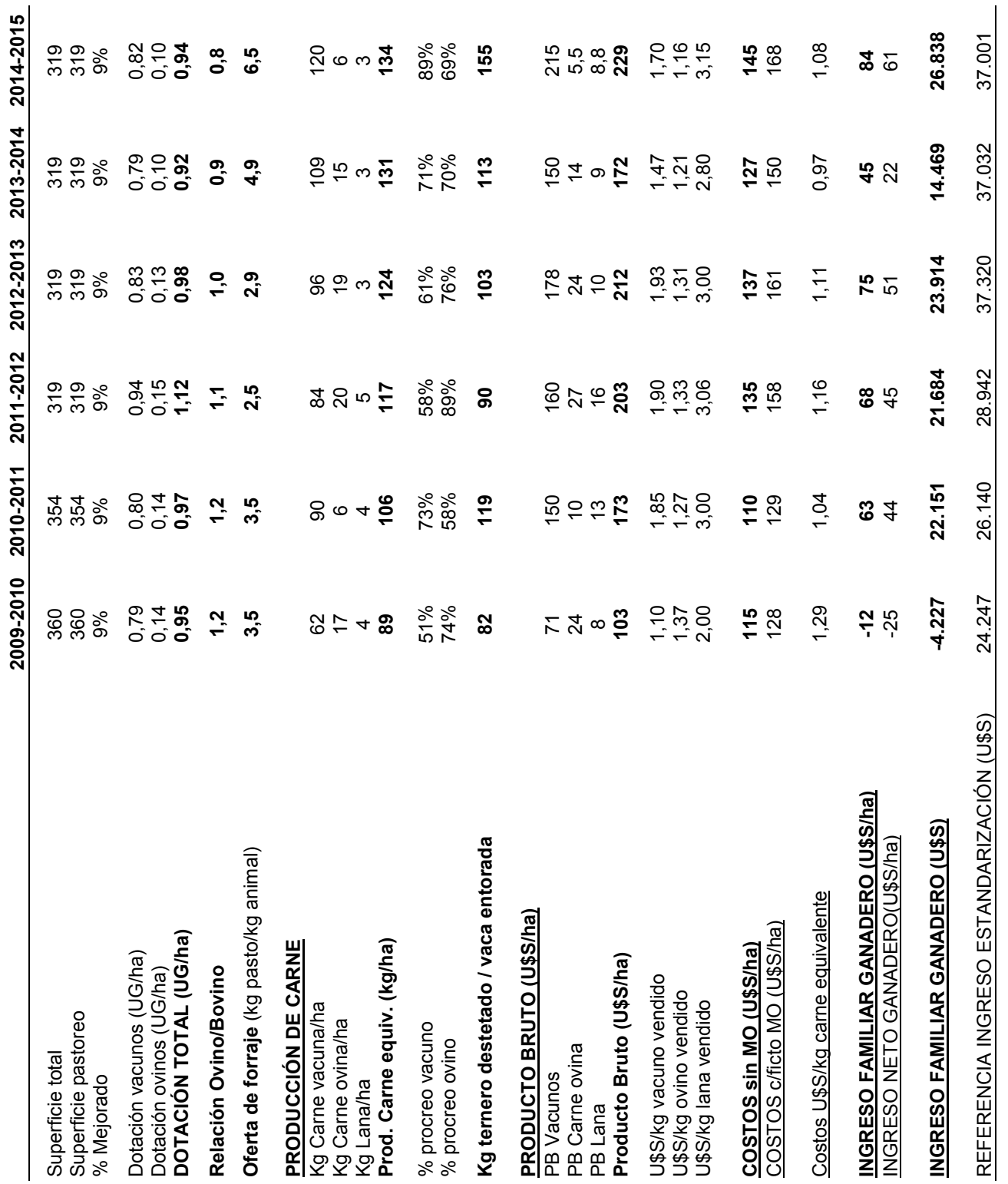




\section{Anexo 5}

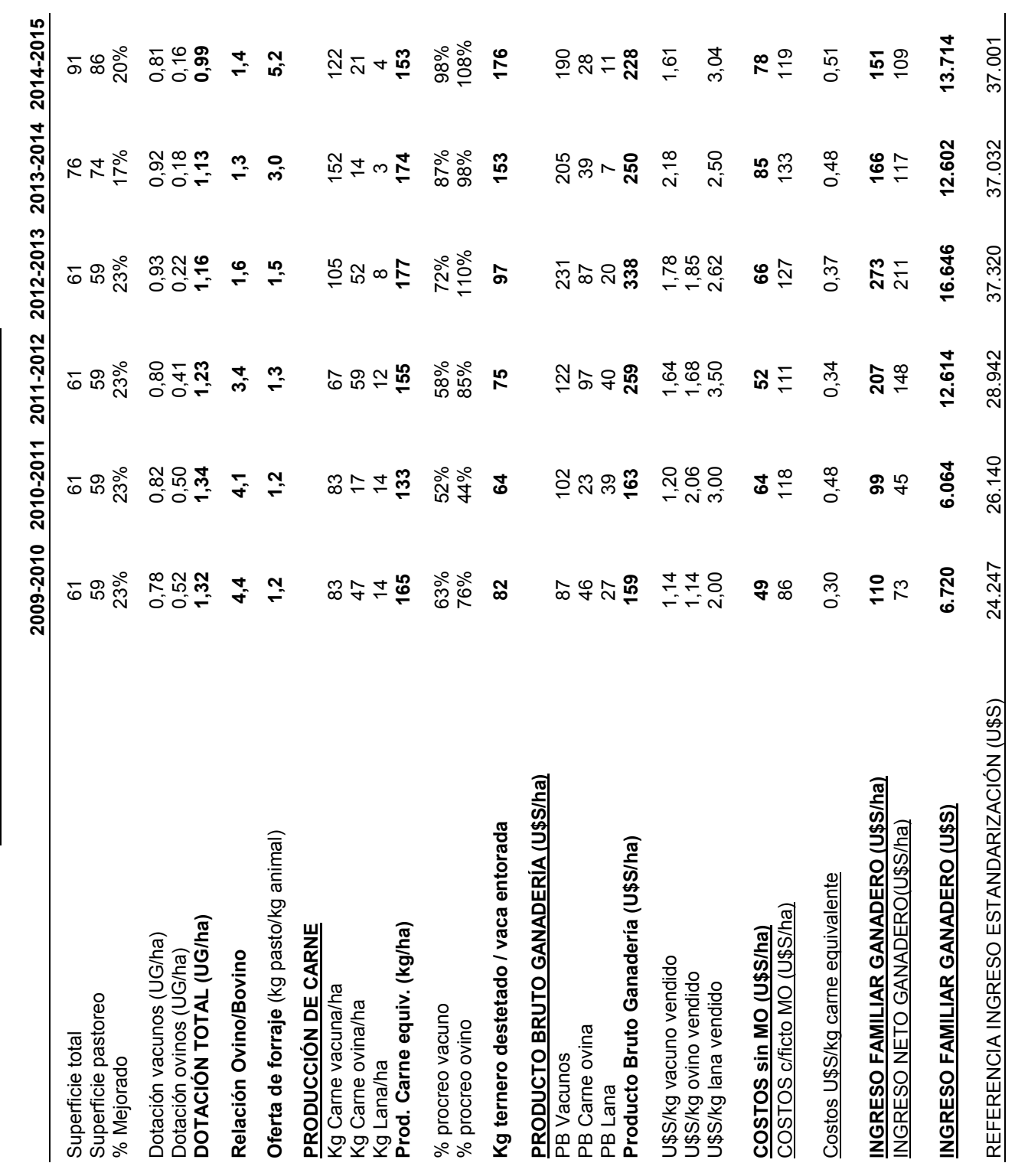




\section{Anexo 6}

商|

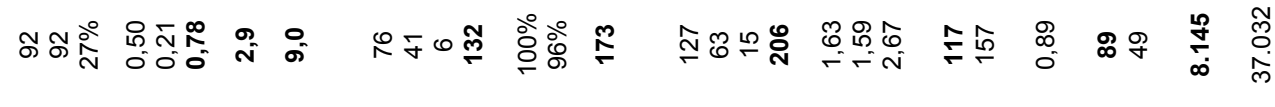

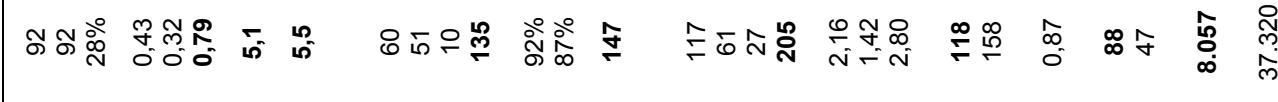

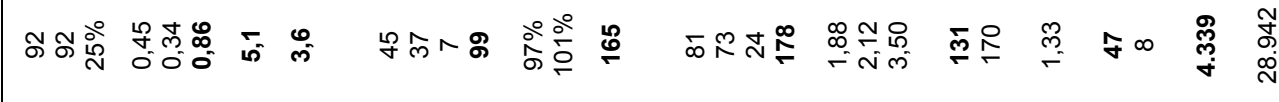

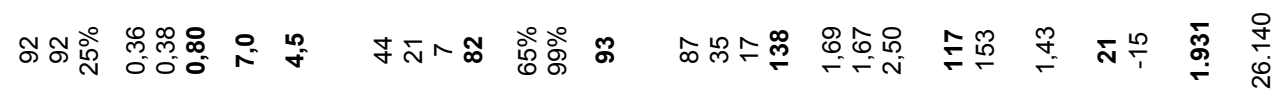

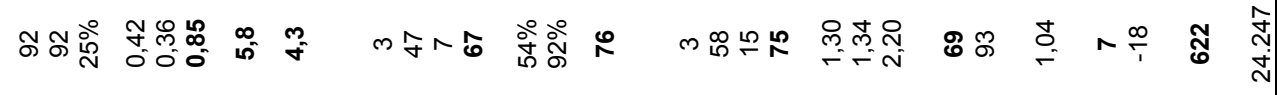

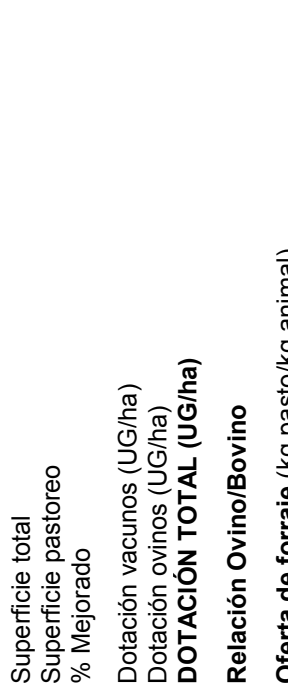




\section{Anexo 7}

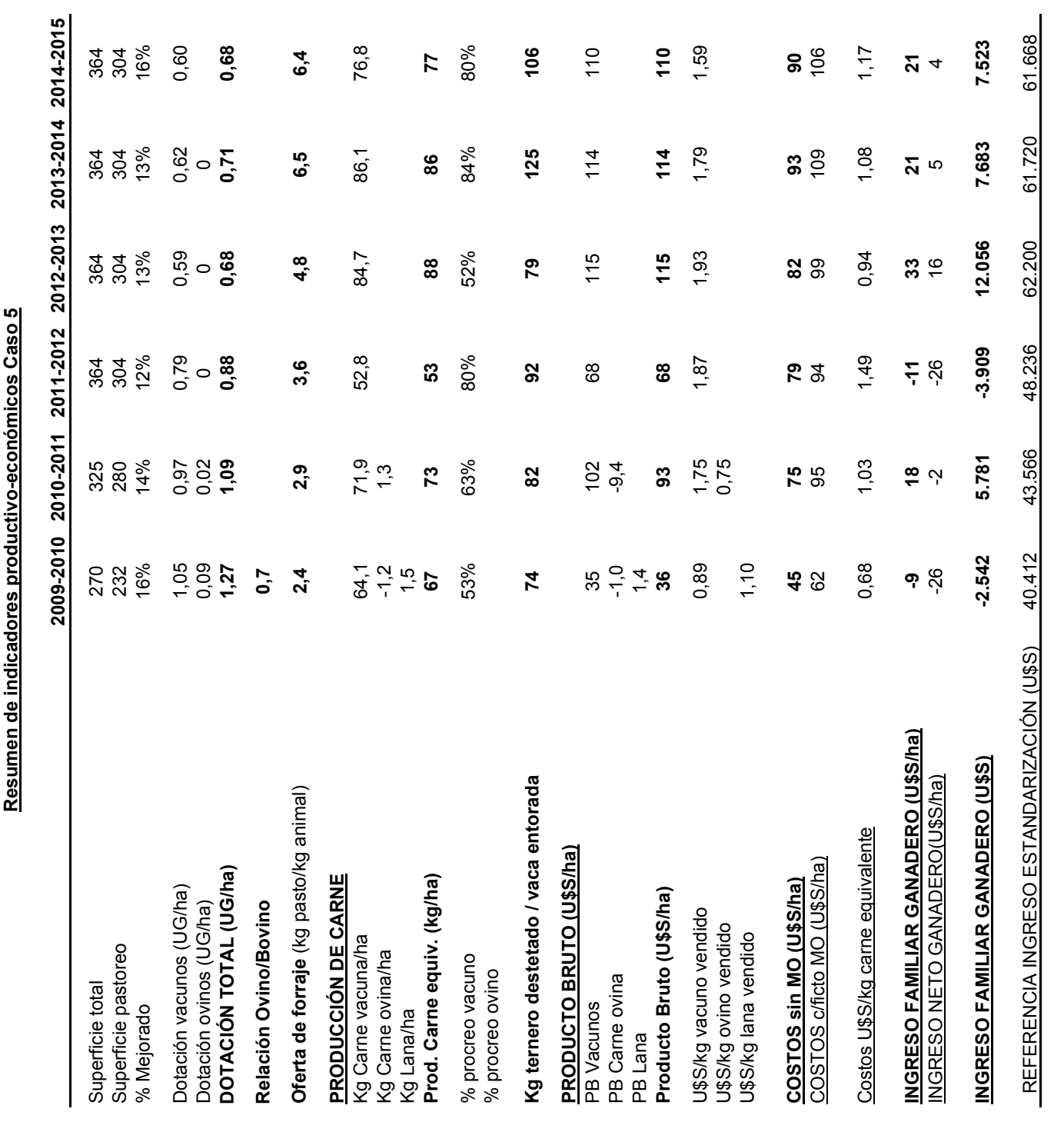




\section{Anexo 8}

刺

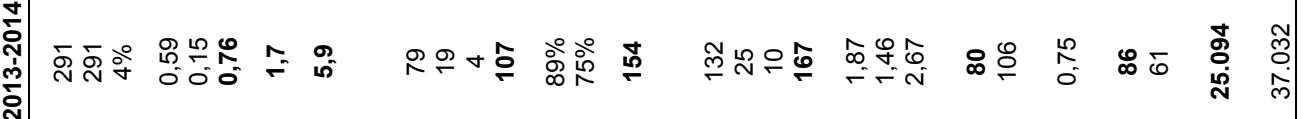
商

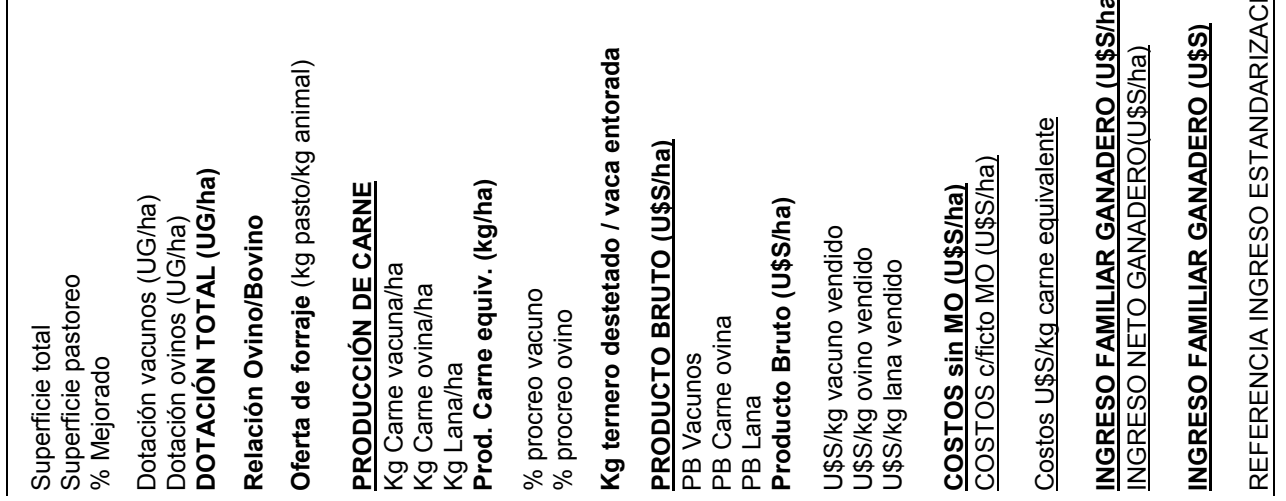




\section{Anexo 9}

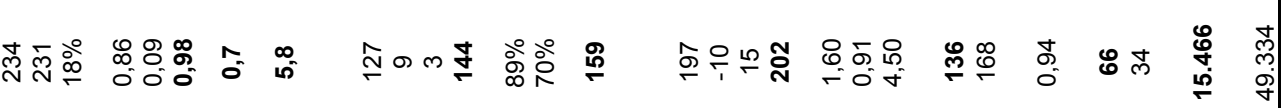

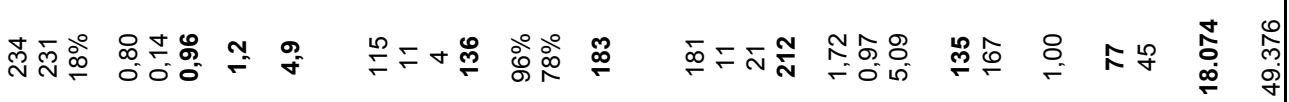

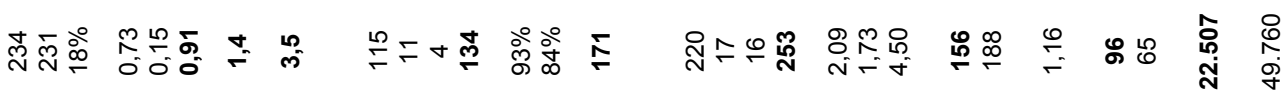

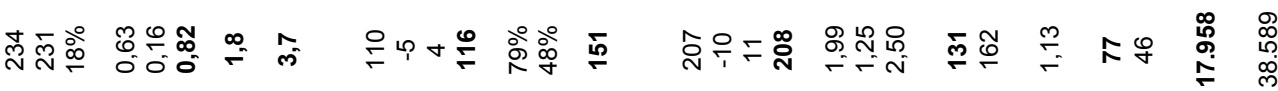

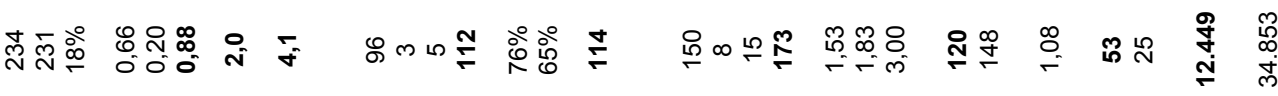

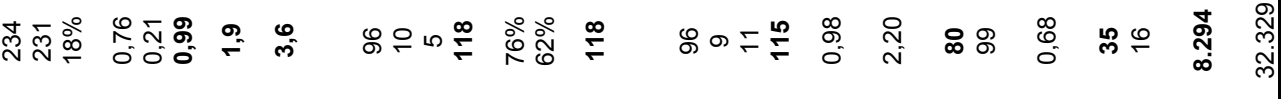
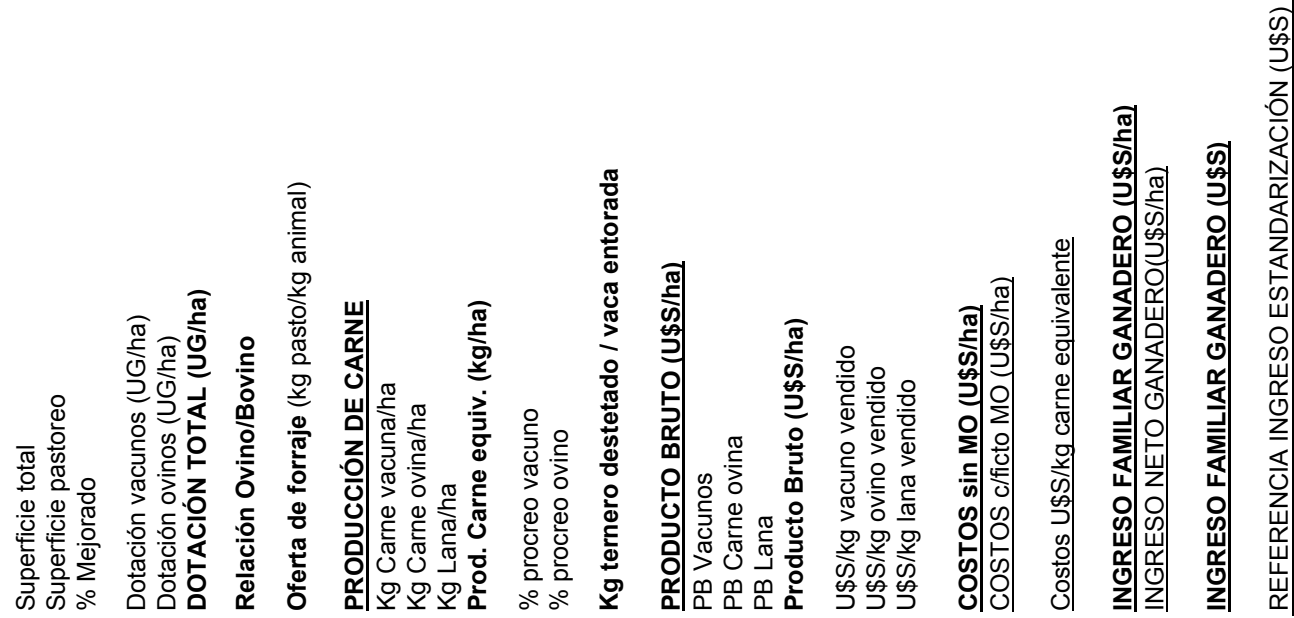


\section{Anexo 10}

商

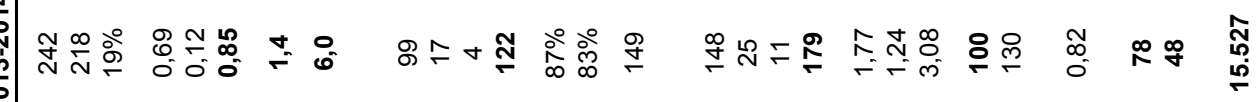

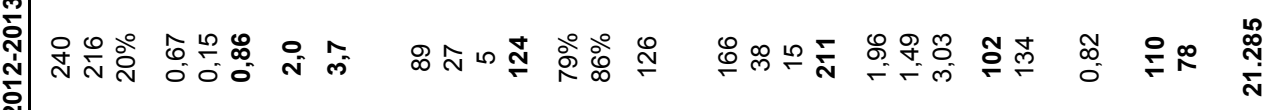

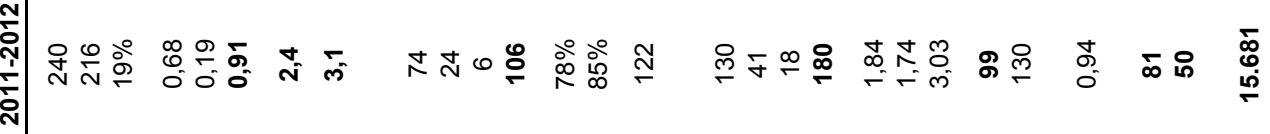
商

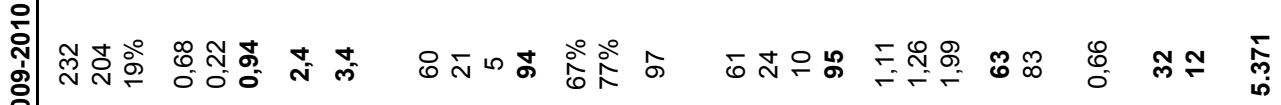
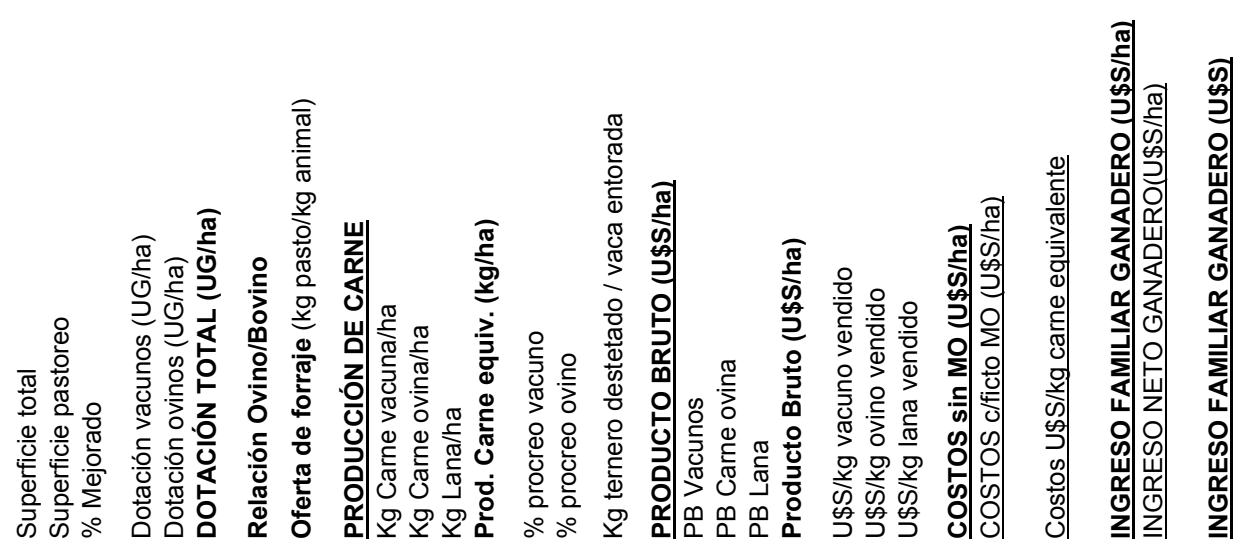
Anexo 11

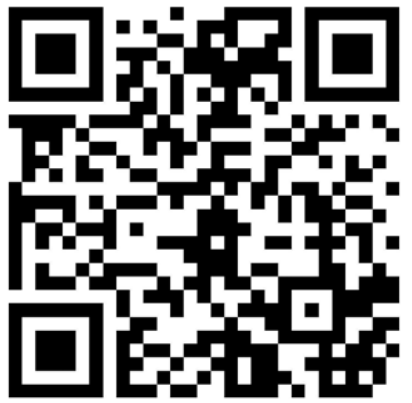

Acceso web a través de código QR para el video Versión completa - Co-innovando para el desarrollo sostenible de sistemas de producción familiar

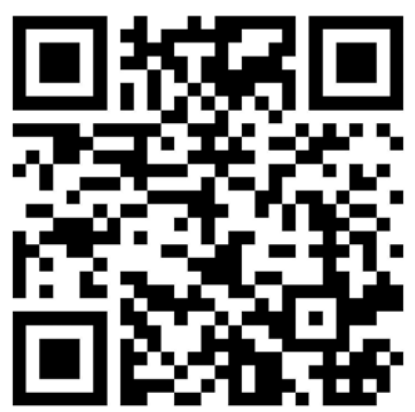

Acceso web a través de código QR para el video Versión resumida - Co-innovando para el desarrollo sostenible de sistemas de producción familiar

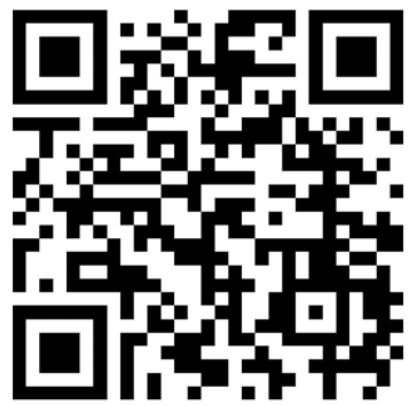

Acceso web a través de código QR para el video Trabajo en predios - Coinnovando para el desarrollo sostenible de sistemas de producción familiar

Impreso en Marzo de 2018

en PRONTOGRÁFICA

Cerro Largo 850 - Tel.: 29023172 Montevideo Uruguay

E-mail: prontografica@prontografica.com.uy Dep. Legal 369.750 
INIA Dirección Nacional

Andes 1365, P. 12

Montevideo

Tel. 59829020550

Fax 59829023633

iniadn@dn.inia.org.uy

INIA La Estanzuela Ruta 50, Km 11 Colonia

Tel. 59845748000

Fax 59845224061

iniale@le.inia.org.uy

INIA Las Brujas Ruta 48, Km 10

Canelones

Tel. 59823677641

Fax 59823677609 inia_lb@lb.inia.org.uy

INIA Salto Grande

Camino al Terrible

Salto

Tel. 59847335156

Fax 59847329624 inia_sg@sg.inia.org.uy

INIA Tacuarembó Ruta 5, Km 386

Tacuarembó

Tel. 59846322407

Fax 59846323969

iniatbo@tb.inia.org.uy

INIA Treinta y Tres Ruta 8, Km 281

Treinta y Tres

Tel. 59844522305

Fax 59844525701 iniatt@tyt.inia.org.uy

www.inia.uy 